Published in final edited form as:

Cochrane Database Syst Rev. ; (6): CD004718. doi:10.1002/14651858.CD004718.pub3.

\title{
Early intervention for psychosis
}

\author{
Max Marshall ${ }^{1}$ and John Rathbone ${ }^{2}$ \\ ${ }^{1}$ University of Manchester, The Lantern Centre, Preston., UK \\ ${ }^{2}$ HEDS, ScHARR, The University of Sheffield, Sheffield, UK
}

\begin{abstract}
Background-Proponents of early intervention have argued that outcomes might be improved if more therapeutic efforts were focused on the early stages of schizophrenia or on people with prodromal symptoms. Early intervention in schizophrenia has two elements that are distinct from standard care: early detection, and phase-specific treatment (phase-specific treatment is a psychological, social or physical treatment developed, or modified, specifically for use with people at an early stage of the illness).

Early detection and phase-specific treatment may both be offered as supplements to standard care, or may be provided through a specialised early intervention team. Early intervention is now well established as a therapeutic approach in America, Europe and Australasia.
\end{abstract}

Objectives-To evaluate the effects of: (a) early detection; (b) phase-specific treatments; and (c) specialised early intervention teams in the treatment of people with prodromal symptoms or firstepisode psychosis.

Search methods-We searched the Cochrane Schizophrenia Group Trials Register (March 2009), inspected reference lists of all identified trials and reviews and contacted experts in the field.

Selection criteria-We included all randomised controlled trials (RCTs) designed to prevent progression to psychosis in people showing prodromal symptoms, or to improve outcome for people with first-episode psychosis. Eligible interventions, alone and in combination, included: early detection, phase-specific treatments, and care from specialised early intervention teams. We accepted cluster-randomised trials but excluded non-randomised trials.

Copyright (C) 2011 The Cochrane Collaboration. Published by John Wiley \& Sons, Ltd

Contact address: Max Marshall, University of Manchester, The Lantern Centre, Vicarage Lane, Of Watling Street Road, Fulwood, Preston., Lancashire, UK. max.marshall@manchester.ac.uk.max.marshall@lancashirecare.nhs.uk.

CONTRIBUTIONS OF AUTHORS Max Marshall - designed the review, developed the search strategy, screened the search results, appraised the papers and extracted data, analysed and interpreted the data and wrote the final report.

John Rathone - (2006/2011 update) screened the search results, appraised the papers and extracted data, analysed and interpreted the data and helped write the final report.

Editorial group: Cochrane Schizophrenia Group.

Publication status and date: New search for studies and content updated (conclusions changed), published in Issue 6, 2011.

Review content assessed as up-to-date: 3 June 2009.

DECLARATIONS OF INTEREST Max Marshall - received funding for the review from the UK Department of Health, which is committed to a policy of implementing Early Intervention teams across England and are in the early stages of developing a fidelity scale for early intervention teams. Max Marshall is Clinical Director of the Lancashire Early Intervention Service.

John Rathbone - none. 
Data collection and analysis-We reliably selected studies, quality rated them and extracted data. For dichotomous data, we estimated relative risks (RR), with the $95 \%$ confidence intervals (CI). Where possible, we calculated the number needed to treat/harm statistic $(\mathrm{NNT} / \mathrm{H})$ and used intention-to-treat analysis (ITT).

Main results-Studies were diverse, mostly small, undertaken by pioneering researchers and with many methodological limitations (18 RCTs, total $n=1808$ ). Mostly, meta-analyses were inappropriate. For the six studies addressing prevention of psychosis for people with prodromal symptoms, olanzapine seemed of little benefit ( $\mathrm{n}=60,1 \mathrm{RCT}, \mathrm{RR}$ conversion to psychosis $0.58 \mathrm{CI}$ 0.3 to 1.2 ), and cognitive behavioural therapy (CBT) equally so ( $n=60,1$ RCT, RR conversion to psychosis $0.50 \mathrm{CI} 0.2$ to 1.7). A risperidone plus CBT plus specialised team did have benefit over specialist team alone at six months ( $\mathrm{n}=59,1 \mathrm{RCT}$, RR conversion to psychosis $0.27 \mathrm{CI} 0.1$ to 0.9 , NNT 4 CI 2 to 20), but this was not seen by 12 months (n=59, 1 RCT, RR 0.54 CI 0.2 to 1.3). Omega 3 fatty acids (EPA) had advantage over placebo ( $n=76,1$ RCT, RR transition to psychosis 0.13 CI 0.02 to 1.0 , NNT 6 CI 5 to 96). We know of no replications of this finding.

The remaining trials aimed to improve outcome in first-episode psychosis. Phase-specific CBT for suicidality seemed to have little effect, but the single study was small $(\mathrm{n}=56,1 \mathrm{RCT}$, RR suicide $0.81 \mathrm{CI} 0.05$ to 12.26). Family therapy plus a specialised team in the Netherlands did not clearly affect relapse (n=76, RR 1.05 CI 0.4 to 3.0), but without the specialised team in China it may ( $\mathrm{n}=83,1 \mathrm{RCT}$, RR admitted to hospital 0.28 CI 0.1 to 0.6 , NNT 3 CI 2 to 6 ). The largest and highest quality study compared specialised team with standard care. Leaving the study early was reduced ( $\mathrm{n}=547,1 \mathrm{RCT}$, RR $0.59 \mathrm{CI} 0.4$ to 0.8 , NNT 9 CI 6 to 18) and compliance with treatment improved ( $\mathrm{n}=507$, RR stopped treatment $0.20 \mathrm{CI} 0.1$ to 0.4 , NNT 9 CI 8 to 12). The mean number of days spent in hospital at one year were not significantly different ( $\mathrm{n}=507, \mathrm{WMD},-1.39 \mathrm{CI}-2.8$ to 0.1 ), neither were data for 'Not hospitalised' by five years ( $n=547$, RR 1.05 CI 0.90 to 1.2). There were no significant differences in numbers 'not living independently' by one year $(n=507$, RR 0.55 CI 0.3 to 1.2). At five years significantly fewer participants in the treatment group were 'not living independently' ( $\mathrm{n}=547$, RR 0.42 CI 0.21 to 0.8 , NNT 19 CI 14 to 62). When phasespecific treatment (CBT) was compared with befriending no significant differences emerged in the number of participants being hospitalised over the 12 months ( $\mathrm{n}=62,1 \mathrm{RCT}, \mathrm{RR} 1.08 \mathrm{CI} 0.59$ to 1.99).

Phase-specific treatment E-EPA oils suggested no benefit ( $\mathrm{n}=80,1 \mathrm{RCT}$, RR no response $0.90 \mathrm{CI}$ 0.6 to 1.4 ) as did phase-specific treatment brief intervention ( $n=106,1$ RCT, RR admission 0.86 CI 0.4 to 1.7). Phase-specific ACE found no benefit but participants given vocational intervention were more likely to be employed ( $\mathrm{n}=41,1 \mathrm{RCT}$, RR 0.39 CI 0.21 to 0.7 , NNT 2 CI 2 to 4). Phasespecific cannabis and psychosis therapy did not show benefit ( $\mathrm{n}=47$, RR cannabis use $1.30 \mathrm{CI} 0.8$ to 2.2) and crisis assessment did not reduce hospitalisation ( $\mathrm{n}=98$, RR 0.85 CI 0.6 to 1.3 ). Weight was unaffected by early behavioural intervention.

Authors' conclusions-There is emerging, but as yet inconclusive evidence, to suggest that people in the prodrome of psychosis can be helped by some interventions. There is some support for specialised early intervention services, but further trials would be desirable, and there is a question of whether gains are maintained. There is some support for phase-specific treatment focused on employment and family therapy, but again, this needs replicating with larger and longer trials. 


\section{Medical Subject Headings (MeSH)}

*Psychotic Disorders [diagnosis; therapy]; *Schizophrenia [diagnosis; therapy]; Cognitive Therapy; Early Diagnosis; Randomized Controlled Trials as Topic; Suicidal Ideation; Time Factors

\section{MeSH check words}

Humans

\section{BACKGROUND}

Schizophrenia and other functional psychoses cause enormous suffering for individuals and their families, and are a financial burden to the NHS and other health services. The estimated total cost of schizophrenia in England was £6.7 billion in 2004/05; the direct cost of treatment and care was $£ 2$ billion, whilst the indirect cost to society was $£ 4.7$ billion, and the cost of informal care and private expenditure was $£ 615$ million (Mangalore 2007). Despite new medications and the development of community care, about one-third of people with schizophrenia have a poor long-term outcome (Mason 1997). An overview of studies investigating outcomes has shown that people with schizophrenia have a one-year relapse rate of $15 \%$ to $35 \%$, rising to $80 \%$ within five years (Larsen 1998). Achievement of full remission becomes less likely after each relapse, and about $10 \%$ of sufferers eventually commit suicide (Wiersma 1998).

\section{Description of the condition}

Schizophrenia is a chronic, relapsing mental illness and has a worldwide lifetime prevalence of about $1 \%$ irrespective of culture, social class and race. Schizophrenia is characterised by positive symptoms such as hallucinations, delusions and jumbled thinking; and negative symptoms such as apathy, poverty of speech, and withdrawal from social activities.

\section{Description of the intervention}

Early intervention in psychosis has two elements that are distinct from standard care: early detection and phase-specific treatment. Early detection may be defined as either the identification of people thought likely to develop psychosis (i.e. those who display prodromal symptoms, but have never been psychotic (Schaffner 2001)) or the identification of people who are already psychotic, but have not yet received adequate treatment (Wyatt 2001).

Phase-specific treatments are defined as treatments (psychological, social or physical) that are especially targeted at people in the prodrome or early stages of schizophrenia (Miller 1999). Phase-specific treatments may be directed at preventing progression to psychosis (in people with prodromal symptoms), or at promoting recovery (in people who have recently experienced their first episode of psychosis).

Early detection and phase-specific treatments may be provided as supplements to standard psychiatric care, or they may be provided by means of a specialised early intervention team 
(Garety 2000). Such teams provide care exclusively to people who have prodromal symptoms or are in early stages of schizophrenia (Edwards 2000). Prodromal patients are usually assessed by the attenuated psychotic symptom criteria, using either the criteria by Yung 2005 or the Scale of Psychotic Symptoms (SOPS, Miller 1999). A second method, is the detection of 'basic symptoms' developed in Germany (Schultze-Lutter 2007). When people are referred to as 'ultra high risk' they are using the Yung 2005 criteria. When they are referred to as early or late initial prodrome state, they are using basic symptoms.

\section{How the intervention might work}

Until recently, the orthodox approach to treating schizophrenia was to concentrate therapeutic resources on those people who developed severe and chronic disabilities (McGorry 1999). This approach has been challenged by proponents of early intervention, who have argued that greater investment of resources in the early stages of the disorder might substantially reduce the numbers of people developing chronic disabilities (Wyatt 1991). This argument has been strengthened by the observation that there may be an association between various outcome parameters and the duration of untreated psychosis (the time from the development of the first psychotic symptom to the receipt of adequate drug treatment) (Norman 2001). This has led to the proposition that untreated psychosis may be 'toxic' and that early intervention might prevent irreversible harm (Sheitman 1998).

\section{Why it is important to do this review}

The arguments in favour of early intervention have been so persuasive that early intervention teams are well-established in America, Europe and Australasia (Edwards 2002). In 2000, the UK government announced its intention to set up 50 early intervention teams in England to provide specialised care to all young people with a first episode of psychosis (DoH 2000). It remains unclear, however, how far these service developments are underpinned by evidence of effectiveness. There is particular concern over the ethics of early intervention with prodromal patients, when the benefits of early detection and treatment are unclear, and there is no certainty that they will go on to develop psychosis (Rosen 2000).

\section{OBJECTIVES}

To evaluate the effects of early intervention in the treatment of early psychosis.

The two specific objectives were to determine the following.

1. The effects of early detection and treatment of people with 'prodromal' symptoms, in terms of:

1.1 prevention of progression to full-blown psychosis;

1.2 clinical and social outcomes;

1.3 process variables and costs. 
2. To determine the effects of early detection and treatment of people in their first episode of psychosis, in terms of:

2.1 clinical and social outcomes;

2.2 prevention of relapse;

2.3 process variables and costs;

2.4 reduction in duration of untreated psychosis.

We defined 'Treatment' as including both phase-specific treatments and care from a specialised early intervention team. We are not concerned with evaluating the accuracy of methods of predicting who is likely to develop psychosis.

\section{METHODS}

\section{Criteria for considering studies for this review}

Types of studies-We included studies if they were randomised controlled trials (RCTs). We accepted cluster-randomised trials and listed non-randomised trials in the Characteristics of excluded studies table.

In broad terms we have included two types of trial in this review.

1. Trials to prevent the development of psychosis: These studies involved treatments and/or methods of management that are given to people who are believed to be showing prodromal (pre-psychotic) symptoms and are therefore considered at high risk of developing psychosis. The primary aim of such studies was to prevent progression to psychosis, and invariably the interventions they offered were combined with some method of early detection of people at risk.

\section{Trials to improve outcome in first-episode psychosis: These studies involved} treatments and/or methods of management designed for people in the early stages of psychosis. The primary aim of such studies was to improve the long term outcome. Early detection might be offered in addition to the treatments, with the aim of ensuring that the treatment was offered as early as possible after the onset of psychosis.

Types of participants-1. For trials to prevent the development of psychosis, we included people who were judged by the trialists to be in a prodromal phase of psychosis, on the basis of showing prodromal symptoms (however defined).

2. For trials to improve outcome in first-episode psychosis, we included people who were in their first episode of psychosis, or were in the process of recovering from their first episode. People with psychosis were defined as those presenting with any combination of delusions, hallucinations or thought disorder, or those who had been given a diagnosis of schizophrenia or schizophrenia-like disorder, bipolar disorder (manic episode i.e. with psychotic symptoms), or depression with psychotic features. 
We excluded trials where the majority of participants were suffering from a learning disability or an organic psychosis. We did not exclude anyone for reasons such as age or type of psychosis (for example, affective psychosis). Where studies included both first and second episode participants, we excluded trials if more than $10 \%$ of the participants included in the study had experienced a second episode,

Types of interventions-In trials of early intervention there are many possible combinations of intervention and control condition. This depends on: the type of participant (prodromal or first episode); whether the trial involved early detection (which could involve the whole sample or just the treatment group); the type of intervention (phase-specific or specialised team); the nature of any phase-specific treatment (cognitive therapy, family therapy etc); and the type of control (no treatment, standard psychiatric care, care from a specialised team but not phase specific intervention, etc.). In this section the most likely combinations of intervention and control conditions are listed for trials to prevent the development of psychosis and trials to improve outcome in first-episode psychosis.

\section{Trials to prevent the development of psychosis in prodromal patients: These trials} require prodromal patients, and since such patients do not normally present to psychiatric services, the trials therefore require some form of early detection to be applied to the whole sample. The intervention may consist of: phase-specific treatment (medication, psychological treatment or other) or care from a specialised team (which might offer phasespecific treatments). The control condition may consist of no treatment, or standard psychiatric care, or care from a specialised team (in which case the intervention will consist of care from a specialised team plus a phase specific intervention). The various types of intervention and control condition are described in more detail below.

1.1 Phase-specific treatment: In the context of preventing psychosis, phase-specific treatments are discrete interventions including medication regimes, which have been specifically developed for use in patients experiencing prodromal symptoms. A phasespecific treatment could be offered by an individual therapist or provided in the context of receiving care from a specialised team (see 1.2 below). More than one phase-specific treatment might be offered at the same time (for example, medication regime and cognitive therapy).

1.2 Care from a specialised team: In the context of preventing psychosis, this is defined as a multi-disciplinary psychiatric team, specialising in the treatment of patients with prodromal symptoms. Such a team would normally provide comprehensive psychiatric care to its patients and would be an alternative, rather than an addition, to standard psychiatric care. In the context of a trial it is likely that any specialised team would also offer phase-specific interventions.

1.3 Control conditions: In the context of preventing psychosis, the common control conditions are: no treatment; non-specific supportive therapy or care from a specialised team (which did not offer phase-specific treatments to prevent onset of psychosis). 
2. Trials to improve outcome in first-episode psychosis: The intervention may consist of: early detection; phase-specific treatments (medication, psychological intervention or other) or care from a specialised team (which might offer phase-specific treatments). The control condition may consist of standard psychiatric care or care from a specialised team (in which case the intervention will consist of care from a specialised team plus a phase-specific intervention). A 'no treatment' control group is not an ethically acceptable option in firstepisode psychosis trials. The various types of intervention and control condition are described in more detail below.

2.1 Early detection: In trials to improve outcome in first-episode psychosis it is possible to use early detection as an intervention applied to the treatment group alone; this is in contrast to the situation in trials designed to prevent psychosis (see 1. above) where early detection must be applied to both treatment and control groups. The theoretical basis for using early detection as an intervention is that shortening the duration of untreated psychosis in itself improves outcome. In trials where early detection is the intervention being tested, the unit of randomisation must be a cluster (for example, general practices or catchment areas), since it is not possible to individually randomise patients who have not yet been diagnosed.

2.2 Phase-specific treatment: In the context of improving outcome in the first episode, phase-specific treatments are discrete treatments and include medication regimes which have been specifically developed for use in the early stages of psychosis. A phase-specific treatment can be offered by an individual therapist or provided in the context of receiving care from a specialised team (see 2.3 below). More than one phase-specific treatment might be offered at the same time (for example, medication regime and cognitive therapy).

2.3 Care from a specialised team: In the context of improving outcome in first episode, this is defined as a multi-disciplinary psychiatric team, specialising in the treatment of patients with first-episode psychosis. Such a team would normally provide comprehensive psychiatric care to its patients and is an alternative, rather than an addition, to standard psychiatric care. In the context of a trial, it is likely that any specialised team would also offer phase-specific interventions.

2.4 Control conditions: In the context of improving outcome in first episode, the common control conditions are standard care, or care from a specialised team (which does not offer the phase-specific treatment being provided in the treatment arm of the trial). Standard care would be the normal service for people with severe psychiatric illness in the region where the trial took place, and would normally consist of out-patient follow up, medication, and support form a community mental health team, but would not involve any phase-specific treatment or specialised team.

3. Excluded interventions: We considered treatment with low doses of neuroleptic medication (atypical or standard) a phase-specific treatment if given to prevent progression to psychosis, or in the context of a medication protocol designed specifically for treating patients in their first episode of psychosis. However, simple comparisons of atypical neuroleptic medication versus standard neuroleptics in first-episode patients were beyond the scope of this review. 


\section{Types of outcome measures}

Primary outcomes: For trials to prevent the development of psychosis (i.e. prodromal participants) the primary outcomes were as follows.

\section{General}

1.1 Converting to psychosis during follow-up period: For trials to improve the outcome of first-episode psychosis the outcomes were as follows.

\section{General}

Secondary outcomes: For trials to prevent the development of psychosis (i.e. prodromal participants) the secondary outcomes were as follows.

1. General: 1.1 Overall functioning

1.2 Duration of hospital stay

1.3 Loss to follow up

1.4 Satisfaction with treatment - participant/carer

1.5 Remaining in contact

2. Mental state: 2.1 General symptoms

2.2 Specific symptoms

2.2.1 Positive symptoms (delusions, hallucinations, disordered thinking)

2.2.2 Negative symptoms (avolition, poor self-care, blunted affect)

2.2.3 Mood - depression

3. Behaviour: 3.1 General behaviour

3.2 Specific behaviours (for example, aggressive or violent behaviour)

3.2.1 Social functioning

3.2.2 Employment status during trial (employed/unemployed)

3.2.3 Occurrence of violent incidents (to self, others or property)

4. Adverse effects: 4.1 General

4.2 Specific

4.2.1 Death (suicide and non-suicide) 
4.2.2 Movement disorders (extrapyramidal side effects, specifically tardive dyskinesia and neuroleptic malignant syndrome)

\subsubsection{Sedation}

4.2.4 Dry mouth

4.2.5 Weight gain

5. Economic: 5.1 Cost of care

6. Quality of life: 6.1 No substantial improvement in quality of life

For trials to improve the outcome of first-episode psychosis the secondary outcomes were:

1. General: 1.1 Overall functioning

1.2 Hospital readmission

1.3 Duration of hospital stay

1.4 Loss to follow-up

1.5 Satisfaction with treatment - participant/carer

1.6 Remaining in contact with services

2. Mental state: 2.1 General symptoms

2.2 Specific symptoms

2.2.1 Positive symptoms (delusions, hallucinations, disordered thinking)

2.2.2 Negative symptoms (avolition, poor self-care, blunted affect)

2.2.3 Mood - depression

3. Behaviour: 3.1 General behaviour

3.2 Specific behaviours (for example, aggressive or violent behaviour)

3.2.1 Social functioning

3.2.2 Employment status during trial (employed/unemployed)

3.2.3 Occurrence of violent incidents (to self, others or property)

4. Adverse effects: 4.1 General

4.2 Specific 
4.2.1 Death (suicide and non-suicide)

4.2.2 Movement disorders (extrapyramidal side-effects, specifically tardive dyskinesia and neuroleptic malignant syndrome)

\subsubsection{Sedation}

4.2.4 Dry mouth

4.2.5 Weight gain

\section{Economic: 5.1 Cost of care}

\section{Search methods for identification of studies}

We applied no language restrictions within the limitations of the search.

\section{Electronic searches}

1. Cochrane Schizophrenia Group Trials Register (March 2009): The register was searched using the phrase:

[early* in title, abstract or keywords of REFERENCE] or [Early* in intervention or prodromal* or early*' in Health Care Condition of STUDY]

This register is compiled by systematic searches of major databases, hand searches and conference proceedings (see Group Module).

\section{Previous searches for earlier versions of this review: Please see Appendix 1.}

\section{Searching other resources}

1. Reference lists: We inspected reference lists of all identified trials and reviews for additional trials.

2. Personal contact: We contacted experts in the field within the European First Episode Network (2003) to identify unpublished trials.

\section{Data collection and analysis}

Selection of studies-We (MM and AL) searched The Cochrane Schizophrenia Group's register. Working independently we examined the papers identified from the search strategy. We discarded obviously irrelevant publications and retained only those in which some form of early intervention had been compared against a control treatment, and obtained copies of papers relating to relevant trials. Once we had obtained these papers, we decided whether the trials were eligible. We resolved any disagreements by discussion. For the 2006 update we (MM and JR) independently inspected citations. Where disagreement occurred, we sought to resolve this by discussion, or where doubt remained, we acquired the full article for further inspection. Once we had obtained the full articles, we independently decided whether they met the review criteria. We resolved any disagreements that occurred by 
discussion, and when this was not possible we added trials to the list of those awaiting assessment until we acquired further information. For the 2009 update we (MM and JR) inspected all study citations identified by the searches, and obtained full reports of the studies of agreed relevance.

\section{Data extraction and management}

1. Extraction: We (MM, AL) independently extracted and entered trial data into Review Manager (RevMan) twice, cross-checking for consistency (RevMan 2008). An initial analysis included all trials meeting inclusion criteria, whilst a second sensitivity analysis excluded all but the highest quality trials (Category A and B). For the 2006 and 2010 update, we (MM and JR) independently extracted and entered data into RevMan, cross-checking again for consistency. Where disputes arose, we attempted to resolve these by discussion. When this was not possible and further information was needed to resolve the dilemma, we did not enter the data, and added this outcome of the trial to the list of those awaiting assessment.

\section{Management}

2.1 Forms: We extracted the data onto standard, simple forms.

2.2 Direction of graphs: Where possible, we entered data into RevMan in such a way that the area to the left of the 'line of no effect' indicates a 'favourable' outcome for early intervention. Where this was not possible, (for example, scales that calculate higher scores=improvement) we inserted a minus sign into the data tables to reverse the graphical display in RevMan analyses so that the direction of effect was clear.

2.3 Scale-derived data: Unpublished scales are known to be subject to bias in trials of treatments for schizophrenia (Marshall 2000). Therefore we only included continuous data from rating scales were if the measuring instrument had been described in a peer-reviewed journal.

2.4 Skewed data: Continuous data on outcomes in trials relevant to mental health issues are often not normally distributed. To avoid the pitfall of applying parametric tests to nonparametric data we applied the following standards to continuous final value endpoint data before inclusion: (a) standard deviations and means were reported in the paper or were obtainable from the authors; (b) when a scale started from zero, the standard deviation, when multiplied by two, should be less than the mean (otherwise the mean is unlikely to be an appropriate measure of the centre of the distribution - Altman 1996); in cases with data that are greater than the mean we entered them into the 'Other data' table as skewed data. Where the skewed data are derived from a trial with $\geqq 200$ participants, the skewed data pose less of a problem when looking at means if the sample size is large and were entered into syntheses.

If a scale starts from a positive value (such as PANSS, which can have values from 30 to 210) the calculation described above in (b) should be modified to take the scale starting point into account. In these cases skewness is present if $2 \mathrm{SD}>(\mathrm{S}-\mathrm{Smin})$, where $\mathrm{S}$ is the mean 
score and Smin is the minimum score. We reported non-normally distributed data (skewed) in the 'other data types' tables. For change data (mean change from baseline on a rating scale) it is impossible to tell whether data are non-normally distributed (skewed) or not, unless individual patient data are available. After consulting the ALLSTAT electronic statistics mailing list, we entered change data in RevMan analyses and reported the finding in the text to summarise available information. In doing this, we assumed either that data were not skewed or that the analysis could cope with the unknown degree of skew.

2.5 Final endpoint value versus change data: Where both final endpoint data and change data were available for the same outcome category, only final endpoint data were presented. We acknowledge that by doing this much of the published change data may be excluded, but argue that endpoint data is more clinically relevant and that if change data were to be presented along with endpoint data, it would be given undeserved equal prominence. Where studies reported only change data we contacted authors for endpoint figures.

2.6 Common measure: To facilitate comparison between trials, we converted variables (such as days in hospital) that could be reported in different metrics (mean days per year, per week or per month) to a common metric (for example, mean days per month).

2.7 Conversion of continuous to binary: Where possible, efforts were made to convert outcome measures to dichotomous data. This could be done by identifying cut-off points on rating scales and dividing participants accordingly into 'clinically improved' or 'not clinically improved'. It was generally assumed that if there had been a 50\% reduction in a scale-derived score such as the Brief Psychiatric Rating Scale (BPRS, Overall 1962) or the Positive and Negative Syndrome Scale (PANSS, Kay 1986), this could be considered as a clinically significant response (Leucht 2005a; Leucht 2005b). If data based on these thresholds were not available, we used the primary cut-off presented by the original authors.

2.8 Summary of findings table: For the 2011 version of the review we had available to us the possibility of producing Summary of Findings tables. These should be considered before being biased by the results of analyses, but for us this is impossible. We have chosen to present two - but this choice is post hoc. We chose to present data from PACE-Australia and OPUS-Scandinavia as these are benchmark trials in this area and outcomes from these trials that we think to be clinically important.

- Progression to psychosis

- Compliance with treatment - treatment stopped in spite of need

- Leaving the study early

- Service use: 1 . Average mean number of days per month in hospital

- Service use: 2. Not hospitalised

- Social outcomes: 1. Not living independently

- Social outcomes: 2. Not working or in education 
Assessment of risk of bias in included studies-Again working independently, we assessed risk of bias using the tool described in the Cochrane Handbook for Systematic Reviews of Interventions (Higgins 2008). This tool encourages consideration of how the sequence was generated, how allocation was concealed, the integrity of blinding at outcome, the completeness of outcome data, selective reporting and other biases. We would not have included studies where sequence generation was at high risk of bias or where allocation was clearly not concealed.

The categories are defined below.

- YES - low risk of bias

- NO - high risk of bias

- UNCLEAR - uncertain risk of bias

If disputes arose as to which category we should allocate a trial, again, we achieved resolution by discussion, after working with a third reviewer.

Earlier versions of this review used a different, less well-developed, means of categorising risk of bias (see Appendix 2).

\section{Measures of treatment effect}

1. Binary data: For binary outcomes we calculated an estimate of the risk ratio (RR) and its 95\% (fixed-effect) confidence intervals (CI). RR is more intuitive (Boissel 1999) than odds ratios and odds ratios tend to be interpreted as RR by clinicians (Deeks 2000). This misinterpretation then leads to an overestimate of the impression of the effect. When the overall results were significant we calculated the number needed to treat/harm (NNT/NNH) using Visual Rx.

2. Continuous data: For continuous outcomes we estimated mean difference (MD) between groups. We preferred not to calculate effect size measures (standardised mean difference SMD). However, had scales of very considerable similarity been used, we would have presumed there was a small difference in measurement, and we would have calculated effect size and transformed the effect back to the units of one or more of the specific instruments.

\section{Unit of analysis issues}

1. Cluster trials: Studies increasingly employ cluster randomisation (such as randomisation by clinician or practice), but analysis and pooling of clustered data pose problems. Firstly, authors often fail to account for intra-class correlation in clustered studies, leading to a unitof-analysis error (Divine 1992) whereby P values are spuriously low, confidence intervals unduly narrow and statistical significance overestimated. This causes Type I errors (Bland 1997; Gulliford 1999).

Where clustering had not been accounted for in primary studies, we presented the data in a table, with a (*) symbol to indicate the presence of a probable unit of analysis error. In subsequent versions of this review we will seek to contact first authors of studies to obtain 
intra-class correlation co-efficients (ICCs) of their clustered data and to adjust for this using accepted methods (Gulliford 1999). Where clustering has been incorporated into the analysis of primary studies, we will also present these data as if from a non-cluster randomised study, but adjusted for the clustering effect.

We have sought statistical advice and have been advised that the binary data as presented in a report should be divided by a design effect. This is calculated using the mean number of participants per cluster (M) and the ICC (Design effect=1+ (M -1)*ICC) (Donner 2002). If the ICC is not reported we assumed it to be 0.1 (Ukoumunne 1999). If cluster studies had been appropriately analysed taking into account ICCs and relevant data documented in the report, we synthesised these with other studies using the generic inverse variance technique.

2. Cross-over design: A major concern of cross-over trials is the carry-over effect. It occurs if an effect (for example, pharmacological, physiological or psychological) of the treatment in the first phase is carried over to the second phase. As a consequence, on entry to the second phase the participants can differ systematically from their initial state, despite a wash-out phase. For the same reason cross-over trials are not appropriate if the condition of interest is unstable (Elbourne 2002). As both effects are very likely in schizophrenia, we will only use data of the first phase of cross-over studies.

3. Studies with multiple treatment groups: We presented studies involving more than two treatment arms, if relevant, in comparisons.

\section{Dealing with missing data}

1. Overall loss of credibility: At some degree of loss to follow-up data must lose credibility (Xia 2007). We are forced to make a judgment where this is for the trials likely to be included in this review. Should more than $50 \%$ of data be unaccounted for by eight weeks, we did not reproduce these data or use them within analyses.

\section{Intention to treat analysis}

2.1 Binary data: We excluded data from studies where more than 50\% of participants in any group were lost to follow-up (this did not include the outcome of 'leaving the study early'). In studies with less than 50\% dropout rate, people leaving early were considered to have had the negative outcome, For example, those lost to follow-up for the outcome of relapse were treated in the analysis as having relapsed. Suicide was treated as relapse.

\subsection{Continuous data}

2.2.1 Attrition: In the case where attrition for a continuous outcome is between $0 \%$ and $50 \%$ and completer-only data were reported, we have reproduced these.

2.2.2 Standard deviations: We first tried to obtain the missing values from the authors. If not available, where there were missing measures of variance for continuous data but an exact standard error and confidence interval were available for group means, and either $\mathrm{P}$ value or $\mathrm{T}$ value were available for differences in mean, we noted these, and in future versions will calculate them according to the rules described in the Handbook (Higgins 
2008): When only the standard error (SE) is reported, standard deviations (SDs) can be calculated by the formula $\mathrm{SD}=\mathrm{SE} *$ square root (n). Chapters 7.7.3 and 16.1.3 of the Handbook (Higgins 2008) present detailed formula for estimating SDs from P values, T or F values, confidence intervals, ranges or other statistics. If these formula do not apply, we, in the future will calculate SDs according to a validated imputation method which is based on the SDs of the other included studies (Furukawa 2006). Some of these imputation strategies can introduce error. The alternative would be to exclude a given study's outcome and thus to lose information. We will examine the validity of the imputations in a sensitivity analysis excluding imputed values.

2.2.3 Last observation carried forward: We anticipated that in some studies the method of last observation carried forward (LOCF) would be employed within the study report. As with all methods of imputation to deal with missing data, LOCF introduces uncertainty about the reliability of the results. Therefore, where LOCF data have been used in the trial, if less than $50 \%$ of the data had been assumed, we reproduced these data and indicated that they are the product of LOCF assumptions.

\section{Assessment of heterogeneity}

1. Clinical heterogeneity: We considered all included studies initially, without seeing comparison data, to judge clinical heterogeneity. We simply inspected all studies for clearly outlying situations or people which we had not predicted would arise. When such situations or participant groups arose, we would have fully discussed these.

2. Methodological heterogeneity: We considered all included studies initially, without seeing comparison data, to judge methodological heterogeneity. We simply inspected all studies for clearly outlying methods which we had not predicted would arise. Should such methodological outliers arise we would have fully discussed these.

\section{Statistical heterogeneity}

3.1 Visual inspection: We visually inspected graphs to investigate the possibility of statistical heterogeneity.

3.2 Employing the $\mathbf{I}^{2}$ statistic: We investigated heterogeneity between studies by considering the $\mathrm{I}^{2}$ method alongside the $\mathrm{Chi}^{2} \mathrm{P}$ value. The $\mathrm{I}^{2}$ provides an estimate of the percentage of inconsistency thought to be due to chance (Higgins 2003). The importance of the observed value of $\mathrm{I}^{2}$ depends on $\mathrm{i}$. magnitude and direction of effects and ii. strength of evidence for heterogeneity (e.g. P value from $\mathrm{Chi}^{2}$ test, or a confidence interval for $\mathrm{I}^{2}$ ). We interpreted $\mathrm{I}^{2}$ estimate greater than or equal to $50 \%$ accompanied by a statistically significant $\mathrm{Chi}^{2}$ statistic as evidence of substantial levels of heterogeneity (Section 9.5.2 Higgins 2008). When substantial levels of heterogeneity were found in the primary outcome, we explored reasons for heterogeneity (Subgroup analysis and investigation of heterogeneity).

Assessment of reporting biases-Reporting biases arise when the dissemination of research findings is influenced by the nature and direction of results. These are described in 
section 10.1 of the Handbook (Higgins 2006). We are aware that funnel plots may be useful in investigating reporting biases but are of limited power to detect small-study effects (Egger 1997). We did not use funnel plots for outcomes where there were 10 or fewer studies, or where all studies were of similar sizes. In other cases, where funnel plots were possible, we sought statistical advice in their interpretation.

Data synthesis-Where possible we employed a fixed-effect model for analyses. We understand that there is no closed argument for preference for use of fixed-effect or randomeffects models. The random-effects method incorporates an assumption that the different studies are estimating different, yet related, intervention effects. This does seem true to us; however, random-effects does put added weight onto the smaller of the studies - those trials that are most vulnerable to bias. For this reason we favour using the fixed-effect model.

\section{Subgroup analysis and investigation of heterogeneity}

1. Subgroup analyses: We did not anticipate subgroup analyses.

2. Investigation of heterogeneity: If inconsistency was high, we have reported this. First we investigated whether data had been entered correctly. Second, if data had been correct, we visually inspected the graph and successively removed studies outside of the company of the rest to see if homogeneity was restored. Should this occur with no more than $10 \%$ of the data being excluded, we have presented data. If not, we have not pooled data and have discussed relevant issues.

Should unanticipated clinical or methodological heterogeneity be obvious we simply stated hypotheses regarding these for future reviews or versions of this review. We did not anticipate undertaking analyses relating to these.

Sensitivity analysis-For the 2011 version of this review we did not anticipate undertaking any additional sensitivity analyses.

\section{RESULTS}

\section{Description of studies}

See: Characteristics of included studies; Characteristics of excluded studies; Characteristics of studies awaiting classification; Characteristics of ongoing studies.

For substantive descriptions of studies, please see Characteristics of included studies; Characteristics of excluded studies; Characteristics of ongoing studies.

Results of the search-The original search strategy identified 9279 abstracts, of which 184 referred to potentially eligible studies and 155 reviews of early intervention (Figure 1). From these we identified 100 relevant studies, of which 43 did not meet inclusion criteria. We were able to include three studies and the remainder are awaiting classification. For substantive descriptions of studies, please see the Characteristics of included studies and Characteristics of excluded studies tables. 
For the 2006 update search we identified 159 new citations and were able to include four additional studies.

During the 2009 update search we identified 830 references (from 420 studies) and were able to include 11 additional studies (Alvarez-Spain; Amminger-Austria; Berger-Australia; Edwards-Australia; EIPS-Germany; Jackson-Australia; Killackey-Australia; Leavey-UK; LEO-CAT-UK; LIPS-Germany; Uzenoff-USA).

Included studies-We included 18 studies with 1808 participants.

1. Methods: For description of methods - please see Risk of bias in included studies.

\section{Participants and setting}

2.1 Participants with prodromal symptoms - and setting: Six trials (Amminger-Austria, EIPS-Germany, EDIE-UK, LIPS-Germany, PACE-Australia, PRIME-USA) were concerned with preventing the onset of psychosis.

EIPS-Germany undertook the research in community settings in Cologne, Bonn, Dusseldorf, and Munich. The participants had a mean age of 26 years and were judged at risk of psychosis because they met the criteria for the Early Initial Prodrome State according to the presence of Basic Symptoms. The LIPS-Germany study was undertaken in the same settings as EIPS-Germany, but included late prodrome participants who were at risk of psychosis according to the Basic Symptom criteria for Late Initial Prodrome State (where conversion to psychosis is considered more imminent than in the Early Initial Prodrome State).

Participants had a mean age of 25 years. EDIE-UK recruited participants from primary care teams (general practitioners, practice nurses and psychological therapists), student counselling services, accident and emergency departments, specialist services (community drug and alcohol teams, child and adolescent psychiatry and adult psychiatry services) and voluntary sector agencies. Participants had a mean age of 21 years and were judged to have an 'ultra high risk' of developing a first episode of psychosis (Yung's Criteria Yung 2005).PACE-Australia recruited participants referred to the Personal Assessment and Crisis Evaluation clinic, which is part of the EPPIC programme. Participants were from 14 to 30 years of age, and met Yung criteria for an 'ultra high risk' mental state (see included studies table for details). PRIME-USA recruited people from referrals and by participants responding to study advertisements. Participants were aged from 12 to 36 years with a diagnosis of being at risk of developing psychosis according to SOPS criteria (similar to Yung's criteria for the 'ultra high risk' mental state). Participants were recruited at four sites (three in the USA and one in Canada). Amminger-Austria recruited outpatients at the Vienna General Hospital who were at risk of developing first-episode psychosis according to Yung's criteria for the 'ultra high risk' mental state. Participants were eligible if they were aged from 13-24 years; the mean age of the participants was 16.4 years.

2.2 Participants with first-episode psychosis and setting: Twelve trials were concerned with improving outcome in first-episode psychosis (Alvarez-Spain; Berger-Australia; EdwardsAustralia; Jackson-Australia; Killackey-Australia; Leavey-UK; LEO-CAT-UK; LifeSPANAustralia; Linszen-Amsterdam; OPUS-Scandinavia; Uzenoff-USA; Zhang-China). 
Alvarez-Spain included drug naïve participants with a DSM-IV diagnosis of psychosis, and a mean age of 26 years; the trial was set in the community. Edwards-Australia included participants with first-episode psychosis diagnosed as having a psychotic disorder using DSM-IV criteria. The study was undertaken at the EPPIC centre in Melbourne, Australia. Berger-Australia recruited participants in Melbourne, Australia (EPPIC Centre); participants had an average age of 20 years, and a mean antipsychotic treatment exposure prior to study of 17.5 days. Jackson-Australia included people with a mean onset of psychosis at 22 years; the settings used were at the participant's home, a neutral location or the EPPIC centre. Leavey-UK included first-episode psychosis patients who had been diagnosed within the last six months and were recruited from psychiatric services in North London. LEO-CAT-UK included participants with first-episode psychosis (Yung's criteria) with a mean age of 23 years. The study was undertaken in community settings within the borough of Lambeth, London, UK. LifeSPAN-Australia recruited participants from the Western region of Melbourne, Australia and is part of the EPPIC programme, which includes an early detection and crisis assessment team. Participants were aged 15 to 29 years, and were acutely suicidal. Linszen-Amsterdam recruited participants aged from 15 to 26 who were experiencing their first episode of schizophrenia and living in close contact with parents or relatives. All participants were recruited from an adolescent clinic and had to agree to an initial three months' inpatient programme before randomisation. Subsequent treatment took place on an outpatient basis. OPUS-Scandinavia recruited first-episode psychosis (ICD 10) patients from inpatient and outpatient departments in Denmark; participants were aged 18 to 45. Zhang-China recruited only men who had just been discharged from Suhoz Psychiatric Hospital in China, following their first admission for schizophrenia. The intervention and standard care were provided on an outpatient basis. Killackey-Australia enrolled participants from the EPPIC programme with first-episodepsychosis; participants had a mean age of 21 years. Uzenoff-USA recruited participants with first episode schizophrenia in the USA.

3. Study size: OPUS-Scandinavia was the largest study, and had a sample size $(n=547)$ which was arrived at using a pre-study power calculation. The other trials were small and, in ascending order of size, were:Uzenoff-USA (24), Killackey-Australia (41), EdwardsAustralia (47), LifeSPAN-Australia (56), PACE-Australia (59), EDIE-UK (60), PRIMEUSA (60), Alvarez-Spain (61), Jackson-Australia (62), Linszen-Amsterdam (76), BergerAustralia (80), Amminger-Austria (81), Zhang-China (83), Leavey-UK (106), LEO-CATUK (113), LIPS-Germany (124) and EIPS-Germany (128).

\section{Intervention}

4.1 Trials to prevent the onset of psychosis: Six trials (Amminger-Austria; EIPS-Germany; LIPS-Germany; EDIE-UK; PACE-Australia; PRIME-USA) were concerned with preventing the onset of psychosis.

Amminger-Austria compared omega-3 fatty acids (eicosapentaenoic acid and docosahexaenoic acid) with placebo over three months in adolescents at risk of first-episode psychosis according to the criteria of Yung 2005. 
EIPS-Germany employed a complex intervention consisting of 12 months of cognitive behaviour therapy (CBT) delivered in group and individual therapy sessions, supplemented by cognitive remediation therapy. The participants were at risk of developing first episode of psychosis and met the early initial prodromal state criteria. The control group were given supportive therapy sessions which only provided minimal support involving psychoeducation and counselling.

LIPS-Germany employed a needs focused intervention combined with amisulpride (mean dose $118 \mathrm{mg} /$ day) in participants judged at risk of psychosis because of the presence of prodromal symptoms. The control group also received the needs focused intervention but without amisulpride. The needs focused intervention included psychoeducation, crisis intervention, family counselling and assistance with education or work related difficulties according to the patient's need.

The Early Detection and Intervention Evaluation trial (EDIEUK) used cognitive therapy, limited to a maximum of 26 sessions over six months, following the principles developed by Beck 1976. The therapy was problem-orientated and time limited and was carried out by experienced cognitive therapists. Both control and treatment group received regular monitoring. Whilst participants (treatment and control) were not given medication, both treatment and control received elements of case management in order to resolve crises regarding social issues and mental health risk.

In PACE-Australia the intervention involved prescription of low dose risperidone (1-2 mg/ day) combined with modified CBT, which aimed to enhance understanding and control of symptoms. Both the intervention and control groups also received case management from a PACE therapist. This involved supportive psychotherapy, assistance with accommodation and education/employment, and family support. Participants in the control and intervention groups received standard treatment if they developed psychosis, but control patients were not otherwise prescribed neuroleptics. Both groups could be prescribed antidepressants and benzodiazepines.

The Prevention through Risk Identification Management and Education study (PRIMEUSA) randomised participants to olanzapine $5-15 \mathrm{mg} /$ day (mean $8 \mathrm{mg} /$ day) or placebo for one year, and then followed up for a further year without medication. Individual and family psychosocial interventions with supportive and psychoeducational components were available to all patients during the first year. The nature of the psychoeducational components varied across sites despite efforts to apply them in a uniform way. The psychosocial intervention available at the New Haven centre was modelled on the Problem Solving Training approach (D'Zurilla 1971; D'Zurilla 1986).

4.2 Trials to improve the outcome of first-episode psychosis: Twelve trials were concerned with improving outcome in first-episode psychosis (Alvarez-Spain; Berger-Australia; Edwards-Australia; Jackson-Australia; Killackey-Australia; Leavey-UK; LEO-CAT-UK; LifeSPAN-Australia; Linszen-Amsterdam; OPUS-Scandinavia; Uzenoff-USA; ZhangChina). 
In Alvarez-Spain, drug naive first-episode participants were randomised to three different antipsychotics (risperidone, olanzapine, haloperidol) and then randomised to either Early Behavoural Intervention or the control group (routine clinical care).

In Berger-Australia, the first-episode psychosis participants were given ethyleicosapentaenoic acid oil (E-EPA) at a dose of $500 \mathrm{mg}$ twice Daily, with a flexible dose of atypical antipsychotics. The control group received placebo capsules with a flexible dose of atypical antipsychotics.

In Edwards-Australia, the intervention group received a behavioural modification intervention, Cannabis and Psychosis Therapy (CAP). This consisted of weekly sessions of CBT provided by trained clinicians over three months. The aim of the CAP intervention was to reduce cannabis intake and to improve clinical and psychosocial functioning. CAP involved an assessment of engagement, followed by education about cannabis and psychosis and developing motivation to change. The focus of therapy was determined by the phase of commitment to change and could include further educational sessions, motivational interviewing, goal setting, and discussion about relapse prevention. An active control group was used which consisted of psychoeducation, which explained psychosis, medication and other treatments, and relapse prevention, but did not discuss cannabis.

In Jackson-Australia, the intervention group received CBT with 20 sessions provided for 45 minutes, plus antipsychotics. The control group were given a befriending service in addition to antipsychotics.

In Killackey-Australia, the intervention group received individual placement and support, which is an intervention designed to help people with mental illness to find and keep competitive employment. The support provided in the programme continued after employment was obtained, and was adapted to the needs of the individual. The control group received treatment as usual.

In Leavey-UK, the intervention group received a brief intervention and treatment as usual. The brief intervention was provided over seven sessions, lasting about one hour, and included: information gathering from the relative, plus sessions on: psychotic illness, symptoms and early warning signs, treatment, help seeking; coping strategies, problem solving and communication with the patient. The control group were given treatment as usual.

LEO-CAT-UK was a cluster-randomised trial in which primary care (GP) practices were randomly allocated to receive training in early detection of psychosis and direct access to LEO-CAT (a specialised treatment team for first-episode psychosis). The control group of General Practice clinics did not receive training in early detection and continued to refer new cases of psychosis to local mental health services who could then refer on to the LEOCAT programme.

In LifeSPAN-Australia, the intervention group received standard clinical care plus LifeSPAN therapy which draws on the experience at EPPIC with Cognitive Orientated Therapy for Early Psychosis (COPE) and suicide manuals such as Choosing to Live and 
Cognitive Therapy of Suicide Behaviour. Four phases are used for the intervention: (a) initial engagement, (b) suicide risk assessment/formulation, (c) cognitive modules and (d) final closure/handover.

In Linszen-Amsterdam the intervention was behavioural family therapy for one year. Eighteen family therapy sessions were held over a 12-month period. Each family was treated by two co-therapists, from a team of two psychologists and one social worker, all of whom had at least one year of experience in providing family interventions for schizophrenia. The intervention was based on the behavioural family management approach of Falloon 1984 and involved psychoeducation, communication training and development of problem solving skills. Both intervention and control groups also received care from a specialised first-episode team involving individual-oriented therapy consisting of maintenance medication and disease and stress management.

In OPUS-Scandinavia, participants received integrated treatment or standard care. Integrated treatment consisted of high fidelity assertive community treatment supplemented by behavioral family therapy and social skills training. Standard care consisted of care at a community mental health centre. All participants were offered antipsychotic drugs according to guidelines from the Danish Psychiatric Society, which recommends a low-dose atypical antipsy chotic strategy for first episodes of psychotic illness. Each participant was usually in contact with a physician, community mental health nurse and in some cases a social worker. In a small proportion of cases, standard care also included psychosocial interventions such as training in social skills or Daily living activities, or supportive contacts with the family. Antipsychotics were given to both groups based on the psychiatrists' clinical assessment.

The Uzenoff-USA study provided participants with Adherence Coping Education (ACE) which consists of 14 sessions lasting between 30 and 45 minutes over six months. It is a manual-based psychotherapy grouped into four phases: (1) establishing therapeutic alliance; (2) promoting treatment adherence; (3) developing a plan for maintenance treatment and (4) rehabilitation. The control group received supportive therapy which involved (1) establishing the therapeutic relationship, and (2) providing emotional support plus discussion of non-illness issues or topics.

Zhang-China also used family therapy, but in the form of group and individual family sessions which were delivered on an outpatient basis over the 18-month follow-up period. Both intervention and control groups also received care from the outpatients department, (consisting of medication and review) but no regular appointments or community follow-ups were provided.

5. Trial duration: The six trials concerned with preventing the onset of psychosis reported data from between two months and two years:EIPS-Germany at 12 months; EDIE-UK at 12 months and 36 months; PACE-Australia at six and 12 months (the first six months being the period during which the intervention was received);PRIME-USA at two months, 12 months (first 12 months study intervention given) and 24 months (last 12 months without intervention); LIPS-Germany at three months (although the study is planned to last 24 months), and Amminger-Austria at three months. 
The 12 trials concerned with improving outcome of first-episode psychosis also reported data at various time points (range three months to five years): Alvarez-Spain reported data at 13 weeks; Berger-Australia reported data at three months; Jackson-Australia followed participants for 12 months; Leavey-UK reported data at nine months. Four trials (EdwardsAustralia; Killackey-Australia; LifeSPAN-Australia; Uzenoff-USA) reported data at six months. Linszen-Amsterdam reported at 12 months following an initial three-month inpatient admission and also reported a five-year follow-up, but data were provided for the whole sample only, not by group allocation. OPUS-Scandinavia reported data at 12 and 24 months, whereas Zhang-China reported at 18 months.

\section{Outcomes}

6.1 Non-scale data: We were able to report dichotomous data on suicide, death, leaving the study early, conversion to psychosis, adverse effects, hospital admission, days in hospital, compliance with medication, antipsychotic drug use, living independently and employment.

6.2 Scale derived data: Only details of the outcome scales that provided usable data are shown below. Reasons for exclusions of data are given under 'Outcomes' in Characteristics of included studies.

6.2.1 Global state scales: a. Global Assessment of Functioning - GAF (APA 1994)

This is an observer rated scale for measuring overall severity of functional impairment. GAF consists of nine behavioural descriptors. Patients are rated between 0 (most severe) and 90 (least severe) for each descriptor. PRIME-USA, PACE-Australia, OPUS-Scandinavia and LIPS-Germany reported data from this scale.

b. Clinical Global Impression - CGI (Guy 1970)

The CGI is a three-item scale commonly used in studies on schizophrenia that enables clinicians to quantify severity of illness and overall clinical improvement. The items are: severity of illness; global improvement and efficacy index. A seven-point scoring system is usually used with low scores indicating decreased severity and/or greater recovery. PRIMEUSA reported data from this scale.

c. Knowledge About Psychosis Questionnaire - KAPQ (Birchwood 1992)

This questionnaire tests the patients understanding about psychosis and treatments. Data from this scale were reported by Edwards-Australia.

6.2.2 Mental state scales: a. Brief Psychopathological Rating Scale - BPRS (Overall 1962)

The BPRS is an 18-item scale measuring positive symptoms, general psychopathology and affective symptoms. The original scale has 16 items, but a revised 18-item scale is commonly used. Scores can range from 0-126. Each item is rated on a seven-point scale varying from 'not present' to 'extremely severe', with high scores indicating more severe symptoms. Data from this scale were reported by Edwards-Australia. In PACE-Australia the scale was used primarily to report severity of psychotic symptoms. 
b. Positive and Negative Symptom Scale - PANSS (Kay 1987)

The Positive and Negative Symptom Scale was developed from the BPRS and the Psychopathology Rating Scale. It is used as a method for evaluating positive, negative and other symptom dimensions in schizophrenia. The scale has 30 items, and each item can be defined on a seven-point scoring system varying from one (absent) to seven (extreme). This scale can be divided into three sub-scales for measuring the severity of general psychopathology, positive symptoms (PANSS-P) and negative symptoms (PANSS-N). A low score indicates low levels of symptoms. EDIE-UK used this scale to determine transition to psychosis. PRIME-USA and LIPS-Germany reported data from the PANSS.

c. Scale of Psychotic Symptoms - SOPS (Miller 1999)

The SOPS scale was modelled on the PANSS scale and is designed to measure the presence/ absence of prodromal states. It consists of five positive symptom items, six negative symptom items, four disorganisation symptoms items, and four general symptom items. Each has a severity rating from 0 (never, absent) to six (severe/extreme - and psychotic for the positive items). The severity of the prodromal state is based on the sum of the rating from the SOPS items and ranges between 0 and 114. PRIME-USA reported data from this scale.

d. Hamilton Rating Scale for Anxiety - HRSA (Hamilton 1959)

The Hamilton Anxiety Scale (HAMA) is a rating scale developed to quantify the severity of anxiety symptoms, often used in psychotropic drug evaluation. It consists of 14 items, each defined by a series of symptoms. Each item is rated on a five-point scale, ranging from 0 (not present) to 4 (severe). The 14 items consist of: anxious mood; tension; fears; insomnia; intellectual; depressed mood; somatic complaints (muscular); somatic complaints (sensory); cardiovascular symptoms; respiratory symptoms; gastrointestinal symptoms; genitourinary symptoms; autonomic symptoms and behaviour at Interview. Higher scores indicate greater anxiety. PACE-Australia reported data from this scale.

\section{e. Hamilton Rating Scale for Depression - HRSD (Hamilton 1960)}

This is an interviewer rated scale for measuring depression. It is used for quantifying the results of an interview and depends on the skill of the interviewer in eliciting the necessary information. It contains 17 variables measured on either a five point or a three-point rating scale. The variables include: depressed mood; suicide; employment and loss of interest; retardation; agitation; gastrointestinal symptoms; general somatic symptoms; hypochondriasis; loss of insight and loss of weight. Higher scores indicate more severe depression. PACE-Australia reported data from this scale.

f. Calgary Depression Rating Scale - CDRS (Addington 1990)

The Calgary Depression Scale for Schizophrenia is a nine-item scale ( $0=$ absent; $1=$ mild; $2=$ moderate; $3=$ severe.) that was specifically developed for assessment of depression in patients with schizophrenia. It has been evaluated in both relapsed and remitted patients, and 
is provided as a semi-structured interview. High scores indicated worse outcome. UzenoffUSA reported data from this scale.

g. Montgomery Asberg Depression Rating Scale - MADRS (Montgomery 1979)

This is a 65 -item comprehensive psychopathology scale used to identify the 17 most commonly occurring symptoms in primary depressive illness. Ratings are based on 10 items, with higher scores indicating more symptoms. This scale was used by LIPS-Germany.

h. Beck Depression Inventory - BDI-SF (Beck 1961)

This is a 21-item self-rating scale for depression. Each item comprises four statements (rated $0-4)$ describing increasing severity of the abnormality concerned. The person completing the scale is required to read each group of statements and identify the one that best describes the way they have felt over the preceding week. A total of 12/13 is an indicative score for presence of significant depression. The short form of this scale was used by EdwardsAustralia.

i. Presence of Psychosis Scale - POPS (Olsen 2006)

The Presence of Psychosis Scale (POPS), is part of the Structured Interview for Prodromal Syndromes scale (SIPS). It marks onset of psychosis by the presence of positive symptoms at the psychotic level of intensity and of sufficient frequency and duration. PRIME-USA reported data from this scale.

j. Scale for the Assessment of Negative Symptoms - SANS (Andreasen 1983)

This is also an interviewer rated scale for measuring the severity of negative symptoms of schizophrenia such as alogia, affective blunting, avolition-apathy, anhedonia-asociality and attention impairment. Items are rated on a six-point scale with higher scores indicating more symptoms. Edwards-Australia and PACE-Australia reported data from this scale.

k. Young Mania Scale - YMS (Young 1978)

Again an interviewer rated scale, but this time for measuring the severity of symptoms of mania. Higher scores indicate more severe symptoms. PRIME-USA and PACE-Australia reported data from this scale.

6.2.3 Social functioning: a. Social Functioning Scale II - SAS II (Weissman 1976)

The SAS II is an interviewer-administered scale adapted from the self-report Social Adjustment Scale for use with people with schizophrenia. It contains 52 questions that are administered in a semi-structured interview by a trained rater. The SAS II assesses current functioning with scores ranging from 1 to 5 , with higher scores indicating worse functioning. EIPS-Germany reported data from this scale.

b. Social and Occupational Functioning Assessment Scale - SOFAS (APA 1994) 
The SOFAS is a new instrument similar to the Global Assessment of Functioning is format, and attempts to assess the social and or occupational functioning independent of the overall severity of the illness. Higher scores indicate worse social functioning. Edwards-Australia and Jackson-Australia reported data from this scale.

\subsubsection{Adverse effects: a. Simpson Angus Scale - SAS (Simpson 1970)}

The SAS is a 10-item scale used to evaluate the presence and severity of drug-induced parkinsonian symptoms. The 10 items focus on rigidity rather than bradykinesia and do not assess subjective rigidity or slowness. The scale comprises a 10-item rating scale, each item rated on a five-point scale with zero meaning the complete absence of condition and four meaning the presence of condition in extreme. A low score indicates low levels of parkinsonism. PRIME-USA reported data from this scale,

b. Barnes Akathisia Rating Scale - BAS (Barnes 1989)

The Barnes Akathisia Rating Scale is a four-item scale to assess the presence and severity of drug-induced movement disorder akathisia. It is a widely used comprehensive rating scale for akathisia. Items include restless movements that characterise akathisia, the subjective awareness of restlessness and any distress associated with the condition. These items are rated from zero (normal) to three (severe). In addition, there is an item for rating the global severity that starts from zero (absent) to five (severe). A low score indicates low levels of akathisia. PRIME-USA reported data from this scale.

c. Abnormal Involuntary Movement Scale - AIMS (Guy 1976)

The Abnormal Involuntary Movement Scale has been used to assess abnormal involuntary movements associated with antipsychotic drugs, such as tardive dyskinesia and chronic akathisia, as well as 'spontaneous' motor disturbance related to the illness itself. Tardive dyskinesia is a long-term, drug-induced movement disorder. However, using this scale in short-term trials may also be helpful to assess some rapidly occurring abnormal movement disorders such as tremor. Scoring consists of rating movement severity in the anatomical areas (facial/oral, extremities, and trunk) on a five-point scale (0-4). A low score indicates low levels of dyskinetic movements. PRIME-USA reported data from this scale.

6.2.5 Quality of life: a. Quality of Life Scale - QLS (Heinrichs 1984)

This is a semi-structured interview administered and rated by trained clinicians. It contains 21 items rated on a seven-point scale based on the interviewer's judgement of patient functioning. Higher scores indicate better quality of life. PACE-Australia and Uzenoff-USA reported data from this scale.

6.2.6 Satisfaction with care: a. The Client Satisfaction Questionnaire - CSQ-8 (De-Wilde 2005)

The CSQ-8 is an eight-item self-report of global measure of patient satisfaction with services. The CSQ is substantially correlated with treatment dropout, number of therapy sessions attended, and with change in client-reported symptoms. The CSQ-8 consists of 
eight items rated on a four-point Likert scale. The items are concerned with quality of services received, how well services met the client's needs and general satisfaction. The total score ranges from eight to 32 . Higher scores indicate greater satisfaction of the responders OPUS-Scandinavia reported data from this scale.

6.2.7 Substance use: a. Cannabis and Substance Use Assessment Schedule - CASUAS (Wing 1990)

This scale measures the percentage of days using cannabis in the past four weeks and includes an index of severity of cannabis use. The scale is modified from the Schedule for Clinical Assessment on Neuropsychiatry and includes similar information to the Addiction Severity Index. Data from this scale were used by Edwards-Australia.

6.3 Redundant data: Some studies reported data only as $\mathrm{P}$ values or statements of significant or non-significant differences, and other continuous data could not be extracted because the number of participants was missing or standard deviations were not reported.

Excluded studies-There are currently 68 excluded studies. We have summarised reasons for exclusion in Table 1.

1. Awaiting classification: Thirty studies are awaiting assessment; 13 are brief reports where additional data are required; seven Chinese studies require further clarification; five studies are unclear regarding whether the status of participants is first episode or not; five studies are being sought. Ultimately, we will exclude studies where data are unobtainable.

2. Ongoing studies: We are awaiting data from 10 studies (see descriptions in Characteristics of ongoing studies table). This is an active area for research.

\section{Risk of bias in included studies}

Judgement of risks are illustrated in Figure 2.

Allocation-All 18 included studies were stated to be randomised. Only five described how randomisation had been performed, using computer-generated random numbers (Alvarez-Spain; Edwards-Australia; EIPS-Germany; Killackey-Australia; OPUSScandinavia). Attempts to conceal allocation were described in five studies which were judged to be adequately concealed. In the remaining studies allocation concealment was either not described or only briefly commented on and we were unable to determine in these instances if concealment is adequate.

Blinding-Blinding of participants and clinicians proved difficult in most studies. PRIMEUSA blinded participants, investigators and dispensers to group assignment. Other studies used independent raters, some of whom were blind to allocation. PACE-Australia and OPUS-Scandinavia used raters who were independent of the study group, but were not blind to treatment allocation. In EDIE-UK, single blinding was attempted for the rater, but blinding was not maintained due to participants divulging information, or using language that suggested they were receiving cognitive therapy. Edwards-Australia and Leavey-UK 
also used a single blind design. Zhang-China used independent raters blind to allocation, whereas the LifeSPAN-Australia study was described as only single blind. In LinszenAmsterdam the status of the raters was unclear. EIPS-Germany did not state whether blinding had been attempted. Berger-Australia and Amminger-Austria used a double-blind design, whilst LIPS-Germany was an open-label study. In the LEO-CAT-UK study, the unit of randomisation were the GP practices and clinicians were not blinded to the intervention. Both Alvarez-Spain and Jackson-Australia used a single blinding. In Killackey-Australia blinding was not reported. Uzenoff-USA used blind raters. Overall, due to the nature of the intervention, blinding proved difficult in these studies and most studies are at risk of bias.

Incomplete outcome data-Follow-up rates where reported were quite high (see Table 2). Overall, study attrition did not suggest a risk of bias.

Outcomes were recorded, reported and analysed in many different ways. Even in this limited, relatively recent, research community, there is no indication of a consistency of approach and incomplete and selective reporting could easily be operating. PACE-Australia provided all outcomes on an intention-to-treat (ITT) basis. EDIE-UK used an ITT analysis but two people originally randomised to the treatment group were subsequently omitted from the analysis because they were found to be psychotic at the time of randomisation. (Because these exclusions are not compatible with an ITT analysis of relapse we counted such data as relapses and included these in the final analysis.)PRIME-USA also used an ITT analysis and reported scale data as change scores rather than endpoint scores. LifeSPANAustralia only provided dichotomous data for leaving the study early and suicide. LinszenAmsterdam only provided data on relapse at 12 months on an ITT basis. Berger-Australia only reported usable data on the number of participants not responding to treatment. Jackson-Australia did not report data on relapse or severity of illness, only data on hospitalisation, suicide and social functioning were usable. Killackey-Australia only reported usable data for employment and attrition. Leavey-UK used an ITT analysis. In the EIPS-Germany study 15 participants were not accounted for after randomisation. OPUSScandinavia used an ITT analysis. Zhang-China reported data on number of people readmitted and compliant on an ITT basis, but data on mental state and overall functioning were reported only for people who were not admitted to hospital. (This rendered data unusable.) Uzenoff-USA included only 24 participants and used a modified ITT analysis on 19 of this group. This small sample may have resulted in treatment effects being undetected. In Amminger-Austria, five participants were not accounted for after randomisation and is a potential source of bias to the outcome data. In LEO-CAT-UK much of the data were unusable due to the reporting of outcomes without the denominator; additionally, we divided binary data by a design effect to adjust for the excessive weight given to this cluster randomised trial. Edwards-Australia used the last observation carried forward method and all 47 participants were utilised in the reporting of outcome data.

Selective reporting-Outcome data from the SAPS scale were not reported by AlvarezSpain. We did not identify overt under reporting of outcomes in the other included studies, although we did not have access to study protocols to check whether other data were recorded and not reported in the final papers. 
Other potential sources of bias-Six of the 18 studies were undertaken at the pioneering EPPIC Centre in Melbourne, Australia (Berger-Australia; Edwards-Australia; Jackson-Australia; Killackey-Australia; LifeSPAN-Australia; PACE-Australia). This could lead to issues with applicability (see Overall completeness and applicability of evidence). However, as with the Australian studies, many of the trials were undertaken by leading figures in the world of early intervention who could have a vested interest in the findings just as industry has in the outcomes for the drugs they manufacture. Early intervention studies are now less novel than a decade ago. The initial flourish of research has settled into a more steady stream and it will be interesting to see how findings average across time.

\section{Effects of interventions}

See: Summary of findings for the main comparison PHASE SPECIFIC TREATMENT (RISPERIDONE + CBT) + SPECIALISED TEAM compared to SPECIALISED TEAM for psychosis; Summary of findings 2 SPECIALISED TEAM compared to STANDARD CARE for psychosis

1. Obvious heterogeneity-Meta-analyses were often not possible because of the heterogeneity of the interventions and outcomes. In trials aiming to prevent onset of psychosis it was not possible to add together Amminger-Austria which used omega-3-fatty acids with other antipsychotic trials. PACE-Australia used risperidone and CBT and cannot be added to trials that used only antipsyhchotics. LIPS-Germany used amisulpride and a psychoeducaton programme, whilst PRIME-USA used only olanzapine. Two studies (EDIEUK, EIPS-Germany) were added together under the same comparison group, but the reported outcomes were dissimilar and we could not undertake meta-analysis. In trials aiming to improve outcome of first-episode psychosis Leavey-UK and Zhang-China were somewhat similar but it is not known what type of class of antipsychotic were given. In trials using cognitive therapy the focus of trials was different. Jackson-Australia targeted symptoms, Edwards-Australia targeted cannabis misuse, and LifeSPAN-Australia targeted suicidal ideas. We did perform an exploratory meta-analysis with three trials (JacksonAustralia; Leavey-UK; Uzenoff-USA), but this was limited by only few outcome measures being similar.

2. Trials to prevent the development of psychosis-Six studies addressed the question of prevention of psychosis by interventions for patients with prodromal symptoms.

\subsection{COMPARISON 1. Phase specific intervention (olanzapine) + non specific supportive therapy versus placebo + non specific supportive therapy (all data from PRIME-USA)}

2.1.1 Leaving the study early: In PRIME-USA we found the numbers of people leaving the study early by eight weeks ( $\mathrm{n}=60$, RR 1.29 CI 0.6 to 2.7 ) and also by 12 months to be equivocal ( $\mathrm{n}=60$, RR 1.59 CI 0.9 to 2.9$)$.

2.1.2 Conversion to psychosis (POPS): By about 12 months the number of people converting to psychosis was $8 / 31$ olanzapine group and 13/29 for the placebo group. This difference did not reach statistical significance ( $\mathrm{n}=60$, RR 0.58 CI 0.3 to 1.2). 


\subsubsection{Global state}

2.1.3.1 Clinical Global Impression (CGI): We found the Clinical Global Impression change score 'severity of illness' equivocal by 12 months (n=59, WMD -0.23 CI -0.8 to 0.4 ).

2.1.3.2 Global Assessment of Functioning (GAF): We also found the Global Assessment of Functioning 'current' change score by 12 months to be equivocal (n=59, WMD $2.43 \mathrm{CI}-4.8$ to 9.6).

\subsubsection{Mental state}

2.1.4.1 Scale of Prodromal Symptoms (SOPS): PRIME-USA reported several outcomes as mean change scores from the SOPS at 12 months. We found the total score, positive score, negative score, disorganisation and general scores were not significantly different between the olanzapine and placebo group.

2.1.4.2 Positive and Negative Symptom Score (PANSS): We found the PANSS total $(n=59$, WMD $0.48 \mathrm{CI}-10.7$ to 11.7 ), PANSS positive ( $=59$, WMD $-0.57 \mathrm{CI}-3.8$ to 2.6 ), PANSS negative ( $\mathrm{n}=59$, WMD $0.52 \mathrm{CI}-2.6$ to 3.6 ), and the PANSS general score ( $\mathrm{n}=59$, WMD $0.54 \mathrm{CI}-5.4$ to 6.5 ) were not significantly different between olanzapine and placebo groups.

2.1.4.3 Young Mania Rating Scale (YMRS): We found change scores by 12 months were equivocal ( $\mathrm{n}=59$, WMD $-0.91 \mathrm{CI}-3.8$ to 2.0 ).

2.1.4.4 Montgomery and Asberg Depression Rating Scale (MADRS): We found depression change scores at 12 months were equivocal ( $\mathrm{n}=59$, WMD $0.68 \mathrm{CI}-3.8$ to 5.2).

\subsubsection{Adverse effects}

2.1.5.1 Simpson \& Angus (SAS): Extrapyramidal symptoms were found to be equivocal between the olanzapine (mean $8 \mathrm{mg} / \mathrm{day}$, range $5-15 \mathrm{mg} / \mathrm{day}$ ) and the placebo group by eight weeks ( $\mathrm{n}=59$, WMD $0.10 \mathrm{CI}-0.6$ to 0.8 ).

2.1.5.2 Barnes Akathisia Scale (BAS): We also found change scores for akathisia to be equivocal by eight weeks ( $\mathrm{n}=59$, WMD $0.50 \mathrm{CI}-0.6$ to 1.6 ).

2.1.5.3 Abnormal Involuntary Movement Scale (AIMS): We found involuntary movement scores were not significantly different for those given low dose olanzapine by eight weeks compared with placebo ( $\mathrm{n}=59$, WMD $0.60 \mathrm{CI}-0.3$ to 1.5 ).

2.1.5.4 Weight change: We found the olanzapine group had a statistically significant increase in weight compared with the placebo group by 12 months (n=59, WMD 7.63 CI 4.0 to 11.2). We also found dichotomous data supported this finding, with the olanzapine group having significantly more weight gain (criteria not stated) than placebo by 12 months ( $\mathrm{n}=60$, RR 3.55, CI 1.5 to 8.3 , NNH 3 CI 2 to 11 ).

2.1.5.5 Cardiovascular measures: Systolic and diastolic blood pressure values were measured sitting and standing (at eight weeks), and we found all data to be not statistically significantly different between olanzapine and placebo groups. Pulse rates were also measured (standing and sitting at eight weeks) and we again found data to be equivocal. 
Twelve-month outcome data for change in pulse rates (sitting) did significantly favour the placebo group ( $\mathrm{n}=58$, WMD 8.31 CI 0.5 to 16.1 ), with the assumption that a lower pulse rate indicated an improvement. However, this significant finding was not replicated for pulse data recorded whilst standing, with data being non-significant.

2.1.5.6 Treatment emergent adverse events (CoStart terms): Somnolence, increased appetite, anxiety, nervousness, asthenia, joint disorder, abnormal thoughts were all equivocal by eight weeks. We found weight gain to be significantly higher in the olanzapine group ( $\mathrm{n}=60, \mathrm{RR} 10.29$, CI 1.4 to $74.8, \mathrm{NNH} 4$ CI 2 to 70 ) by eight weeks compared with placebo.

2.1.5.7 Fatigue: We found the number of participants experiencing fatigue were significantly higher in the olanzapine group compared with the placebo control $(n=60, R R$ 8.42 CI 1.1 to 62.4 , NNH 4 CI 2 to 211 ).

\subsection{COMPARISON 2. Phase specific intervention (cognitive behavioural therapy) + non-specific supportive therapy versus non specific supportive therapy (all data from EDIEUK and EIPS-Germany)}

2.2.1 Leaving the study early: We found the numbers of people leaving the study early in EDIEUK were similar for both CBT (11/37) and control group (7/23) with no significant differences at 12 months ( $\mathrm{n}=60$, RR $0.98 \mathrm{CI} 0.4$ to 2.2). Two-year data also revealed no significant difference ( $\mathrm{n}=60 \mathrm{RR} 0.96$ CI 0.6 to 1.5 ).

2.2.2 Transition to psychosis: The number of people who became psychotic during 12 months of observation were not significantly different for the CBT and monitoring groups (EDIE-UK, $\mathrm{n}=60$, RR 0.50 CI 0.2 to 1.7 ).

2.2.3 Social functioning: SAS II: We found no significant differences for the outcomes of social activities, well-being, or employment. Global Social Adjustment scores also revealed no significant difference (EIPS-Germany, $\mathrm{n}=69$, WMD $-0.10 \mathrm{CI}-0.4$ to 0.2 ).

\subsection{COMPARISON 3. Phase specific intervention (risperidone + cognitive behavioural therapy) + specialised team versus specialised team (all data from PACE-Australia)}

2.3.1 Leaving the study early: No participants were lost to follow-up at 12 months in either treatment $(0 / 31)$ or control group $(0 / 28)$.

2.3.2 Progression to psychosis (primary outcome): We found that participants with prodromal symptoms who received the intervention were significantly less likely to have developed psychosis at the six-month follow-up than controls (n=59, RR 0.27 CI 0.1 to 0.9 , NNT 4 CI 2 to 20). However, this effect became non-significant by 12 months ( $\mathrm{n}=59, \mathrm{RR}$ $0.54 \mathrm{CI} 0.2$ to 1.3$)$.

2.3.3 Global state: PACE-Astralia used the GAF to rate overall functioning. At 12 months, data were skewed and no significant differences were found between the phase-specific treatment plus specialised team and the group receiving care from a specialised team $(n=59$, WMD $0.00 \mathrm{CI}-5.2$ to 5.2 ). 
2.3.4 Mental state: There were no significant differences between intervention and control groups at six or 12 month follow up on any of the measures of mental state, but confidence intervals were generally wide. The BPRS results at both six and 12 months were equivocal and considerably skewed ( $\mathrm{n}=59$, WMD at 6 months $-0.50 \mathrm{CI}-2.3$ to 1.3 ; WMD at 12 months $0.70 \mathrm{CI}-1.0$ to 2.4 ). This also applied to the SANS negative symptoms scores $(\mathrm{n}=59, \mathrm{WMD}$ at six months $-4.6 \mathrm{CI}-12.7$ to 3.5 ; WMD at 12 months $-0.80 \mathrm{CI}-7.9$ to 6.3 ). Ratings of anxiety, depression and mania all had wide confidence intervals and data were skewed. No findings were statistically significant, either at six or 12 months.

2.3.5 Quality of life: We found no significant differences between intervention and control groups at six or 12 month follow up on the quality of life measure (n=59, WMD at 6 months $-1.40 \mathrm{CI}-13.6$ to 10.8 ; WMD at 12 months $0.80 \mathrm{CI}-10.2$ to 11.8 ).

\subsection{COMPARISON 4. Phase specific intervention (amisulpride + needs focused interventions - NFI) versus needs focused interventions (all data from LIPS-Germany)}

2.4.1 Leaving the study early: Fewer participants dropped out of the amisulpride plus NFI group ( $\mathrm{n}=124$, RR 0.59 CI 0.4 to 0.9 , NNT 5 CI 4 to 34) compared with those given just Needs Focused Interventions.

2.4.2 Mental state: PANSS: The PANSS global scores and PANSS-positive scores favoured participants given amisulpride plus NFI (PANSS-G, $\mathrm{n}=102$, WMD $-3.40 \mathrm{CI}-6.9$ to 0.1 ), (PANSS +ve, $\mathrm{n}=102$, WMD $-2.10 \mathrm{CI}-3.7$ to -0.5 ) compared with the control group receiving NFI. We found no significant difference for PANSS negative symptoms $(n=103$, WMD -1.30 CI -3.3 to 0.7 ). Depression scores also revealed no significant differences $(\mathrm{n}=102$, WMD $-1.10 \mathrm{CI}-4.5$ to 2.3$)$.

2.4.3 Global state: GAF: Global Assessment of Functioning scores favoured the amisulpride plus NFI ( $\mathrm{n}=102$, WMD $-6.10 \mathrm{CI}-11.8$ to -0.5 ) compared with participants given Needs Focused Interventions alone.

\subsection{COMPARISON 5. Omega 3 fatty acids (epa) versus PLACEBO (all data from Amminger-Austria)}

2.5.1 Transition to psychosis: We found that participants who were given the essential fatty acid regime were significantly less likely to develop psychosis than the placebo group (n=76, RR 0.13 CI 0.02 to 1.0 , NNT 6 CI 5 to 96 ).

\section{Trials to improve outcome in first-episode psychosis}

\subsection{COMPARISON 6. Phase-specific treatment (cognitive behavioural therapy for suicidality) + specialised team versus specialised team (all data are from a single study LifeSPAN-Australia)}

3.1.2 Leaving the study early: We found the number of people leaving the study early by six months were not significantly different between the LifeSpan therapy group and those receiving standard care ( $\mathrm{n}=56, \mathrm{RR} 2.02 \mathrm{CI} 0.7$ to 5.7$)$. 
3.1.3 Suicide: Two people died from suicide during the six-month study, one from each intervention group.

\subsection{COMPARISON 7. Phase-specific treatment (family therapy) + specialised team versus specialised team (all data from Linszen-Amsterdam)}

3.2.1 Relapse (primary outcome): In Linszen-Amsterdam we found no significant difference between intervention and control groups at 12 months for the outcome of relapse ( $\mathrm{n}=76$, RR 1.05 CI 0.4 to 3.0).

\subsection{COMPARISON 8. Phase-specific treatment (family therapy) + standard care versus standard care (all data from Zhang-China)}

3.3.1 Leaving the study early: In Zhang-China we found only five people in a study of 83 participants were lost by 18 months. There were no significant differences in the number of people lost to follow-up for the two groups ( $\mathrm{n}=83$, RR $1.46 \mathrm{CI} 0.3$ to 8.3).

3.3.2 Admitted to hospital: We found that participants receiving the intervention were significantly less likely to be admitted to hospital at 18 months than people allocated to the standard care control group ( $\mathrm{n}=83$, RR 0.28 CI 0.1 to 0.6 , NNT 3 CI 2 to 6 ).

3.3.3 Not compliant with medication: In both groups most people were compliant with medication. We found no significant difference in the number of people not compliant with medication at 18 months' follow-up, although the data suggested a trend favouring the intervention ( $\mathrm{p}=0.06, \mathrm{n}=83$, RR 0.57 CI 0.3 to 1.0 ).

\subsection{COMPARISON 9. Specialised team versus standard care (all data from OPUS-Scandinavia)}

3.4.1 Leaving the study early: We found the numbers of people leaving early by one year were significantly lower in the integrated treatment group ( $\mathrm{n}=547$, RR $0.59 \mathrm{CI} 0.4$ to 0.8 , NNT 9 CI 6 to 18) compared with the standard care group. By two years, numbers of people leaving the study early remained significantly lower in the integrated treatment group $(\mathrm{n}=$ 547, RR 0.64 CI 0.5 to 0.8, NNT 7 CI 6 to 14). Five-year data, however were not significantly different ( $\mathrm{n}=547$, RR $1.01 \mathrm{CI} 0.8$ to 1.2$)$.

3.4.2 Global state - Global Assessment of Functioning (GAF): We found GAF 'symptom' endpoint scores to significantly favour the integrated treatment group $(n=419$, WMD -3.71 CI -6.7 to -0.7 ) by one year. Two-year outcome data were, however, not significantly different ( $\mathrm{n}=369$, WMD $-2.51 \mathrm{CI}-5.7$ to 0.7 ), and by five years follow-up data were equivocal. The GAF 'function' endpoint scores at 12 months were not significantly different ( $n=419$, WMD $-2.30 \mathrm{CI}-5.25$ to 0.6 ), but by two years results significantly favoured integrated treatment compared with standard care ( $\mathrm{n}=369$, WMD $-4.03 \mathrm{CI}-7.2$ to -0.8 ), although by five years' follow-up functioning scores were equivocal.

3.4.3 User satisfaction - Client Satisfaction Questionnaire Score (CSQ-8): Overall satisfaction with levels of care were significantly better for the integrated treatment group ( $\mathrm{n}=419, \mathrm{WMD}-1.90 \mathrm{CI}-3.1$ to -0.7$)$ compared with the standard care control at 12 
months; this finding continued during the second year of follow-up (n=369, WMD $-3.20 \mathrm{CI}$ -4.1 to -2.3$)$.

3.4.4 Compliance with treatment: We found 'treatment stopped in spite of need' - measured at one year significantly favoured the integrated treatment group ( $n=507$, RR 0.20 CI 0.1 to 0.4, NNT 9 CI 8 to 12) compared with standard care. However, by two years we did not find any statistically significant differences between the treatment and control group ( $n=436, R R$ 0.66 CI 0.3 to 1.5 ).

3.4.5 Death/Suicide: Two people committed suicide (one from each treatment group) during the first year of the study. Also two people died in the control group, one an accidental death; the cause of the other death could not be ascertained.

3.4.6 Service use: We found the mean number of days spent in hospital at one year were not significantly different ( $\mathrm{n}=507, \mathrm{WMD},-1.39 \mathrm{CI}-2.8$ to 0.1 ) and did indicate a trend favouring integrated treatment $(\mathrm{p}=0.06$ ), but by two and five years' follow-up the data revealed no significant differences. Also we found no significant difference in dichotomous data 'Not hospitalised' by five years ( $\mathrm{n}=547$, RR 1.05 CI 0.90 to 1.2$)$.

3.4.7 Social outcomes: We found no significant differences in the numbers of people 'not living independently' by one year ( $\mathrm{n}=507$, RR 0.55 CI 0.3 to 1.2 ), and two-year data were also non-significant. However, by five years' follow-up, integrated treatment had significantly fewer participants 'not living independently' (n=547, RR $0.42 \mathrm{CI} 0.21$ to 0.8 , NNT 19 CI 14 to 62) compared with the those receiving standard care. The numbers of participants who were either 'not working or in education' measured over one year showed no significant differences between the study groups, but by two years the integrated treatment group had significantly lower levels of not being in work or education ( $n=436, R R$ 0.72 CI 0.5 to 1.0 , NNT 11 CI 7 to 99), compared with the control group. However by five years this advantage is not sustained and data were equivocal.

\subsection{COMPARISON 10. Phase-specific treatment (CBT) + antipsychotics versus befriending + antipsychotics (all data from Jackson-Australia)}

3.5.1 Leaving the study early: We found no significant difference in study attrition between treatment groups ( $\mathrm{n}=62,0.57 \mathrm{CI} 0.2$ to 1.8 ).

3.5.2 Hospitalised: No significant differences emerged in the number of participants being hospitalised over 12 months ( $\mathrm{n}=62$, RR 1.08 CI 0.59 to 1.99 ).

3.5.3 Suicide: Two people died due to suicide in the cognitive behavioural treatment group and none from the befriending group. This did not indicate a significant difference.

3.5.4 Social functioning: SOFAS: We found no significant difference in mean total endpoint scores from the SOFAS social functioning scale ( $\mathrm{n}=62$, RR $1.30 \mathrm{CI}-6.3$ to 8.9 ) by 12 months' assessment. Similarly, we found no significant differences in SOFRAS positive and negative symptoms scores. 
3.6 COMPARISON 11. Phase-specific treatment E-EPA oils + atypicals versus placebo + atypical (all data from Berger-Australia)

3.6.1 Leaving the study early: For this short term study of 12 weeks we found study attrition to be equivocal ( $\mathrm{n}=80$, RR 0.83 CI 0.3 to 2.5 ).

3.6.2 Global state: not responded to treatment: We found that participants given the E-EPA oils in addition to antipsychotics had similar rates of non-response (18/40) to treatment compared with the control group (20/40) ( $\mathrm{n}=80$, RR 0.90 CI 0.6 to 1.4$)$.

\subsection{COMPARISON 12. Phase-specific treatment brief intervention + antipsychotics versus treatment as usual (all data from Leavey-UK)}

3.7.1 Leaving the study: We found no significant differences in the number of people leaving the study early by nine months ( $\mathrm{n}=106$, RR 0.72 CI 0.3 to 1.5$)$.

3.7.2 Hospital admission: Hospital admissions were reported before four months ( $\mathrm{n}=106$, RR 1.19 CI 0.9 to 1.6), and at up to four months ( $n=106$, RR 0.75 CI 0.4 to 1.4) and between four and nine months ( $\mathrm{n}=106$, RR $0.86 \mathrm{CI} 0.4$ to 1.7 ); we found no significant difference between the intervention groups.

3.8 COMPARISON 13. Phase-specific treatment (ACE) + antipsychotics versus treatment as usual (all data from Uzenoff-USA)

3.8.1 Leaving the study early: We found no significant differences ( $n=24$, RR 1.27 CI 0.3 to 6.3) at six months between ACE therapy and the control group.

3.8.2 Mental state: We found no significant differences for PANSS positive, negative, general or total scores ( $\mathrm{n}=17, \mathrm{MD}-1.57 \mathrm{CI}-7.7$ to 4.5 ). Depression rating from the CDRS also revealed no significant differences $(n=17, \mathrm{MD}-1.46 \mathrm{CI}-4.2$ to 1.3$)$.

3.8.3 Quality of life: We found quality of life scores as measured by the HeinrichsCarpenter scale to be equivocal ( $\mathrm{n}=16 \mathrm{MD}-2.93 \mathrm{CI}-25.6$ to 19.7$)$.

3.9 COMPARISON 14. Phase-specific treatment vocational intervention + TAU versus treatment as usual (all data from Killackey-Australia)

3.9.1 Not employed: We found participants who were given the vocational intervention were more likely to be employed ( $\mathrm{n}=41$, RR 0.39 CI 0.21 to 0.7 , NNT 2 CI 2 to 4 ).

3.9.2 Leaving the study early: We found no significant differences in study attrition by six months ( $\mathrm{n}=41$, RR $0.21 \mathrm{CI} 0.03$ to 1.6 ).

\subsection{COMPARISON 15. Phase-specific treatment (cannabis and psychosis therapy) + antipsychotics versus psychoeducation + antipsychotic (all data from Edwards-Australia)}

3.10.1 Cannabis usage: We found no significant difference between the CAP intervention group and PE for use of cannabis at three months' assessment ( $\mathrm{n}=47$, RR 1.04 CI 0.6 to 1.7). Data at nine months were also not significantly different ( $n=47$, RR 1.30 CI 0.8 to 2.2). 
The percentage of days using cannabis and the severity of cannabis usage were also reported by Edwards-Australia but data were skewed and are reported in 'other data' tables. Both outcomes were, however, non-significant.

3.10.2 Global state: KAPQ: We found no significant difference in the knowledge of psychosis and treatments lbetween the participants at three months (n=47, WMD $0.80 \mathrm{CI}$ -1.8 to 3.4 ) or nine months ( $\mathrm{n}=47$, WMD $0.90-1.4$ to 3.2 ).

\subsubsection{Mental state}

3.10.3.1 BPRS: We found average endpoint BPRS-extended scale scores at the three-month $(\mathrm{n}=47$, WMD $-3.60 \mathrm{CI}-12.8$ to 5.6) and nine-month assessment time point ( $\mathrm{n}=47$, WMD $0.80 \mathrm{CI}-7.5$ to 9.1 ) were not significantly different between the cannabis and psychosis therapy group, and those given psychoeducation. BPRS positive symptom scores were evaluated by Edwards-Australia, but data were skewed and are reported in 'other data' tables.

3.10.3.2 SANS: Data from the Scale for the Assessment of Negative Symptoms were skewed; the authors reported no significant differences in negative symptom scores between groups.

3.10.3.3 BDI: We found that the Beck Depression Inventory scores contained wide confidence intervals (skewed data) and have not reported these here.

3.10.4 Social functioning: SOFAS: We found no significant improvement in social functioning in the CAP group compared with PE at the three-month ( $=47$, WMD $-0.80 \mathrm{CI}$ -10 to 8.4 ) or the nine-month assessment ( $n=47$, WMD $-4.70 \mathrm{CI}-14.5$ to 5.1 ).

\subsection{COMPARISON 16. Crisis assessment versus standard care (all data from LEO-CAT UK)}

3.11.1 Hospitalisation: We found no significant difference in the number of participants being emitted to hospital between those who receiving crisis assessment and the control group who were given usual care ( $\mathrm{n}=98$, RR 0.85 CI 0.6 to 1.3 ).

3.11.2 Referred to mental health services: Crisis assessment did not result in significantly more participants being referred to mental health services, either by accident and emergency departments or emergency medical services ( $\mathrm{n}=98$, RR 0.85 CI 0.6 to 1.3 ).

\subsection{COMPARISON 17. Early behavioural intervention versus routine care interval (all data from Alverez-Spain)}

3.12.1 Weight: Measures of weight and body mass index were made. Data were skewed but we found no appreciable differences between the Early Behavioral Intervention and Routine Care Intervention groups in this small study $(\mathrm{n}=61)$. 


\subsection{COMPARISON 18. Phase-specific intervention versus control (Exploratory meta-analysis)}

3.13.1 Leaving the study early: We pooled three studies in the meta-analysis (JacksonAustralia; Leavey-UK; Uzenoff-USA) and found no significant difference in the number of participants who left the study early ( $\mathrm{n}=192$, RR 0.72 CI 0.4 to 1.3 ).

3.13.2 Hospitalisation: Hospitalisation rates were equivocal between the phase-specific treatment and the control group ( $\mathrm{n}=168$, RR 0.97 CI 0.6 to 1.5$)$ when we meta-analysed data from Jackson-Australia and Leavey-UK.

\section{DISCUSSION}

\section{General}

Studies were undertaken in the UK, Australia, Holland, Austria, Germany, Scandinavia, the USA and China. Six studies (Amminger-Austria; EDIE-UK; EIPS-Germany; LIPS-

Germany; PACE-Australia; PRIME-USA) were concerned with preventing the development of psychosis in prodromal patients; 11 evaluated interventions for improving outcome in first-episode psychosis (Berger-Australia; Edwards-Australia; Jackson-Australia; KillackeyAustralia; LEO-CAT-UK; Leavey-UK; LifeSPAN-Australia; Linszen-Amsterdam; OPUSScandinavia; Uzenoff-USA; Zhang-China).

\section{Summary of main results}

\section{Trials to prevent the development of psychosis}

1.1 COMPARISION 1. Phase specific intervention (olanzapine) + non-specific supportive therapy versus placebo + non-specific supportive therapy - PRIME-USA: This study randomised a total of 60 people; we think this number is probably too small to detect a treatment affect. Attrition rates were not significantly different, although slightly more people did leave the olanzapine group by 12 months ( $65 \%$ by 12 months).

Olanzapine did not alter the numbers of people converting to psychosis over 12 months when compared with placebo. Also the Clinical Global Impression 'severity of illness' and the Global Assessment of Functioning 'current' change scores were both nonsignificant. Data were limited by study size, and larger groups may well have produced a different outcome. We did not find any significant outcome data from the SOPS scale during 12 months of evaluation. The PANSS, YMRS and MADRS scores were also equivocal, indicating that no real change in mental state occurred over a 12-month period for the olanzapine and placebo group.

For adverse effects, extrapyramidal symptoms were not more frequent in the olanzapine group compared with the placebo group (SAS, BAS and AIMS), even though olanzapine dosage levels were within the lower end of the normal dose range. Olanzapine did produce a statistically significant increase in weight compared with the placebo group. This limited data supports other recent reports of olanzapine's association with weight gain (Duggan 2005; Lieberman 2005). CoStart terms were also recorded and all were equivocal except for weight gain, with significantly more people gaining weight in the olanzapine group. 
Cardiovascular measures were taken on blood pressure and pulse whilst sitting and standing over eight weeks with all data being equivocal. Twelve-month data (sitting) pulse rates were significantly lower in the placebo group, but this may have been a chance finding since all other data were non-significant. Fatigue was higher in the olanzapine group with a NNH of four.

\subsection{COMPARISON 2. Phase specific intervention (cognitive behavioural therapy) + non-specific supportive therapy versus non-specific supportive therapy- EDIE-UK,} EIPS-Germany): Again there were few data to find (total $n=188$ ). We found no differences for numbers of participants leaving the study early by 12 months ( $n=60$, RR 0.98 CI 0.4 to $2.2)$, and again at two years ( $n=60$, RR $0.96 \mathrm{CI} 0.6$ to 1.5$)$ and as a proxy measure of treatment acceptability, CBT did not enhance or worsen compliance in the (EDIE-UK) study.

The numbers of participants becoming psychotic over 12 months of observation were low and no significant differences between CBT (4/37) and the monitoring group (5/23) were found for this primary outcome (EDIE-UK).

Social functioning data were also non-significant (EIPS-Germany).

This approach, as with many others in this review, should be considered experimental.

\subsection{COMPARISON 3. Phase-specific treatment (risperidone + cognitive behavioural} therapy) + specialised team versus specialised team (PACE-Australia): All participants $(n=59)$ remained in the study for one year, which is unusual for randomised trials of this length (Summary of findings for the main comparison). The adherence to the study may have been due to participants being relatively well (i.e. prodromal) and also being cared for by a specialist team. This greatly limits applicability.

Initial findings from this comparison suggest that a phase-specific treatment combining risperidone and CBT can delay, but not prevent the onset of psychosis (Analysis 3.2). Whilst these findings are of interest, they are not definitive, as the single included trial (PACEAustralia) is substantially under-powered at the 12-month end-point. Moreover the use of a combination of phase-specific treatments makes it unclear how far each contributes to the outcome, though a sub-analysis by the trialists suggests that risperidone makes the primary contribution.

Global function (GAF) did not appear to have any effect on outcome in terms of global state, and again with such a small number of participants doubts will remain regarding efficacy. Delaying the onset of psychosis does not appear to have a substantial effect on medium-term outcome, in terms of mental state. This could be because the trial is under powered, or it may be that the benefits of delaying onset of psychosis are less than anticipated. It is also difficult to evaluate the benefits of delaying psychosis without more information on the impact of treatment from the perspective of service users and carers. 
No improvements in quality of life occurred in the early intervention group, even though they were given CBT. However, they also received risperidone, which may have negated any gains in quality of life, due to its adverse effects profile.

\subsection{COMPARISON 4. Phase specific intervention (amisulpride + needs focused} interventions versus needs focused interventions (LIPS-Germany): Participants (total $\mathrm{n}=124$ ) given both needs focused therapy and also amisulpride remained in the study more than the group given only needs focused intervention. This is not necessarily a beneficial outcome given the adverse effects of the amisulpride in a group of participants that are at risk of developing psychosis.

Global Assessment of Functioning scores favoured amisulpride plus NFI. Although the study reports data on global state of the prodromal participants, information on transition to psychosis would have been more useful in interpreting the value of such treatment combinations. Mental state measures in terms of PANSS global scores and PANSS-positive scores did favour amisulpride plus NFI. However, no significant differences were found for PANSS negative symptoms, or depression scores. Again, transition to psychosis data would have been more useful and are notable by their absence.

1.5 COMPARISON 5. Omega 3 fatty acids (EPA) versus placebo (Amminger-Austria): This study aimed to assess the effects of omega- 3 fatty acids in preventing psychosis. The treatment group were significantly less likely to develop psychosis compared with the placebo group at 12 weeks. A NNT of 6 in a sample of 76 is an important result. This study should be replicated with a larger sample and participants followed for at least six months to determine whether a sustained treatment effect is present.

\section{Trials to improve outcome in first-episode psychosis}

\subsection{COMPARISON 6. Phase-specific treatment (cognitive behavioural therapy for} suicidality) + specialised team versus specialised team (LifeSPAN-Australia): The LifeSPAN study involved only 56 participants. Therapy did not affect the numbers of people leaving the study early over six months; larger sample sizes and perhaps longer study time may have produced less equivocal data. Two people committed suicide, one in each group. The study size is too small to determine whether LifeSPAN therapy can reduce suicide.

\subsection{COMPARISON 7. Phase-specific treatment (family therapy) + specialised team} versus specialised team (Linszen-Amsterdam): This was another important but small $(n=76)$ study. Adding family therapy to care from a specialised team did not affect relapse rates, but Linszen-Amsterdam was substantially under powered, so that no definitive conclusions can be drawn. An unusual characteristic of the trial was that all participants had to consent to a three-month inpatient admission before randomisation. This may have limited the ability of the intervention to show an effect by excluding any differences in relapse rates occurring in the first three months after onset. It also limits applicability of findings to other early intervention services, which tend to be oriented towards reducing or avoiding admissions, rather than extending them (Edwards 2002). 
2.3 COMPARISON 8. Phase-specific treatment (family therapy) + standard care versus standard care (Zhang-China): Retention of the 83 study participants over 18 months of care was good, with only $6 \%$ being lost to follow-up; the phase-specific intervention with family therapy did not prove either a benefit or hindrance to study attrition.

Family therapy in addition to standard care did reduce readmission rates and possibly helped compliance. Unfortunately other outcome data were not presented on an intention-to-treat basis and are impossible to use. The main limitation of this trial was the particular nature of the standard care given, which appeared to be a low-key form of outpatient treatment, with little continuity and no community follow-up. This makes it difficult to be certain how far the reduced admission rate in the intervention group was a non-specific effect of substantially increased contact with patients and their families, rather than a particular effect of family therapy. No data were available on how far the finding of fewer admissions was accompanied by improvements in outcome, or service user and carer satisfaction.

Family therapy did not appear, from limited participant numbers, to improve treatment compliance and larger sample sizes are needed to evaluate this outcome.

\subsection{COMPARISON 9. Specialised team versus standard care (OPUS-Scandinavia):}

This is the only large study in the review ( $\mathrm{n}=547$, Summary of findings 2 ). Integrated treatment significantly reduced the numbers of people leaving the study early by 12 months (NNT 9) and as a proxy measure of treatment acceptability was found to be more acceptable than placebo. By two years, attrition rates were still significantly favouring integrated treatment (NNT 7). It appears participants were prepared to remain in treatment longer when care was given from a specialist team, which for people with psychosis is an important outcome.

Global Assessment of Functioning 'symptom' scores significantly favoured integrated treatment by 12 months, but this was not sustained and two-year data were equivocal; GAF 'function' scores were equivocal at 12 months, but by two years did significantly favour integrated treatment. These outcomes seem to confound each other and more research is needed to adequately determine if this form of care can indeed improve global state.

Participants were significantly more satisfied with services in the integrated treatment group by 12 months, and this was sustained over two years. This result does fit with the positive findings for retention rates in the integrated treatment group. Overall, participants in the integrated care group were more compliant with treatment and outpatient visits than the standard care group. This effect was seen over one- and two-year time points, suggesting integrated treatment is more acceptable to people with first-episode psychosis than the standard care available to the control group. Again this result is consistent with attrition and user satisfaction outcomes.

Two people died from suicide, one person from each group.

We did not find any significant differences in the mean number of days per month participants spent in hospital and integrated treatment offered no advantages compared with the control group in terms of reducing the need for hospital care. Unfortunately, no data 
were reported on relapse. Relapse is a primary outcome for this review and an important measure of treatment efficacy for people with first-episode psychosis, clinicians and health care managers.

We did not find integrated treatment to have any significant effect on participants' ability to live independently over one- and two-year assessments. Integrated treatment did significantly improve participants' employment and educational circumstances with 'not employed or in education' being lower by two years (NNT 11). However one-year data were non-significant, suggesting that two years of care are needed before benefits are obtained, although more data are needed to show this effect, especially as most outcome data were not significant.

OPUS-Scandinavia is an important study. It is a large study - but even it should be replicated.

\subsection{COMPARISON 10. Phase-specific treatment cognitive behavioural treatment +} antipsychotics versus befriending + antipsychotics (Jackson-Australia): Neither CBT or the befriending intervention managed to retain significantly more of the 62 participants over the 12 months of the study.

Although two deaths from suicide occurred, this did not suggest a significant difference between the two study groups.

We did not find advantage for CBT participants in their social functioning compared with the control befriending group.

\subsection{COMPARISON 11. Specific intervention E-EPA oils + atypicals versus placebo +} atypical (Berger-Australia): Neither intervention proved to be more advantageous in retaining the 80 participants within the study.

The number of people showing no response to treatment did not reveal any significant difference, in this short-term trial of 12 weeks' duration.

\subsection{COMPARISON 12. Phase-specific treatment brief intervention + antipsychotics} versus treatment as usual (Leavey-UK): At the end of the nine-month intervention, both treatments were similarly acceptable to the 106 participants, with no differences emerging in study attrition.

Over the course of nine months hospital admissions were not significantly lower in either intervention group.

\subsection{COMPARISON 13. Phase-specific treatment (ACE) + antipsychotics versus}

treatment as usual (Uzenoff-USA): This was a study involving 24 participants. During the six months of the study, the interventions' study attrition was not significantly different.

We were able to report several mental state outcomes (PANSS positive, negative, general or total scores, depression rating scale scores), and all were non-significant. However, with 
only 24 participants it is unlikely that any treatment effect would reach statistical significance.

Quality of life as measured using the Heinrichs-Carpenter Scale was equivocal.

2.9 COMPARISON 14. Phase-specific treatment vocational intervention + TAU versus treatment as usual (Killackey-Australia): The emphasis of this study of 41 people was the use of vocational-based interventions. Data revealed that the vocational training group was employed significantly more than the control group during the six months of evaluation.

No advantage emerged for either group in retaining participants within the study.

\subsection{COMPARISON 15. Phase-specific treatment (cap) +antipsychotics versus} psychoeducation (Edwards-Australia): The study (total $n=47$ ) aimed to minimise cannabis usage in people with first-episode psychosis. We found no significant difference between groups. The small sample size may have contributed to the lack of any treatment effect.

The participants understanding of psychosis, measured with the KAPQ questionnaire, did not reveal any differences at three and nine months' assessment. The use of an active control may have contributed to the non-significant finding. The BPRS-derived data on the positive symptoms of psychosis failed to reveal any significant benefits for CAP therapy compared with psychoeducation.

We found that neither CAP or psychoeducation improved social functioning over nine months in this small study; a larger scale trial would have increased the likelihood of finding statistically significant data.

2.11 COMPARISON 16. Crisis assessment versus standard care (LEO-CAT UK): This comparison involved 113 participants. From limited data, we found that hospital admissions were not increased or decreased for participants given crisis assessment. Similarly, participants given crisis assessment were no more likely to be referred to mental health services than the control group. Again, from such a small study it is possible that real effects of interventions are not being highlighted.

\subsection{COMPARISON 17. Early behavioural intervention versus routine care interval} (all data from Alverez-Spain): As with most of the other trials, Alvarez-Spain was too small to really produce results with confidence. We are not sure if early behavioral intervention helps people whose weight is a problem $(n=61)$.

2.13 COMPARISON 18. Phase-specific intervention versus control (Exploratory metaanalysis): Meta-analyses proved problematic because of the heterogeneity in the intervention and outcomes. No two studies were sufficiently alike to perform meta-analyses without reservations of their clinical meaningfulness. Only leaving the study early and hospitalisation data were pooled and in both cases no significant differences were found. An agreed set of core outcome measures in trials assessing early intervention for psychosis would increase the estimate of any treatment effects (COMET). 


\section{Overall completeness and applicability of evidence}

From the comprehensive search, we included 18 studies, most of which have small sample sizes. OPUS-Scandinavia is the exception with over 500 people randomised. Additionally, only two studies were similar to be grouped together under the same comparison; the rest used different interventions or controls. These limitations are a source of uncertainty in our results.

1. Completeness-We had hoped to gather information from trials on a whole series of outcomes such as duration of hospital stay, employment status, quality of life and costs. We have identified a series of pioneering studies, none of which provide data on all outcomes, most of which are inappropriate to synthesise together and therefore data are incomplete for every outcome for every one of the many comparisons in this review.

2. Applicability-Six of the 18 studies were undertaken at the EPPIC Centre in Melbourne, Australia and work embedded in this region's excellent, pioneering and worldclass services may not be widely applicable. However, and understandably, many of the other trials were undertaken by leading figures in the world of early intervention. Again, services within these studies may be better than is standard. This would serve to narrow any differences between intervention and control group.

Often in meta-analyses we have data from trials undertaken all around the world, in different cultures of care, synthesised. In these cases basically homogeneous findings would point to wide applicability of findings. In this review, however, meta-analyses have been very limited and, therefore, we have to remain very cautious regarding applicability.

\section{Quality of the evidence}

All studies were randomised, although in terms of allocation concealment, the quality of included studies was acceptable but not good, since precise details of the method of randomisation were lacking for most studies. One study (EDIE-UK) attempted to blind raters, but this proved difficult and was not adequately maintained as participants 'divulged' sufficient information to inform the rater which treatment participants were receiving. Edwards-Australia, Zhang-China and LifeSPAN-Australia also used raters who were blind to group allocation, but they did not report whether allocation concealment was maintained. One study (PRIME-USA) did use double-blind methodology, made possible by both groups receiving the same psychosocial intervention with the variable being medication (olanzapine or placebo), which was easier to blind for than non-pharmaceutical interventions. OPUSScandinavia, Linszen-Amsterdam and PACE-Australia used independent raters not blinded to treatment. The nature of these therapies is not suited to the raters being blind to treatment allocation and where this was attempted (as with EDIE-UK) it proved difficult to maintain throughout the study. In two trials (Linszen-Amsterdam; Zhang-China) key data were presented in a way that did not permit an intention-to-treat analysis on most outcomes. Rates of follow-up were particularly good in two trials (PACE-Australia; Zhang-China) and unclear (but probably acceptable) in one (Linszen-Amsterdam). Numbers of people lost to follow-up was not excessive in the other trials, but not good - EDIE-UK 70\%, PRIME-USA $65 \%$, OPUS-Scandinavia $77 \%$ and LifeSPAN-Australia $75 \%$. One study did find significant 
differences in follow-up rates between treatment and controls (OPUS-Scandinavia); the effects of this are unclear but may have had an impact on the findings of this review. A substantial omission from most trials was an attempt to capture the perspective of service users and their carers, by, for example, using satisfaction scales.

\section{Potential biases in the review process}

We have been able to identify only published reports; by doing this, we may be perpetuating reporting and publishing biases. It is possible that small studies have not been published, but we feel that large scale published studies would have been identified.

Also, we now have considerable knowledge of these trials and it is possible that we view the data in a way that others could consider biased or skewed in some way. We are keen to receive feedback via peer review before and after publication.

\section{Agreements and disagreements with other studies or reviews}

This review updates earlier versions (Marshall 2004).

\section{AUTHORS' CONCLUSIONS}

\section{Implications for practice}

The current update now includes 18 studies; however, due to the variety of interventions used we have added only two studies under the same comparison category, but because they did not measure the same outcomes we have not synthesised the data. We are, therefore, unable to make any firm recommendations for practice.

\section{For people presenting with prodromal symptoms of psychosis-At the} moment it is not clear whether treating people presenting with prodromal symptoms of schizophrenia provides benefits. There is inconclusive evidence on the personal and social consequences of providing treatment to people who will not necessarily become unwell. Further evidence is needed before recommendations can be given.

2. For people in their first episode of psychosis-There is some support for specialised early intervention services but again further evidence is needed. However, since such people do require treatment in some form, the ethical issues are less intense than for people presenting with prodromal symptoms. Moreover, there is also little evidence to support the 'standard care', which is the alternative to the employment of specialised firstepisode teams (NICE 2002). The use of first-episode teams is therefore ethical even though there is not, as yet, strong evidence to support it.

Phase-specific treatments for people in their first episode of psychosis may help with employment and family therapy. Whilst this evidence is limited, it should be viewed in the broader context that family therapy is known to be effective for people with schizophrenia as a whole (Pharoah 2006). On this basis, it would seem reasonable to recommend family therapy to people experiencing their first episode of psychosis, but there is insufficient data to suggest that they should be given this intervention as a priority over people with established illness. 
There is no evidence from clinical trials to support the benefits of early detection of patients in their first episode of psychosis.

3. For clinicians-Family intervention may be of value for people in their first episode of psychosis, as it may for people with longer established illnesses. It is important for clinicians to continue to keep up to date with this fast-expanding field.

4. For policy makers-It is premature to implement wide-spread treatment programmes for people with prodromal symptoms. Such treatment programmes should only be implemented within the context of a well-designed randomised study.

\section{Implications for research}

1. General-If CONSORT recommendations (Begg 1996; Moher 2001) had been followed by authors of the included studies and the editors of the journals in which those reports were published, the effects of early intervention for psychoses would be more evident.

2. Specific-This review has identified a discrepancy between the global rate of growth of early intervention services and the paucity of underpinning evidence. Whilst there is a compelling theoretical case for early intervention, much of the supporting evidence is circumstantial (based on the correlation between duration of untreated psychosis and outcome) rather than definitive (based on improved outcome in clinical trials). If this discrepancy persists, the obvious risk is that, eventually, early intervention will become routine practice, without its efficacy ever being definitively established. Whilst this review has found some evidence of a growing body of research in the field, there is no room for complacency over the amount of work that needs to be done. Possible combinations of early detection, type of participant (prodromal or first episode), type of control, and type of intervention (phase-specific or specialised team) generate at least 17 possible types of trial. However, the review has identified 18 included trials, most of which are clearly underpowered. The current substantial international interest in early intervention offers an opportunity to make major positive changes in psychiatric practice, but this opportunity may be missed without a concerted international programme of research to address key unanswered questions.

These key questions are:

- Can phase-specific treatments prevent people with prodromal symptoms from developing psychosis and, if so, do they or their carers benefit as a result?

- Can early detection reduce the duration of untreated psychosis, and if so, does this lead to improvements in outcome for service users and carers?

- Are there phase-specific treatments that improve outcome for people with firstepisode psychosis, or for their carers?

- Do specialised early intervention teams offer improvements in outcome over and above those provided by phase-specific treatments alone? 
These questions give rise to two important points, which if borne in mind at the design stage, might increase the value of future trials in the field. Firstly, a phase-specific treatment should not be a priority for investigation unless it is known to be substantially different from existing interventions that are already known to be helpful to people at all stages of schizophrenia. For example, there is little point in investigating the effects of behavioural family therapy with minor modifications for first-episode patients, when this intervention is known to be generally effective in schizophrenia (Pharoah 2006). Phase-specific treatments ought to be given priority for evaluation only when they are substantial departures from what would be considered standard care, or where there is evidence that they are likely to be more effective when offered in the early stages of the illness.

Secondly, great care must be taken in defining the characteristics and activities of specialised early intervention teams. The complexity of 'early intervention' makes it likely that no two specialised teams will be identical. Unless the essence of an early intervention team can be adequately characterised, it is inevitable that disappointing findings will lead to arguments over whether a particular specialised team was really practising early intervention. Years of research effort can be wasted in this way. Lessons should be learned from research which has already been undertaken with other specialised psychiatric teams (such as assertive outreach teams) and fidelity scales developed as an early priority.

\title{
Acknowledgments
}

Mark Fenton and Clive E Adams of the Cochrane Schizophrenia Group for conducting the initial database search. Many thanks to Sarah Uzenoff for providing additional data.

Many thanks to Austin Lockwood - who co-ordinated the review and collected data, screened the search results, organised the retrieval of papers, appraised the papers and extracted data, managed the data and entered data in RevMan, analysed and interpreted the data and wrote the final report, during the first publication of the review (Marshall 2004).

The Cochrane Schizophrenia Group produces and maintains a template Methods section. We have used this and adapted it to make it relevant for our review.

\section{SOURCES OF SUPPORT}

Internal sources

- $\quad$ Lancashire Care NHS Trust, UK.

External sources

- Department of Health, UK.

- Cochrane Incentive Scheme, UK.

\section{CHARACTERISTICS OF STUDIES}

Characteristics of included studies [ordered by study ID]

\author{
Alvarez-Spain
}


Setting: community.

Duration: interventions offered for 3 months

\begin{tabular}{|c|c|c|}
\hline Participants & \multicolumn{2}{|c|}{$\begin{array}{l}\text { Diagnosis: drug-naive first-episode psychosis (DSM-IV). } \\
\text { N=61. } \\
\text { Sex: } 46 \mathrm{M}, 15 \mathrm{~F} \text {. } \\
\text { Age: mean } 26 \text { years. } \\
\text { Inclusion criteria: } 15 \text { to } 60 \text { years, DSM criteria for schizophrenia, schizophreniform } \\
\text { disorder, schizoaffective disorder, delusional disorder, brief reactive psychosis, or } \\
\text { psychosis not otherwise specified. } \\
\text { Excluded: patients with neurological disease, head injury, mental retardation, and } \\
\text { drug dependence. } \\
\text { History: all patients experiencing their first episode of psychosis and had not } \\
\text { received more than } 6 \text { weeks of adequate antipsychotic treatment }\end{array}$} \\
\hline Interventions & \multicolumn{2}{|c|}{$\begin{array}{l}\text { 1. Early Behavoural Intervention*. } \mathrm{N}=28 \text {. } \\
\text { 2. Routine Care Intervention**. } \mathrm{N}=33 \text {. } \\
\text { Interventions started when participants reached a minimum clinical stabilisation, } \\
\text { defined by a global score of }<5 \text { on the SAPS scale, or otherwise treatment began } \\
\text { within } 6 \text { weeks of randomisation }\end{array}$} \\
\hline Outcomes & \multicolumn{2}{|c|}{$\begin{array}{l}\text { Body weight. } \\
\text { Body Mass Index. } \\
\text { Unable to use - } \\
\text { Leaving the study early- no data. } \\
\text { Mental state: SAPS (no data reported). }\end{array}$} \\
\hline Notes & \multicolumn{2}{|c|}{$\begin{array}{l}\text { * This package of care was specifically designed to teach strategies to enhance } \\
\text { control over factors associated with antipsychotic-induced weight gain and } \\
\text { consisted of } 8 \text { flexible intervention modules that incorporated behavioural } \\
\text { interventions, nutrition and exercise. } \\
\text { ** The control group were informed about potential weight gain and advised to } \\
\text { increase their exercise and limit food intake. } \\
\text { Participants were first randomised to } 3 \text { antipsychotics (olanzapine mean dose } 13 \\
\text { mg/day, risperidone mean dose } 4.2 \mathrm{mg} / \text { day or haloperidol mean dose } 4.9 \mathrm{mg} / \mathrm{day} \text { ), } \\
\text { then randomly assigned to either EBI or RCI }\end{array}$} \\
\hline \multicolumn{3}{|l|}{ Risk of bias } \\
\hline Bias & Authors' judgement & Support for judgement \\
\hline Adequate sequence generation? & Low risk & $\begin{array}{l}\text { Randomised using computer generated } \\
\text { random numbers }\end{array}$ \\
\hline Allocation concealment? & Unclear risk & No details. \\
\hline $\begin{array}{l}\text { Blinding? } \\
\text { All outcomes }\end{array}$ & High risk & Single \\
\hline $\begin{array}{l}\text { Incomplete outcome data } \\
\text { addressed? } \\
\text { All outcomes }\end{array}$ & High risk & Study attrition not reported \\
\hline Free of selective reporting? & High risk & SAPS data not reported \\
\hline Free of other bias? & Unclear risk & No details. \\
\hline
\end{tabular}

Amminger-Austria

\begin{tabular}{ll}
\hline Methods & Allocation: randomised, no further details. \\
& Blinding: double blind. \\
Setting: Vienna, Austria. \\
Inclusion criteria: not stated. \\
Exclusion criteria: not stated. \\
Follow up: 12 weeks. \\
\hline Participants & Diagnosis: Adolescents at risk of 1st episode psychosis (Yung criteria). \\
& N=81*. \\
Age: range 3-24 years; mean age 16.4. \\
Sex: no details. \\
History: no details. \\
\hline
\end{tabular}


Interventions

\begin{tabular}{|c|c|c|}
\hline Outcomes & \multicolumn{2}{|c|}{$\begin{array}{l}\text { Transition to psychosis**. } \\
\text { Unable to use - } \\
\text { Leaving the study early } \\
\text { Mental state: BPRS, PANSS (no usable data) } \\
\text { Global state: GAF (no usable data). } \\
\text { Adverse effects: UKU. }\end{array}$} \\
\hline Notes & \multicolumn{2}{|c|}{$\begin{array}{l}\text { *5 participants not accounted for. } \\
* * \text { Operationally defined, based on Yung et al's criteria, using cut-off points on } \\
\text { PANSS subscales, ( } 4 \text { or more on hallucinations, } 4 \text { or more on delusions, and } 5 \text { or } \\
\text { more on conceptual disorganization), and the frequency of symptoms (at least } \\
\text { several times a week) and their duration (more than one week) }\end{array}$} \\
\hline \multicolumn{3}{|l|}{ Risk of bias } \\
\hline Bias & Authors' judgement & Support for judgement \\
\hline Adequate sequence generation? & Unclear risk & Randomised, no further details. \\
\hline Allocation concealment? & Unclear risk & No described. \\
\hline $\begin{array}{l}\text { Blinding? } \\
\text { All outcomes }\end{array}$ & Unclear risk & Double blind, untested. \\
\hline $\begin{array}{l}\text { Incomplete outcome data } \\
\text { addressed? } \\
\text { All outcomes }\end{array}$ & High risk & Study attrition not described. \\
\hline Free of selective reporting? & Unclear risk & No details. \\
\hline Free of other bias? & Unclear risk & No details. \\
\hline
\end{tabular}

\section{Berger-Australia}

\begin{tabular}{|c|c|}
\hline Methods & $\begin{array}{l}\text { Allocation: randomised. } \\
\text { Blinding: double blind. } \\
\text { Setting: single centre Melbourne, Australia (EPPIC Centre). } \\
\text { Inclusion criteria: age between 15-29 years, currently psychotic. } \\
\text { Exclusion criteria: drug induced psychosis; first-episode mania; psychotic } \\
\text { disorders due to organic illness. } \\
\text { Follow-up: } 12 \text { weeks. }\end{array}$ \\
\hline Participants & $\begin{array}{l}\text { Diagnosis: psychosis (DSM-IV). } \\
\text { N=80. } \\
\text { Age: mean } 20 \text { years. } \\
\text { Sex: male and female. } \\
\text { History: first-episode psychosis; mean antipsychotic treatment prior to study } \\
17.5 \text { days }\end{array}$ \\
\hline Interventions & $\begin{array}{l}\text { 1. Ethyl-Eicosapentaenoic Acid oil (E-EPA): dose } 500 \mathrm{mg} / \mathrm{bid} \text {, plus flexible } \\
\text { dosage of atypical antipsychotics. } \mathrm{N}=40 \text {. } \\
\text { 2. Placebo capsules: plus flexible dosage of atypical antipsychotics. } \mathrm{N}=40 \text {. } \\
\text { Benzodiazepines, chlorpromazine or zuclopenthixol acetate allowed for } \\
\text { behavioural control when indicated }\end{array}$ \\
\hline Outcomes & $\begin{array}{l}\text { Leaving the study early. } \\
\text { Global state: Not responded to treatment. } \\
\text { Unable to use - } \\
\text { Mental state: BPRS, SANS, MADRAS (no data). } \\
\text { Global state: CGI, GAF (no data). } \\
\text { Social functioning: SOFAS no data). } \\
\text { Adverse events: SAS, UKU (no usable data). } \\
\text { Social functioning: SAS II. }\end{array}$ \\
\hline \multicolumn{2}{|l|}{ Notes } \\
\hline Risk of bias & \\
\hline
\end{tabular}




\begin{tabular}{lll} 
Bias & Authors' judgement & Support for judgement \\
\hline Adequate sequence generation? & Unclear risk & Randomised, no further details. \\
\hline Allocation concealment? & Unclear risk & No details. \\
\hline $\begin{array}{l}\text { Blinding? } \\
\text { All outcomes }\end{array}$ & Unclear risk & Double blind, untested. \\
\hline $\begin{array}{l}\text { Incomplete outcome data } \\
\text { addressed? }\end{array}$ & Low risk & Study attrition reported. \\
All outcomes & & \\
\hline Free of selective reporting? & Unclear risk & No details. \\
\hline Free of other bias? & Low risk & Funded by Swiss National Science Foundation; \\
& & $\begin{array}{l}\text { Margaret and Walter Lichtenstein Foundation, National } \\
\text { Health and Medical Research Council of Australia' the } \\
\text { Colonial Foundation of Australia, and a National }\end{array}$ \\
& & $\begin{array}{l}\text { Alliance for Reasearch on Schizophrenia and } \\
\text { Depression }\end{array}$ \\
\hline
\end{tabular}

\section{EDIE-UK}

\begin{tabular}{|c|c|}
\hline Methods & $\begin{array}{l}\text { Allocation: randomised, stratified according to gender and genetic risk } \\
\text { (independent clerical worker, sealed envelopes). } \\
\text { Blinding: single blind (raters), attempts made to keep assessors blind*. } \\
\text { Setting: community, Salford, Manchester. } \\
\text { Inclusion criteria: based on an adaptation of the PACE criteria, and an age range } \\
\text { between } 16-36 \text {. } \\
\text { Exclusion criteria: current of past receipt of antipsychotic medication. } \\
\text { Follow-up: } 1 \text { year and } 3 \text { years. } \\
\text { Evaluation: conducted by research assistants. }\end{array}$ \\
\hline Participants & $\begin{array}{l}\text { Diagnosis: ultra high risk of developing } 1 \text { st episode of psychosis (Yung modified } \\
\text { criteria). } \\
\text { N=60. } \\
\text { Age: mean } 21 \text { years. } \\
\text { Sex: male and female. } \\
\text { History: not reported. }\end{array}$ \\
\hline Interventions & $\begin{array}{l}\text { 1. Cognitive therapy: dose maximum of } 26 \text { sessions, over } 6 \text { months. } N=37 \\
\text { 2. Monitoring control group. } N=23 \text {. }\end{array}$ \\
\hline Outcomes & $\begin{array}{l}\text { Leaving the study early. } \\
\text { Transition to psychosis (based on PANSS criteria). } \\
\text { Unable to use - } \\
\text { Transition to psychosis ( } 3 \text { year data, } 53 \% \text { lost to follow-up). } \\
\text { Mental state: PANSS (no usable data). } \\
\text { Global state: GAF, GHQ (no usable data). } \\
\text { Sociotropy - Autonomy Scale (no usable data). } \\
\text { Meta-Cognitions Questionnaire (no usable data). } \\
\text { Oxford-Liverpool Inventory of Feelings and Experiences (no usable data) }\end{array}$ \\
\hline Notes & $\begin{array}{l}\text { *Blinding was not adequately maintained due to participants divulging information } \\
\text { about their therapist, or used language that suggested they were receiving cognitive } \\
\text { therapy. Three-year outcome data not used due to }>50 \% \text { study attrition }\end{array}$ \\
\hline \multicolumn{2}{|l|}{ Risk of bias } \\
\hline Bias & Support for judgement \\
\hline Adequate sequence generation? & Randomised, no further details. \\
\hline Allocation concealment? & $\begin{array}{l}\text { By independent clerical worker, using } \\
\text { sealed envelopes. }\end{array}$ \\
\hline $\begin{array}{l}\text { Blinding? } \\
\text { All outcomes }\end{array}$ & Single blind. \\
\hline $\begin{array}{l}\text { Incomplete outcome data } \\
\text { addressed? }\end{array}$ & Study attrition reported. \\
\hline
\end{tabular}

Cochrane Database Syst Rev. Author manuscript; available in PMC 2014 September 15. 
All outcomes

\begin{tabular}{lll}
\hline Free of selective reporting? & Unclear risk & No details. \\
\hline Free of other bias? & Low risk & Funded by North-West NHS Executive. \\
\hline
\end{tabular}

Edwards-Australia

\begin{tabular}{|c|c|}
\hline Methods & $\begin{array}{l}\text { Allocation: randomised, computer generated, placed in sealed envelopes. } \\
\text { Blinding: single; attempts to maintain rater blindness included use of separate } \\
\text { rooms and admin procedures for staff. } \\
\text { Duration: } 3 \text { months intervention phase followed by } 6 \text { months of follow-up. } \\
\text { Country: Melbourne, Australia. } \\
\text { Setting: youth mental health service; early psychosis, prevention and intervention } \\
\text { centre (EPPIC). } \\
\text { Analyses: ITT analyses were used and last observation carried forward }\end{array}$ \\
\hline Participants & $\begin{array}{l}\text { Diagnosis: first-episode psychosis (DSM-IV). } \\
\text { N=47. } \\
\text { Age: } 15-29 \text { years. } \\
\text { Sex: male and female. } \\
\text { History: patients continuing to use cannabis after initial treatment for first episode } \\
\text { psychosis. } \\
\text { Inclusion criteria: DSM-IV diagnosis of a psychotic disorder (i.e. schizophrenia, } \\
\text { schizophreniform, schizoaffective, delusional disorder, bipolar disorder, major } \\
\text { depressive disorder with psychotic features, psychosis not otherwise stated, brief } \\
\text { reactive psychosis). } \\
\text { Exclusion criteria: only participants with at least } 10 \text { weeks continuous cannabis } \\
\text { usage prior to study were eligible for study inclusion }\end{array}$ \\
\hline Interventions & $\begin{array}{l}\text { 1. Cannabis and Psychosis Therapy: mean no. of CAP sessions } 8 . \mathrm{N}=23 \\
\text { 2. Psychoeducation: mean no. of sessions } 8 \text {. } \mathrm{N}=24 \text {. }\end{array}$ \\
\hline Outcomes & $\begin{array}{l}\text { Behavioural: CASUAS. } \\
\text { Mental state: BPRS, SANS, BDI-SF. } \\
\text { Social functioning: SOFAS. } \\
\text { Global state: KAPQ. }\end{array}$ \\
\hline Notes & $\begin{array}{l}\text { CAP therapy consisted of a cognitive-behavioural-orientated programme delivered } \\
\text { in weekly sessions by trained clinicians over } 3 \text { months } \\
\text { Psychoeducation was an active control. }\end{array}$ \\
\hline \multicolumn{2}{|l|}{ Risk of bias } \\
\hline Bias & Support for judgement \\
\hline Adequate sequence generation? & Computer generated randomisation. \\
\hline Allocation concealment? & Insufficient details. \\
\hline $\begin{array}{l}\text { Blinding? } \\
\text { All outcomes }\end{array}$ & Single blind. \\
\hline $\begin{array}{l}\text { Incomplete outcome data } \\
\text { addressed? } \\
\text { All outcomes }\end{array}$ & Study attrition not reported. \\
\hline Free of selective reporting? & Unclear risk \\
\hline Free of other bias? & Unclear risk \\
\hline
\end{tabular}

\section{EIPS-Germany}

Allocation: randomised computer generated by block using sealed envelopes.
Blinding: not stated.

Setting: community, Cologne, Bonn, Dusseldorf, and Munich.

Inclusion criteria: EIPS criteria. 
Exclusion criteria: attenuated of brief limited intermittent psychotic symptoms; present or past diagnosis of schizophrenia; alcohol or drug dependence. Follow-up: 12 months therapy.

\begin{tabular}{|c|c|c|}
\hline Participants & \multicolumn{2}{|c|}{$\begin{array}{l}\text { Diagnosis: people at risk of developing } 1 \text { st episode of psychosis. } \\
\mathrm{N}=128^{*} \text {. } \\
\text { Age: mean age } \sim 26 \text { years. } \\
\text { Sex: male and female. } \\
\text { History: not reported. }\end{array}$} \\
\hline Interventions & \multicolumn{2}{|c|}{$\begin{array}{l}\text { 1. Cognitive Behavioural Therapy: sessions over } 12 \text { months, group therapy session } \\
\mathrm{n}=15 \text {, individual therapy session } \mathrm{n}=25 \text {, plus cognitive remediation } 12 \text { sessions. } \\
\mathrm{N}=54 \text {. } \\
\text { 2. Supportive Therapy: sessions over } 12 \text { months, minimal support involving } \\
\text { psychoeducation and counselling. } \mathrm{N}=59\end{array}$} \\
\hline Outcomes & \multicolumn{2}{|c|}{$\begin{array}{l}\text { Social functioning: SAS II. } \\
\text { Unable to use - } \\
\text { Leaving the study early - no usable data. }\end{array}$} \\
\hline Notes & \multicolumn{2}{|c|}{$\begin{array}{l}* 15 \text { participants not accounted for after randomisation. EIPS - early initial } \\
\text { prodromal state }\end{array}$} \\
\hline \multicolumn{3}{|l|}{ Risk of bias } \\
\hline Bias & Authors' judgement & Support for judgement \\
\hline Adequate sequence generation? & Low risk & $\begin{array}{l}\text { Randomised by computer generated } \\
\text { numbers. }\end{array}$ \\
\hline Allocation concealment? & Unclear risk & Using sealed envelopes. \\
\hline $\begin{array}{l}\text { Blinding? } \\
\text { All outcomes }\end{array}$ & High risk & Not stated. \\
\hline $\begin{array}{l}\text { Incomplete outcome data } \\
\text { addressed? } \\
\text { All outcomes }\end{array}$ & High risk & Study attrition only part reported. \\
\hline Free of selective reporting? & Unclear risk & No details. \\
\hline Free of other bias? & Low risk & $\begin{array}{l}\text { Funded by the German Federal Ministry } \\
\text { of Education and Research }\end{array}$ \\
\hline
\end{tabular}

Jackson-Australia

\begin{tabular}{ll}
\hline Methods & Allocation: randomised (stratified according to affective and non-effective \\
psychosis, by independent statistician). & Blinding: single blind. \\
& Setting: participant's home, neutral location or EPPIC centre (Psychosis \\
& Prevention and Intervention Centre) Melbourne, Australia. \\
& Follow-up: one year. \\
& Inclusion criteria: \\
& Exclusion criteria: IQ < 70, psychosis due to a medical condition; exhibiting \\
& violent behaviour. \\
& Evaluation: research assistants blind to treatment. \\
& Diagnosis: psychosis. \\
& N=62. \\
Age: mean 22 years. \\
Sex: $45 \mathrm{M}, 17 \mathrm{~F}$. \\
History: mean onset age of psychosis 22 years. \\
\hline 1. Cognitive Behavioural Therapy (ACE): dose 20 sessions* for 45 minutes, plus \\
neuroleptics. N=31. \\
2. Befriending, plus neuroleptics. N=31. \\
Leaving the study early. \\
Suicide. \\
Hospital admission (not hospitalised). \\
Social functioning: Social and Occupational \\
Functioning Assessment Scale (SOFRAS). \\
\hline
\end{tabular}


Notes

*Participants could receive a maximum of 20 sessions over 14 weeks for approximately 45 minutes.

ACE - Active Cognitive Therapy for Early Psychosis.

\begin{tabular}{lll}
\hline Risk of bias & & \\
\hline Bias & Authors' judgement & Support for judgement \\
\hline Adequate sequence generation? & Unclear risk & Randomised, no further details. \\
\hline Allocation concealment? & Low risk & Randomised by independent statistician. \\
\hline $\begin{array}{l}\text { Blinding? } \\
\text { All outcomes }\end{array}$ & High risk & Single, untested. \\
\hline $\begin{array}{l}\text { Incomplete outcome data } \\
\text { addressed? }\end{array}$ & Low risk & Study attrition reported. \\
\hline All outcomes & & \\
\hline Free of selective reporting? & Unclear risk & No details. \\
\hline Free of other bias? & Low risk & Funded by NH\&MRC grant. \\
\hline
\end{tabular}

\section{Killackey-Australia}

\begin{tabular}{|c|c|}
\hline Methods & $\begin{array}{l}\text { Allocation: randomised, computer generated. } \\
\text { Blinding: not stated. } \\
\text { Setting: Early Psychosis Prevention and Intervention Centre (EPPIC) in } \\
\text { Melbourne, Australia. } \\
\text { Follow-up: } 6 \text { months. } \\
\text { Inclusion criteria: Individuals were eligible for the study if they wanted to find } \\
\text { work (including a different job if they currently held one) and had at least } 6 \text { months } \\
\text { of care left at EPPIC (EPPIC is limited to providing } 18 \text { months of care). } \\
\text { Exclusion criteria: lack of fluency in English. }\end{array}$ \\
\hline Participants & $\begin{array}{l}\text { Diagnosis: schizophrenia } 1 \text { st episode. } \\
\text { N=41. } \\
\text { Age: mean } 21 \text { years. } \\
\text { Sex: } 33 \mathrm{M}, 8 \mathrm{~F} \text {. } \\
\text { History: length of illness IPS } 16 \text { months, TAU } 12 \text { months. }\end{array}$ \\
\hline Interventions & $\begin{array}{l}\text { 1. IPS plus TAU. } \mathrm{N}=20 \text {. } \\
\text { 2. TAU. } \mathrm{N}=21 .\end{array}$ \\
\hline Outcomes & $\begin{array}{l}\text { Employment. } \\
\text { Leaving the study early. }\end{array}$ \\
\hline Notes & $\begin{array}{l}\text { *IPS is focused on competitive employment; it is open to any person with mental } \\
\text { illness who chooses to look for work and acceptance into the programme is not } \\
\text { determined by measures of work-readiness or illness variables; the support } \\
\text { provided in the programme is time-unlimited, continuing after employment is } \\
\text { obtained, and is adapted to the needs of the individual }\end{array}$ \\
\hline \multicolumn{2}{|l|}{ Risk of bias } \\
\hline Bias & Support for judgement \\
\hline Adequate sequence generation? & Randomised, computer generated. \\
\hline Allocation concealment? & Not reported. \\
\hline $\begin{array}{l}\text { Blinding? } \\
\text { All outcomes }\end{array}$ & Not reported. \\
\hline $\begin{array}{l}\text { Incomplete outcome data } \\
\text { addressed? } \\
\text { All outcomes }\end{array}$ & Study attrition reported. \\
\hline Free of selective reporting? & Unclear risk \\
\hline Free of other bias? & Unclear risk \\
\hline
\end{tabular}

Cochrane Database Syst Rev. Author manuscript; available in PMC 2014 September 15. 


\section{Leavey-UK}

\begin{tabular}{|c|c|}
\hline Methods & $\begin{array}{l}\text { Allocation: randomised by block and placed into sealed envelopes, and drawn by } \\
\text { individual with no connection to the study. } \\
\text { Blinding: single blind. } \\
\text { Setting: outpatients, London, UK. } \\
\text { Follow-up: } 9 \text { months. } \\
\text { Inclusion criteria: people with a } 1 \text { st episode psychosis within the last } 6 \text { months. } \\
\text { Exclusion criteria: organic disorders, or learning difficulties. } \\
\text { Evaluation: assessment made by research assistants blind to allocation }\end{array}$ \\
\hline Participants & $\begin{array}{l}\text { Diagnosis: first-episode psychosis (ICD-9). } \\
\text { N=106 patients and their carers*. } \\
\text { Age: } 16+\text { years. } \\
\text { Sex: } 68 \mathrm{M}, 38 \mathrm{~F} \text {. } \\
\text { History: } 1 \text { st episode psychosis, recruited from psychiatric services in North } \\
\text { London }\end{array}$ \\
\hline Interventions & $\begin{array}{l}\text { 1. Brief intervention and treatment as usual. } \mathrm{N}=57 \text {. } \\
\text { 2. Treatment as usual with usual support from psychiatric services. } \mathrm{N}=49 \text {. } \\
\text { Brief intervention was provided over seven sessions, lasting about one hour and } \\
\text { included information gathering from the relative, an educational component on } \\
\text { psychotic illness, symptoms and early warning signs, treatment, and help seeking; } \\
\text { coping strategies, problem solving and communication with the patient }\end{array}$ \\
\hline Outcomes & $\begin{array}{l}\text { Leaving the study early. } \\
\text { Hospital admission. } \\
\text { Unable to use - } \\
\text { Satisfaction: Verona Service Satisfaction Questionnaire (no usable data). } \\
\text { Perceived severity of illness. }\end{array}$ \\
\hline Notes & $\begin{array}{l}\text { *Carers/relatives were blind to treatment allocation. } \\
\text { ITT analysis used. }\end{array}$ \\
\hline \multicolumn{2}{|l|}{ Risk of bias } \\
\hline Bias & Support for judgement \\
\hline Adequate sequence generation? & Randomised, no further details. \\
\hline Allocation concealment? & $\begin{array}{l}\text { Using sealed envelopes, drawn by } \\
\text { individuals with no connection to the } \\
\text { study }\end{array}$ \\
\hline $\begin{array}{l}\text { Blinding? } \\
\text { All outcomes }\end{array}$ & Single, untested. \\
\hline $\begin{array}{l}\text { Incomplete outcome data } \\
\text { addressed? } \\
\text { All outcomes }\end{array}$ & Study attrition reported. \\
\hline Free of selective reporting? & Unclear risk \\
\hline Free of other bias? & $\begin{array}{l}\text { Funded by NHS Executive, London } \\
\text { Research and Development Programme }\end{array}$ \\
\hline
\end{tabular}

\section{LEO-CAT-UK}

\begin{tabular}{ll}
\hline Methods & Allocation: cluster randomised with 46 GP practices. \\
& Blinding: open study. \\
& Setting: community health centre, London, UK. \\
& Follow-up: over 12 months. \\
\hline Participants & Diagnosis: psychosis (CAARMS*) \\
& N=113. \\
Age: mean age 23 years. & Sex: $81 \mathrm{M}, 32 \mathrm{~F}$. \\
Excluded: participants with a history of contact with mental health services for \\
psychosis for more than 6 months or antipsychotic treatment for more than a \\
month.
\end{tabular}

Cochrane Database Syst Rev. Author manuscript; available in PMC 2014 September 15. 
History: first-episode psychosis.

\begin{tabular}{lll}
\hline Interventions & $\begin{array}{l}\text { 1. GP education in early detection with access to LEO-CAT. N=23 practices, } \\
\text { N=50 participants. } \\
\text { 2. Usual care, with access to LEO-CAT. N=23 practices, N=63 participants }\end{array}$ \\
\hline Outcomes & $\begin{array}{l}\text { Hospitalisation. } \\
\text { Referred to Mental Health Services by Accident and Emergency or Emergency } \\
\text { Health services }\end{array}$ \\
\hline Notes & $\begin{array}{l}\text { *Comprehensive Assessment of At-Risk Mental States (CAARMS) (Yung 2005). } \\
\text { LEO-CAT- Lambeth Early Onset Crisis Assessment Team. GP practices } \\
\text { randomised into the intervention group received both the GP education training } \\
\text { and direct access to the LEO CAT team for referrals. }\end{array}$ \\
\hline Risk of bias & Authors' judgement & Support for judgement \\
\hline Bias & Unclear risk & Randomised, no further details. \\
\hline Adequate sequence generation? & Unclear risk & No details. \\
\hline Allocation concealment? & High risk & Open study. \\
\hline $\begin{array}{l}\text { Blinding? } \\
\text { All outcomes }\end{array}$ & High risk & Study attrition not reported. \\
\hline $\begin{array}{l}\text { Incomplete outcome data } \\
\text { addressed? } \\
\text { All outcomes }\end{array}$ & Unclear risk & No details. \\
\hline Free of selective reporting? & Unclear risk & No details. \\
\hline Free of other bias? & & \\
\hline
\end{tabular}

\section{LifeSPAN-Australia}

\begin{tabular}{|c|c|}
\hline Methods & $\begin{array}{l}\text { Allocation: randomised (no further details). } \\
\text { Blinding: single, no further details. } \\
\text { Setting: Early Psychosis Prevention and Intervention Centre (EPPIC). } \\
\text { Follow-up: } 10 \text { weeks and } 6 \text { months. } \\
\text { Inclusion criteria: scoring from } 4 \text { to } 7 \text { on the expanded version of the BPRS } \\
\text { suicidality subscore. } \\
\text { Exclusion criteria: attended the EPPIC centre for more than one year. } \\
\text { Evaluation: 'conducted blind to therapy'. }\end{array}$ \\
\hline Participants & $\begin{array}{l}\text { Diagnosis: first-episode psychosis and acutely suicidal. } \\
\mathrm{N}=56 \text {. } \\
\text { Age: range } 15-29 \text { years. } \\
\text { Sex: not reported. } \\
\text { History: not reported. }\end{array}$ \\
\hline Interventions & $\begin{array}{l}\text { 1. LifeSPAN therapy: dose } 8 \text { to } 10 \text { sessions }+ \text { standard clinical care. } \mathrm{N}=31 \\
\text { 2. Standard care. } \mathrm{N}=25 \text {. } \\
\text { LifeSPAN is a brief individual cognitively orientated therapy specifically designed } \\
\text { for acutely suicidal youths with severe mental illness }\end{array}$ \\
\hline Outcomes & $\begin{array}{l}\text { Leaving the study early. } \\
\text { Death from suicide. } \\
\text { Unable to use - } \\
\text { Mental state: BPRS, SANS: (no usable data). } \\
\text { Global state: GAF: (no usable data). } \\
\text { Quality of life: (no usable data). } \\
\text { Beck Hopelessness Scale: (no usable data). } \\
\text { Self Esteem Scale: (no usable data). } \\
\text { Self Report Problem Solving Rating Scale: (no usable data). } \\
\text { Suicide Ideation Questionnaire: (no usable data). } \\
\text { Suicide Intent Scale: (no usable data). } \\
\text { Reasons for Living Inventory: (no usable data). }\end{array}$ \\
\hline \multicolumn{2}{|l|}{ Notes } \\
\hline Risk of bias & \\
\hline
\end{tabular}

Cochrane Database Syst Rev. Author manuscript; available in PMC 2014 September 15. 


\begin{tabular}{lll} 
Bias & Authors' judgement & Support for judgement \\
\hline Adequate sequence generation? & Unclear risk & Randomised, no further details. \\
\hline Allocation concealment? & Unclear risk & No details. \\
\hline $\begin{array}{l}\text { Blinding? } \\
\text { All outcomes }\end{array}$ & High risk & Single blind. \\
\hline $\begin{array}{l}\text { Incomplete outcome data } \\
\text { addressed? } \\
\text { All outcomes }\end{array}$ & Low risk & Study attrition reported. \\
\hline Free of selective reporting? & Unclear risk & \\
\hline Free of other bias? & Low risk & No details. \\
\hline
\end{tabular}

\section{Linszen-Amsterdam}

\begin{tabular}{|c|c|}
\hline Methods & $\begin{array}{l}\text { Allocation: 'randomly assigned'. } \\
\text { Blinding: unclear if raters blind to treatment condition. } \\
\text { Setting: In-patient unit for adolescents, Amsterdam, Netherlands. } \\
\text { Follow-up: } 12 \text { months (following on from initial } 3 \text { month inpatient admission), } \\
\text { then } 5 \text { years. } \\
\text { Inclusion criteria: first episode of schizophrenia, age 15-26, living or in close } \\
\text { contact with parents or other relatives, Dutch speakers, no primary drug problem. } \\
\text { Evaluation: 'independent raters'. }\end{array}$ \\
\hline Participants & $\begin{array}{l}\text { Diagnosis: schizophrenia. } \\
\text { N=76. } \\
\text { Age: mean } 20.6 \text {. } \\
\text { Sex: M } 53 \text { F } 23 \text {. } \\
\text { History: mean DUP } 5.4 \text { months. }\end{array}$ \\
\hline Interventions & $\begin{array}{l}\text { 1. Behavioural family therapy }+ \text { individual-orientated therapy. } \mathrm{N}=37 \\
\text { 2. Individual-orientated therapy alone. } \mathrm{N}=39 \text {. }\end{array}$ \\
\hline Outcomes & $\begin{array}{l}\text { Relapse. } \\
\text { Unable to use - } \\
\text { Mental state: BPRS: (data not reported). } \\
\text { Compliance: (data not reported). } \\
\text { Lost to follow up: (exact figures unclear, though no evidence of substantial loss) }\end{array}$ \\
\hline Notes & $\begin{array}{l}\text { First Episode Trial - care from a specialised team plus phase specific intervention } \\
\text { versus care from specialised team } \\
\text { Unclear when randomisation took place, possible the initial sample size was 97, in } \\
\text { which case not intention to treat } \\
\text { Five year data reported for whole sample, not by group allocation }\end{array}$ \\
\hline \multicolumn{2}{|l|}{ Risk of bias } \\
\hline Bias & Support for judgement \\
\hline Adequate sequence generation? & Randomised, no further details. \\
\hline Allocation concealment? & Unclear risk \\
\hline $\begin{array}{l}\text { Blinding? } \\
\text { All outcomes }\end{array}$ & No details. \\
\hline $\begin{array}{l}\text { Incomplete outcome data } \\
\text { addressed? } \\
\text { All outcomes }\end{array}$ & Study attrition not reported. \\
\hline Free of selective reporting? & Unclear risk \\
\hline Free of other bias? & Part funded by 'Praeventiefonds'. \\
\hline
\end{tabular}

\section{LIPS-Germany}




\begin{tabular}{|c|c|c|}
\hline Methods & \multicolumn{2}{|c|}{$\begin{array}{l}\text { Allocation: randomised, no further details. } \\
\text { Blinding: open label. } \\
\text { Setting: Germany, outpatient clinic. } \\
\text { Follow-up: two years. } \\
\text { Evaluation: not blinded. }\end{array}$} \\
\hline Participants & \multicolumn{2}{|c|}{$\begin{array}{l}\text { Diagnosis: prodromal at risk of psychosis. } \\
\text { N=124. } \\
\text { Age: mean age } 25 \text { years. } \\
\text { Sex: M 70, F } 54 \text {. } \\
\text { Inclusion criteria: adapted ERIraos criteria, age range restricted between 18-36 } \\
\text { years. } \\
\text { Exclusion criteria: any lifetime DSM-IV diagnosis of schizophrenia, bipolar } \\
\text { disorder, any DSM-IV diagnosis of brief psychotic episode with a duration of more } \\
\text { than } 1 \text { week; delirium, dementia, and other cognitive disorders, mental retardation, } \\
\text { mental disorders due to a general medical condition or mental disturbances due to } \\
\text { psychotropic substances, alcohol abuse or drugs within the past } 3 \text { months. } \\
\text { History: no details. }\end{array}$} \\
\hline Interventions & \multicolumn{2}{|c|}{$\begin{array}{l}\text { 1. Needs Focused Intervention* with amisulpride mean dose } 118 \mathrm{mg} / \mathrm{day} \text {. N=65. } \\
\text { 2. Needs Focused Intervention. N=59. } \\
\text { Use of chloral hydrate or short-acting benzodiazepines were allowed to treat } \\
\text { agitation or sleep disturbances, and biperiden permitted for EPS. Citalopram } \\
\text { permitted for depression }\end{array}$} \\
\hline Outcomes & \multicolumn{2}{|l|}{$\begin{array}{l}\text { Leaving the study early. } \\
\text { Mental state: PANSS. } \\
\text { Global state: GAF. } \\
\text { Adverse events. }\end{array}$} \\
\hline Notes & \multicolumn{2}{|c|}{$\begin{array}{l}\text { *Needs Focused Intervention included psychoeducation, crisis intervention, family } \\
\text { counselling and assistance with education or work-related difficulties according to } \\
\text { the patient's need }\end{array}$} \\
\hline \multicolumn{3}{|l|}{ Risk of bias } \\
\hline Bias & Authors' judgement & Support for judgement \\
\hline Adequate sequence generation? & Unclear risk & Randomised, no further details. \\
\hline Allocation concealment? & Unclear risk & No details. \\
\hline $\begin{array}{l}\text { Blinding? } \\
\text { All outcomes }\end{array}$ & High risk & Open label. \\
\hline $\begin{array}{l}\text { Incomplete outcome data } \\
\text { addressed? } \\
\text { All outcomes }\end{array}$ & Low risk & Study attrition reported. \\
\hline Free of selective reporting? & Unclear risk & No details. \\
\hline Free of other bias? & High risk & $\begin{array}{l}\text { Funded by German Federal Ministry for } \\
\text { Educaton and research BMBF grant and } \\
\text { Sanofi Synthelabo, Germany }\end{array}$ \\
\hline
\end{tabular}

\section{OPUS-Scandinavia}

Allocation: randomised (computer computer-generated ratio of 1:1 in blocks of 6,
and stratified for each of 5 centres. In Aarhus, the researchers contacted a secretary
by telephone when they had finished the entry assessment of each patient. The
secretary then drew 1 lot from among 5 red and 5 white lots out of a black box.
When the block of 10 was used, the lots were redrawn. Block sizes were unknown
to the investigators).
Blinding: raters not blind to treatment allocation, but independent of study group;
raters at the 5 -year follow-up were blinded to patients' previous treatment
allocation.
Setting: Copenhagen, Denmark, multicentre, 5 centres, participants visited in their
homes or other places in the community, or at their primary team members office.
Exclusion criteria: taking antipsychotics for more than 12 weeks.
Duration: 2 years with 5 year follow-up.

Cochrane Database Syst Rev. Author manuscript; available in PMC 2014 September 15. 
Evaluations: by independent investigators, not blinded to treatment allocation

\begin{tabular}{|c|c|c|}
\hline Participants & \multicolumn{2}{|c|}{$\begin{array}{l}\text { Diagnosis: first-episode schizophrenia spectrum disorder (ICD 10, codes in the F2 } \\
\text { category). } \\
\text { N=547. } \\
\text { Age: range } 18-45 \text { years. } \\
\text { Sex: M } 256, \mathrm{~F} 291 \text {. } \\
\text { History: participants included in and outpatients who had not received } \\
\text { antipsychotics for more than } 12 \text { weeks continuously }\end{array}$} \\
\hline Interventions & \multicolumn{2}{|c|}{$\begin{array}{l}\text { 1. Integrated treatment. } \mathrm{N}=275 \text {. } \\
2 \text {. Treatment as usual. } \mathrm{N}=272 \text {. } \\
\text { Integrated treatment is an assertive community treatment, enhanced by better } \\
\text { specific content via family involvement and social skill training. Treatment as usual } \\
\text { consisted of care at a community mental health centre. The treatment was carried } \\
\text { out for two years and patients follow up for a further } 3 \text { years } \\
\text { All participants were offered antipsychotic drugs according to guidelines from the } \\
\text { Danish Psychiatric Society, which recommends low dose, atypical antipsychotic } \\
\text { strategy for } 1 \text { st episodes of psychotic illness }\end{array}$} \\
\hline Outcomes & \multicolumn{2}{|c|}{$\begin{array}{l}\text { Leaving the study early. } \\
\text { Global state: GAF. } \\
\text { Client Satisfaction: CSQ-8. } \\
\text { Suicide attempts. } \\
\text { Social outcome: Social Network Schedule, not living independently; no working or } \\
\text { in education. } \\
\text { Service utilisation: average number of days in hospital. } \\
\text { Compliance with treatment. } \\
\text { Unable to use - } \\
\text { Mental state: SAPS, SANS: (no usable data). }\end{array}$} \\
\hline \multicolumn{3}{|l|}{ Notes } \\
\hline \multicolumn{3}{|l|}{ Risk of bias } \\
\hline Bias & Authors' judgement & Support for judgement \\
\hline Adequate sequence generation? & Low risk & Randomised, computer generated. \\
\hline Allocation concealment? & Low risk & $\begin{array}{l}\text { Secretary drew lots, which the investigators } \\
\text { had no knowledge }\end{array}$ \\
\hline $\begin{array}{l}\text { Blinding? } \\
\text { All outcomes }\end{array}$ & Low risk & $\begin{array}{l}\text { Independent assessors aware of treatment } \\
\text { allocation; 5-year follow-up assessors unaware } \\
\text { of treatment allocation }\end{array}$ \\
\hline $\begin{array}{l}\text { Incomplete outcome data } \\
\text { addressed? } \\
\text { All outcomes }\end{array}$ & Low risk & Study attrition reported. \\
\hline Free of selective reporting? & Unclear risk & No details. \\
\hline Free of other bias? & Low risk & $\begin{array}{l}\text { Grants from the Danish Ministry of Health, } \\
\text { Danish Ministry of Social Affairs, University } \\
\text { of Copenhagen, Copenhagen Hospital } \\
\text { Cooperation, Danish Medical Research } \\
\text { Council, Wørners Foundation, and the Stanley } \\
\text { Wada Research Foundation }\end{array}$ \\
\hline
\end{tabular}

\section{PACE-Australia}

\begin{tabular}{ll}
\hline Methods & Allocation: simple randomisation by study co-ordinator. \\
& Blinding: independent rater, not blind. \\
& Setting: PACE clinic (Personal Assessment and Crisis Evaluation), part of EPPIC \\
program, Melbourne, Australia. & Inclusion criteria: age 14-30, living in Melbourne, met one of 3 criteria for an Ultra \\
& High Risk mental state. \\
& Follow-up: 0, 6, 12 months. \\
\hline Participants & Diagnosis: 'ultra high risk' of developing psychosis.* \\
& N=59. \\
& Age: mean 20.
\end{tabular}

Cochrane Database Syst Rev. Author manuscript; available in PMC 2014 September 15. 
Sex: M 34, F 25.

History: not reported.

\begin{tabular}{|c|c|c|}
\hline Interventions & \multicolumn{2}{|c|}{$\begin{array}{l}\text { 1. Specific Preventive Intervention: dose risperidone } 1-2 \mathrm{mg} / \text { day }+ \text { cognitive } \\
\text { behavioural therapy + needs-based case management }+ \text { supportive psychotherapy. } \\
\mathrm{N}=31 \\
\text { 2. Needs based intervention alone. } \mathrm{N}=28 \text {. }\end{array}$} \\
\hline Outcomes & \multicolumn{2}{|c|}{$\begin{array}{l}\text { Progressing to psychosis. } \\
\text { Mental state: BPRS, HRSA, HRSD, SANS, YMS. } \\
\text { Quality of Life: QLS. } \\
\text { Overall functioning: GAF. }\end{array}$} \\
\hline Notes & \multicolumn{2}{|c|}{$\begin{array}{l}\text { Prodromal Trial - Care from a specialised team plus a phase specific intervention } \\
\text { versus care from a specialised team } \\
\text { * Defined as either: family history of psychotic disorder \& non specific symps \& } \\
\text { decrease in functioning on GAF of } 30 \text { points or more in last } 12 \mathrm{~ms} \text {, or attenuated } \\
\text { psychotic symptoms sustained for at least } 1 \text { week, or brief episodes of psychotic } \\
\text { symptoms not sustained beyond a week }\end{array}$} \\
\hline \multicolumn{3}{|l|}{ Risk of bias } \\
\hline Bias & Authors' judgement & Support for judgement \\
\hline Adequate sequence generation? & Unclear risk & Randomised, no further details. \\
\hline Allocation concealment? & Unclear risk & No details. \\
\hline $\begin{array}{l}\text { Blinding? } \\
\text { All outcomes }\end{array}$ & High risk & Not blinded. \\
\hline $\begin{array}{l}\text { Incomplete outcome data } \\
\text { addressed? } \\
\text { All outcomes }\end{array}$ & High risk & Study attrition not reported. \\
\hline Free of selective reporting? & Unclear risk & No details. \\
\hline Free of other bias? & Unclear risk & $\begin{array}{l}\text { Funding by the Commonwealth } \\
\text { Government of Australia Research and } \\
\text { Development Grants Advisory } \\
\text { Committee, and Janssen-Cilag } \\
\text { Pharmaceuticals; Australian Rotary } \\
\text { Health Research Fund grant }\end{array}$ \\
\hline
\end{tabular}

\section{PRIME-USA}

\begin{tabular}{ll}
\hline Methods & Allocation: randomised. \\
Blinding: double, pills dispensed in prepackaged packs, prelabelled by site number \\
and sequential subject number within site. \\
Setting: North America, 4 sites*, outpatient clinic. \\
Inclusion criteria: age range 12-45 years. \\
Exclusion criteria: past or current DSM-IV psychotic disorder; suffering from a \\
psychiatric disorder that could account for the prodromal symptoms; judged to be \\
suicidal or homicidal; prodromal symptoms due to drug or alcohol use. IQ less than \\
80; seizure disorders. \\
Follow-up: one-year medication with one-year follow-up without medication. \\
Evaluation: 'patient, investigator, prescriber and rater were maintained blind to \\
group assignment throughout the study' \\
Diagnosis: prodromal at risk of psychosis (SIPS, SOPS). \\
N=60. \\
Age: range 12-36 years, mean 18 years. \\
Sex: M $39, \mathrm{~F} 21$. \\
History: participants included those who had responded to advertisements, or were \\
referred by clinicians. \\
Exclusion criteria: past or current psychotic disorder, a treatable psychiatric \\
disorder that could account for the prodromal symptoms, suicidal or homicidal \\
ideation, or drug or alcohol use that could be responsible for their symptoms. \\
Duration: 12 months. \\
1. Olanzapine: dose 5-15 mg/day, mean 8 mg/day. N=31. \\
2. Placebo. N=29.
\end{tabular}

Cochrane Database Syst Rev. Author manuscript; available in PMC 2014 September 15. 
Olanzapine was adjusted within a range of $5-15 \mathrm{mg} / \mathrm{day}$ based on the clinician's judgement. Individual and family psychosocial interventions were available. Lorazepam ( $\max 8 \mathrm{mg} /$ day) diazepam ( $\max 40 \mathrm{mg} /$ day) and chloral hydrate ( $\max$ $100 \mathrm{mg} /$ day) were used for agitation and/or insomnia. Benztropine mesylate or biperiden up to $6 \mathrm{mg} /$ day allowed to treat EPS. Nizatidine 300-600 mg/day for weight gain, beginning towards the end of the study

\begin{tabular}{|c|c|c|}
\hline Outcomes & \multicolumn{2}{|c|}{$\begin{array}{l}\text { Leaving the study early. } \\
\text { Progressing to psychosis: POPS scale. } \\
\text { Mental state: PANSS, MADRS, YMRS, SOPS. } \\
\text { Global state: CGI-S, GAF. } \\
\text { Adverse effects: SAS, AIMS, BAS, weight gain, vital signs, CoStart terms } \\
\text { Unable to use - } \\
\text { Quality of life: no data. } \\
\text { Resource utilisation: no usable data. } \\
\text { Adverse effects: EPS (no usable data). } \\
\text { Neurocognitive function: no data. } \\
\text { Premorbid functioning: Cannon-Spoor Premorbid Adjustment Scale }\end{array}$} \\
\hline Notes & \multicolumn{2}{|c|}{$\begin{array}{l}\text { *Yale University, New Haven, Connecticut; University of Toronto, Canada; } \\
\text { University of North Carolina, USA; University of Carolina, Canada }\end{array}$} \\
\hline \multicolumn{3}{|l|}{ Risk of bias } \\
\hline Bias & Authors' judgement & Support for judgement \\
\hline Adequate sequence generation? & Unclear risk & Randomised, no further details. \\
\hline Allocation concealment? & Low risk & $\begin{array}{l}\text { Pills dispensed in prepackaged packs, } \\
\text { prelabelled by site number and sequential } \\
\text { subject number within site }\end{array}$ \\
\hline $\begin{array}{l}\text { Blinding? } \\
\text { All outcomes }\end{array}$ & Unclear risk & Double blind, untested. \\
\hline $\begin{array}{l}\text { Incomplete outcome data } \\
\text { addressed? } \\
\text { All outcomes }\end{array}$ & Low risk & Study attrition reported. \\
\hline Free of selective reporting? & Unclear risk & No details. \\
\hline Free of other bias? & High risk & Funding Eli Lilly and Company. \\
\hline
\end{tabular}

\section{Uzenoff-USA}

\begin{tabular}{ll}
\hline Methods & Allocation: randomised. \\
& Blinding: assessors blind to treatment group. \\
Setting: no details. & Inclusion criteria: 16 years or older, DSM -IV schizophrenia, schizoaffective \\
disorder or schizophreniform disorder and in treatment of a first episode of less \\
than 12 months. \\
Follow-up: 6 months. \\
Evaluation: 3 and 6 months. \\
\hline Participants & Diagnosis: schizophrenia first episode (DSM IV). \\
& N=24. \\
& Age: no details. \\
& Sex: men and women. \\
& History: no details. \\
\hline Interventions & 1. Adherance Coping Education* (ACE) with usual care. N=13. \\
& 2. Supportive therapy* with usual care. N=11. \\
\hline Outcomes & Leaving the study early. \\
& Mental state: PANSS, CDPS, CDRS. \\
Quality of life: Heinrichs-Carpenter. \\
\hline Notes & *ACE 14 sessions lasting between 30-45 minutes over six months. It is a manual- \\
& based psychotherapy consisting of 4 phases: (1) establishing therapeutic alliance; \\
& (2) promoting treatment adherence; (3) developing a plan for maintenance \\
treatment and (4) rehabilitation.
\end{tabular}

Cochrane Database Syst Rev. Author manuscript; available in PMC 2014 September 15. 
*Supportive therapy had two phases (1) establishment of the therapeutic relationship and (2) provide emotional support and discussion of non-illness issues or topics.

A modified ITT analysis was used based on 19 participants.

Risk of bias

\begin{tabular}{lll}
\hline Bias & Authors' judgement & Support for judgement \\
\hline Adequate sequence generation? & Unclear risk & Randomised, no further details. \\
\hline Allocation concealment? & Unclear risk & No details. \\
\hline $\begin{array}{l}\text { Blinding? } \\
\text { All outcomes }\end{array}$ & High risk & Not blinded. \\
\hline $\begin{array}{l}\text { Incomplete outcome data } \\
\text { addressed? }\end{array}$ & Low risk & Study attrition reported. \\
\hline Free of selective reporting? & Unclear risk & \\
\hline Free of other bias? & Unclear risk & No details. \\
\hline
\end{tabular}

\section{Zhang-China}

\begin{tabular}{|c|c|}
\hline Methods & $\begin{array}{l}\text { Allocation: 'randomly assigned'. } \\
\text { Blinding: not reported. } \\
\text { Setting: psychiatric hospital, Suzhou, China. } \\
\text { Inclusion criteria: male, just discharged after first episode for schizophrenia, no } \\
\text { other medical conditions. } \\
\text { Follow-up: } 18 \text { months. } \\
\text { Evaluation: by 'attending physicians' blind to allocation. }\end{array}$ \\
\hline Participants & $\begin{array}{l}\text { Diagnosis: schizophrenia (Chinese Medical Association Criteria). } \\
\text { N=83. } \\
\text { Age: mean } 23.8 . \\
\text { Sex: all male. } \\
\text { History: mean DUP } 34.6 \text { months. }\end{array}$ \\
\hline Interventions & $\begin{array}{l}\text { 1. Family psychoeducation in individual and group sessions plus standard out- } \\
\text { patient care. } N=42 \\
\text { 2. Out-patient care. } N=41 \text {. }\end{array}$ \\
\hline Outcomes & $\begin{array}{l}\text { Readmitted. } \\
\text { Lost to follow-up. } \\
\text { Compliant with medication. } \\
\text { Unable to use - } \\
\text { Chlorpromazine equivalent dosage of medication: (not a clinical or social } \\
\text { outcome). } \\
\text { Mental state: Chinese BPRS (excluded readmitted patients). } \\
\text { Overall functioning: Chinese GAS (excluded readmitted patients) }\end{array}$ \\
\hline Notes & $\begin{array}{l}\text { First Episode Trial - phase-specific treatment plus standard care versus standard } \\
\text { care }\end{array}$ \\
\hline \multicolumn{2}{|l|}{ Risk of bias } \\
\hline Bias & Support for judgement \\
\hline Adequate sequence generation? & Randomised, no further details. \\
\hline Allocation concealment? & Unclear risk \\
\hline $\begin{array}{l}\text { Blinding? } \\
\text { All outcomes }\end{array}$ & Not reported. \\
\hline $\begin{array}{l}\text { Incomplete outcome data } \\
\text { addressed? } \\
\text { All outcomes }\end{array}$ & Study attrition reported. \\
\hline Free of selective reporting? & Unclear risk \\
\hline
\end{tabular}

Cochrane Database Syst Rev. Author manuscript; available in PMC 2014 September 15. 
CAARMS - Comprehensive Assessment of At-Risk Mental States

COPS - Criteria of Prodromal Syndromes

DSM - Diagnostic and Statistical Manual

ICD-10 - International Classification of Diseases

SIPS - Structured Interview for Prodromal Syndromes

Rating Scales:

Mental state

BDI - Beck Depression Inventory

BPRS - Brief Psychiatric Rating Scale

CDRS - Calgary Depression Rating Scale

HRSA - Hamilton Rating Scale for Anxiety

HRSD - Hamilton Rating Scale for Depression

MADRS - Mongomery and Asberg Depression Rating Scale

PANSS - Positive and Negative Symptom Scale

POPS - Presence of Psychosis Scale

SANS - Schedule for the Assessment of Negative Symptoms

SOPS - Scale of Prodromal Symptoms

YMRS - Young Mania Rating Scale

YMS - Young Mania Scale

Global state

CGI - Clinical Global Impression

GAF - Global Assessment of Functioning

GAS - Global Adjustment Scale

Adverse effects

AIMS - Abnormal and Involuntary Movement Scales

BAS - Barnes Akathisia Scale

SAS - Simpson \& Angus

User satisfaction

CSQ-8 - Client Satisfaction Questionnaire-8

Others

APQ - Alcohol Problems Questionnaire

DUP - Duration of untreated psychosis

EM - Explanatory Model scale

EIPS - early initial prodromal state

GSI - General Symptom Index of the SCL-90-R

IS/O - Integration/Sealing Over

IPS - Individual Placement and Support

ITT - Intention to Treat

LOCF - Last Observation Carried Forward

MCQ - Meta-Cognitions Questionnaire

OLIFE - Oxford-Liverpool Inventory of Feelings and Experiences

PACE - Personal Assessment and Crisis Evaluation 
QLS - Quality of Life Scale

RCI - Reliable Change Index

SAC - Sociotropy - Autonomy Scale

TAU - Treatment as Usual

UHR - Ultra high risk (of developing psychosis)

\section{Characteristics of excluded studies [ordered by study ID]}

\begin{tabular}{|c|c|}
\hline Study & Reason for exclusion \\
\hline Addington 1999 & Allocation: not randomised, before and after design. \\
\hline Agius 2007 & Allocation: not randomised, no control group. \\
\hline Alanen 1994 & Allocation: not randomised, before and after design. \\
\hline Albiston 1998 & Allocation: not randomised, before and after design with historical control \\
\hline Anonymous 1987 & $\begin{array}{l}\text { Allocation: randomised. } \\
\text { Participants: people with first-episode psychosis. } \\
\text { Intervention: medication only (pimozide versus flupenthixol) at standard doses without specific } \\
\text { early intervention protocol }\end{array}$ \\
\hline Bao 2005 & $\begin{array}{l}\text { Allocation: randomised. } \\
\text { Participants: people with psychosis. } \\
\text { Interventions: no early intervention programme. }\end{array}$ \\
\hline Birchwood 1989 & $\begin{array}{l}\text { Allocation: not randomised, service description. } \\
\text { Participants: not first-episode patients (study of early detection of signs of relapse) }\end{array}$ \\
\hline Clare 1994 & $\begin{array}{l}\text { Allocation: not randomised, service description. } \\
\text { Participants: not first-episode patients (study of early signs of depression in long term patients) }\end{array}$ \\
\hline COPE-Melbourne & $\begin{array}{l}\text { Allocation: non-randomised quasi-experimental design, controls selected from a similar location } \\
\text { to the experimental site }\end{array}$ \\
\hline Craig 2004b & $\begin{array}{l}\text { Allocation: randomised. } \\
\text { Participants: people with 1st \& 2nd episode psychosis. }\end{array}$ \\
\hline Crow 1986 & $\begin{array}{l}\text { Allocation: randomised. } \\
\text { Participants: people with first-episode psychosis. } \\
\text { Intervention: neuroleptic medication at standard doses versus no medication, no specific early } \\
\text { intervention protocol }\end{array}$ \\
\hline Culberg 1998 & Allocation: not randomised - before and after design with historical controls \\
\hline Davidson 2004 & $\begin{array}{l}\text { Allocation: randomised. } \\
\text { Participants: people with early psychosis. } \\
\text { Interventions: atypical versus conventional antipsychotic. }\end{array}$ \\
\hline DeHaan 1997 & Allocation: not randomised - before and after design. \\
\hline Drury 2000 & $\begin{array}{l}\text { Allocation: randomised. } \\
\text { Participants: not people with first-episode psychosis. }\end{array}$ \\
\hline Emsley 1999 & $\begin{array}{l}\text { Allocation: randomised. } \\
\text { Participants: people with first-episode psychosis. } \\
\text { Intervention: medication only (risperidone versus haloperidol), no specific early intervention } \\
\text { protocol }\end{array}$ \\
\hline Emsley 2004 & $\begin{array}{l}\text { Allocation: randomised. } \\
\text { Participants: people with recent onset schizophrenia. } \\
\text { Interventions: medication only (risperidone versus haloperidol) }\end{array}$ \\
\hline Falloon 1992 & Allocation: not randomised, no controls. \\
\hline Fisher 2001 & Allocation: not randomised - service description, outcome assessed by qualitative survey \\
\hline Fitzgerald 1998 & Allocation: not randomised - before and after design. \\
\hline Fresan 2001 & Allocation: not randomised - before and after study. \\
\hline Gaebel 2004 & $\begin{array}{l}\text { Allocation: randomised. } \\
\text { Participants: people with first-episode schizophrenia. }\end{array}$ \\
\hline
\end{tabular}

Cochrane Database Syst Rev. Author manuscript; available in PMC 2014 September 15. 


\begin{tabular}{|c|c|}
\hline Study & Reason for exclusion \\
\hline & Interventions: medication only (risperidone versus low-dose haloperidol) \\
\hline Grawe 1998 & $\begin{array}{l}\text { Allocation: randomised. } \\
\text { Participants: people with first-episode psychosis. } \\
\text { Interventions: no early intervention programme. }\end{array}$ \\
\hline Hartmann 1974 & Allocation: not randomised - retrospective study. \\
\hline Heydebrand 2004 & $\begin{array}{l}\text { Allocation: randomised. } \\
\text { Participants: people with first-episode schizophrenia. } \\
\text { Interventions: haloperidol versus risperidone. }\end{array}$ \\
\hline Jenner 2001 & $\begin{array}{l}\text { Allocation: not randomised - no control group. } \\
\text { Participants: not people with first-episode psychosis (adolescents, but on average in treatment for } \\
\text { about } 3 \text { years) }\end{array}$ \\
\hline Jenner 2004 & $\begin{array}{l}\text { Allocation: randomised. } \\
\text { Participants: people with chronic psychosis. }\end{array}$ \\
\hline Jolley 2003 & $\begin{array}{l}\text { Allocation: randomised. } \\
\text { Participants: people with 1st \& 2nd episode psychosis. }\end{array}$ \\
\hline Jones 2005 & $\begin{array}{l}\text { Allocation: randomised. } \\
\text { Participants: people with psychosis - not first episode. }\end{array}$ \\
\hline Kadota 1992 & Allocation: not randomised - uncontrolled follow-up study of response to neuroleptic treatment \\
\hline Kauranen 2000 & Allocation: not randomised - uncontrolled follow-up study. \\
\hline Kavanagh 2004 & $\begin{array}{l}\text { Allocation: randomised. } \\
\text { Participants: people with 1st and 2nd episode psychosis. }\end{array}$ \\
\hline Keefe 2000 & $\begin{array}{l}\text { Allocation: randomised. } \\
\text { Participants: people with first-episode psychosis. } \\
\text { Intervention: medication only (olanzapine versus haloperidol) at standard doses without specific } \\
\text { early intervention protocol }\end{array}$ \\
\hline Keshavan 1998 & Allocation: not randomised - before and after study with historical control group \\
\hline Kopala 2003 & $\begin{array}{l}\text { Allocation: randomised. } \\
\text { Participants: people with recent onset schizophrenia. } \\
\text { Interventions: risperidone versus haloperidol. }\end{array}$ \\
\hline Kuipers 2004 & $\begin{array}{l}\text { Allocation: randomised. } \\
\text { Participants: people with schizophrenia, 1st and 2nd or more episodes }\end{array}$ \\
\hline Li 2004 & $\begin{array}{l}\text { Allocation: randomised. } \\
\text { Participants: early schizophrenia, probably not } 1 \text { st episode. } \\
\text { Inteventions: no early intervention program. }\end{array}$ \\
\hline Lieberman $2005 b$ & $\begin{array}{l}\text { Allocation: randomised. } \\
\text { Participants: people with first-episode psychosis and healthy volunteers. } \\
\text { Interventions: medication only (haloperidol versus olanzapine) }\end{array}$ \\
\hline Malla 2001 & Allocation: not randomised - before and after study, no control group \\
\hline McCay 2007 & Allocation: quasi-randomised. \\
\hline McGorry 1996 & Allocation: not randomised - before and after study with historical controls \\
\hline Mosher 1975 & $\begin{array}{l}\text { Allocation: not randomised - allocation on 'a consecutively admitted, space available basis' to } \\
\text { 'Soteria' - a small home like facility in the community which acted as an alternative to admission } \\
\text { for patients in their first-episode of schizophrenia }\end{array}$ \\
\hline Mottaghipour 2000 & $\begin{array}{l}\text { Allocation: not randomised, no control group (participants compared with a group of families of } \\
\text { long term patients) }\end{array}$ \\
\hline Newton 2005 & Allocation: none randomised study (before and after design). \\
\hline Nuechterlein 2005 & $\begin{array}{l}\text { Allocation: randomised. } \\
\text { Participants: people with first-episode psychosis. } \\
\text { Interventions: no early intervention programme. }\end{array}$ \\
\hline Parlato 1999 & Allocation: non-randomised - a description of a service. \\
\hline Perez 2003 & $\begin{array}{l}\text { Allocation: randomised. } \\
\text { Participants: people with first-episode psychosis. }\end{array}$ \\
\hline
\end{tabular}

Cochrane Database Syst Rev. Author manuscript; available in PMC 2014 September 15. 


\begin{tabular}{|c|c|}
\hline Study & Reason for exclusion \\
\hline & Interventions: medication only (olanzapine versus risperidone versus haloperidol) \\
\hline Power 2004 & $\begin{array}{l}\text { Allocation: randomised. } \\
\text { Participants: people with } 1 \text { st and } 2 \text { nd episode psychosis. }\end{array}$ \\
\hline Purdon 2000 & $\begin{array}{l}\text { Allocation: randomised. } \\
\text { Participants: people with first-episode psychosis. } \\
\text { Intervention: medication only (olanzapine versus risperidone versus haloperidol) without specific } \\
\text { early intervention protocol }\end{array}$ \\
\hline Rund 1994 & Allocation: not randomised, before and after study with historical control \\
\hline Sanger 1999 & $\begin{array}{l}\text { Allocation: randomised. } \\
\text { Participants: people with first-episode psychosis. } \\
\text { Intervention: medication only (olanzapine versus haloperidol) without specific early intervention } \\
\text { protocol }\end{array}$ \\
\hline Schooler 2003 & $\begin{array}{l}\text { Allocation: randomised. } \\
\text { Participants: people with recent onset schizophrenia. } \\
\text { Interventions: medication only (risperidone versus haloperidol) }\end{array}$ \\
\hline SOCRATES-UK & $\begin{array}{l}\text { Allocation: randomised. } \\
\text { Participants: not first-episode patients, participants could be in either first or second admission, as } \\
\text { long as second admission within } 2 \text { years of first admission (estimated that } 61 / 309 \text { participants } \\
\text { were not first episode) }\end{array}$ \\
\hline Szymanski 1994 & Allocation: not randomised - before and after study without control group \\
\hline Thomas 1979 & $\begin{array}{l}\text { Allocation: not randomised - no control group. } \\
\text { Participants: not first-episode patients, although all were adolescents, some were experiencing an } \\
\text { exacerbation of chronic schizophrenia }\end{array}$ \\
\hline TIPS 2006 & Allocation: not randomised. \\
\hline Turetz 1997 & $\begin{array}{l}\text { Allocation: not randomised - no control group. } \\
\text { Participants: probably not first-episode patients, although all participants were children, they } \\
\text { were selected on the basis of treatment resistance and so probably not in the first episode }\end{array}$ \\
\hline Ueland 2004 & $\begin{array}{l}\text { Allocation: randomised. } \\
\text { Participants: people with psychosis, not first episode. }\end{array}$ \\
\hline Walczewski 1998 & $\begin{array}{l}\text { Allocation: not randomised - a quasi-experimental design, patients receiving a psychosocial } \\
\text { treatment program were compared with a group receiving an individual treatment programme }\end{array}$ \\
\hline Wang 2000 & $\begin{array}{l}\text { Allocation: randomised. } \\
\text { Participants: people with first-episode psychosis. } \\
\text { Intervention: medication only (risperidone versus clozapine) without specific early intervention } \\
\text { protocol }\end{array}$ \\
\hline Welch 2000 & Allocation: not randomised - service description. \\
\hline Whitehorn 1998 & Allocation: not randomised - before and after study without control \\
\hline Whitwell 2000 & Allocation: not randomised - service description. \\
\hline Wieneke 2000 & Allocation: not randomised - service description. \\
\hline Wunderink 2003 & $\begin{array}{l}\text { Allocation: randomised. } \\
\text { Participants: people with early onset psychosis. } \\
\text { Intervention: drug trial - not early intervention. }\end{array}$ \\
\hline Wykes 2007 & $\begin{array}{l}\text { Allocation: randomised. } \\
\text { Participants: people with psychosis, but not first episode, (only early onset) }\end{array}$ \\
\hline Yap 2001 & Allocation: not randomised - before and after study without control group \\
\hline Zhang-Wong 1999 & $\begin{array}{l}\text { Allocation: not randomised - prospective uncontrolled study to determine optimal dose of } \\
\text { haloperidol }\end{array}$ \\
\hline
\end{tabular}

\section{Characteristics of studies awaiting assessment [ordered by study ID]}

\section{Addington-2001}

Cochrane Database Syst Rev. Author manuscript; available in PMC 2014 September 15. 


\begin{tabular}{ll}
\hline Methods & No details. \\
\hline Participants & People with psychosis. \\
\hline Interventions & Early psychosis programme. \\
\hline Outcomes & No details. \\
\hline Notes & \\
\hline
\end{tabular}

\section{Alaghband-rad 2006a}

\begin{tabular}{ll}
\hline Methods & Randomised. \\
\hline Participants & People with psychosis. \\
\hline Interventions & Early intervention. \\
\hline Outcomes & No data. \\
\hline Notes & \\
\hline
\end{tabular}

Berger 2006

\begin{tabular}{ll}
\hline Methods & No details. \\
\hline Participants & People at risk of developing psychosis. \\
\hline Interventions & Lithium. \\
\hline Outcomes & No details. \\
\hline Notes & \\
\hline
\end{tabular}

\section{Cornblatt 2009}

\begin{tabular}{ll}
\hline Methods & No details. \\
\hline Participants & People at risk of developing psychosis. \\
\hline Interventions & Risperidone versus sertraline. \\
\hline Outcomes & No details. \\
\hline Notes & \\
\hline
\end{tabular}

Dai

\begin{tabular}{ll}
\hline Methods & Randomised. \\
\hline Participants & People with psychosis. \\
\hline Interventions & Group or individual psychoeducation versus antipsychotic maintenance \\
\hline
\end{tabular}




\begin{tabular}{ll} 
Outcomes $\quad$ No details. \\
\hline Notes
\end{tabular}

Deng 2006

\begin{tabular}{ll}
\hline Methods & Randomised. \\
\hline Participants & People with schizophrenia. \\
\hline Interventions & Early intervention and routine care versus routine care alone \\
\hline Outcomes & No details. \\
\hline Notes & \\
\hline
\end{tabular}

Doering 1998

\begin{tabular}{ll}
\hline Methods & No details. \\
\hline Participants & People with psychosis. \\
\hline Interventions & No details. \\
\hline Outcomes & No details. \\
\hline Notes & \\
\hline
\end{tabular}

Edwards 2003 EPPIC

\begin{tabular}{ll}
\hline Methods & Randomised. \\
\hline Participants & People with first-episode psychosis. \\
\hline Interventions & Clozapine versus CBT. \\
\hline Outcomes & No details. \\
\hline Notes & \\
\hline
\end{tabular}

Fillatre-1998

\begin{tabular}{ll}
\hline Methods & Unclear. \\
\hline Participants & People with psychosis. \\
\hline Interventions & Unclear. \\
\hline Outcomes & Unclear. \\
\hline Notes & \\
\hline
\end{tabular}

Furimsky 2005 


\begin{tabular}{ll}
\hline Methods & No details. \\
\hline Participants & No details. \\
\hline Interventions & No details. \\
\hline Outcomes & No details. \\
\hline Notes & \\
\hline
\end{tabular}

Gleeson 2008

\begin{tabular}{ll}
\hline Methods & Controlled trial. \\
\hline Participants & People with early psychosis. \\
\hline Interventions & Cognitive and family therapy relapse prevention. \\
\hline Outcomes & No details. \\
\hline Notes & \\
\hline
\end{tabular}

Humphries 2005

\begin{tabular}{ll}
\hline Methods & No details. \\
\hline Participants & People with early psychosis. \\
\hline Interventions & No details. \\
\hline Outcomes & No details. \\
\hline Notes & \\
\hline
\end{tabular}

Johnson 2004

\begin{tabular}{ll}
\hline Methods & Cluster randomised trial. \\
\hline Participants & People with early psychosis. \\
\hline Interventions & Specialist team versus augmented community mental health teams \\
\hline Outcomes & No details. \\
\hline Notes & \\
\hline
\end{tabular}

Keshavan 2003

\begin{tabular}{ll}
\hline Methods & Controlled trial. \\
\hline Participants & People with early psychosis. \\
\hline Interventions & Psychoeducation and collaboration enhancement. \\
\hline
\end{tabular}




\begin{tabular}{ll} 
Outcomes $\quad$ No details. \\
\hline Notes & \\
\hline
\end{tabular}

\section{Keshavan 2005}

\begin{tabular}{ll}
\hline Methods & No details. \\
\hline Participants & People with early psychosis. \\
\hline Interventions & No details. \\
\hline Outcomes & No details. \\
\hline Notes & \\
\hline
\end{tabular}

\section{Lecomte 2006}

\begin{tabular}{ll}
\hline Methods & Randomised. \\
\hline Participants & People with early episodes of psychosis. \\
\hline Interventions & Group CBT versus skills training. \\
\hline Outcomes & No details. \\
\hline Notes & $\begin{array}{l}\text { Recent onset psychosis i.e. early episode psychosis. Text is confusing as mentions first episode but is } \\
\text { including people with 2 years established psychosis for example, having consulted for the first time a } \\
\text { professional for psychotic symptoms in the past two years }\end{array}$ \\
\hline
\end{tabular}

Lee 2007

\begin{tabular}{ll}
\hline Methods & No details. \\
\hline Participants & Adolescents with schizophrenia. \\
\hline Interventions & No details. \\
\hline Outcomes & No details. \\
\hline Notes & \\
\hline
\end{tabular}

Li 2004b

\begin{tabular}{ll}
\hline Methods & Randomised. \\
\hline Participants & People with first-episode schizophrenia. \\
\hline Interventions & Early intervention programme. \\
\hline Outcomes & Quality of life. \\
\hline Notes & \\
\hline
\end{tabular}

Li 2007

Cochrane Database Syst Rev. Author manuscript; available in PMC 2014 September 15. 


\begin{tabular}{ll}
\hline Methods & No details. \\
\hline Participants & People with schizophrenia. \\
\hline Interventions & Psychotherapy. \\
\hline Outcomes & No details. \\
\hline Notes & \\
\hline
\end{tabular}

Richtand 2007

\begin{tabular}{ll}
\hline Methods & No details. \\
\hline Participants & People with early schizophrenia. \\
\hline Interventions & Omega-3 fatty acid. \\
\hline Outcomes & No details. \\
\hline Notes & \\
\hline
\end{tabular}

Schepp 1999

\begin{tabular}{ll}
\hline Methods & No details. \\
\hline Participants & People with schizophrenia. \\
\hline Interventions & Self-management therapy. \\
\hline Outcomes & No details. \\
\hline Notes & \\
\hline
\end{tabular}

Tao 2004

\begin{tabular}{ll}
\hline Methods & Randomised. \\
\hline Participants & People with first-episode psychosis. \\
\hline Interventions & Early intervention programme. \\
\hline Outcomes & No details. \\
\hline Notes & \\
\hline
\end{tabular}

\section{Vinogradov 2008}

\begin{tabular}{ll}
\hline Methods & No details. \\
\hline Participants & People at risk of psychosis. \\
\hline Interventions & Neuroadaptive cognitive training. \\
\hline
\end{tabular}




\begin{tabular}{ll} 
Outcomes $\quad$ No details. \\
\hline Notes & \\
\hline
\end{tabular}

\section{Williams 2005}

\begin{tabular}{ll}
\hline Methods & No details. \\
\hline Participants & People with early psychosis. \\
\hline Interventions & Psychosocial interventions. \\
\hline Outcomes & No details. \\
\hline Notes & \\
\hline
\end{tabular}

\section{Woo 2009}

\begin{tabular}{ll}
\hline Methods & No details. \\
\hline Participants & People with schizophrenia. \\
\hline Interventions & Tiagabine. \\
\hline Outcomes & No details. \\
\hline Notes & \\
\hline
\end{tabular}

\section{Woods 2005}

\begin{tabular}{ll}
\hline Methods & No details. \\
\hline Participants & People with prodromal psychosis. \\
\hline Interventions & Glycine. \\
\hline Outcomes & No details. \\
\hline Notes & \\
\hline
\end{tabular}

Woods 2008

\begin{tabular}{ll}
\hline Methods & No details. \\
\hline Participants & People with prodromal psychosis. \\
\hline Interventions & Ziprasidone. \\
\hline Outcomes & No details. \\
\hline Notes & \\
\hline
\end{tabular}

Xu 2003 


\begin{tabular}{ll}
\hline Methods & No details. \\
\hline Participants & People with first-episode schizophrenia. \\
\hline Interventions & Psychotherapy. \\
\hline Outcomes & No details. \\
\hline Notes & \\
\hline
\end{tabular}

Yu 2005

\begin{tabular}{ll}
\hline Methods & Randomised. \\
\hline Participants & People with first-episode schizophrenia. \\
\hline Interventions & No details. \\
\hline Outcomes & No details. \\
\hline Notes & \\
\hline
\end{tabular}

\section{Characteristics of ongoing studies [ordered by study ID]}

Addington 2007

\begin{tabular}{ll}
\hline Trial name or title & A randomised controlled trial of individual therapy for first-episode psychosis \\
\hline Methods & Randomised. \\
\hline Participants & People with schizophrenia. \\
\hline Interventions & CBT versus usual care. \\
\hline Outcomes & Social Functioning Scale (SFS) \\
& Positive and Negative Syndrome Scale (PANSS) \\
& Psychotic Symptom Rating Scales (PSYRATS) \\
& Calgary Depression Scale for Schizophrenia (CDSS) \\
& The Time-Line Follow Back (TLFB) \\
& Alcohol and Drug Use Scale (AUS; DUS) \\
& Medication Event Monitoring System (MEMS) \\
& Rosenberg Self-Esteem Scale \\
& Maastricht Assessment of Coping Skills (MACS) \\
\hline Starting date & June 2007. \\
\hline Contact information & Jean_Addington@ camh.net \\
\hline Notes & \\
\hline
\end{tabular}

\section{Arends 2006}

\begin{tabular}{ll}
\hline Trial name or title & Prodromal symptoms and early intervention to prevent a relapse \\
\hline Methods & No details. \\
\hline Participants & People with schizophrenia. \\
\hline
\end{tabular}


Interventions The Symptom Management Module (SMM) versus treatment as usual

Outcomes $\quad$ Occurrence of a psychotic relapse: a worsening of at least two points on the CGI as assessed by psychiatrist and verified by researcher by a PANSS-interview within a week.

\begin{tabular}{ll}
\hline Starting date & No details. \\
\hline Contact information & Johan.Arends@GGZDrenthe.nl \\
\hline Notes & \\
\hline
\end{tabular}

EDIE-2 Morrison 2007

\begin{tabular}{ll}
\hline Trial name or title & Early detection and psychological intervention for individuals at high risk of psychosis (EDIE 2) \\
\hline Methods & Randomised. \\
\hline Participants & People with high risk of psychosis. \\
\hline Interventions & CBT plus regular monitoring versus monitoring alone. \\
\hline Outcomes & Transition to psychosis. \\
\hline Starting date & No details. \\
\hline Contact information & No details. \\
\hline Notes & \\
\hline
\end{tabular}

\section{Furimski 2005}

\begin{tabular}{ll}
\hline Trial name or title & Access, detection and psychological treatments. \\
\hline Methods & No details. \\
\hline Participants & People at risk of developing psychosis. \\
\hline Interventions & Psychological intervention in preventing or delaying the onset of a psychotic illness. \\
\hline Outcomes & Psychosis. \\
\hline Starting date & August 2004. \\
\hline Contact information & No details. \\
\hline Notes & \\
\hline
\end{tabular}

\section{Gaebel 2005}

\begin{tabular}{ll}
\hline Trial name or title & Maintenance treatment versus stepwise drug discontinuation in first-episode schizophrenia \\
\hline Methods & Randomised. \\
\hline Participants & People with schizophrenia. \\
\hline Interventions & Maintenance treatment. \\
\hline Outcomes & Relapse. \\
\hline Starting date & November 2001. \\
\hline Contact information & No details. \\
\hline
\end{tabular}

Cochrane Database Syst Rev. Author manuscript; available in PMC 2014 September 15. 
Notes

\section{Heresco-Levy 2006}

\begin{tabular}{ll}
\hline Trial name or title & Sarcosine preventive therapy for individuals at high risk for schizophrenia \\
\hline Methods & Randomised. \\
\hline Participants & People with the prodromal stage of schizophrenia. \\
\hline Interventions & Sarcosine versus placebo. \\
\hline Outcomes & Delay or prevention of illness. \\
\hline Starting date & June 2006. \\
\hline Contact information & No details. \\
\hline Notes & \\
\hline
\end{tabular}

Lester 2006

\begin{tabular}{ll}
\hline Trial name or title & Birmingham early detection in untreated psychosis trial (REDIRECT) \\
\hline Methods & Cluster randomised. \\
\hline Participants & People with first-episode psychosis, aged 14-30 years. \\
\hline Interventions & Early detection training versus detection as usual. \\
\hline Outcomes & $\begin{array}{l}\text { The primary outcome is the number of general practitioner referrals of young people with first- } \\
\text { episode psychosis to early intervention services. Secondary outcomes are duration of untreated } \\
\text { psychosis, time to recovery, use of the Mental Health Act, and general practitioner consultation } \\
\text { rate }\end{array}$ \\
\hline Starting date & 2004. \\
\hline Contact information & No details. \\
\hline Notes & \\
\hline
\end{tabular}

\section{McFarlane 2007}

\begin{tabular}{ll}
\hline Trial name or title & Early detection and intervention prevention of psychosis. \\
\hline Methods & Randomised, single blind (outcomes assessor). \\
\hline Participants & People with a high risk of psychosis. \\
\hline Interventions & Psychoeducational multifamily group treatment plus antipsychotics versus case management \\
\hline Outcomes & Conversion to psychosis. \\
\hline Starting date & No details. \\
\hline Contact information & mcfarw@mmc.org \\
\hline Notes & \\
\hline
\end{tabular}

Srihari 2006

Cochrane Database Syst Rev. Author manuscript; available in PMC 2014 September 15. 


\begin{tabular}{ll}
\hline Trial name or title & $\begin{array}{l}\text { Specialized treatment early in psychosis (STEP): a pragmatic randomized controlled trial in the } \\
\text { US public sector }\end{array}$ \\
\hline Methods & Randomised. \\
\hline Participants & People with early psychosis. \\
\hline Interventions & Specialized treatment for early psychosis. \\
\hline Outcomes & No details. \\
\hline Starting date & No details. \\
\hline Contact information & No details. \\
\hline Notes & \\
\hline
\end{tabular}

\section{Stain 2006}

\begin{tabular}{ll}
\hline Trial name or title & The depth project: a multi site RCT for youths at risk for psychosis \\
\hline Methods & Randomised. \\
\hline Participants & People at risk of psychosis. \\
\hline Interventions & $\begin{array}{l}\text { Cognitive behavioural therapy and person centred therapy in ameliorating 'at risk mental states' } \\
\text { for psychosis }\end{array}$ \\
\hline Outcomes & No details. \\
\hline Starting date & No details. \\
\hline Contact information & No details. \\
\hline Notes & \\
\hline
\end{tabular}

\section{DATA AND ANALYSES}

\section{Comparison 1}

PHASE SPECIFIC TREATMENT (OLANZAPINE) + NONSPECIFICSUPPORTIVETHERAPY vs PLACEBO + NON-SPECIFIC SUPPORTIVE

\begin{tabular}{|c|c|c|c|c|}
\hline Outcome or subgroup title & No. of studies & No. of participants & Statistical method & Effect size \\
\hline $\begin{array}{l}1 \text { Leaving the study early } \\
\text { (for reasons other than } \\
\text { psychosis) }\end{array}$ & 1 & & $\begin{array}{l}\text { Risk Ratio (M-H, } \\
\text { Fixed, 95\% CI) }\end{array}$ & Subtotals only \\
\hline 1.1 by eight weeks & 1 & 60 & $\begin{array}{l}\text { Risk Ratio (M-H, } \\
\text { Fixed, 95\% CI) }\end{array}$ & $1.29[0.60,2.74]$ \\
\hline 1.2 by one year & 1 & 60 & $\begin{array}{l}\text { Risk Ratio (M-H, } \\
\text { Fixed, 95\% CI) }\end{array}$ & $1.59[0.88,2.88]$ \\
\hline $\begin{array}{l}2 \text { Converted to psychosis: } \\
\text { POPS }\end{array}$ & 1 & & $\begin{array}{l}\text { Risk Ratio (M-H, } \\
\text { Fixed, 95\% CI) }\end{array}$ & Subtotals only \\
\hline 2.1 over one year & 1 & 60 & $\begin{array}{l}\text { Risk Ratio (M-H, } \\
\text { Fixed, } 95 \% \mathrm{CI})\end{array}$ & $0.58[0.28,1.18]$ \\
\hline $\begin{array}{l}3 \text { Global state: } 1 \text {. Average } \\
\text { total change score }- \text { by } 1 \\
\text { month (CGI-severity of } \\
\text { illness, high score=worse) }\end{array}$ & 1 & 59 & $\begin{array}{l}\text { Mean Difference (IV, } \\
\text { Fixed, 95\% CI) }\end{array}$ & $-0.23[-0.82,0.36]$ \\
\hline
\end{tabular}




\begin{tabular}{|c|c|c|c|c|}
\hline Outcome or subgroup title & No. of studies & No. of participants & Statistical method & Effect size \\
\hline $\begin{array}{l}4 \text { Global state: } 2 \text {. Average } \\
\text { total change score - by } 12 \\
\text { months (GAF-current, high } \\
\text { score=good) }\end{array}$ & 1 & 59 & $\begin{array}{l}\text { Mean Difference (IV, } \\
\text { Fixed, 95\% CI) }\end{array}$ & $2.43[-4.77,9.63]$ \\
\hline $\begin{array}{l}5 \text { Mental state: } 1 \text {. Average } \\
\text { total change score - by } 12 \\
\text { months (SOPS, high } \\
\text { score=worse) }\end{array}$ & 1 & & $\begin{array}{l}\text { Mean Difference (IV, } \\
\text { Fixed, 95\% CI) }\end{array}$ & Subtotals only \\
\hline 5.1 total score & 1 & 59 & $\begin{array}{l}\text { Mean Difference (IV, } \\
\text { Fixed, 95\% CI) }\end{array}$ & $-2.76[-12.03,6.51]$ \\
\hline 5.2 positive score & 1 & 59 & $\begin{array}{l}\text { Mean Difference (IV, } \\
\text { Fixed, 95\% CI) }\end{array}$ & $-2.73[-6.18,0.72]$ \\
\hline 5.3 negative & 1 & 59 & $\begin{array}{l}\text { Mean Difference (IV, } \\
\text { Fixed, 95\% CI) }\end{array}$ & $0.28[-3.02,3.58]$ \\
\hline 5.4 disorganisation & 1 & 59 & $\begin{array}{l}\text { Mean Difference (IV, } \\
\text { Fixed, 95\% CI) }\end{array}$ & $-0.49[-2.69,1.71]$ \\
\hline 5.5 general & 1 & 59 & $\begin{array}{l}\text { Mean Difference (IV, } \\
\text { Fixed, } 95 \% \text { CI) }\end{array}$ & $0.18[-1.84,2.20]$ \\
\hline $\begin{array}{l}6 \text { Mental state: } 2 \text {. Average } \\
\text { total change score - by } 12 \\
\text { months (PANSS, high } \\
\text { score=worse) }\end{array}$ & 1 & & $\begin{array}{l}\text { Mean Difference (IV, } \\
\text { Fixed, 95\% CI) }\end{array}$ & Subtotals only \\
\hline 6.1 total & 1 & 59 & $\begin{array}{l}\text { Mean Difference (IV, } \\
\text { Fixed, 95\% CI) }\end{array}$ & $0.48[-10.69,11.65]$ \\
\hline 6.2 positive & 1 & 59 & $\begin{array}{l}\text { Mean Difference (IV, } \\
\text { Fixed, 95\% CI) }\end{array}$ & $-0.57[-3.75,2.61]$ \\
\hline 6.3 negative & 1 & 59 & $\begin{array}{l}\text { Mean Difference (IV, } \\
\text { Fixed, 95\% CI) }\end{array}$ & $0.52[-2.60,3.64]$ \\
\hline 6.4 general & 1 & 59 & $\begin{array}{l}\text { Mean Difference (IV, } \\
\text { Fixed, 95\% CI) }\end{array}$ & $0.54[-5.44,6.52]$ \\
\hline $\begin{array}{l}7 \text { Mental state: } 3 \text {. Average } \\
\text { total change score - by } 12 \\
\text { months (YMRS, high } \\
\text { score=worse) }\end{array}$ & 1 & 59 & $\begin{array}{l}\text { Mean Difference (IV, } \\
\text { Fixed, 95\% CI) }\end{array}$ & $-0.91[-3.77,1.95]$ \\
\hline $\begin{array}{l}8 \text { Mental state: } 4 \text {. Average } \\
\text { total change score - by } 12 \\
\text { months (MADRS, high } \\
\text { score=worse) }\end{array}$ & 1 & 59 & $\begin{array}{l}\text { Mean Difference (IV, } \\
\text { Fixed, 95\% CI) }\end{array}$ & $0.68[-3.81,5.17]$ \\
\hline $\begin{array}{l}9 \text { Adverse effects: } 1 . \\
\text { Average total change score - } \\
\text { by } 8 \text { weeks (SAS, high } \\
\text { score=worse) }\end{array}$ & 1 & 59 & $\begin{array}{l}\text { Mean Difference (IV, } \\
\text { Fixed, 95\% CI) }\end{array}$ & $0.10[-0.59,0.79]$ \\
\hline $\begin{array}{l}10 \text { Adverse effects: } 2 \text {. } \\
\text { Average total change score - } \\
\text { by } 8 \text { weeks (BAS, high } \\
\text { score=worse) }\end{array}$ & 1 & 59 & $\begin{array}{l}\text { Mean Difference (IV, } \\
\text { Fixed, 95\% CI) }\end{array}$ & $0.5[-0.58,1.58]$ \\
\hline $\begin{array}{l}11 \text { Adverse effects: } 3 \text {. } \\
\text { Average total change score - } \\
\text { by } 8 \text { weeks (AIMS, high } \\
\text { score=worse) }\end{array}$ & 1 & 59 & $\begin{array}{l}\text { Mean Difference (IV, } \\
\text { Fixed, 95\% CI) }\end{array}$ & $0.60[-0.34,1.54]$ \\
\hline $\begin{array}{l}12 \text { Adverse effects: } 4 . \\
\text { Average total weight change } \\
\text { score }(\mathrm{kg}) \text { - by } 12 \text { months }\end{array}$ & 1 & 59 & $\begin{array}{l}\text { Mean Difference (IV, } \\
\text { Fixed, 95\% CI) }\end{array}$ & $7.63[4.04,11.22]$ \\
\hline $\begin{array}{l}13 \text { Adverse effects: } 5 \text {. } \\
\text { Weight gain - by } 12 \text { months }\end{array}$ & 1 & 60 & $\begin{array}{l}\text { Risk Ratio (M-H, } \\
\text { Fixed, 95\% CI) }\end{array}$ & $3.55[1.53,8.28]$ \\
\hline $\begin{array}{l}14 \text { Adverse effects: } 6 \text {. } \\
\text { Average total change score - } \\
\text { by } 8 \text { weeks (Cardiovascular) }\end{array}$ & 1 & & $\begin{array}{l}\text { Mean Difference (IV, } \\
\text { Fixed, 95\% CI) }\end{array}$ & Subtotals only \\
\hline
\end{tabular}




\begin{tabular}{|c|c|c|c|c|}
\hline Outcome or subgroup title & No. of studies & No. of participants & Statistical method & Effect size \\
\hline $\begin{array}{l}14.1 \text { sitting systolic blood } \\
\text { pressure }\end{array}$ & 1 & 59 & $\begin{array}{l}\text { Mean Difference (IV, } \\
\text { Fixed, 95\% CI) }\end{array}$ & $1.0[-4.28,6.28]$ \\
\hline $\begin{array}{l}14.2 \text { sitting diastolic blood } \\
\text { pressure }\end{array}$ & 1 & 59 & $\begin{array}{l}\text { Mean Difference (IV, } \\
\text { Fixed, 95\% CI) }\end{array}$ & $0.70[-4.43,5.83]$ \\
\hline $\begin{array}{l}14.3 \text { standing systolic } \\
\text { blood pressure }\end{array}$ & 1 & 59 & $\begin{array}{l}\text { Mean Difference (IV, } \\
\text { Fixed, 95\% CI) }\end{array}$ & $-2.80[-9.18,3.58]$ \\
\hline $\begin{array}{l}14.4 \text { standing diastolic } \\
\text { blood pressure }\end{array}$ & 1 & 59 & $\begin{array}{l}\text { Mean Difference (IV, } \\
\text { Fixed, 95\% CI) }\end{array}$ & $0.20[-4.96,5.36]$ \\
\hline 14.5 sitting pulse rate & 1 & 58 & $\begin{array}{l}\text { Mean Difference (IV, } \\
\text { Fixed, 95\% CI) }\end{array}$ & $7.20[-1.04,15.44]$ \\
\hline 14.6 standing pulse rate & 1 & 57 & $\begin{array}{l}\text { Mean Difference (IV, } \\
\text { Fixed, 95\% CI) }\end{array}$ & $3.90[-4.87,12.67]$ \\
\hline $\begin{array}{l}15 \text { Adverse effects: } 7 \text {. } \\
\text { Average total change score - } \\
\text { by } 12 \text { months (Pulse, BPM) }\end{array}$ & 1 & & $\begin{array}{l}\text { Mean Difference (IV, } \\
\text { Fixed, 95\% CI) }\end{array}$ & Subtotals only \\
\hline 15.1 sitting pulse rate & 1 & 58 & $\begin{array}{l}\text { Mean Difference (IV, } \\
\text { Fixed, 95\% CI) }\end{array}$ & $8.31[0.53,16.09]$ \\
\hline 15.2 standing pulse rate & 1 & 57 & $\begin{array}{l}\text { Mean Difference (IV, } \\
\text { Fixed, 95\% CI) }\end{array}$ & $2.86[-6.69,12.41]$ \\
\hline $\begin{array}{l}16 \text { Adverse effects: } 8 \text {. } \\
\text { Treatment emergent adverse } \\
\text { events - by } 8 \text { weeks (CoStart } \\
\text { Term) }\end{array}$ & 1 & & $\begin{array}{l}\text { Risk Ratio (M-H, } \\
\text { Fixed, 95\% CI) }\end{array}$ & Subtotals only \\
\hline 16.1 somnolence & 1 & 60 & $\begin{array}{l}\text { Risk Ratio (M-H, } \\
\text { Fixed, 95\% CI) }\end{array}$ & $2.25[0.90,5.59]$ \\
\hline 16.2 weight gain & 1 & 60 & $\begin{array}{l}\text { Risk Ratio (M-H, } \\
\text { Fixed, 95\% CI) }\end{array}$ & $10.29[1.42,74.79]$ \\
\hline 16.3 increased appetite & 1 & 60 & $\begin{array}{l}\text { Risk Ratio (M-H, } \\
\text { Fixed, 95\% CI) }\end{array}$ & $1.87[0.51,6.80]$ \\
\hline 16.4 anxiety & 1 & 60 & $\begin{array}{l}\text { Risk Ratio (M-H, } \\
\text { Fixed, 95\% CI) }\end{array}$ & $4.68[0.58,37.68]$ \\
\hline 16.5 nervousness & 1 & 60 & $\begin{array}{l}\text { Risk Ratio (M-H, } \\
\text { Fixed, 95\% CI) }\end{array}$ & $1.87[0.37,9.46]$ \\
\hline 16.6 asthenia & 1 & 60 & $\begin{array}{l}\text { Risk Ratio (M-H, } \\
\text { Fixed, 95\% CI) }\end{array}$ & $3.74[0.44,31.55]$ \\
\hline 16.7 joint disorder & 1 & 60 & $\begin{array}{l}\text { Risk Ratio (M-H, } \\
\text { Fixed, 95\% CI) }\end{array}$ & $0.94[0.20,4.27]$ \\
\hline 16.8 abnormal thoughts & 1 & 60 & $\begin{array}{l}\text { Risk Ratio (M-H, } \\
\text { Fixed, } 95 \% \mathrm{CI})\end{array}$ & $1.40[0.25,7.81]$ \\
\hline $\begin{array}{l}17 \text { Adverse effects: } 9 \text {. } \\
\text { Fatigue - by } 12 \text { months }\end{array}$ & 1 & 60 & $\begin{array}{l}\text { Risk Ratio (M-H, } \\
\text { Fixed, 95\% CI) }\end{array}$ & $8.42[1.14,62.40]$ \\
\hline
\end{tabular}

Comparison 2

PHASE SPECIFIC TREATMENT (CBT) + NON-SPECIFIC SUPPORTIVE THERAPY vs NON-SPECIFIC SUPPORTIVE THERAPY

\begin{tabular}{lllll}
\hline $\begin{array}{l}\text { Outcome or subgroup } \\
\text { title }\end{array}$ & No. of studies & No. of participants & Statistical method & Effect size \\
\hline 1 Leaving the study early & 1 & & $\begin{array}{l}\text { Risk Ratio (M-H, Fixed, } \\
95 \% \text { CI) }\end{array}$ & Subtotals only \\
& 1 & 60 & $\begin{array}{l}\text { Risk Ratio (M-H, Fixed, } \\
95 \% \text { CI) }\end{array}$ & $0.98[0.44,2.16]$
\end{tabular}




\begin{tabular}{|c|c|c|c|c|}
\hline $\begin{array}{l}\text { Outcome or subgroup } \\
\text { title }\end{array}$ & No. of studies & No. of participants & Statistical method & Effect size \\
\hline 1.2 by 3 years & 1 & 60 & $\begin{array}{l}\text { Risk Ratio (M-H, Fixed, } \\
95 \% \text { CI) }\end{array}$ & $0.96[0.60,1.52]$ \\
\hline $\begin{array}{l}2 \text { Transition to psychosis - } \\
\text { by } 12 \text { months }\end{array}$ & 1 & 60 & $\begin{array}{l}\text { Risk Ratio (M-H, Fixed, } \\
95 \% \text { CI) }\end{array}$ & $0.50[0.15,1.66]$ \\
\hline $\begin{array}{l}3 \text { Social Functioning: } 1 . \\
\text { SAS II endpoint data (long } \\
\text { term, high score=worse, } \\
\text { LOCF) }\end{array}$ & 1 & & $\begin{array}{l}\text { Mean Difference (IV, } \\
\text { Fixed, 95\% CI) }\end{array}$ & Subtotals only \\
\hline 3.1 global & 1 & 67 & $\begin{array}{l}\text { Mean Difference (IV, } \\
\text { Fixed, } 95 \% \text { CI) }\end{array}$ & $0.40[-0.05,0.85]$ \\
\hline 3.2 social activities & 1 & 67 & $\begin{array}{l}\text { Mean Difference (IV, } \\
\text { Fixed, } 95 \% \text { CI) }\end{array}$ & $0.10[-0.28,0.48]$ \\
\hline 3.3 well-being & 1 & 67 & $\begin{array}{l}\text { Mean Difference (IV, } \\
\text { Fixed, } 95 \% \text { CI) }\end{array}$ & $0.10[-0.22,0.42]$ \\
\hline 3.4 work & 1 & 67 & $\begin{array}{l}\text { Mean Difference (IV, } \\
\text { Fixed, } 95 \% \text { CI) }\end{array}$ & $-0.10[-0.38,0.18]$ \\
\hline
\end{tabular}

Comparison 3

\section{PHASE SPECIFIC TREATMENT (RISPERIDONE + CBT) + SPECIALISED TEAM vs SPECIALISED TEAM}

\begin{tabular}{|c|c|c|c|c|}
\hline $\begin{array}{l}\text { Outcome or subgroup } \\
\text { title }\end{array}$ & No. of studies & No. of participants & Statistical method & Effect size \\
\hline $\begin{array}{l}1 \text { Leaving the study } \\
\text { early - by } 12 \text { months }\end{array}$ & 1 & 59 & $\begin{array}{l}\text { Risk Ratio (M-H, Fixed, } \\
95 \% \text { CI) }\end{array}$ & $0.0[0.0,0.0]$ \\
\hline $\begin{array}{l}2 \text { Progression to } \\
\text { psychosis }\end{array}$ & 1 & & $\begin{array}{l}\text { Risk Ratio (M-H, Fixed, } \\
95 \% \text { CI) }\end{array}$ & Subtotals only \\
\hline 2.1 by 6 months & 1 & 59 & $\begin{array}{l}\text { Risk Ratio (M-H, Fixed, } \\
95 \% \text { CI) }\end{array}$ & $0.27[0.08,0.89]$ \\
\hline 2.2 by 12 months & 1 & 59 & $\begin{array}{l}\text { Risk Ratio (M-H, Fixed, } \\
95 \% \text { CI) }\end{array}$ & $0.54[0.23,1.30]$ \\
\hline $\begin{array}{l}3 \text { Global state: Average } \\
\text { endpoint score (GAF, } \\
\text { high score=worse) }\end{array}$ & 1 & & $\begin{array}{l}\text { Mean Difference (IV, } \\
\text { Fixed, 95\% CI) }\end{array}$ & Subtotals only \\
\hline 3.1 at baseline & 1 & 59 & $\begin{array}{l}\text { Mean Difference (IV, } \\
\text { Fixed, 95\% CI) }\end{array}$ & $4.20[-2.57,10.97]$ \\
\hline 3.2 by 12 months & 1 & 59 & $\begin{array}{l}\text { Mean Difference (IV, } \\
\text { Fixed, 95\% CI) }\end{array}$ & $0.0[-5.21,5.21]$ \\
\hline $\begin{array}{l}4 \text { Mental state: 1a. } \\
\text { Average endpoint score } \\
\text { (BPRS psychotic } \\
\text { symptoms -general, } \\
\text { high score=worse, } \\
\text { skewed data) }\end{array}$ & 1 & & $\begin{array}{l}\text { Mean Difference (IV, } \\
\text { Fixed, 95\% CI) }\end{array}$ & Subtotals only \\
\hline 4.1 at baseline & 1 & 59 & $\begin{array}{l}\text { Mean Difference (IV, } \\
\text { Fixed, 95\% CI) }\end{array}$ & $0.10[-1.25,1.45]$ \\
\hline 4.2 by 6 months & 1 & 59 & $\begin{array}{l}\text { Mean Difference (IV, } \\
\text { Fixed, 95\% CI) }\end{array}$ & $-0.5[-2.25,1.25]$ \\
\hline 4.3 by 12 months & 1 & 59 & $\begin{array}{l}\text { Mean Difference (IV, } \\
\text { Fixed, 95\% CI) }\end{array}$ & $0.70[-0.99,2.39]$ \\
\hline $\begin{array}{l}5 \text { Mental state: } 1 \mathrm{~b} \text {. } \\
\text { Average endpoint score } \\
\text { (SANS, psychotic } \\
\text { symptoms - negative, }\end{array}$ & 1 & & $\begin{array}{l}\text { Mean Difference (IV, } \\
\text { Fixed, 95\% CI) }\end{array}$ & Subtotals only \\
\hline
\end{tabular}




\begin{tabular}{|c|c|c|c|c|}
\hline $\begin{array}{l}\text { Outcome or subgroup } \\
\text { title }\end{array}$ & No. of studies & No. of participants & Statistical method & Effect size \\
\hline \multicolumn{5}{|l|}{$\begin{array}{l}\text { high score=worse, } \\
\text { skewed data) }\end{array}$} \\
\hline 5.1 at baseline & 1 & 59 & $\begin{array}{l}\text { Mean Difference (IV, } \\
\text { Fixed, 95\% CI) }\end{array}$ & $-3.20[-9.80,3.40]$ \\
\hline 5.2 by 6 months & 1 & 59 & $\begin{array}{l}\text { Mean Difference (IV, } \\
\text { Fixed, 95\% CI) }\end{array}$ & $-4.60[-12.72,3.52]$ \\
\hline 5.3 by 12 months & 1 & 59 & $\begin{array}{l}\text { Mean Difference (IV, } \\
\text { Fixed, 95\% CI) }\end{array}$ & $-0.80[-7.87,6.27]$ \\
\hline $\begin{array}{l}6 \text { Mental state: } 2 \mathrm{a} \text {. } \\
\text { Average endpoint score } \\
\text { anxiety (HRSA, high } \\
\text { score=worse, skewed } \\
\text { data) }\end{array}$ & 1 & & $\begin{array}{l}\text { Mean Difference (IV, } \\
\text { Fixed, 95\% CI) }\end{array}$ & Subtotals only \\
\hline 6.1 at baseline & 1 & 59 & $\begin{array}{l}\text { Mean Difference (IV, } \\
\text { Fixed, 95\% CI) }\end{array}$ & $-0.70[-4.85,3.45]$ \\
\hline 6.2 by 6 months & 1 & 59 & $\begin{array}{l}\text { Mean Difference (IV, } \\
\text { Fixed, 95\% CI) }\end{array}$ & $-1.10[-4.81,2.61]$ \\
\hline 6.3 by 12 months & 1 & 59 & $\begin{array}{l}\text { Mean Difference (IV, } \\
\text { Fixed, 95\% CI) }\end{array}$ & $0.60[-4.18,5.38]$ \\
\hline $\begin{array}{l}7 \text { Mental state: } 2 \mathrm{~b} \text {. } \\
\text { Average endpoint score } \\
\text { depression (HRSD, } \\
\text { high score=worse, } \\
\text { skewed data) }\end{array}$ & 1 & & $\begin{array}{l}\text { Mean Difference (IV, } \\
\text { Fixed, 95\% CI) }\end{array}$ & Subtotals only \\
\hline 7.1 at baseline & 1 & 59 & $\begin{array}{l}\text { Mean Difference (IV, } \\
\text { Fixed, 95\% CI) }\end{array}$ & $-1.0[-5.51,3.51]$ \\
\hline 7.2 by 6 months & 1 & 59 & $\begin{array}{l}\text { Mean Difference (IV, } \\
\text { Fixed, 95\% CI) }\end{array}$ & $-0.20[-4.77,4.37]$ \\
\hline 7.3 by 12 months & 1 & 59 & $\begin{array}{l}\text { Mean Difference (IV, } \\
\text { Fixed, 95\% CI) }\end{array}$ & $1.20[-3.22,5.62]$ \\
\hline $\begin{array}{l}8 \text { Mental state: } 2 \mathrm{c} \text {. } \\
\text { Average endpoint score } \\
\text { mania (YMS, high } \\
\text { score=worse, skewed } \\
\text { data) }\end{array}$ & 1 & & $\begin{array}{l}\text { Mean Difference (IV, } \\
\text { Fixed, 95\% CI) }\end{array}$ & Subtotals only \\
\hline 8.1 at baseline & 1 & 59 & $\begin{array}{l}\text { Mean Difference (IV, } \\
\text { Fixed, 95\% CI) }\end{array}$ & $0.80[-1.38,2.98]$ \\
\hline 8.2 by 6 months & 1 & 59 & $\begin{array}{l}\text { Mean Difference (IV, } \\
\text { Fixed, 95\% CI) }\end{array}$ & $0.70[-2.46,3.86]$ \\
\hline 8.3 by 12 months & 1 & 59 & $\begin{array}{l}\text { Mean Difference (IV, } \\
\text { Fixed, 95\% CI) }\end{array}$ & $0.0[-1.76,1.76]$ \\
\hline $\begin{array}{l}9 \text { Quality of life: } \\
\text { Average endpoint score } \\
\text { (QLS, high } \\
\text { score=worse) }\end{array}$ & 1 & & $\begin{array}{l}\text { Mean Difference (IV, } \\
\text { Fixed, 95\% CI) }\end{array}$ & Subtotals only \\
\hline 9.1 at baseline & 1 & 59 & $\begin{array}{l}\text { Mean Difference (IV, } \\
\text { Fixed, 95\% CI) }\end{array}$ & $-3.10[-14.12,7.92]$ \\
\hline 9.2 by 6 months & 1 & 59 & $\begin{array}{l}\text { Mean Difference (IV, } \\
\text { Fixed, 95\% CI) }\end{array}$ & $-1.40[-13.63,10.83]$ \\
\hline 9.3 by 12 months & 1 & 59 & $\begin{array}{l}\text { Mean Difference (IV, } \\
\text { Fixed, } 95 \% \mathrm{Cl} \text { ) }\end{array}$ & $0.80[-10.15,11.75]$ \\
\hline
\end{tabular}


Comparison 4

PHASE-SPECIFIC TREATMENT (AMISULPRIDE) + NEEDS FOCUSED INTERVENTIONS vs NEEDS FOCUSED INTERVENTIONS

\begin{tabular}{|c|c|c|c|c|}
\hline $\begin{array}{l}\text { Outcome or subgroup } \\
\text { title }\end{array}$ & No. of studies & No. of participants & Statistical method & Effect size \\
\hline $\begin{array}{l}1 \text { Leaving the study } \\
\text { early }\end{array}$ & 1 & & $\begin{array}{l}\text { Risk Ratio (M-H, Fixed, } \\
95 \% \text { CI) }\end{array}$ & Subtotals only \\
\hline $\begin{array}{l}2 \text { Mental state: } 1 . \\
\text { PANSS, endpoint score } \\
\text { (by } 12 \text { weeks, higher } \\
\text { scores=worse, LOCR) }\end{array}$ & 1 & & $\begin{array}{l}\text { Mean Difference (IV, } \\
\text { Fixed, 95\% CI) }\end{array}$ & Subtotals only \\
\hline 2.1 PANSS-G & 1 & 102 & $\begin{array}{l}\text { Mean Difference (IV, } \\
\text { Fixed, 95\% CI) }\end{array}$ & $-3.40[-6.85,0.05]$ \\
\hline 2.2 PANSS-P & 1 & 102 & $\begin{array}{l}\text { Mean Difference (IV, } \\
\text { Fixed, 95\% CI) }\end{array}$ & $-2.10[-3.69,-0.51]$ \\
\hline 2.3 PANSS-N & 1 & 102 & $\begin{array}{l}\text { Mean Difference (IV, } \\
\text { Fixed, 95\% CI) }\end{array}$ & $-1.30[-3.26,0.66]$ \\
\hline $\begin{array}{l}3 \text { Mental state: } 1 . \\
\text { MADRS, endpoint } \\
\text { score (by } 12 \text { weeks, } \\
\text { higher scores=worse, } \\
\text { LOCF) }\end{array}$ & 1 & 102 & $\begin{array}{l}\text { Mean Difference (IV, } \\
\text { Fixed, 95\% CI) }\end{array}$ & $-1.10[-4.49,2.29]$ \\
\hline $\begin{array}{l}4 \text { Global state: } 1 \text {. GAF, } \\
\text { endpoint score (by } 12 \\
\text { weeks, higher } \\
\text { scores=better) }\end{array}$ & 1 & 102 & $\begin{array}{l}\text { Mean Difference (IV, } \\
\text { Fixed, 95\% CI) }\end{array}$ & $-6.10[-11.76,-0.44]$ \\
\hline
\end{tabular}

\section{Comparison 5}

OMEGA 3 FATTY ACIDS (EPA) versus PLACEBO

\begin{tabular}{lllll}
\hline $\begin{array}{l}\text { Outcome or subgroup } \\
\text { title }\end{array}$ & No. of studies & No. of participants & Statistical method & Effect size \\
\hline $\begin{array}{l}1 \text { Transition to } \\
\text { psychosis }\end{array}$ & 1 & 76 & $\begin{array}{l}\text { Risk Ratio (M-H, Fixed, 95\% } \\
\text { CI) }\end{array}$ & $0.13[0.02,0.95]$ \\
\hline
\end{tabular}

\section{Comparison 6}

PHASE-SPECIFIC TREATMENT (CBT for SUICIDALITY) + SPECIALISED TEAM vs SPECIALISED TEAM

\begin{tabular}{lllll}
\hline $\begin{array}{l}\text { Outcome or subgroup } \\
\text { title }\end{array}$ & No. of studies & No. of participants & Statistical method & Effect size \\
\hline $\begin{array}{l}\text { 1 Leaving the study } \\
\text { early - by 6 months }\end{array}$ & 1 & 56 & $\begin{array}{l}\text { Risk Ratio (M-H, Fixed, 95\% } \\
\text { CI) }\end{array}$ & $2.02[0.72,5.66]$ \\
2 Suicide - by 6 months & 1 & 56 & $\begin{array}{l}\text { Risk Ratio (M-H, Fixed, 95\% } \\
\text { CI) }\end{array}$ & $0.81[0.05,12.26]$ \\
\hline
\end{tabular}


Comparison 7

PHASE-SPECIFIC TREATMENT (FAMILY THERAPY) + SPECIALISED TEAM vs SPECIALISED TEAM

\begin{tabular}{lllll}
\hline $\begin{array}{l}\text { Outcome or subgroup } \\
\text { title }\end{array}$ & No. of studies & No. of participants & Statistical method & Effect size \\
\hline $\begin{array}{l}\text { 1 Relapse by end of } \\
\text { treatment - by 12 months }\end{array}$ & 1 & 76 & $\begin{array}{l}\text { Risk Ratio (M-H, Fixed, } \\
95 \% \text { CI) }\end{array}$ & $1.05[0.37,2.98]$ \\
\hline
\end{tabular}

\section{Comparison 8}

\section{PHASE-SPECIFIC TREATMENT (FAMILY THERAPY) + STANDARD CARE vs STANDARD CARE}

\begin{tabular}{lllll}
\hline $\begin{array}{l}\text { Outcome or subgroup } \\
\text { title }\end{array}$ & No. of studies & No. of participants & Statistical method & Effect size \\
\hline $\begin{array}{l}\text { 1 Leaving the study } \\
\text { early - by 18 months }\end{array}$ & 1 & 83 & $\begin{array}{l}\text { Risk Ratio (M-H, Fixed, 95\% } \\
\text { CI) }\end{array}$ & $1.46[0.26,8.31]$ \\
$\begin{array}{l}\text { 2 Readmitted to hospital } \\
- \text { by 18 months }\end{array}$ & 1 & 83 & $\begin{array}{l}\text { Risk Ratio (M-H, Fixed, 95\% } \\
\text { CI) }\end{array}$ & $0.28[0.13,0.62]$ \\
$\begin{array}{l}\text { 3 Not compliant with } \\
\text { medication }\end{array}$ & 1 & 83 & $\begin{array}{l}\text { Risk Ratio (M-H, Fixed, 95\% } \\
\text { CI) }\end{array}$ & $0.57[0.31,1.04]$ \\
\hline
\end{tabular}

\section{Comparison 9}

\section{SPECIALISED TEAM vs STANDARD CARE}

\begin{tabular}{|c|c|c|c|c|}
\hline $\begin{array}{l}\text { Outcome or subgroup } \\
\text { title }\end{array}$ & No. of studies & No. of participants & Statistical method & Effect size \\
\hline 1 Leaving the study early & 1 & & $\begin{array}{l}\text { Risk Ratio (M-H, Fixed, } \\
95 \% \text { CI) }\end{array}$ & Subtotals only \\
\hline 1.1 by one year & 1 & 547 & $\begin{array}{l}\text { Risk Ratio (M-H, Fixed, } \\
95 \% \text { CI) }\end{array}$ & $0.59[0.43,0.81]$ \\
\hline 1.2 by two years & 1 & 547 & $\begin{array}{l}\text { Risk Ratio (M-H, Fixed, } \\
95 \% \text { CI) }\end{array}$ & $0.64[0.50,0.82]$ \\
\hline 1.3 by five years & 1 & 547 & $\begin{array}{l}\text { Risk Ratio (M-H, Fixed, } \\
95 \% \text { CI) }\end{array}$ & $1.01[0.84,1.21]$ \\
\hline $\begin{array}{l}2 \text { Global state: } 1 . \\
\text { Average endpoint score - } \\
\text { by } 12 \text { and } 24 \text { months } \\
\text { (GAF-symptom, high } \\
\text { score=good) }\end{array}$ & 1 & & $\begin{array}{l}\text { Mean Difference (IV, } \\
\text { Fixed, 95\% CI) }\end{array}$ & Subtotals only \\
\hline 2.1 by one year & 1 & 419 & $\begin{array}{l}\text { Mean Difference (IV, } \\
\text { Fixed, 95\% CI) }\end{array}$ & $-3.71[-6.69,-0.73]$ \\
\hline 2.2 by two years & 1 & 369 & $\begin{array}{l}\text { Mean Difference (IV, } \\
\text { Fixed, 95\% CI) }\end{array}$ & $-2.51[-5.70,0.68]$ \\
\hline 2.3 by 5 years & 1 & 301 & $\begin{array}{l}\text { Mean Difference (IV, } \\
\text { Fixed, 95\% CI) }\end{array}$ & $0.32[-3.57,4.21]$ \\
\hline $\begin{array}{l}3 \text { Global state: } 2 \text {. } \\
\text { Average endpoint score - } \\
\text { by } 12 \text { and } 24 \text { months } \\
\text { (GAF-function, high } \\
\text { score=good) }\end{array}$ & 1 & & $\begin{array}{l}\text { Mean Difference (IV, } \\
\text { Fixed, 95\% CI) }\end{array}$ & Subtotals only \\
\hline
\end{tabular}




\begin{tabular}{|c|c|c|c|c|}
\hline $\begin{array}{l}\text { Outcome or subgroup } \\
\text { title }\end{array}$ & No. of studies & No. of participants & Statistical method & Effect size \\
\hline 3.1 by one year & 1 & 419 & $\begin{array}{l}\text { Mean Difference (IV, } \\
\text { Fixed, 95\% CI) }\end{array}$ & $-2.30[-5.15,0.55]$ \\
\hline 3.2 by two years & 1 & 369 & $\begin{array}{l}\text { Mean Difference (IV, } \\
\text { Fixed, 95\% CI) }\end{array}$ & $-4.03[-7.23,-0.83]$ \\
\hline 3.3 by five years & 1 & 301 & $\begin{array}{l}\text { Mean Difference (IV, } \\
\text { Fixed, } 95 \% \text { CI) }\end{array}$ & $-1.20[-5.23,2.83]$ \\
\hline $\begin{array}{l}4 \text { User satisfaction: } \\
\text { Average endpoint score - } \\
\text { by } 12 \text { and } 24 \text { months } \\
\text { (CSQ- } 8 \text {, high } \\
\text { score=good) }\end{array}$ & 1 & & $\begin{array}{l}\text { Mean Difference (IV, } \\
\text { Fixed, 95\% CI) }\end{array}$ & Subtotals only \\
\hline 4.1 by one year & 1 & 419 & $\begin{array}{l}\text { Mean Difference (IV, } \\
\text { Fixed, 95\% CI) }\end{array}$ & $-1.90[-3.07,-0.73]$ \\
\hline 4.2 by two years & 1 & 369 & $\begin{array}{l}\text { Mean Difference (IV, } \\
\text { Fixed, 95\% CI) }\end{array}$ & $-3.20[-4.14,-2.26]$ \\
\hline $\begin{array}{l}5 \text { Compliance with } \\
\text { treatment }\end{array}$ & 1 & & $\begin{array}{l}\text { Risk Ratio (M-H, Fixed, } \\
95 \% \text { CI) }\end{array}$ & Subtotals only \\
\hline $\begin{array}{l}5.1 \text { treatment stopped } \\
\text { in spite of need - by one } \\
\text { year }\end{array}$ & 1 & 507 & $\begin{array}{l}\text { Risk Ratio (M-H, Fixed, } \\
95 \% \text { CI) }\end{array}$ & $0.20[0.10,0.42]$ \\
\hline $\begin{array}{l}5.2 \text { treatment stopped } \\
\text { in spite of need - by two } \\
\text { years }\end{array}$ & 1 & 436 & $\begin{array}{l}\text { Risk Ratio (M-H, Fixed, } \\
95 \% \text { CI) }\end{array}$ & $0.66[0.29,1.50]$ \\
\hline $\begin{array}{l}6 \text { Suicide: Death - by } 12 \\
\text { months }\end{array}$ & 1 & 506 & $\begin{array}{l}\text { Risk Ratio (M-H, Fixed, } \\
95 \% \text { CI) }\end{array}$ & $0.93[0.06,14.81]$ \\
\hline $\begin{array}{l}7 \text { Death other than } \\
\text { suicide - by } 12 \text { months }\end{array}$ & 1 & & $\begin{array}{l}\text { Risk Ratio (M-H, Fixed, } \\
95 \% \text { CI) }\end{array}$ & Subtotals only \\
\hline 7.1 accident & 1 & 506 & $\begin{array}{l}\text { Risk Ratio (M-H, Fixed, } \\
95 \% \text { CI) }\end{array}$ & $0.31[0.01,7.59]$ \\
\hline 7.2 unexplained & 1 & 507 & $\begin{array}{l}\text { Risk Ratio (M-H, Fixed, } \\
95 \% \text { CI) }\end{array}$ & $0.31[0.01,7.56]$ \\
\hline $\begin{array}{l}8 \text { Service use: } 1 \text {. Average } \\
\text { mean number of days per } \\
\text { month in hospital }\end{array}$ & 1 & & $\begin{array}{l}\text { Mean Difference (IV, } \\
\text { Fixed, 95\% CI) }\end{array}$ & Subtotals only \\
\hline 8.1 by one year & 1 & 507 & $\begin{array}{l}\text { Mean Difference (IV, } \\
\text { Fixed, 95\% CI) }\end{array}$ & $-1.39[-2.83,0.05]$ \\
\hline 8.2 by two years & 1 & 436 & $\begin{array}{l}\text { Mean Difference (IV, } \\
\text { Fixed, 95\% CI) }\end{array}$ & $-0.67[-1.88,0.54]$ \\
\hline 8.3 by five years & 1 & 547 & $\begin{array}{l}\text { Mean Difference (IV, } \\
\text { Fixed, 95\% CI) }\end{array}$ & $-1.11[-3.21,0.99]$ \\
\hline $\begin{array}{l}9 \text { Service use: } 2 . \text { Not } \\
\text { hospitalised - by five } \\
\text { years }\end{array}$ & 1 & 547 & $\begin{array}{l}\text { Risk Ratio (M-H, Fixed, } \\
95 \% \text { CI) }\end{array}$ & $1.05[0.90,1.22]$ \\
\hline $\begin{array}{l}10 \text { Social outcomes: } 1 . \\
\text { Not living independently }\end{array}$ & 1 & & $\begin{array}{l}\text { Risk Ratio (M-H, Fixed, } \\
95 \% \text { CI) }\end{array}$ & Subtotals only \\
\hline 10.1 by one year & 1 & 507 & $\begin{array}{l}\text { Risk Ratio (M-H, Fixed, } \\
\text { 95\% CI) }\end{array}$ & $0.55[0.25,1.17]$ \\
\hline 10.2 by two years & 1 & 436 & $\begin{array}{l}\text { Risk Ratio (M-H, Fixed, } \\
95 \% \text { CI) }\end{array}$ & $0.74[0.36,1.53]$ \\
\hline 10.3 by five years & 1 & 547 & $\begin{array}{l}\text { Risk Ratio (M-H, Fixed, } \\
95 \% \text { CI) }\end{array}$ & $0.42[0.21,0.83]$ \\
\hline $\begin{array}{l}11 \text { Social outcomes: } 2 . \\
\text { Not working or in } \\
\text { education }\end{array}$ & 1 & & $\begin{array}{l}\text { Risk Ratio (M-H, Fixed, } \\
95 \% \text { CI) }\end{array}$ & Subtotals only \\
\hline
\end{tabular}




\begin{tabular}{ccclc}
\hline $\begin{array}{l}\text { Outcome or subgroup } \\
\text { title }\end{array}$ & No. of studies & No. of participants & Statistical method & Effect size \\
\hline 11.1 by one year & 1 & 507 & $\begin{array}{l}\text { Risk Ratio (M-H, Fixed, } \\
95 \% \mathrm{CI})\end{array}$ & 0.87 [0.65, 1.17] \\
11.2 by two years & 1 & 436 & $\begin{array}{l}\text { Risk Ratio (M-H, Fixed, } \\
95 \% \mathrm{CI})\end{array}$ & $0.72[0.54,0.97]$ \\
11.3 by five years & 1 & 547 & $\begin{array}{l}\text { Risk Ratio (M-H, Fixed, } \\
95 \% \mathrm{Cl})\end{array}$ & $1.06[0.92,1.23]$ \\
\hline
\end{tabular}

\section{Comparison 10}

PHASE-SPECIFIC TREATMENT (CBT) + ANTIPSYCHOTICS vs BEFRIENDING + ANTISYCHOTICS

\begin{tabular}{|c|c|c|c|c|}
\hline Outcome or subgroup title & No. of studies & No. of participants & Statistical method & Effect size \\
\hline $\begin{array}{l}1 \text { Leaving the study early by } \\
12 \text { months }\end{array}$ & 1 & 62 & $\begin{array}{l}\text { Risk Ratio (M-H, } \\
\text { Fixed, } 95 \% \text { CI) }\end{array}$ & $0.57[0.19,1.76]$ \\
\hline 2 Hospitalised by 12 months & 1 & 62 & $\begin{array}{l}\text { Risk Ratio (M-H, } \\
\text { Fixed, } 95 \% \mathrm{CI})\end{array}$ & $1.08[0.59,1.99]$ \\
\hline 3 Suicide by 12 months & 1 & 62 & $\begin{array}{l}\text { Risk Ratio (M-H, } \\
\text { Fixed, } 95 \% \mathrm{CI})\end{array}$ & $5.0[0.25,100.08]$ \\
\hline $\begin{array}{l}\text { 4 Social functioning: } \\
\text { SOFRAS by } 12 \text { months } \\
\text { (higher score=worse) }\end{array}$ & 1 & & $\begin{array}{l}\text { Mean Difference (IV, } \\
\text { Fixed, 95\% CI) }\end{array}$ & Subtotals only \\
\hline 4.1 total score & 1 & 62 & $\begin{array}{l}\text { Mean Difference (IV, } \\
\text { Fixed, } 95 \% \text { CI) }\end{array}$ & $-1.30[-8.86,6.26]$ \\
\hline 4.2 positive symptoms & 1 & 62 & $\begin{array}{l}\text { Mean Difference (IV, } \\
\text { Fixed, 95\% CI) }\end{array}$ & $0.35[-1.86,2.56]$ \\
\hline 4.3 negative symptoms & 1 & 62 & $\begin{array}{l}\text { Mean Difference (IV, } \\
\text { Fixed, 95\% CI) }\end{array}$ & $4.89[-1.58,11.36]$ \\
\hline
\end{tabular}

Comparison 11

PHASE-SPECIFIC TREATMENT (E-EPA) + ATYPICALS vs PLACEBO + ATYPICALS

\begin{tabular}{lllll}
\hline $\begin{array}{l}\text { Outcome or subgroup } \\
\text { title }\end{array}$ & No. of studies & No. of participants & Statistical method & Effect size \\
\hline $\begin{array}{l}1 \text { Leaving the study early } \\
\text { by } 12 \text { weeks }\end{array}$ & 1 & 80 & $\begin{array}{l}\text { Risk Ratio (M-H, Fixed, 95\% } \\
\text { CI) }\end{array}$ & $0.83[0.28,2.51]$ \\
$\begin{array}{l}2 \text { Global state: Not } \\
\text { responded to treatment by }\end{array}$ & 1 & 80 & $\begin{array}{l}\text { Risk Ratio (M-H, Fixed, } 95 \% \\
\text { CI) }\end{array}$ & $0.9[0.57,1.43]$ \\
\hline weeks & & & & \\
\hline
\end{tabular}

\section{Comparison 12}

PHASE-SPECIFIC TREATMENT (BRIEF INTERVENTION) + ANTIPSYCHOTICS vs TREAMENT AS USUAL

\begin{tabular}{lllll}
\hline $\begin{array}{l}\text { Outcome or subgroup } \\
\text { title }\end{array}$ & No. of studies & No. of participants & Statistical method & Effect size \\
\hline $\begin{array}{l}\text { 1 Leaving the study } \\
\text { early by nine months }\end{array}$ & 1 & 106 & $\begin{array}{l}\text { Risk Ratio (M-H, Fixed, 95\% } \\
\text { CI) }\end{array}$ & $0.72[0.34,1.51]$
\end{tabular}




\begin{tabular}{|c|c|c|c|c|}
\hline $\begin{array}{l}\text { Outcome or subgroup } \\
\text { title }\end{array}$ & No. of studies & No. of participants & Statistical method & Effect size \\
\hline $\begin{array}{l}2 \text { Hospital admission: } \\
\text { Hospitalised }\end{array}$ & 1 & & $\begin{array}{l}\text { Risk Ratio (M-H, Fixed, 95\% } \\
\text { CI) }\end{array}$ & Subtotals only \\
\hline 2.1 before 4 months & 1 & 106 & $\begin{array}{l}\text { Risk Ratio (M-H, Fixed, 95\% } \\
\text { CI) }\end{array}$ & $1.19[0.89,1.58]$ \\
\hline $2.2 \mathrm{Up}$ to 4 months & 1 & 106 & $\begin{array}{l}\text { Risk Ratio (M-H, Fixed, 95\% } \\
\text { CI) }\end{array}$ & $0.75[0.41,1.38]$ \\
\hline $\begin{array}{l}2.3 \text { between } 4 \text { months } \\
\text { and } 9 \text { months }\end{array}$ & 1 & 106 & $\begin{array}{l}\text { Risk Ratio (M-H, Fixed, 95\% } \\
\text { CI) }\end{array}$ & $0.86[0.43,1.74]$ \\
\hline
\end{tabular}

Comparison 13

PHASE-SPECIFIC TREATMENT (ACE) + ANTIPSYCHOTICS vs TREATMENT AS USUAL

\begin{tabular}{|c|c|c|c|c|}
\hline $\begin{array}{l}\text { Outcome or subgroup } \\
\text { title }\end{array}$ & No. of studies & No. of participants & Statistical method & Effect size \\
\hline $\begin{array}{l}1 \text { Leaving the study } \\
\text { early ( } 6 \text { months) }\end{array}$ & 1 & 24 & $\begin{array}{l}\text { Risk Ratio (M-H, Fixed, } \\
95 \% \text { CI) }\end{array}$ & $1.27[0.26,6.28]$ \\
\hline $\begin{array}{l}2 \text { Mental state: } 1 . \\
\text { PANSS }\end{array}$ & 1 & & $\begin{array}{l}\text { Mean Difference (IV, } \\
\text { Fixed, } 95 \% \mathrm{CI})\end{array}$ & Subtotals only \\
\hline 2.1 total score & 1 & 17 & $\begin{array}{l}\text { Mean Difference (IV, } \\
\text { Fixed, 95\% CI) }\end{array}$ & $-4.80[-18.42,8.82]$ \\
\hline 2.2 positive score & 1 & 17 & $\begin{array}{l}\text { Mean Difference (IV, } \\
\text { Fixed, } 95 \% \mathrm{CI})\end{array}$ & $-1.58[-4.88,1.72]$ \\
\hline 2.3 negative score & 1 & 17 & $\begin{array}{l}\text { Mean Difference (IV, } \\
\text { Fixed, 95\% CI) }\end{array}$ & $-1.64[-8.05,4.77]$ \\
\hline 2.4 general score & 1 & 17 & $\begin{array}{l}\text { Mean Difference (IV, } \\
\text { Fixed, 95\% CI) }\end{array}$ & $-1.57[-7.65,4.51]$ \\
\hline $\begin{array}{l}3 \text { Mental state: } 2 . \\
\text { Calgary Depression } \\
\text { Rating Scale }\end{array}$ & 1 & 17 & $\begin{array}{l}\text { Mean Difference (IV, } \\
\text { Fixed, 95\% CI) }\end{array}$ & $-1.46[-4.17,1.25]$ \\
\hline $\begin{array}{l}4 \text { Quality of Life: } 1 . \\
\text { Heinrichs-Carpenter }\end{array}$ & 1 & 16 & $\begin{array}{l}\text { Mean Difference (IV, } \\
\text { Fixed, 95\% CI) }\end{array}$ & $-2.93[-25.59,19.73]$ \\
\hline \multicolumn{5}{|c|}{ Comparison 14} \\
\hline \multicolumn{5}{|c|}{$\begin{array}{l}\text { PHASE-SPECIFIC TREATMENT (VOCATIONAL INTERVENTION) + TAU vs } \\
\text { TREATMENT AS USUAL }\end{array}$} \\
\hline $\begin{array}{l}\text { Outcome or subgroup } \\
\text { title }\end{array}$ & No. of studies & No. of participants & Statistical method & Effect size \\
\hline 1 Not employed & 1 & 41 & $\begin{array}{l}\text { Risk Ratio (M-H, Fixed, } 95 \% \\
\text { CI) }\end{array}$ & $0.39[0.21,0.71]$ \\
\hline $\begin{array}{l}2 \text { Leaving the study } \\
\text { early }\end{array}$ & 1 & 41 & $\begin{array}{l}\text { Risk Ratio (M-H, Fixed, 95\% } \\
\text { CI) }\end{array}$ & $0.21[0.03,1.64]$ \\
\hline
\end{tabular}


Comparison 15

PHASE-SPECIFIC TREATMENT (CANNABIS AND PSYCHOSIS THERAPY) + ANTIPSYCHOTICS vs PSYCHOEDUCATION + ANTIPSYCHOTICS

\begin{tabular}{|c|c|c|c|c|}
\hline Outcome or subgroup title & No. of studies & No. of participants & Statistical method & Effect size \\
\hline $\begin{array}{l}1 \text { Cannabis use: } 1 \text {. Used } \\
\text { cannabis in last } 4 \text { weeks }\end{array}$ & 1 & & $\begin{array}{l}\text { Risk Ratio (M-H, } \\
\text { Fixed, } 95 \% \text { CI) }\end{array}$ & Subtotals only \\
\hline $\begin{array}{l}1.1 \text { by } 3 \text { months - end of } \\
\text { treatment }\end{array}$ & 1 & 47 & $\begin{array}{l}\text { Risk Ratio (M-H, } \\
\text { Fixed, 95\% CI) }\end{array}$ & $1.04[0.62,1.74]$ \\
\hline $\begin{array}{l}1.2 \text { by } 9 \text { months }-6 \\
\text { months after end of } \\
\text { treatment }\end{array}$ & 1 & 47 & $\begin{array}{l}\text { Risk Ratio (M-H, } \\
\text { Fixed, 95\% CI) }\end{array}$ & $1.30[0.79,2.15]$ \\
\hline $\begin{array}{l}2 \text { Cannabis use: } 2 \text {. } \\
\text { Percentage days used } \\
\text { cannabis in last } 4 \text { weeks } \\
\text { (skewed data) }\end{array}$ & & & Other data & No numeric data \\
\hline $\begin{array}{l}2.1 \text { by } 3 \text { months - end of } \\
\text { treatment }\end{array}$ & & & Other data & No numeric data \\
\hline $\begin{array}{l}2.2 \text { by } 9 \text { months }-6 \\
\text { months after end of } \\
\text { treatment }\end{array}$ & & & Other data & No numeric data \\
\hline $\begin{array}{l}3 \text { Cannabis use: } 3 \text {. Severity } \\
\text { of cannabis use (skewed } \\
\text { data) }\end{array}$ & & & Other data & No numeric data \\
\hline $\begin{array}{l}3.1 \text { by } 3 \text { months - end of } \\
\text { treatment }\end{array}$ & & & Other data & No numeric data \\
\hline $\begin{array}{l}3.2 \text { by } 9 \text { months }-6 \\
\text { months after end of } \\
\text { treatment }\end{array}$ & & & Other data & No numeric data \\
\hline $\begin{array}{l}4 \text { Global state: Average } \\
\text { score (KAPQ total } \\
\text { endpoint, higher=good) }\end{array}$ & 1 & & $\begin{array}{l}\text { Mean Difference (IV, } \\
\text { Fixed, 95\% CI) }\end{array}$ & Subtotals only \\
\hline $\begin{array}{l}4.1 \text { by } 3 \text { months - end of } \\
\text { treatment }\end{array}$ & 1 & 47 & $\begin{array}{l}\text { Mean Difference (IV, } \\
\text { Fixed, 95\% CI) }\end{array}$ & $0.80[-1.78,3.38]$ \\
\hline $\begin{array}{l}\quad 4.2 \text { by } 9 \text { months - } 6 \\
\text { months after end of } \\
\text { treatment }\end{array}$ & 1 & 47 & $\begin{array}{l}\text { Mean Difference (IV, } \\
\text { Fixed, 95\% CI) }\end{array}$ & $0.90[-1.42,3.22]$ \\
\hline $\begin{array}{l}5 \text { Mental state: } 1 \text {. Average } \\
\text { score (BPRS-E total } \\
\text { endpoint, higher } \\
\text { scores=poor) }\end{array}$ & 1 & & $\begin{array}{l}\text { Mean Difference (IV, } \\
\text { Fixed, 95\% CI) }\end{array}$ & Subtotals only \\
\hline $\begin{array}{l}5.1 \text { by } 3 \text { months - end of } \\
\text { treatment }\end{array}$ & 1 & 47 & $\begin{array}{l}\text { Mean Difference (IV, } \\
\text { Fixed, 95\% CI) }\end{array}$ & $-3.60[-12.81,5.61]$ \\
\hline $\begin{array}{l}5.2 \text { by } 9 \text { months }-6 \\
\text { months after end of } \\
\text { treatment }\end{array}$ & 1 & 47 & $\begin{array}{l}\text { Mean Difference (IV, } \\
\text { Fixed, 95\% CI) }\end{array}$ & $0.80[-7.47,9.07]$ \\
\hline $\begin{array}{l}6 \text { Mental state: } 2 \text {. Average } \\
\text { score (BPRS-PS total } \\
\text { endpoint, higher } \\
\text { scores=poor) (skewed data) }\end{array}$ & & & Other data & No numeric data \\
\hline $\begin{array}{l}6.1 \text { by } 3 \text { months - end of } \\
\text { treatment }\end{array}$ & & & Other data & No numeric data \\
\hline $\begin{array}{l}6.2 \text { by } 9 \text { months }-6 \\
\text { months after end of } \\
\text { treatment }\end{array}$ & & & Other data & No numeric data \\
\hline $\begin{array}{l}7 \text { Mental state: } 3 \text {. Average } \\
\text { negative symptom score }\end{array}$ & & & Other data & No numeric data \\
\hline
\end{tabular}




\begin{tabular}{|c|c|c|c|c|}
\hline Outcome or subgroup title & No. of studies & No. of participants & Statistical method & Effect size \\
\hline \multicolumn{5}{|l|}{$\begin{array}{l}\text { (SANS endpoint, higher } \\
\text { scores=poor) (skewed data) }\end{array}$} \\
\hline $\begin{array}{l}7.1 \text { by } 3 \text { months - end of } \\
\text { treatment }\end{array}$ & & & Other data & No numeric data \\
\hline $\begin{array}{l}7.2 \text { by } 9 \text { months }-6 \\
\text { months after end of } \\
\text { treatment }\end{array}$ & & & Other data & No numeric data \\
\hline $\begin{array}{l}8 \text { Mental state: } 4 \text {. Average } \\
\text { score (BDI-SF total } \\
\text { endpoint, higher } \\
\text { scores=poor) (skewed data) }\end{array}$ & & & Other data & No numeric data \\
\hline $\begin{array}{l}8.1 \text { by } 3 \text { months - end of } \\
\text { treatment }\end{array}$ & & & Other data & No numeric data \\
\hline $\begin{array}{l}8.2 \text { by } 9 \text { months }-6 \\
\text { months after end of } \\
\text { treatment }\end{array}$ & & & Other data & No numeric data \\
\hline $\begin{array}{l}9 \text { Social functioning: } \\
\text { Average score (SOFAS } \\
\text { total endpoint, higher } \\
\text { scores=good) }\end{array}$ & 1 & & $\begin{array}{l}\text { Mean Difference (IV, } \\
\text { Fixed, 95\% CI) }\end{array}$ & Subtotals only \\
\hline $\begin{array}{l}9.1 \text { by } 3 \text { months - end of } \\
\text { treatment }\end{array}$ & 1 & 47 & $\begin{array}{l}\text { Mean Difference (IV, } \\
\text { Fixed, 95\% CI) }\end{array}$ & $-0.80[-9.95,8.35]$ \\
\hline $\begin{array}{l}9.2 \text { by } 9 \text { months }-6 \\
\text { months after end of } \\
\text { treatment }\end{array}$ & 1 & 47 & $\begin{array}{l}\text { Mean Difference (IV, } \\
\text { Fixed, 95\% CI) }\end{array}$ & $-4.70[-14.52,5.12]$ \\
\hline
\end{tabular}

Comparison 16

CRISIS ASSESSMENT versus STANDARD CARE (LEO-CAT)

\begin{tabular}{lllll}
\hline $\begin{array}{l}\text { Outcome or subgroup } \\
\text { title }\end{array}$ & No. of studies & No. of participants & Statistical method & Effect size \\
\hline 1 Hospitalisation & 1 & 98 & $\begin{array}{l}\text { Risk Ratio (M-H, Fixed, } \\
95 \% \text { CI) }\end{array}$ & $0.85[0.57,1.27]$ \\
$\begin{array}{l}\text { 2 Referred to Mental Health } \\
\begin{array}{l}\text { Services by A \& E or } \\
\text { emergency medical services }\end{array}\end{array}$ & 1 & 98 & $\begin{array}{l}\text { Risk Ratio (M-H, Fixed, } \\
95 \% \text { CI) }\end{array}$ & $0.85[0.57,1.27]$ \\
\hline
\end{tabular}

Comparison 17

EARLY BEHAVIOURAL INTERVENTION vs ROUTINE CARE INTERVAL (AlverezSpain)

\begin{tabular}{|c|c|c|c|c|}
\hline Outcome or subgroup title & No. of studies & No. of participants & Statistical method & Effect size \\
\hline 1 Weight & & & Other data & No numeric data \\
\hline 1.1 Weight change at 13 weeks & & & Other data & No numeric data \\
\hline 1.2 Body Mass Index & & & Other data & No numeric data \\
\hline
\end{tabular}


Comparison 18

PHASE-SPECIFIC INTERVENTION versus CONTROL (Exploratory meta-analysis)

\begin{tabular}{lllll}
\hline $\begin{array}{l}\text { Outcome or subgroup } \\
\text { title }\end{array}$ & No. of studies & No. of participants & Statistical method & Effect size \\
\hline $\begin{array}{l}\text { 1 Leaving the study } \\
\text { early }\end{array}$ & 3 & 192 & $\begin{array}{l}\text { Risk Ratio (M-H, Fixed, 95\% } \\
\text { CI) }\end{array}$ & 0.72 [0.41, 1.29] \\
2 Hospitalisation & 2 & 168 & $\begin{array}{l}\text { Risk Ratio (M-H, Fixed, 95\% } \\
\text { CI) }\end{array}$ & 0.97 [0.61, 1.54] \\
\hline
\end{tabular}

\section{Analysis 1.1. Comparison 1 PHASE SPECIFIC TREATMENT (OLANZAPINE) + NON-SPECIFIC SUPPORTIVE THERAPY vS PLACEBO + NON-SPECIFIC SUPPORTIVE, Outcome 1 Leaving the study early (for reasons other than psychosis)}

Review: Early intervention for psychosis

Comparison: 1 PHASE SPECIFIC TREATMENT (OLANZAPINE) + NON-SPECIFIC SUPPORTIVE THERAPY vs PLACEBO + NON-SPECIFIC SUPPORTIVE

Outcome: 1 Leaving the study early (for reasons other than psychosis)

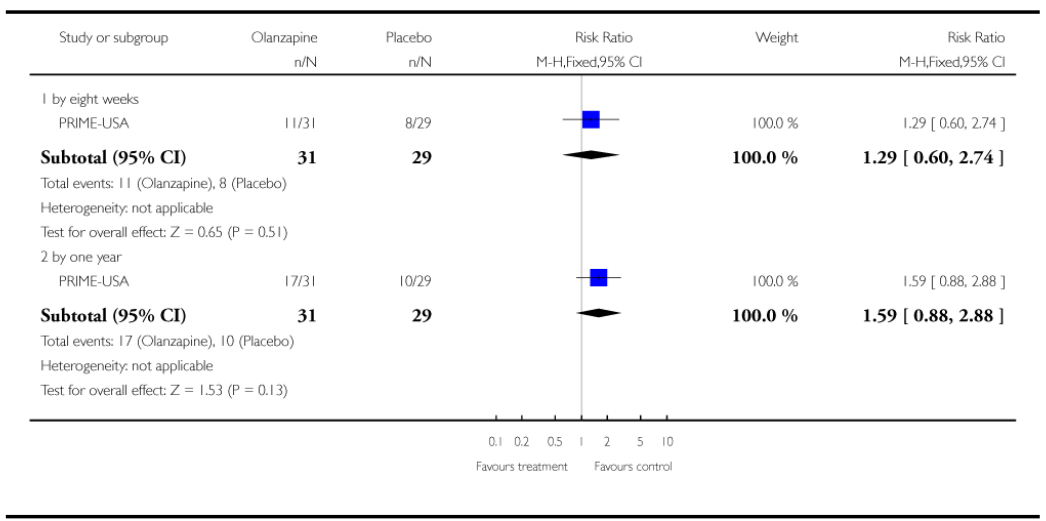

\section{Analysis 1.2. Comparison 1 PHASE SPECIFIC TREATMENT (OLANZAPINE) + NON-SPECIFIC SUPPORTIVE THERAPY vS PLACEBO + NON-SPECIFIC SUPPORTIVE, Outcome 2 Converted to psychosis: POPS}

Review: Early intervention for psychosis

Comparison: 1 PHASE SPECIFIC TREATMENT (OLANZAPINE) + NON-SPECIFIC

SUPPORTIVE THERAPY vs PLACEBO + NON-SPECIFIC SUPPORTIVE

Outcome: 2 Converted to psychosis: POPS 


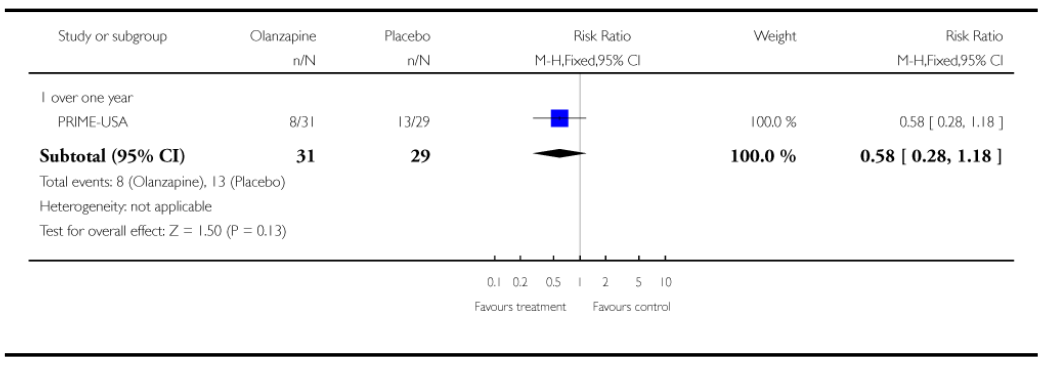

\section{Analysis 1.3. Comparison 1 PHASE SPECIFIC TREATMENT (OLANZAPINE) + NON-SPECIFIC SUPPORTIVE THERAPY vs PLACEBO + NON-SPECIFIC SUPPORTIVE, Outcome 3 Global state: 1. Average total change score - by 1 month (CGI-severity of illness, high score=worse)}

Review: Early intervention for psychosis

Comparison: 1 PHASE SPECIFIC TREATMENT (OLANZAPINE) + NON-SPECIFIC SUPPORTIVE THERAPY vs PLACEBO + NON-SPECIFIC SUPPORTIVE

Outcome: 3 Global state: 1 . Average total change score - by 1 month (CGI-severity of illness, high score=worse)

\begin{tabular}{|c|c|c|c|c|c|c|c|}
\hline \multirow[t]{2}{*}{ Study or subgroup } & \multirow{2}{*}{$\begin{array}{r}\text { Olanzapine } \\
\mathrm{N}\end{array}$} & \multicolumn{3}{|c|}{ Placebo } & $\begin{array}{c}\text { Mean } \\
\text { Difference }\end{array}$ & \multirow[t]{2}{*}{ Weight } & \multirow{2}{*}{$\begin{array}{r}\text { Mear } \\
\text { Difference } \\
\text { IV.Fixed,95\% C }\end{array}$} \\
\hline & & $\operatorname{Mean}(\mathrm{SD})$ & $\mathrm{N}$ & $\operatorname{Mean}(S D)$ & IV.Fixed.95\% Cl & & \\
\hline PRIME-USA & 30 & $3.63(1.06)$ & 29 & $3.86(1.23)$ & 7 & $100.0 \%$ & $-0.23[-0.82,0.36]$ \\
\hline Total $(95 \% \mathrm{CI})$ & 30 & & 29 & & & $100.0 \%$ & $-0.23[-0.82,0.36]$ \\
\hline \multicolumn{8}{|c|}{ Heterogeneity not applicable } \\
\hline \multicolumn{8}{|c|}{ Test for overall effect: $Z=0.77(P=0.44)$} \\
\hline \multicolumn{8}{|c|}{ Test for subgroup differences: Not applicable } \\
\hline & & & & & -0.5 & & \\
\hline
\end{tabular}

\section{Analysis 1.4. Comparison 1 PHASE SPECIFIC TREATMENT (OLANZAPINE) + NON-SPECIFIC SUPPORTIVE THERAPY vS PLACEBO + NON-SPECIFIC SUPPORTIVE, Outcome 4 Global state: 2. Average total change score - by 12 months (GAF-current, high score=good)}

Review: Early intervention for psychosis

Comparison: 1 PHASE SPECIFIC TREATMENT (OLANZAPINE) + NON-SPECIFIC SUPPORTIVE THERAPY vs PLACEBO + NON-SPECIFIC SUPPORTIVE 
Outcome: 4 Global state: 2. Average total change score - by 12 months (GAF-current, high score $=$ good)

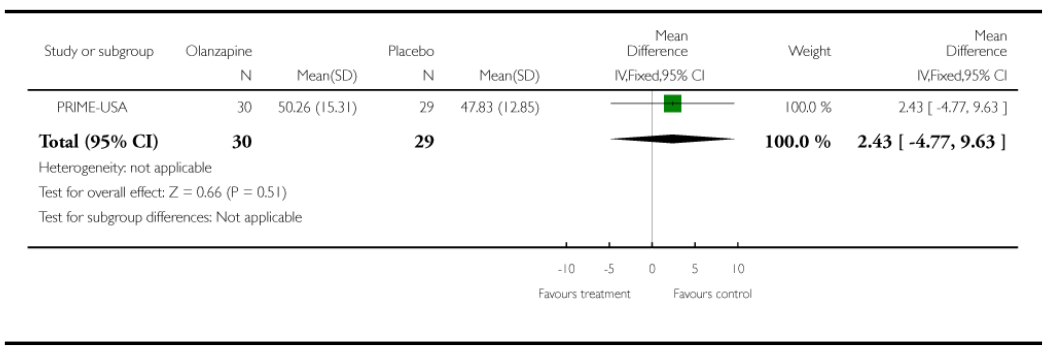

\section{Analysis 1.5. Comparison 1 PHASE SPECIFIC TREATMENT (OLANZAPINE) + NON-SPECIFIC SUPPORTIVE THERAPY vs PLACEBO + NON-SPECIFIC SUPPORTIVE, Outcome 5 Mental state: 1. Average total change score - by 12 months (SOPS, high score=worse)}

Review: Early intervention for psychosis

Comparison: 1 PHASE SPECIFIC TREATMENT (OLANZAPINE) + NON-SPECIFIC SUPPORTIVE THERAPY vs PLACEBO + NON-SPECIFIC SUPPORTIVE

Outcome: 5 Mental state: 1 . Average total change score - by 12 months (SOPS, high score $=$ worse) 


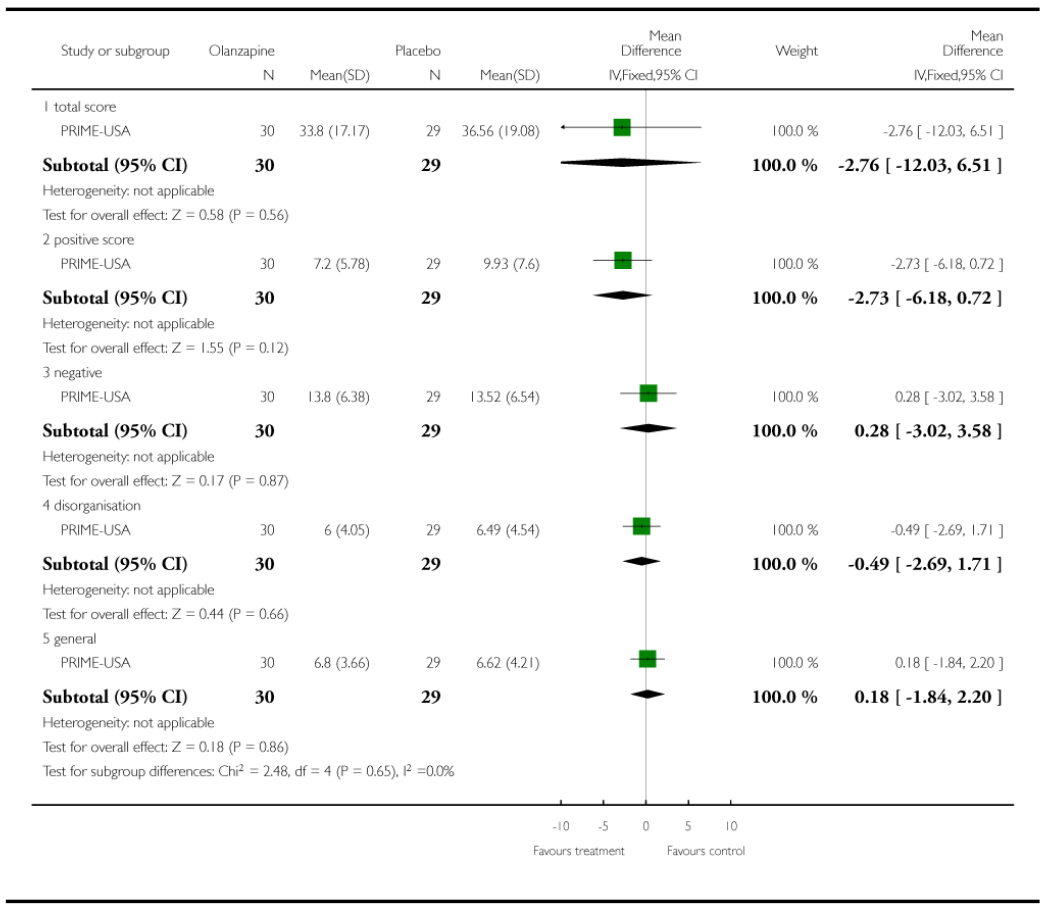

Analysis 1.6. Comparison 1 PHASE SPECIFIC TREATMENT (OLANZAPINE) + NON-SPECIFIC SUPPORTIVE THERAPY vs PLACEBO + NON-SPECIFIC SUPPORTIVE, Outcome 6 Mental state: 2. Average total change score - by 12 months (PANSS, high score=worse)

Review: Early intervention for psychosis

Comparison: 1 PHASE SPECIFIC TREATMENT (OLANZAPINE) + NON-SPECIFIC SUPPORTIVE THERAPY vs PLACEBO + NON-SPECIFIC SUPPORTIVE

Outcome: 6 Mental state: 2. Average total change score - by 12 months (PANSS, high score $=$ worse) 


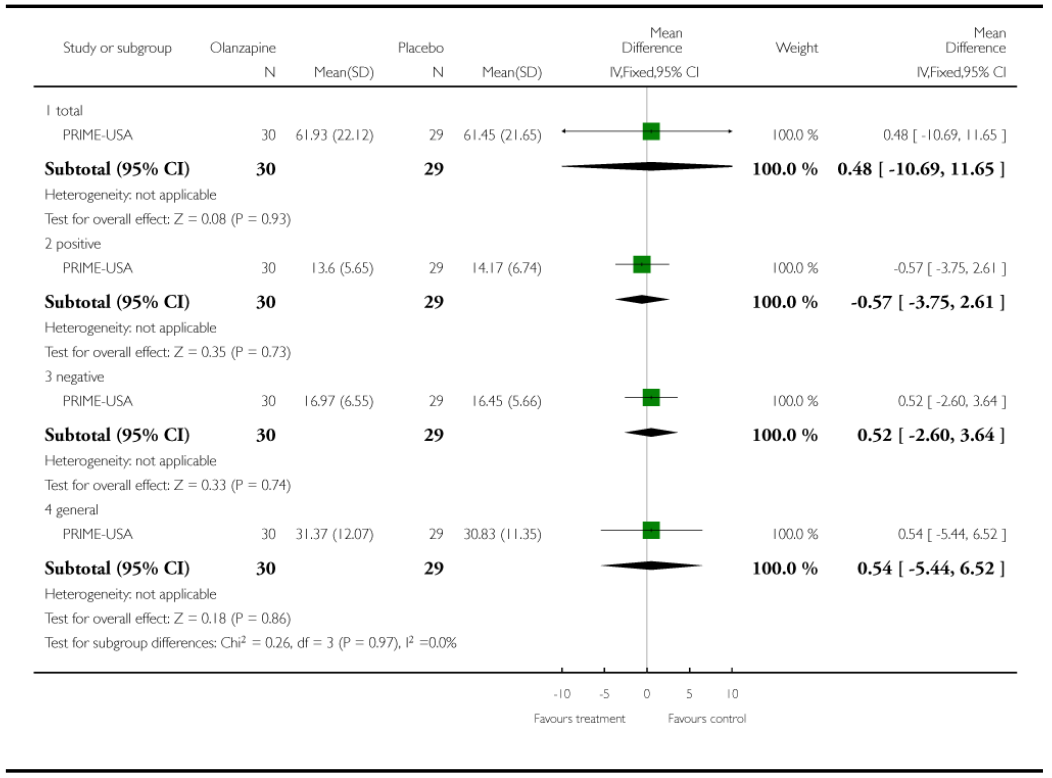

Analysis 1.7. Comparison 1 PHASE SPECIFIC TREATMENT (OLANZAPINE) + NON-SPECIFIC SUPPORTIVE THERAPY vs PLACEBO + NON-SPECIFIC SUPPORTIVE, Outcome 7 Mental state: 3. Average total change score - by 12 months (YMRS, high score=worse)

Review: Early intervention for psychosis

Comparison: 1 PHASE SPECIFIC TREATMENT (OLANZAPINE) + NON-SPECIFIC SUPPORTIVE THERAPY vs PLACEBO + NON-SPECIFIC SUPPORTIVE

Outcome: 7 Mental state: 3. Average total change score - by 12 months (YMRS, high score $=$ worse)

\begin{tabular}{|c|c|c|c|c|c|c|c|}
\hline \multirow[t]{2}{*}{ Study or subgroup } & \multirow{2}{*}{$\begin{array}{r}\text { Olanzapine } \\
N\end{array}$} & \multicolumn{3}{|c|}{ Placebo } & \multirow{2}{*}{$\begin{array}{c}\text { Mean } \\
\text { Difference } \\
\text { IVFixed } 95 \% \text { व }\end{array}$} & \multirow[t]{2}{*}{ Weight } & \multirow{2}{*}{$\begin{array}{r}\text { Mean } \\
\text { Difference } \\
\text { IV.Fixed,95\% CI }\end{array}$} \\
\hline & & $\operatorname{Mean}(S D)$ & N & $\operatorname{Mean}(S D)$ & & & \\
\hline PRIME-USA & 30 & $4.54(5.74)$ & 29 & $5.45(5.48)$ & $=$ & $100.0 \%$ & $-0.91[-3.77,1.95]$ \\
\hline Total $(95 \% \mathrm{CI})$ & 30 & & 29 & & & $100.0 \%$ & $-0.91[-3.77,1.95]$ \\
\hline \multicolumn{8}{|c|}{ Heterogeneity. not applicable } \\
\hline \multicolumn{8}{|c|}{ Test for overall effect: $Z=0.62(P=0.53)$} \\
\hline \multicolumn{8}{|c|}{ Test for subgroup differences: Not applicable } \\
\hline & & & & & 5 & & \\
\hline
\end{tabular}

Analysis 1.8. Comparison 1 PHASE SPECIFIC TREATMENT (OLANZAPINE) + NON-SPECIFIC SUPPORTIVE THERAPY vs PLACEBO + NON-SPECIFIC 
SUPPORTIVE, Outcome 8 Mental state: 4 . Average total change score - by 12 months (MADRS, high score=worse)

Review: Early intervention for psychosis

Comparison: 1 PHASE SPECIFIC TREATMENT (OLANZAPINE) + NON-SPECIFIC SUPPORTIVE THERAPY vs PLACEBO + NON-SPECIFIC SUPPORTIVE

Outcome: 8 Mental state: 4. Average total change score - by 12 months (MADRS, high score $=$ worse)

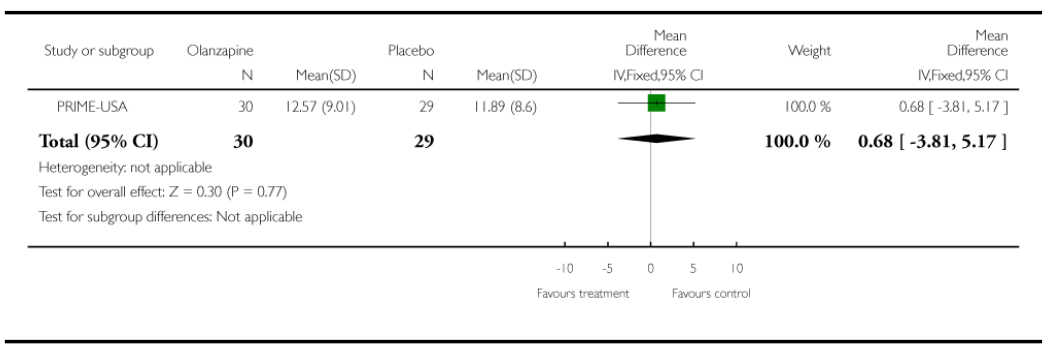

\section{Analysis 1.9. Comparison 1 PHASE SPECIFIC TREATMENT (OLANZAPINE) + NON-SPECIFIC SUPPORTIVE THERAPY vs PLACEBO + NON-SPECIFIC SUPPORTIVE, Outcome 9 Adverse effects: 1. Average total change score - by 8 weeks (SAS, high score=worse)}

Review: Early intervention for psychosis

Comparison: 1 PHASE SPECIFIC TREATMENT (OLANZAPINE) + NON-SPECIFIC SUPPORTIVE THERAPY vs PLACEBO + NON-SPECIFIC SUPPORTIVE

Outcome: 9 Adverse effects: 1. Average total change score - by 8 weeks (SAS, high score $=$ worse)

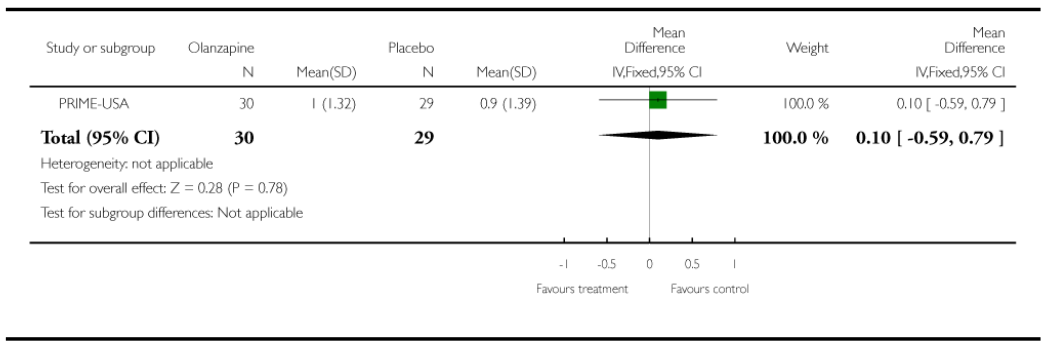

\section{Analysis 1.10. Comparison 1 PHASE SPECIFIC TREATMENT (OLANZAPINE) + NON-SPECIFIC SUPPORTIVE THERAPY vs PLACEBO +}


NON-SPECIFIC SUPPORTIVE, Outcome 10 Adverse effects: 2. Average total change score - by 8 weeks (BAS, high score=worse)

Review: Early intervention for psychosis

Comparison: 1 PHASE SPECIFIC TREATMENT (OLANZAPINE) + NON-SPECIFIC SUPPORTIVE THERAPY vs PLACEBO + NON-SPECIFIC SUPPORTIVE

Outcome: 10 Adverse effects: 2. Average total change score - by 8 weeks (BAS, high score $=$ worse)

\begin{tabular}{|c|c|c|c|c|c|c|c|}
\hline \multirow[t]{2}{*}{ Study or subgroup } & \multirow{2}{*}{$\begin{array}{r}\text { Olanzapine } \\
\mathrm{N}\end{array}$} & \multicolumn{3}{|c|}{ Placebo } & \multirow{2}{*}{$\begin{array}{c}\text { Mean } \\
\text { Difference } \\
\text { IV.Fixed,95\% CI }\end{array}$} & \multirow[t]{2}{*}{ Weight } & \multirow{2}{*}{$\begin{array}{r}\text { Mear } \\
\text { Difference } \\
\text { IV.Fixed,95\% C }\end{array}$} \\
\hline & & $\operatorname{Mean}(\mathrm{SD})$ & $\mathrm{N}$ & $\operatorname{Mean}(\mathrm{SD})$ & & & \\
\hline PRIME-USA & 30 & $0.9(2.3)$ & 29 & $0.4(1.92)$ & + & $100.0 \%$ & $0.50[-0.58,1.58]$ \\
\hline Total $(95 \% \mathrm{CI})$ & 30 & & 29 & & - & $100.0 \%$ & $0.50[-0.58,1.58]$ \\
\hline \multicolumn{8}{|c|}{ Heterogeneity, not applicable } \\
\hline \multicolumn{8}{|c|}{ Test for overall effect: $Z=0.91(P=0.36)$} \\
\hline Test for subgroup diff & ences: Not app & & & & & & \\
\hline
\end{tabular}

\section{Analysis 1.11. Comparison 1 PHASE SPECIFIC TREATMENT} (OLANZAPINE) + NON-SPECIFIC SUPPORTIVE THERAPY vs PLACEBO + NON-SPECIFIC SUPPORTIVE, Outcome 11 Adverse effects: 3. Average total change score - by 8 weeks (AIMS, high score=worse)

Review: Early intervention for psychosis

Comparison: 1 PHASE SPECIFIC TREATMENT (OLANZAPINE) + NON-SPECIFIC SUPPORTIVE THERAPY vs PLACEBO + NON-SPECIFIC SUPPORTIVE

Outcome: 11 Adverse effects: 3. Average total change score - by 8 weeks (AIMS, high score $=$ worse)

\begin{tabular}{|c|c|c|c|c|c|c|c|}
\hline \multirow[t]{2}{*}{ Study or subgroup } & \multirow{2}{*}{$\begin{array}{r}\text { Olanzapine } \\
N\end{array}$} & \multicolumn{3}{|c|}{ Placebo } & \multirow{2}{*}{$\begin{array}{c}\text { Mean } \\
\text { Difference } \\
\text { IV,Fixed,95\% Cl }\end{array}$} & \multirow[t]{2}{*}{ Weight } & \multirow{2}{*}{$\begin{array}{r}\text { Mean } \\
\text { Difference } \\
\text { IV,Fixed,95\% C }\end{array}$} \\
\hline & & $\operatorname{Mean}(\mathrm{SD})$ & $\mathrm{N}$ & $\operatorname{Mean}(\mathrm{SD})$ & & & \\
\hline PRIME-USA & 30 & $0.9(2.4)$ & 29 & $0.3(1.05)$ & $\longrightarrow$ & $100.0 \%$ & $0.60[-0.34,1.54]$ \\
\hline Total $(95 \% \mathrm{CI})$ & 30 & & 29 & & & $100.0 \%$ & $0.60[-0.34,1.54]$ \\
\hline \multicolumn{8}{|c|}{ Heterogeneity not applicable } \\
\hline \multirow{2}{*}{\multicolumn{8}{|c|}{$\begin{array}{l}\text { Test for overall effect: } Z=1.25(P=0.21) \\
\text { Test for subgroup differences: Not applicable }\end{array}$}} \\
\hline Test for subgroup diff & rences: Not app & & & & & & \\
\hline
\end{tabular}

Analysis 1.12. Comparison 1 PHASE SPECIFIC TREATMENT (OLANZAPINE) + NON-SPECIFIC SUPPORTIVE THERAPY vS PLACEBO + 
NON-SPECIFIC SUPPORTIVE, Outcome 12 Adverse effects: 4. Average total weight change score $(\mathrm{kg})$ - by 12 months

Review: Early intervention for psychosis

Comparison: 1 PHASE SPECIFIC TREATMENT (OLANZAPINE) + NON-SPECIFIC SUPPORTIVE THERAPY vs PLACEBO + NON-SPECIFIC SUPPORTIVE

Outcome: 12 Adverse effects: 4 . Average total weight change score $(\mathrm{kg})$ - by 12 months

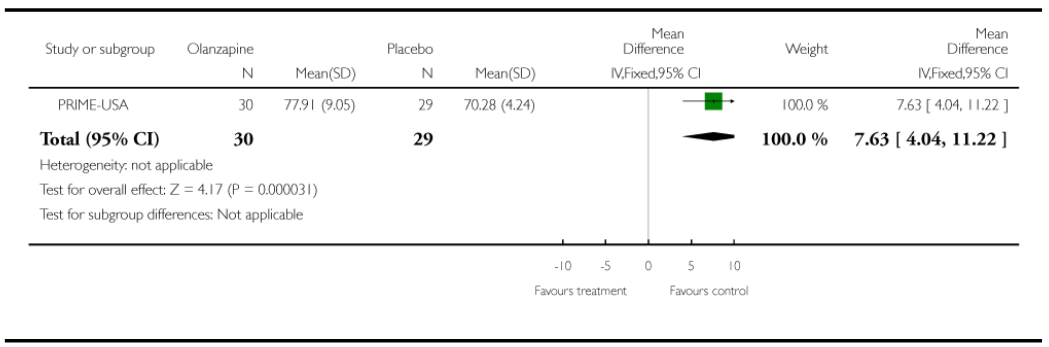

\title{
Analysis 1.13. Comparison 1 PHASE SPECIFIC TREATMENT (OLANZAPINE) + NON-SPECIFIC SUPPORTIVE THERAPY vs PLACEBO +
} NON-SPECIFIC SUPPORTIVE, Outcome 13 Adverse effects: 5. Weight gain by 12 months

\author{
Review: Early intervention for psychosis \\ Comparison: 1 PHASE SPECIFIC TREATMENT (OLANZAPINE) + NON-SPECIFIC \\ SUPPORTIVE THERAPY vs PLACEBO + NON-SPECIFIC SUPPORTIVE \\ Outcome: 13 Adverse effects: 5. Weight gain - by 12 months
}

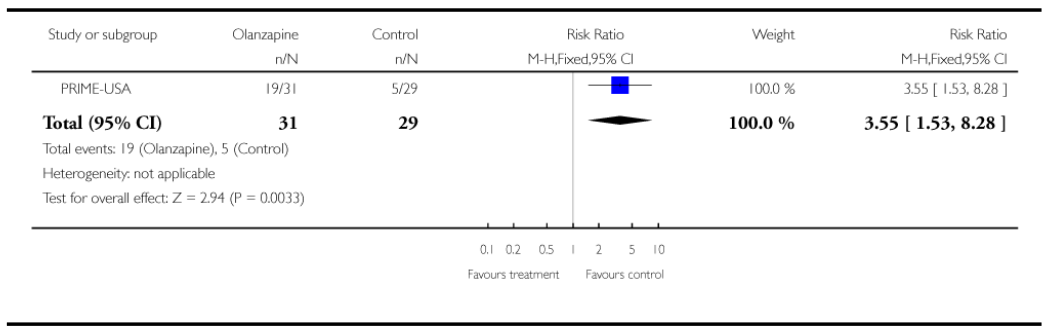

\section{Analysis 1.14. Comparison 1 PHASE SPECIFIC TREATMENT (OLANZAPINE) + NON-SPECIFIC SUPPORTIVE THERAPY vs PLACEBO +}




\section{NON-SPECIFIC SUPPORTIVE, Outcome 14 Adverse effects: 6. Average total change score - by 8 weeks (Cardiovascular)}

Review: Early intervention for psychosis

Comparison: 1 PHASE SPECIFIC TREATMENT (OLANZAPINE) + NON-SPECIFIC

SUPPORTIVE THERAPY vs PLACEBO + NON-SPECIFIC SUPPORTIVE

Outcome: 14 Adverse effects: 6. Average total change score - by 8 weeks (Cardiovascular)

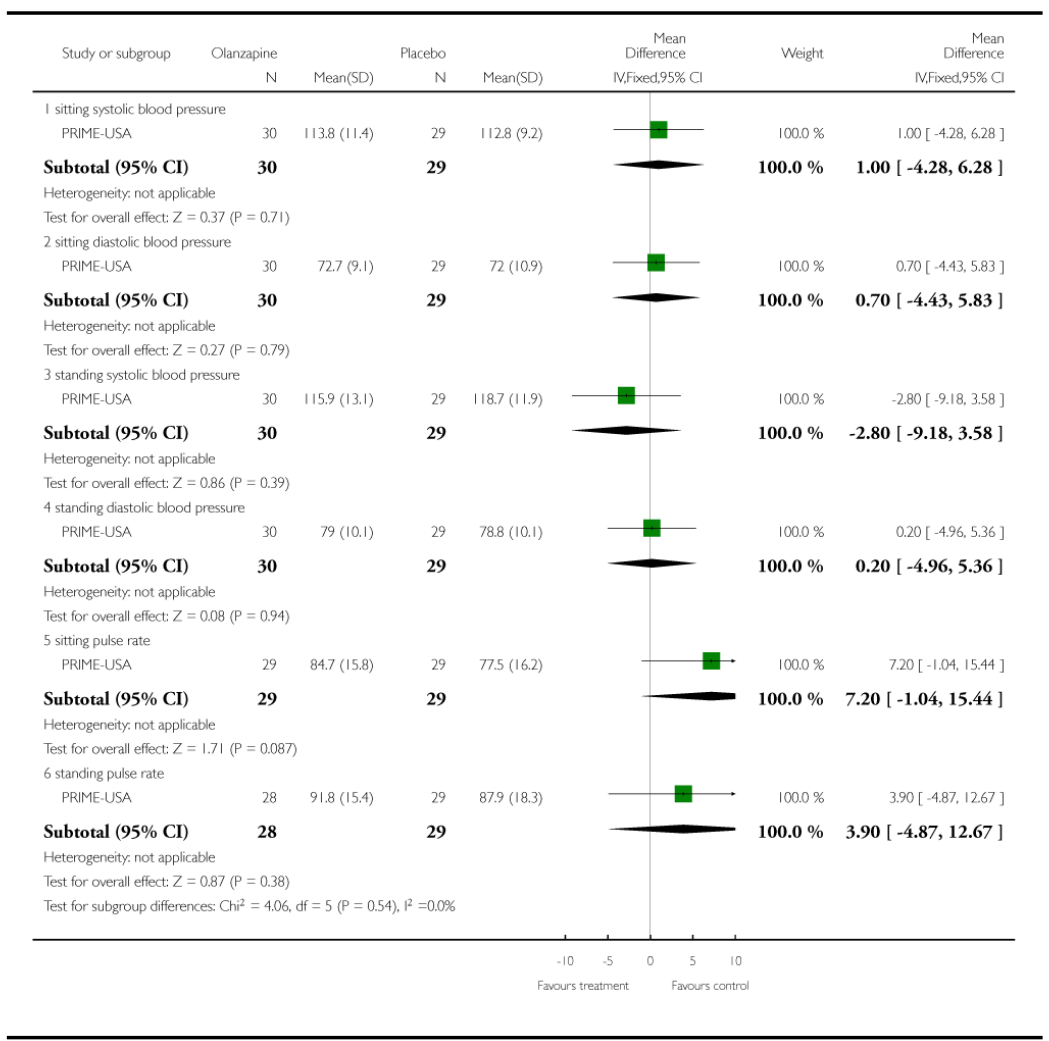

\section{Analysis 1.15. Comparison 1 PHASE SPECIFIC TREATMENT (OLANZAPINE) + NON-SPECIFIC SUPPORTIVE THERAPY vs PLACEBO +} NON-SPECIFIC SUPPORTIVE, Outcome 15 Adverse effects: 7. Average total change score - by 12 months (Pulse, BPM)

Review: Early intervention for psychosis

Comparison: 1 PHASE SPECIFIC TREATMENT (OLANZAPINE) + NON-SPECIFIC

SUPPORTIVE THERAPY vs PLACEBO + NON-SPECIFIC SUPPORTIVE

Outcome: 15 Adverse effects: 7. Average total change score - by 12 months (Pulse, BPM) 


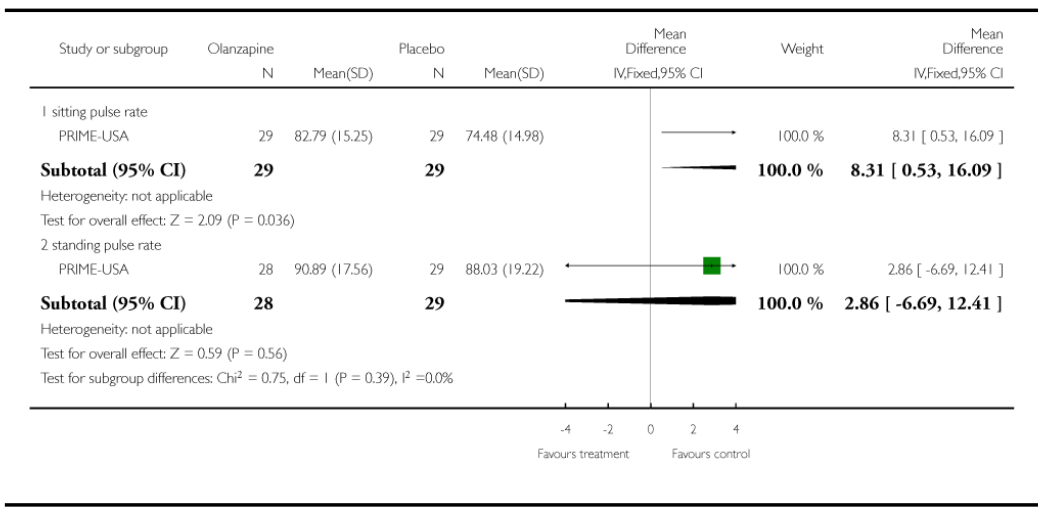

Analysis 1.16. Comparison 1 PHASE SPECIFIC TREATMENT (OLANZAPINE) + NON-SPECIFIC SUPPORTIVE THERAPY vS PLACEBO + NON-SPECIFIC SUPPORTIVE, Outcome 16 Adverse effects: 8. Treatment emergent adverse events - by 8 weeks (CoStart Term)

Review: Early intervention for psychosis

Comparison: 1 PHASE SPECIFIC TREATMENT (OLANZAPINE) + NON-SPECIFIC SUPPORTIVE THERAPY vs PLACEBO + NON-SPECIFIC SUPPORTIVE

Outcome: 16 Adverse effects: 8 . Treatment emergent adverse events - by 8 weeks (CoStart Term) 


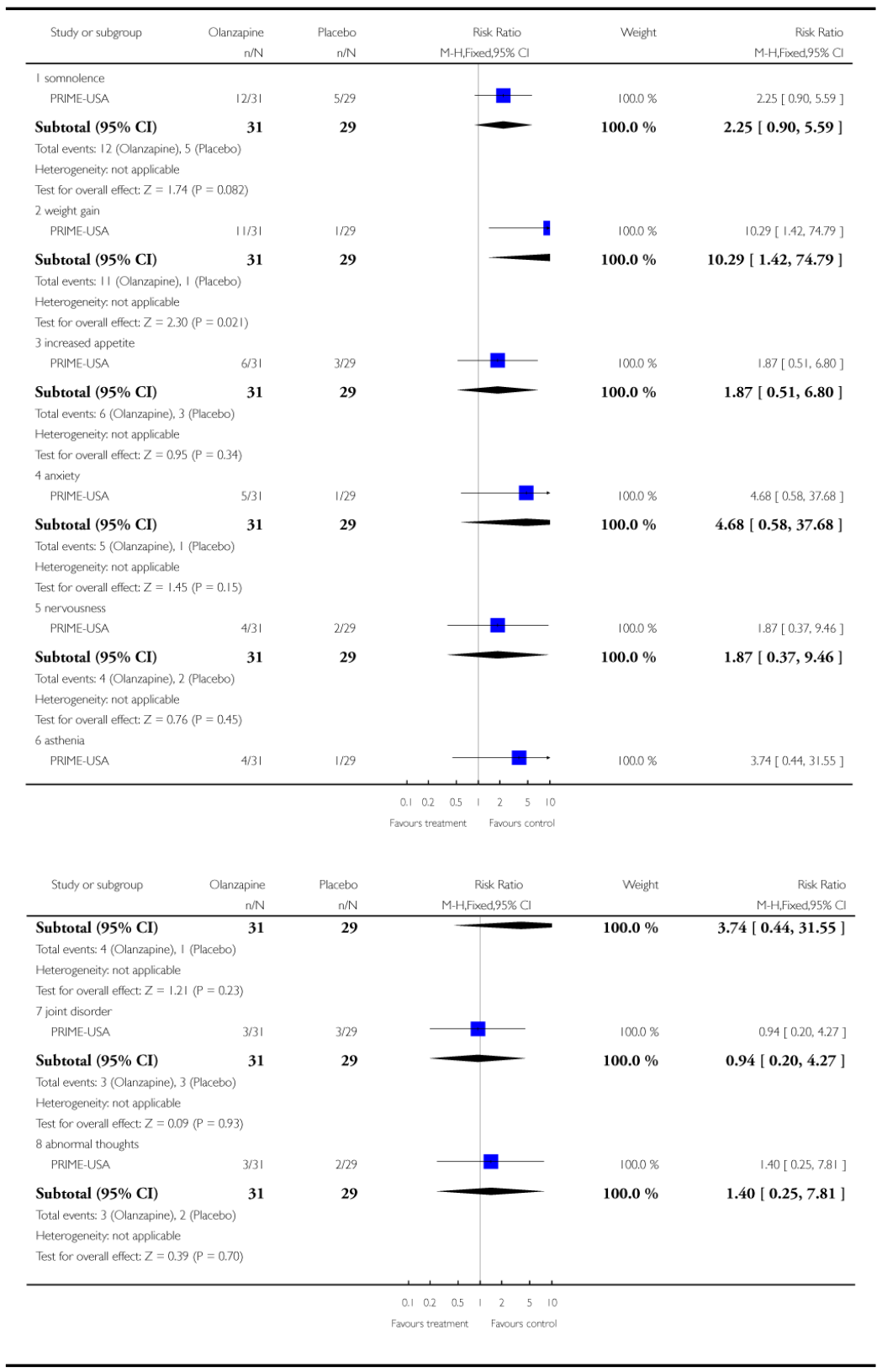

Analysis 1.17. Comparison 1 PHASE SPECIFIC TREATMENT (OLANZAPINE) + NON-SPECIFIC SUPPORTIVE THERAPY vS PLACEBO + NON-SPECIFIC SUPPORTIVE, Outcome 17 Adverse effects: 9. Fatigue - by 12 months

Review: Early intervention for psychosis 
Comparison: 1 PHASE SPECIFIC TREATMENT (OLANZAPINE) + NON-SPECIFIC

SUPPORTIVE THERAPY vs PLACEBO + NON-SPECIFIC SUPPORTIVE

Outcome: 17 Adverse effects: 9. Fatigue - by 12 months

\begin{tabular}{|c|c|c|c|c|c|c|}
\hline Study or subgroup & $\begin{array}{r}\text { Olanzapine } \\
\mathrm{n} / \mathrm{N}\end{array}$ & $\begin{array}{r}\text { Placebo } \\
\mathrm{n} / \mathrm{N}\end{array}$ & \multicolumn{2}{|c|}{$\begin{array}{c}\text { Risk Ratio } \\
\text { M-H,Fixed,95\% Cl } \\
\end{array}$} & Weight & $\begin{array}{r}\text { Risk Ratio } \\
\text { M-H,Fixed,95\% C } \\
\end{array}$ \\
\hline PRIME-USA & $9 / 31$ & $1 / 29$ & & $\longrightarrow$ & $100.0 \%$ & $8.42[1.14,62.40]$ \\
\hline \multirow{6}{*}{\multicolumn{2}{|c|}{$\begin{array}{l}\text { Total (95\% CI) } \\
\text { Total events: } 9 \text { (Olanzapine), I (Placebo) } \\
\text { Heterogeneity, not applicable } \\
\text { Test for overall effect: } Z=208 \text { ( } P=0.037)\end{array}$}} & 29 & & 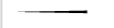 & $100.0 \%$ & $8.42[1.14,62.40]$ \\
\hline & & & & & & \\
\hline & & & & & & \\
\hline & & & & & & \\
\hline & & & $0.5 \quad 0.7$ & $1.5 \quad 2$ & & \\
\hline & & & Favours treatment & Fawours control & & \\
\hline
\end{tabular}

\section{Analysis 2.1. Comparison 2 PHASE SPECIFIC TREATMENT (CBT) + NON- SPECIFIC SUPPORTIVE THERAPY vS NON-SPECIFIC SUPPORTIVE THERAPY, Outcome 1 Leaving the study early}

Review: Early intervention for psychosis

Comparison: 2 PHASE SPECIFIC TREATMENT (CBT) + NON-SPECIFIC SUPPORTIVE THERAPY vs NON-SPECIFIC SUPPORTIVE THERAPY

Outcome: 1 Leaving the study early

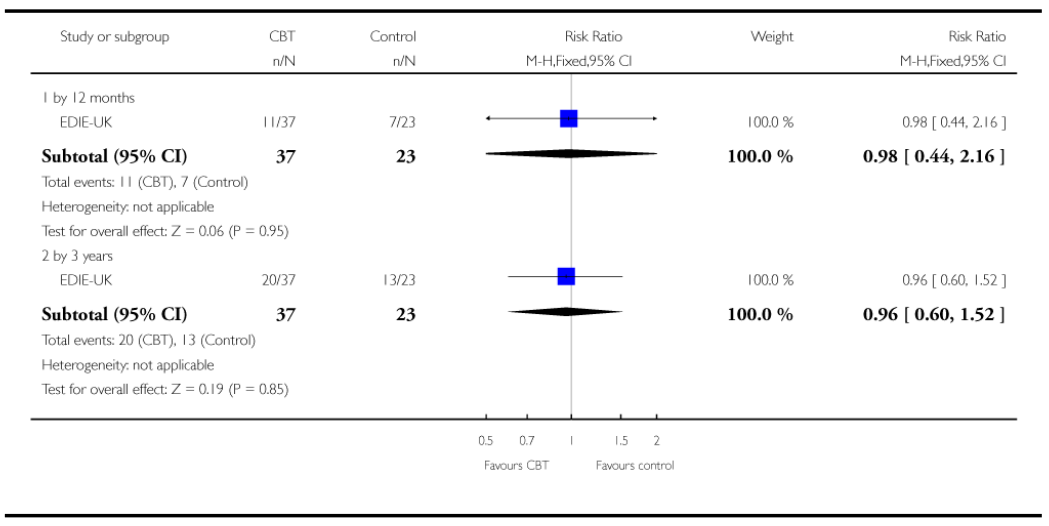

\section{Analysis 2.2. Comparison 2 PHASE SPECIFIC TREATMENT (CBT) + NON- SPECIFIC SUPPORTIVE THERAPY vS NON-SPECIFIC SUPPORTIVE THERAPY, Outcome 2 Transition to psychosis - by 12 months}

Review: Early intervention for psychosis 
Comparison: 2 PHASE SPECIFIC TREATMENT (CBT) + NON-SPECIFIC SUPPORTIVE THERAPY vs NON-SPECIFIC SUPPORTIVE THERAPY

Outcome: 2 Transition to psychosis - by 12 months

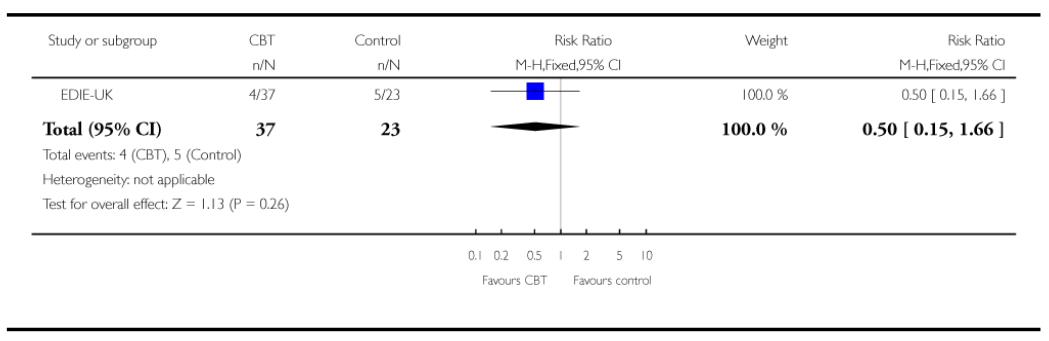

\section{Analysis 2.3. Comparison 2 PHASE SPECIFIC TREATMENT (CBT) + NON- SPECIFIC SUPPORTIVE THERAPY vS NON-SPECIFIC SUPPORTIVE THERAPY, Outcome 3 Social Functioning: 1. SAS II endpoint data (long term, high score=worse, LOCF)}

Review: Early intervention for psychosis

Comparison: 2 PHASE SPECIFIC TREATMENT (CBT) + NON-SPECIFIC SUPPORTIVE THERAPY vs NON-SPECIFIC SUPPORTIVE THERAPY

Outcome: 3 Social Functioning: 1. SAS II endpoint data (long term, high score=worse, LOCF)

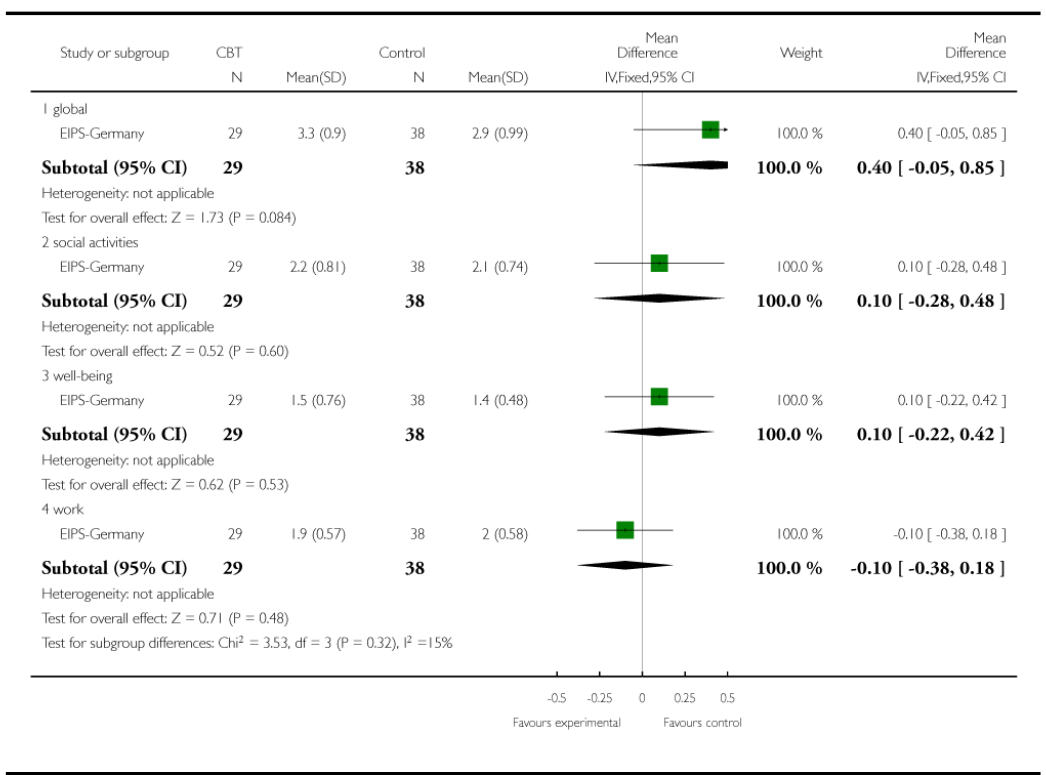




\section{Analysis 3.1. Comparison 3 PHASE SPECIFIC TREATMENT (RISPERIDONE + CBT) + SPECIALISED TEAM vs SPECIALISED TEAM, Outcome 1 Leaving the study early - by 12 months}

Review: Early intervention for psychosis

Comparison: 3 PHASE SPECIFIC TREATMENT (RISPERIDONE + CBT) + SPECIALISED TEAM vs SPECIALISED TEAM

Outcome: 1 Leaving the study early - by 12 months

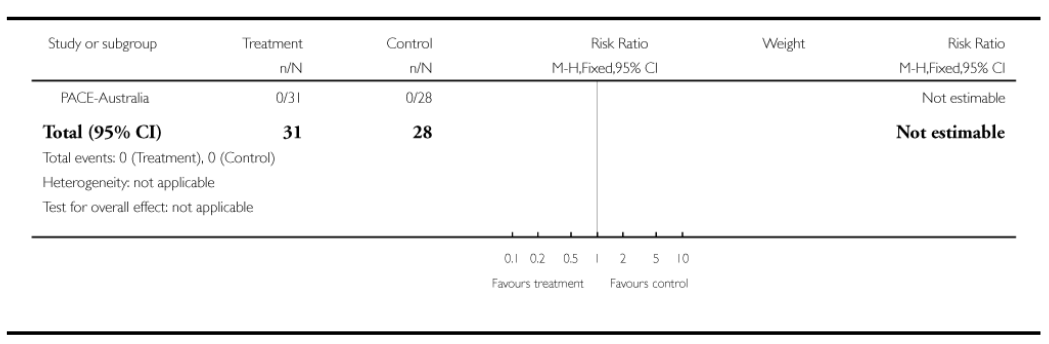

\section{Analysis 3.2. Comparison 3 PHASE SPECIFIC TREATMENT (RISPERIDONE + CBT) + SPECIALISED TEAM vs SPECIALISED TEAM, Outcome 2 Progression to psychosis}

Review: Early intervention for psychosis

Comparison: 3 PHASE SPECIFIC TREATMENT (RISPERIDONE + CBT) + SPECIALISED TEAM vs SPECIALISED TEAM

Outcome: 2 Progression to psychosis

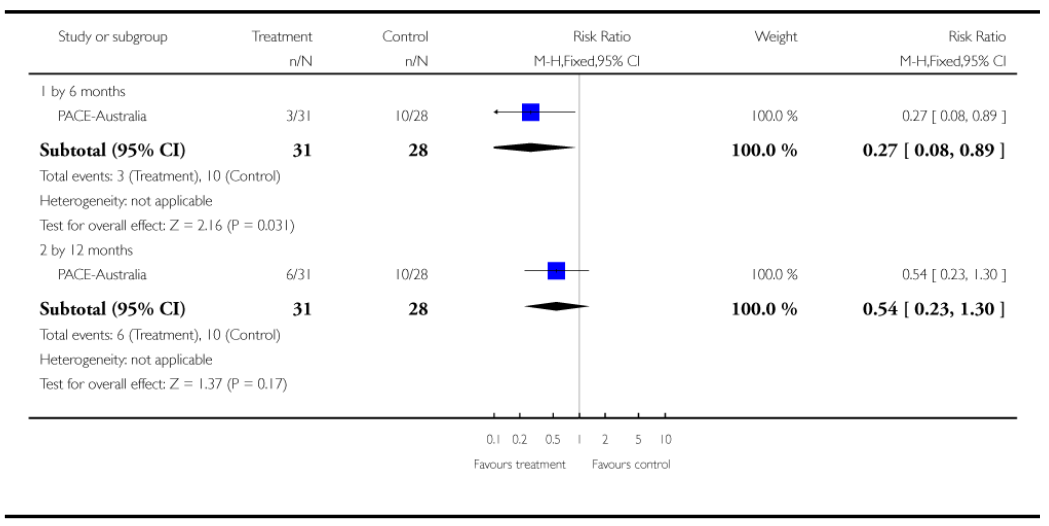




\section{Analysis 3.3. Comparison 3 PHASE SPECIFIC TREATMENT (RISPERIDONE + CBT) + SPECIALISED TEAM vs SPECIALISED TEAM, Outcome 3 Global state: Average endpoint score (GAF, high score=worse)}

Review: Early intervention for psychosis

Comparison: 3 PHASE SPECIFIC TREATMENT (RISPERIDONE + CBT) + SPECIALISED TEAM vs SPECIALISED TEAM

Outcome: 3 Global state: Average endpoint score $(\mathrm{GAF}$, high score=worse)

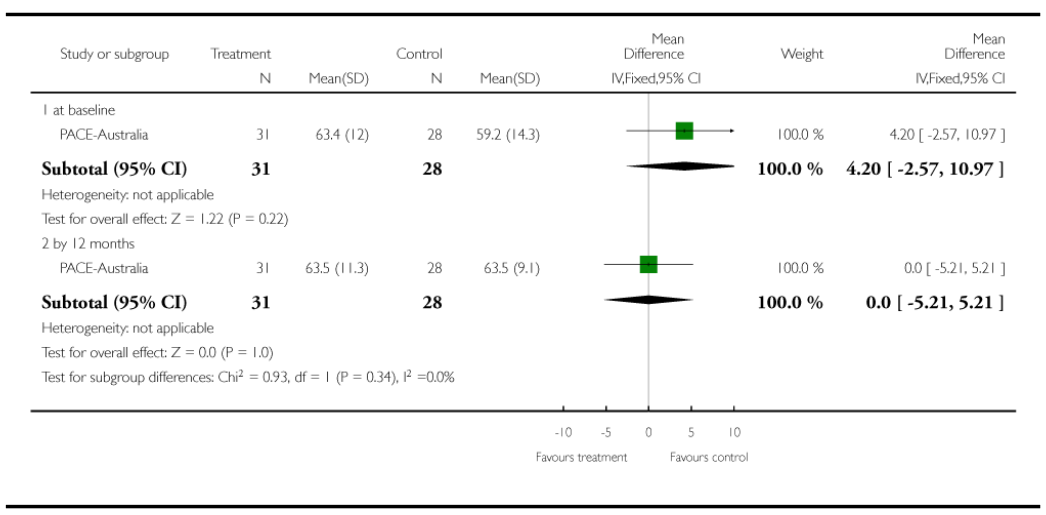

\section{Analysis 3.4. Comparison 3 PHASE SPECIFIC TREATMENT (RISPERIDONE + CBT) + SPECIALISED TEAM vs SPECIALISED TEAM, Outcome 4 Mental state: 1a. Average endpoint score (BPRS psychotic symptoms -general, high score=worse, skewed data)}

Review: Early intervention for psychosis

Comparison: 3 PHASE SPECIFIC TREATMENT (RISPERIDONE + CBT) + SPECIALISED TEAM vs SPECIALISED TEAM

Outcome: 4 Mental state: 1a. Average endpoint score (BPRS psychotic symptoms -general, high score=worse, skewed data) 


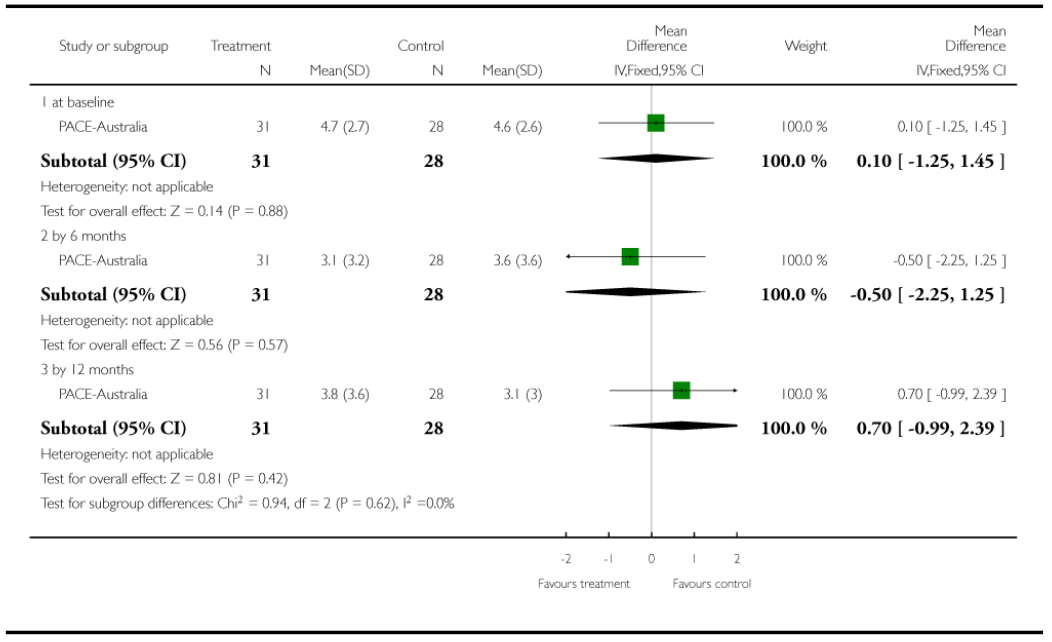

\section{Analysis 3.5. Comparison 3 PHASE SPECIFIC TREATMENT (RISPERIDONE + CBT) + SPECIALISED TEAM vs SPECIALISED TEAM, Outcome 5 Mental state: 1b. Average endpoint score (SANS, psychotic symptoms - negative, high score=worse, skewed data)}

Review: Early intervention for psychosis

Comparison: 3 PHASE SPECIFIC TREATMENT (RISPERIDONE + CBT) + SPECIALISED TEAM vs SPECIALISED TEAM

Outcome: 5 Mental state: $1 \mathrm{~b}$. Average endpoint score (SANS, psychotic symptoms negative, high score $=$ worse, skewed data)

\begin{tabular}{|c|c|c|c|c|c|c|c|}
\hline \multirow[t]{2}{*}{ Study or subgroup } & \multirow{2}{*}{$\begin{array}{r}\text { Treatment } \\
\text { N }\end{array}$} & \multicolumn{3}{|c|}{ Control } & \multirow{2}{*}{$\begin{array}{c}\text { Mean } \\
\text { Difference } \\
\text { IV.Fixed,95\% Cl } \\
\end{array}$} & \multirow[t]{2}{*}{ Weight } & \multirow{2}{*}{$\begin{array}{r}\text { Mean } \\
\text { Difference } \\
\text { IV,Fixed,95\% Cl }\end{array}$} \\
\hline & & $\operatorname{Mean}(S D)$ & $\mathrm{N}$ & $\operatorname{Mean}(\mathrm{SD})$ & & & \\
\hline \multicolumn{8}{|l|}{ I at baseline } \\
\hline PACE-Australia & 31 & $18(11.2)$ & 28 & $21.2(14.3)$ & + & $100.0 \%$ & $-3.20[-9.80,3.40]$ \\
\hline Subtotal $(95 \% \mathrm{CI})$ & 31 & & 28 & & & $100.0 \%$ & $-3.20[-9.80,3.40]$ \\
\hline \multicolumn{8}{|c|}{ Heterogeneity, not applicable } \\
\hline \multicolumn{8}{|c|}{ Test for overall effect: $Z=0.95(P=0.34)$} \\
\hline \multicolumn{8}{|c|}{2 by 6 months } \\
\hline PACE-Australia & 31 & $15.5(11.5)$ & 28 & $20.1(19)$ & 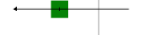 & $100.0 \%$ & $-4.60[-12.72,3.52]$ \\
\hline Subtotal $(95 \% \mathrm{CI})$ & 31 & & 28 & & & $100.0 \%$ & $-4.60[-12.72,3.52]$ \\
\hline \multicolumn{8}{|c|}{ Heterogeneity, not applicable } \\
\hline \multicolumn{8}{|c|}{ Test for overall effect: $Z=1.11(P=0.27)$} \\
\hline \multicolumn{8}{|c|}{3 by 12 months } \\
\hline PACE-Australia & 31 & $16.8(14.3)$ & 28 & $17.6(13.4)$ & $\Rightarrow$ & $100.0 \%$ & $-0.80[-7.87,6.27]$ \\
\hline Subtotal $(95 \% \mathrm{CI})$ & 31 & & 28 & & & $100.0 \%$ & $-0.80[-7.87,6.27]$ \\
\hline \multicolumn{8}{|l|}{ Heterogeneity. not applicable } \\
\hline \multicolumn{8}{|c|}{ Test for overall effect: $Z=0.22(P=0.82)$} \\
\hline \multicolumn{8}{|c|}{ Test for subgroup differences: $C \mathrm{hi}^{2}=0.51$, df $=2(\mathrm{P}=0.78), \mathrm{I}^{2}=0.0 \%$} \\
\hline & & & & & $\begin{array}{cccc}-10 & -5 & 0 & 5 \\
\text { lours treatment } & \text { Favour }\end{array}$ & & \\
\hline
\end{tabular}




\section{Analysis 3.6. Comparison 3 PHASE SPECIFIC TREATMENT (RISPERIDONE + CBT) + SPECIALISED TEAM vs SPECIALISED TEAM, Outcome 6 Mental state: 2a. Average endpoint score anxiety (HRSA, high score=worse, skewed data)}

Review: Early intervention for psychosis

Comparison: 3 PHASE SPECIFIC TREATMENT (RISPERIDONE + CBT) + SPECIALISED TEAM vs SPECIALISED TEAM

Outcome: 6 Mental state: 2a. Average endpoint score anxiety (HRSA, high score=worse, skewed data)

\begin{tabular}{|c|c|c|c|c|c|c|c|}
\hline \multirow[t]{2}{*}{ Study or subgroup } & \multirow{2}{*}{$\begin{array}{r}\text { Treatment } \\
\mathrm{N}\end{array}$} & \multicolumn{3}{|c|}{ Control } & \multirow{2}{*}{$\begin{array}{c}\text { Mean } \\
\text { Difference } \\
\text { IV.Fixed,95\% CI }\end{array}$} & \multirow[t]{2}{*}{ Weight } & \multirow{2}{*}{$\begin{array}{r}\text { Mean } \\
\text { Difference } \\
\text { v.Fixixd,95\% C }\end{array}$} \\
\hline & & $\operatorname{Mean}(S D)$ & N & $\operatorname{Mean}(\mathrm{SD})$ & & & \\
\hline \multicolumn{8}{|l|}{ I at baseline } \\
\hline PACE-Australia & 31 & $16.1(7)$ & 28 & $16.8(9)$ & 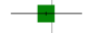 & $100.0 \%$ & $-0.70[-4.85,3.45]$ \\
\hline Subtotal $(95 \% \mathrm{CI})$ & 31 & & 28 & & 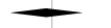 & $100.0 \%$ & $-0.70[-4.85,3.45]$ \\
\hline \multicolumn{8}{|c|}{ Heterogeneity. not applicable } \\
\hline \multicolumn{8}{|c|}{ Test for overall effect: $Z=0.33(P=0.74)$} \\
\hline \multicolumn{8}{|c|}{2 by 6 months } \\
\hline PACE-Australia & 31 & $10.1(5.6)$ & 28 & $11.2(8.5)$ & $\Rightarrow$ & $100.0 \%$ & $-1.10[-4.81,2.61]$ \\
\hline Subtotal $(95 \% \mathrm{CI})$ & 31 & & 28 & & & $100.0 \%$ & $-1.10[-4.81,2.61]$ \\
\hline \multicolumn{8}{|c|}{ Heterogeneity, not applicable } \\
\hline \multicolumn{8}{|c|}{ Test for overall effect: $Z=0.58(P=0.56)$} \\
\hline \multicolumn{8}{|c|}{3 by 12 months } \\
\hline PACE-Australia & 31 & $11.5(9.3)$ & 28 & $10.9(9.4)$ & & $100.0 \%$ & $0.60[-4.18,5.38]$ \\
\hline Subtotal $(95 \% \mathrm{CI})$ & 31 & & 28 & & & $100.0 \%$ & $0.60[-4.18,5.38]$ \\
\hline \multicolumn{8}{|c|}{ Heterogeneity, not applicable } \\
\hline \multicolumn{8}{|c|}{ Test for overall effect: $Z=0.25(P=0.81)$} \\
\hline \multicolumn{8}{|c|}{ Test for subgroup differences: $C h i^{2}=0.31$, df $=2(P=0.86), I^{2}=0.0 \%$} \\
\hline & & & & & $\begin{array}{lll}-5 & 0 & 5\end{array}$ & & \\
\hline & & & & & eatment Favours & & \\
\hline
\end{tabular}

\section{Analysis 3.7. Comparison 3 PHASE SPECIFIC TREATMENT (RISPERIDONE + CBT) + SPECIALISED TEAM vs SPECIALISED TEAM, Outcome 7 Mental state: 2b. Average endpoint score depression (HRSD, high score=worse, skewed data)}

Review: Early intervention for psychosis

Comparison: 3 PHASE SPECIFIC TREATMENT (RISPERIDONE + CBT) + SPECIALISED TEAM vs SPECIALISED TEAM

Outcome: 7 Mental state: 2b. Average endpoint score depression (HRSD, high score=worse, skewed data) 


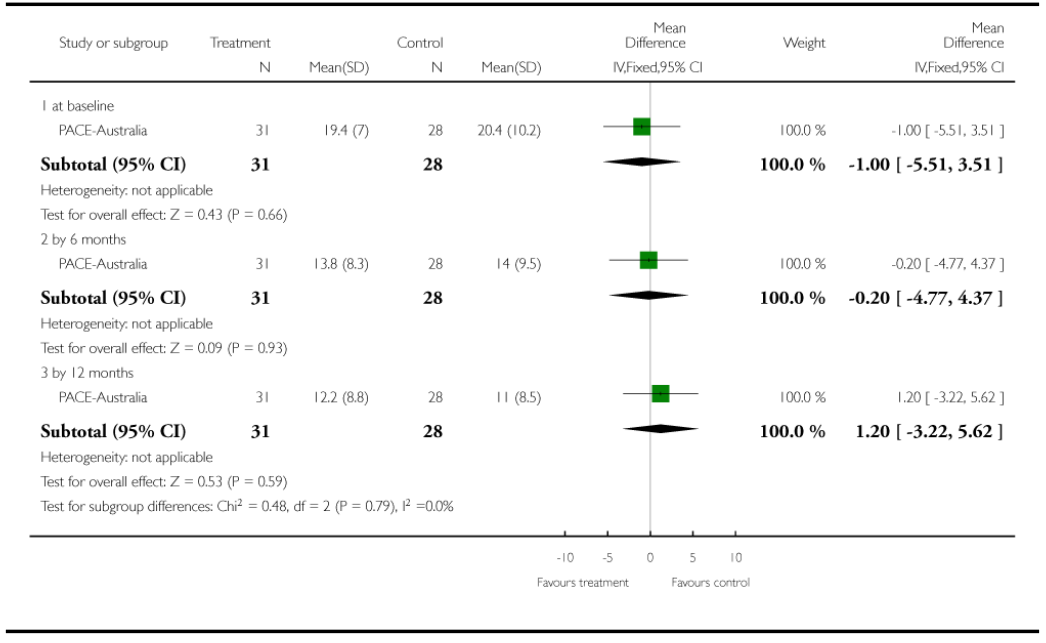

\section{Analysis 3.8. Comparison 3 PHASE SPECIFIC TREATMENT (RISPERIDONE + CBT) + SPECIALISED TEAM vs SPECIALISED TEAM, Outcome 8 Mental state: 2c. Average endpoint score mania (YMS, high score=worse, skewed data)}

Review: Early intervention for psychosis

Comparison: 3 PHASE SPECIFIC TREATMENT (RISPERIDONE + CBT) + SPECIALISED TEAM vs SPECIALISED TEAM

Outcome: 8 Mental state: 2c. Average endpoint score mania (YMS, high score=worse, skewed data)

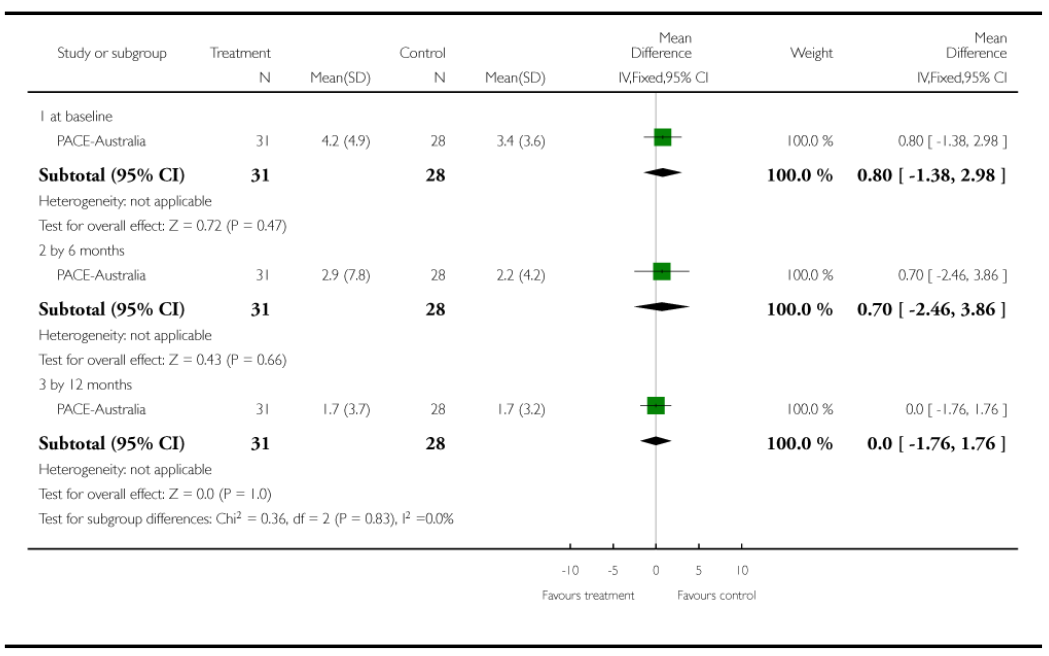




\section{Analysis 3.9. Comparison 3 PHASE SPECIFIC TREATMENT (RISPERIDONE + CBT) + SPECIALISED TEAM vs SPECIALISED TEAM, Outcome 9 Quality of life: Average endpoint score (QLS, high score=worse)}

Review: Early intervention for psychosis

Comparison: 3 PHASE SPECIFIC TREATMENT (RISPERIDONE + CBT) + SPECIALISED TEAM vs SPECIALISED TEAM

Outcome: 9 Quality of life: Average endpoint score (QLS, high score=worse)

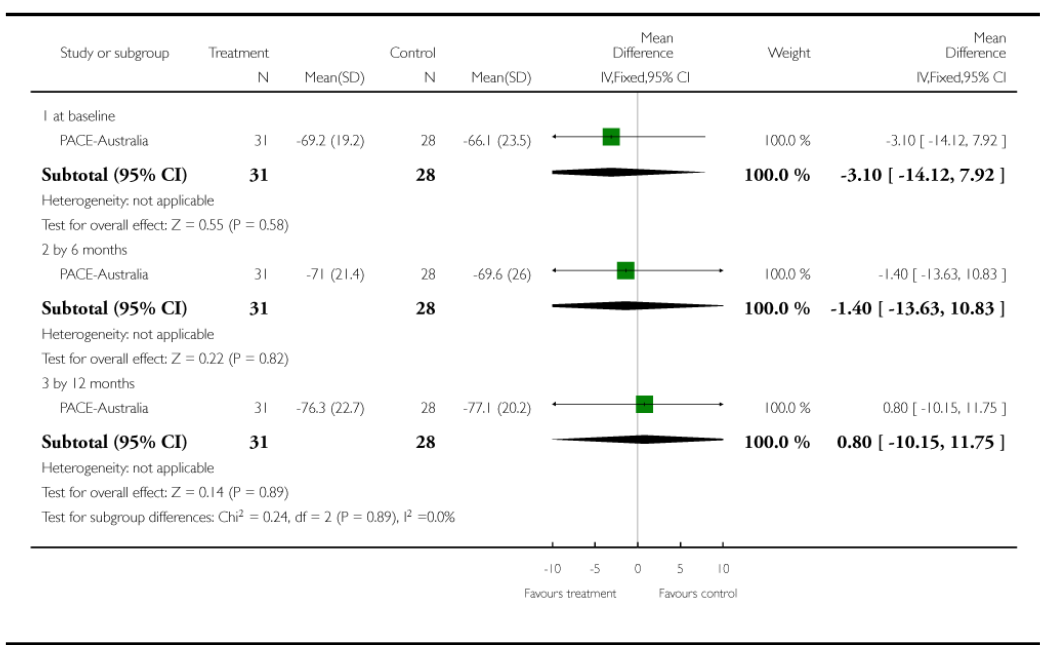

\section{Analysis 4.1. Comparison 4 PHASE-SPECIFIC TREATMENT (AMISULPRIDE) + NEEDS FOCUSED INTERVENTIONS vs NEEDS FOCUSED INTERVENTIONS, Outcome 1 Leaving the study early}

Review: Early intervention for psychosis

Comparison: 4 PHASE-SPECIFIC TREATMENT (AMISULPRIDE) + NEEDS FOCUSED INTERVENTIONS vs NEEDS FOCUSED INTERVENTIONS

Outcome: 1 Leaving the study early 


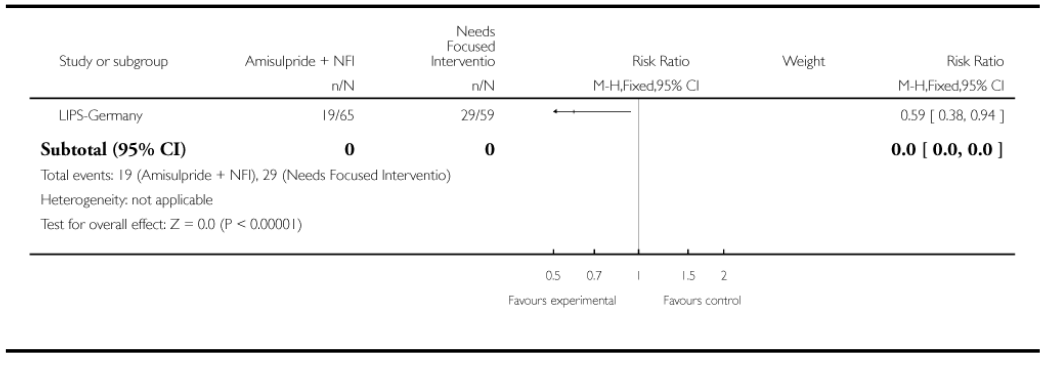

\section{Analysis 4.2. Comparison 4 PHASE-SPECIFIC TREATMENT (AMISULPRIDE) + NEEDS FOCUSED INTERVENTIONS vs NEEDS FOCUSED INTERVENTIONS, Outcome 2 Mental state: 1. PANSS, endpoint score (by 12 weeks, higher scores=worse, LOCR)}

Review: Early intervention for psychosis

Comparison: 4 PHASE-SPECIFIC TREATMENT (AMISULPRIDE) + NEEDS FOCUSED INTERVENTIONS vs NEEDS FOCUSED INTERVENTIONS

Outcome: 2 Mental state: 1. PANSS, endpoint score (by 12 weeks, higher scores=worse, LOCR)

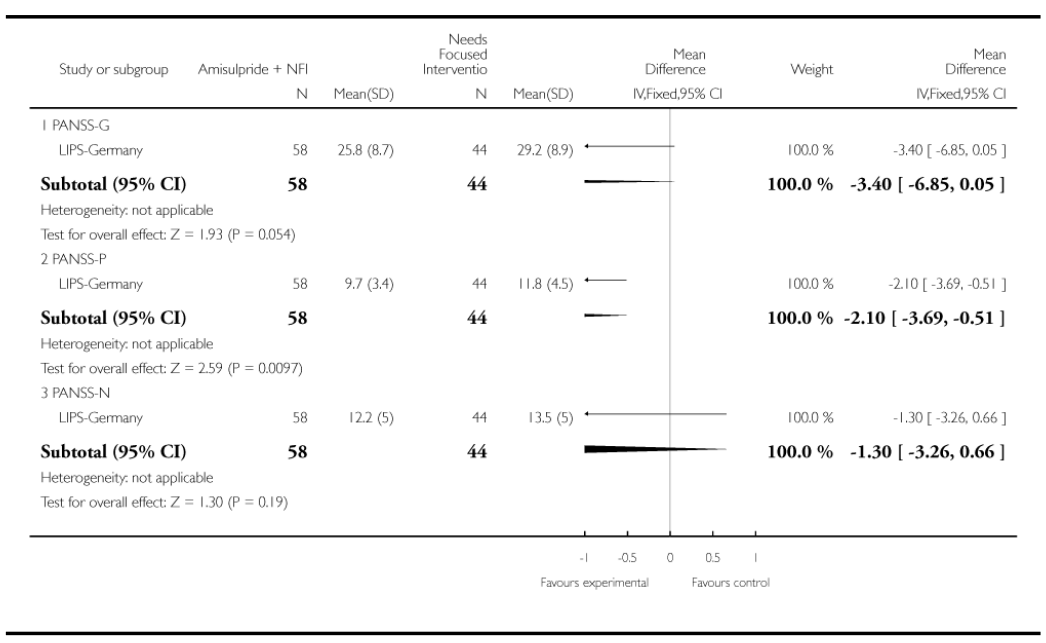

\section{Analysis 4.3. Comparison 4 PHASE-SPECIFIC TREATMENT (AMISULPRIDE) + NEEDS FOCUSED INTERVENTIONS vs NEEDS FOCUSED}


INTERVENTIONS, Outcome 3 Mental state: 1. MADRS, endpoint score (by 12 weeks, higher scores=worse, LOCF)

Review: Early intervention for psychosis

Comparison: 4 PHASE-SPECIFIC TREATMENT (AMISULPRIDE) + NEEDS FOCUSED INTERVENTIONS vs NEEDS FOCUSED INTERVENTIONS

Outcome: 3 Mental state: 1 . MADRS, endpoint score (by 12 weeks, higher scores=worse, LOCF)

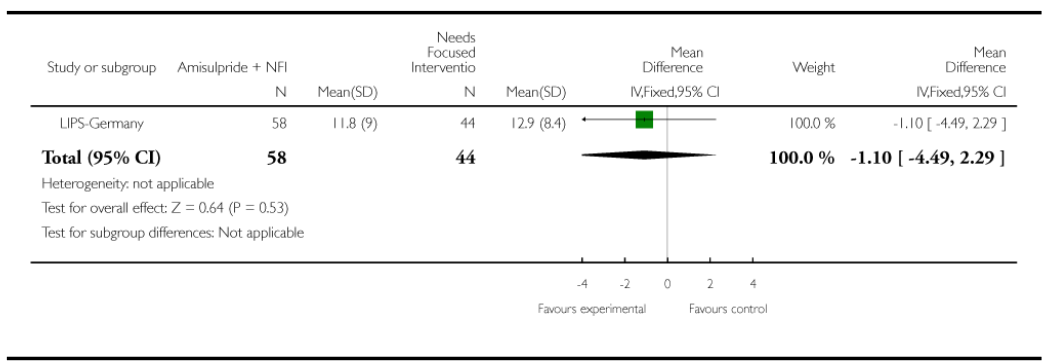

\section{Analysis 4.4. Comparison 4 PHASE-SPECIFIC TREATMENT (AMISULPRIDE) + NEEDS FOCUSED INTERVENTIONS vs NEEDS FOCUSED \\ INTERVENTIONS, Outcome 4 Global state: 1. GAF, endpoint score (by 12 weeks, higher scores=better)}

Review: Early intervention for psychosis

Comparison: 4 PHASE-SPECIFIC TREATMENT (AMISULPRIDE) + NEEDS FOCUSED INTERVENTIONS vs NEEDS FOCUSED INTERVENTIONS

Outcome: 4 Global state: 1 . GAF, endpoint score (by 12 weeks, higher scores=better)

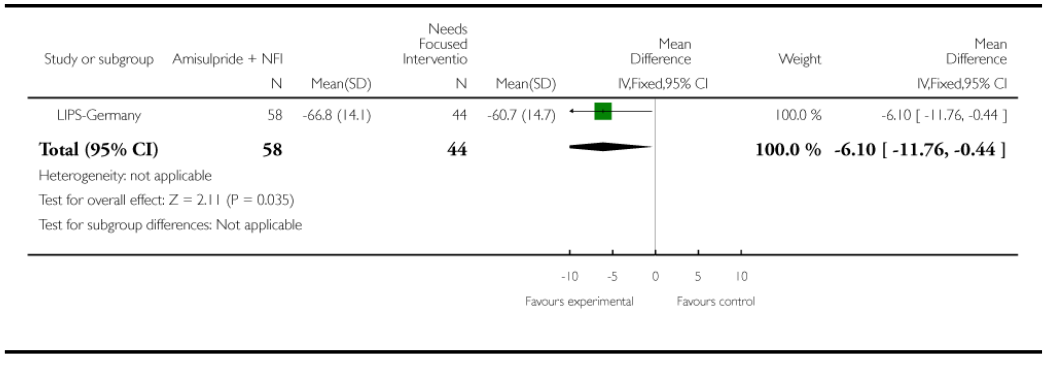




\section{Analysis 5.1. Comparison 5 OMEGA 3 FATTY ACIDS (EPA) versus PLACEBO, Outcome 1 Transition to psychosis}

Review: Early intervention for psychosis

Comparison: 5 OMEGA 3 FATTY ACIDS (EPA) versus PLACEBO

Outcome: 1 Transition to psychosis

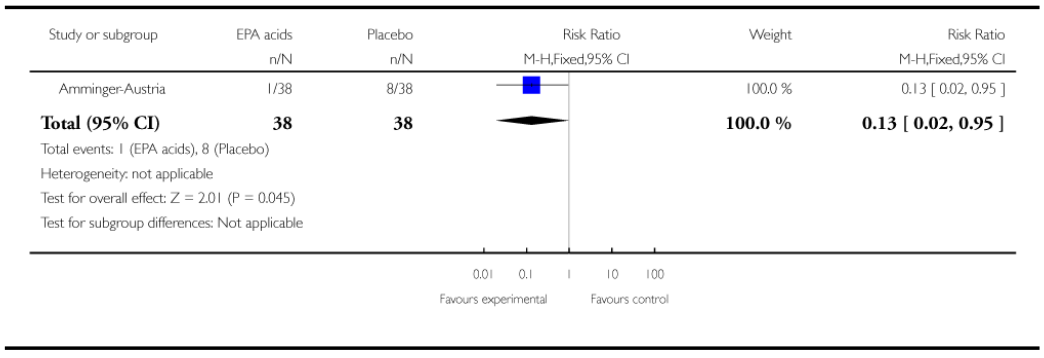

\section{Analysis 6.1. Comparison 6 PHASE-SPECIFIC TREATMENT (CBT for SUICIDALITY) + SPECIALISED TEAM vs SPECIALISED TEAM, Outcome 1 \\ Leaving the study early - by 6 months}

Review: Early intervention for psychosis

Comparison: 6 PHASE-SPECIFIC TREATMENT (CBT for SUICIDALITY) + SPECIALISED TEAM vs SPECIALISED TEAM

Outcome: 1 Leaving the study early - by 6 months

\begin{tabular}{|c|c|c|c|c|c|}
\hline Study or subgroup & $\begin{array}{r}\text { Treatment } \\
\mathrm{n} / \mathrm{N}\end{array}$ & $\begin{array}{r}\text { Control } \\
\mathrm{N} / \mathrm{N}\end{array}$ & $\begin{array}{c}\text { Risk Ratio } \\
\text { M-H,Fixed,95\% } \mathrm{Cl}\end{array}$ & Weight & $\begin{array}{r}\text { Risk Ratio } \\
\text { M-H,Fixed,95\% CI }\end{array}$ \\
\hline LifeSPAN-Australi: & $10 / 31$ & $4 / 25$ & - & $100.0 \%$ & $2.02[0.72,5.66]$ \\
\hline \multicolumn{6}{|c|}{ 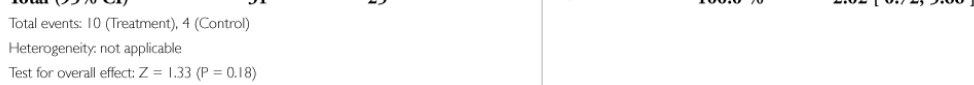 } \\
\hline & & & $\begin{array}{ccc}0.5 & 1 & 2 \\
\text { thent } & \text { Favours co }\end{array}$ & & \\
\hline
\end{tabular}

\section{Analysis 6.2. Comparison 6 PHASE-SPECIFIC TREATMENT (CBT for SUICIDALITY) + SPECIALISED TEAM vs SPECIALISED TEAM, Outcome 2 Suicide - by 6 months}

Review: Early intervention for psychosis 
Comparison: 6 PHASE-SPECIFIC TREATMENT (CBT for SUICIDALITY) + SPECIALISED TEAM vs SPECIALISED TEAM

Outcome: 2 Suicide - by 6 months

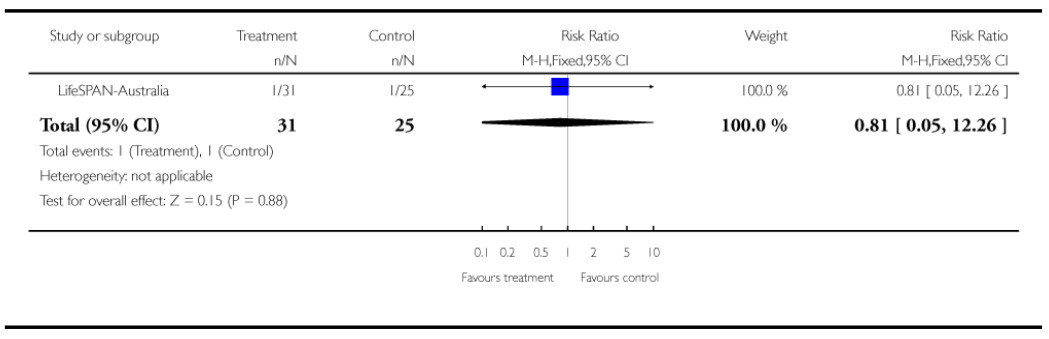

\section{Analysis 7.1. Comparison 7 PHASE-SPECIFIC TREATMENT (FAMILY THERAPY) + SPECIALISED TEAM vs SPECIALISED TEAM, Outcome 1 Relapse by end of treatment - by 12 months}

Review: Early intervention for psychosis

Comparison: 7 PHASE-SPECIFIC TREATMENT (FAMILY THERAPY) + SPECIALISED TEAM vs SPECIALISED TEAM

Outcome: 1 Relapse by end of treatment - by 12 months

\begin{tabular}{|c|c|c|c|c|c|}
\hline Study or subgroup & $\begin{array}{r}\text { Treatment } \\
n / N\end{array}$ & $\begin{array}{r}\text { Control } \\
\mathrm{n} / \mathrm{N}\end{array}$ & $\begin{array}{r}\text { Risk Ratio } \\
\text { M-H,Fixed,95\% CI }\end{array}$ & Weight & $\begin{array}{r}\text { Risk Ratio } \\
\text { M-H,Fixed,95\% CI }\end{array}$ \\
\hline Linszen-Amsterdam & $6 / 37$ & $6 / 39$ & & $100.0 \%$ & $1.05[0.37,2.98]$ \\
\hline Total $(95 \% \mathrm{CI})$ & 37 & 39 & 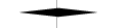 & $100.0 \%$ & $1.05[0.37,2.98]$ \\
\hline \multicolumn{6}{|c|}{ Total events: 6 (Treatment), 6 (Control) } \\
\hline \multirow{2}{*}{\multicolumn{6}{|c|}{$\begin{array}{l}\text { Heterogeneity, not applicable } \\
\text { Test for overall effect: } Z=0.10(P=0.92)\end{array}$}} \\
\hline & & & & & \\
\hline & & & $\begin{array}{llll}2 & 0.5 & 1 & 2\end{array}$ & & \\
\hline
\end{tabular}

\section{Analysis 8.1. Comparison 8 PHASE-SPECIFIC TREATMENT (FAMILY THERAPY) + STANDARD CARE vs STANDARD CARE, Outcome 1 Leaving the study early - by 18 months}

Review: Early intervention for psychosis

Comparison: 8 PHASE-SPECIFIC TREATMENT (FAMILY THERAPY) + STANDARD

CARE vs STANDARD CARE

Outcome: 1 Leaving the study early - by 18 months 


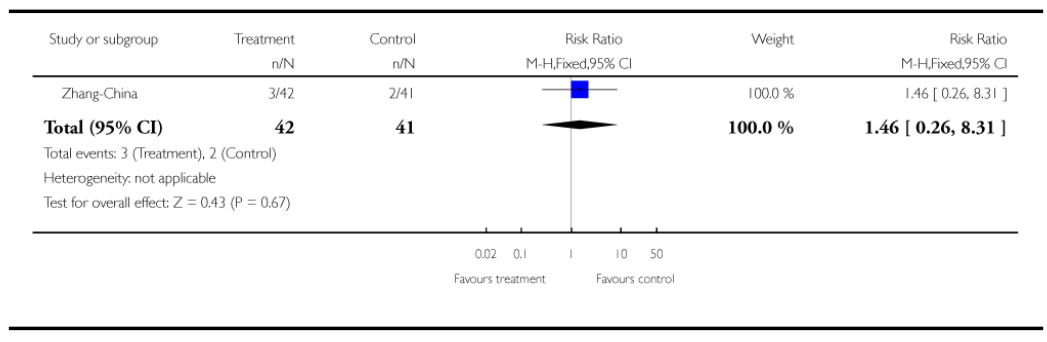

\section{Analysis 8.2. Comparison 8 PHASE-SPECIFIC TREATMENT (FAMILY THERAPY) + STANDARD CARE vs STANDARD CARE, Outcome 2 \\ Readmitted to hospital - by 18 months}

Review: Early intervention for psychosis

Comparison: 8 PHASE-SPECIFIC TREATMENT (FAMILY THERAPY) + STANDARD

CARE vs STANDARD CARE

Outcome: 2 Readmitted to hospital - by 18 months

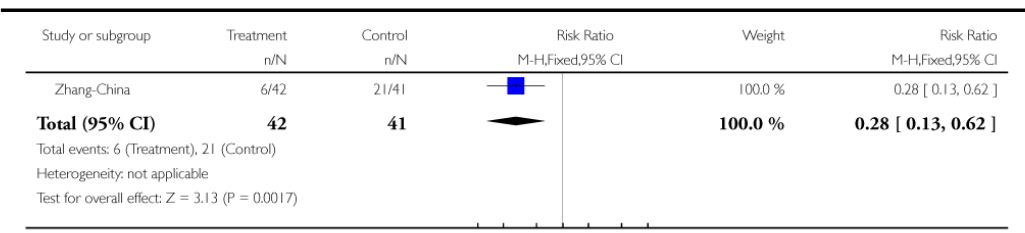

\section{Analysis 8.3. Comparison 8 PHASE-SPECIFIC TREATMENT (FAMILY THERAPY) + STANDARD CARE vs STANDARD CARE, Outcome 3 Not compliant with medication}

Review: Early intervention for psychosis

Comparison: 8 PHASE-SPECIFIC TREATMENT (FAMILY THERAPY) + STANDARD

CARE vs STANDARD CARE

Outcome: 3 Not compliant with medication 


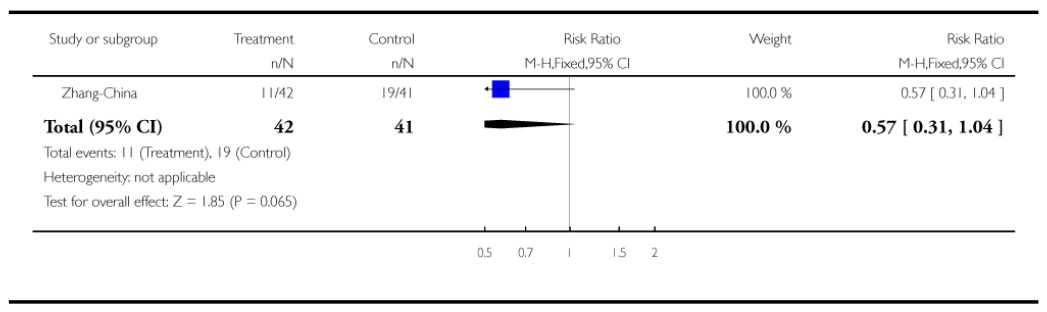

\section{Analysis 9.1. Comparison 9 SPECIALISED TEAM vs STANDARD CARE, Outcome 1 Leaving the study early}

Review: Early intervention for psychosis

Comparison: 9 SPECIALISED TEAM vs STANDARD CARE

Outcome: 1 Leaving the study early

\begin{tabular}{|c|c|c|c|c|c|c|}
\hline Study or subgroup & $\begin{array}{r}\text { Integrated treatment } \\
\mathrm{n} / \mathrm{N}\end{array}$ & $\begin{array}{r}\text { Standard care } \\
n / N\end{array}$ & \multicolumn{2}{|c|}{$\begin{array}{c}\text { Risk Ratio } \\
\text { M-H,Fixed,95\% Cl }\end{array}$} & Weight & $\begin{array}{r}\text { Risk Ratio } \\
\text { M-H,Fixed,95\% CI }\end{array}$ \\
\hline \multicolumn{7}{|l|}{ I by one year } \\
\hline OPUS-Scandinavia & $48 / 275$ & $80 / 272$ & & & $100.0 \%$ & $0.59[0.43,0.81]$ \\
\hline Subtotal $(95 \% \mathrm{CI})$ & 275 & 272 & & & $100.0 \%$ & $0.59[0.43,0.81]$ \\
\hline \multicolumn{7}{|c|}{ Total events: 48 (Integrated treatment), 80 (Standard care) } \\
\hline \multicolumn{7}{|c|}{ Heterogeneity: not applicable } \\
\hline \multicolumn{7}{|c|}{ Test for overall effect: $Z=3.23(P=0.0012)$} \\
\hline \multicolumn{7}{|l|}{2 by two years } \\
\hline OPUS-Scandinavia & $70 / 275$ & 108/272 & 7 & & $100.0 \%$ & $0.64[0.50,0.82]$ \\
\hline Subtotal $(95 \% \mathrm{CI})$ & 275 & 272 & & & $100.0 \%$ & $0.64[0.50,0.82]$ \\
\hline \multicolumn{7}{|c|}{ Total events: 70 (Integrated treatment), 108 (Standard care) } \\
\hline \multicolumn{7}{|c|}{ Heterogeneity. not applicable } \\
\hline \multicolumn{7}{|c|}{ Test for overall effect: $Z=3.49$ (P = 0.00048) } \\
\hline \multicolumn{7}{|c|}{3 by five years } \\
\hline OPUS-Scandinavia & 124/275 & 122272 & & & $100.0 \%$ & $1.01[0.84,1.21]$ \\
\hline Subtotal $(95 \% \mathrm{CI})$ & 275 & 272 & & - & $100.0 \%$ & $1.01[0.84,1.21]$ \\
\hline \multicolumn{7}{|c|}{$\begin{array}{l}\text { Total events: } 124 \text { (Integrated treatment), } 122 \text { (Standard care) } \\
\text { Heterogeneity; not applicable }\end{array}$} \\
\hline \multicolumn{7}{|c|}{ Heterogeneity not applicable } \\
\hline \multicolumn{7}{|c|}{ Test for overall effect: $Z=0.06(P=0.96)$} \\
\hline & & & $\begin{array}{cc}0.5 & 0.7 \\
\text { Favours treatment }\end{array}$ & $\begin{array}{lrl} & 1.5 \\
& \text { Favours }\end{array}$ & & \\
\hline
\end{tabular}

\section{Analysis 9.2. Comparison 9 SPECIALISED TEAM vs STANDARD CARE, Outcome 2 Global state: 1. Average endpoint score - by 12 and 24 months (GAF-symptom, high score $=$ good)}

Review: Early intervention for psychosis

Comparison: 9 SPECIALISED TEAM vs STANDARD CARE

Outcome: 2 Global state: 1 . Average endpoint score - by 12 and 24 months (GAF-symptom, high score=good) 


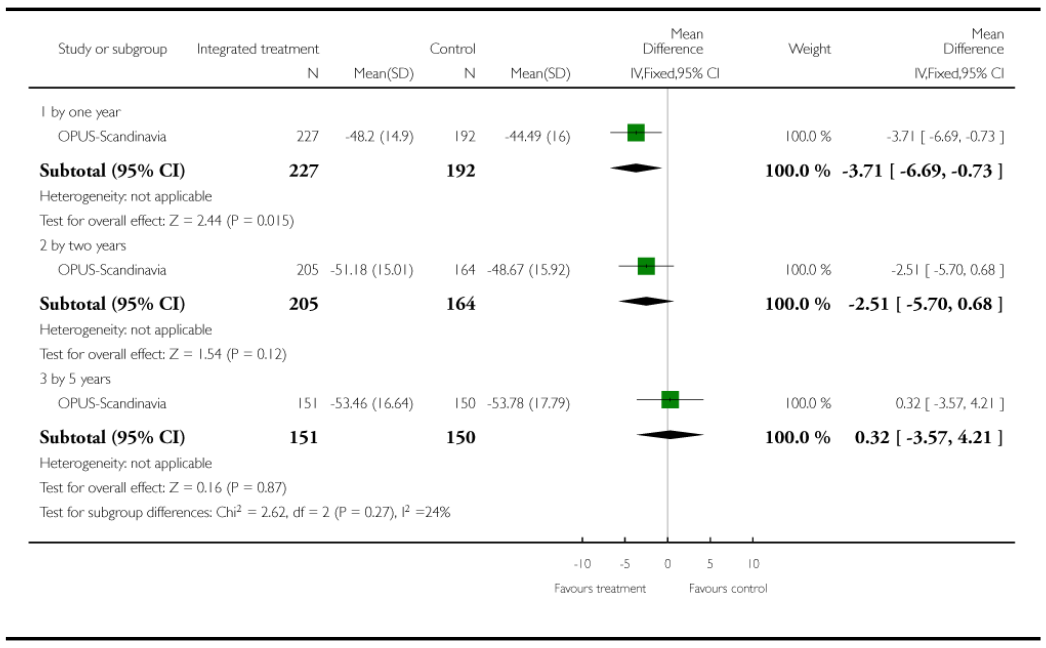

\section{Analysis 9.3. Comparison 9 SPECIALISED TEAM vs STANDARD CARE, Outcome 3 Global state: 2. Average endpoint score - by 12 and 24 months (GAF-function, high score=good)}

Review: Early intervention for psychosis

Comparison: 9 SPECIALISED TEAM vs STANDARD CARE

Outcome: 3 Global state: 2. Average endpoint score - by 12 and 24 months (GAF-function, high score=good)

\begin{tabular}{|c|c|c|c|c|c|c|c|c|}
\hline \multirow{4}{*}{$\begin{array}{l}\text { Study or subgroup } \\
\text { I by one year } \\
\text { OPUS-Scandinavia }\end{array}$} & \multirow{2}{*}{$\begin{array}{r}\text { Integrated treatment } \\
\mathrm{N}\end{array}$} & \multicolumn{3}{|c|}{ Control } & \multirow{2}{*}{\multicolumn{2}{|c|}{ 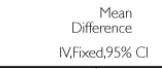 }} & \multirow[t]{2}{*}{ Weight } & \multirow{2}{*}{$\begin{array}{r}\text { Mean } \\
\text { Difference } \\
\text { IV,Fixed,95\% Cl } \\
\end{array}$} \\
\hline & & \multirow[t]{2}{*}{$\operatorname{Mean}(S D)$} & \multirow[t]{2}{*}{$\mathrm{N}$} & \multirow[t]{2}{*}{$\operatorname{Mean}(\mathrm{SD})$} & & & & \\
\hline & & & & & & & & \\
\hline & 227 & $-51.7(15.1)$ & 192 & $-49.4(14.6)$ & 6) $\longleftarrow$ & & $100.0 \%$ & $-2.30[-5.15,0.55]$ \\
\hline Subtotal $(95 \% \mathrm{CI})$ & 227 & & 192 & & & & $100.0 \%$ & $-2.30[-5.15,0.55]$ \\
\hline Heterogeneity, not applic & & & & & & & & \\
\hline Test for overall effect: Z & $=1.58(P=0.11)$ & & & & & & & \\
\hline 2 by two years & & & & & & & & \\
\hline OPUS-Scandinavia & 205 & $-55.16(15.15)$ & 164 & $-51.13(15.92)$ & 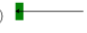 & & $100.0 \%$ & $-4.03[-7.23,-0.83]$ \\
\hline Subtotal $(95 \% \mathrm{CI})$ & 205 & & 164 & & & & $100.0 \%$ & $-4.03[-7.23,-0.83]$ \\
\hline Heterogeneity, not applic & & & & & & & & \\
\hline Test for overall effect: Z & $=2.47(P=0.014)$ & & & & & & & \\
\hline 3 by five years & & & & & & & & \\
\hline OPUS-Scandinavia & 151 & $-55.36(17.28)$ & 150 & $-54.16(18.41)$ & 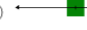 & & $100.0 \%$ & $-1.20[-5.23,2.83]$ \\
\hline Subtotal $(95 \% \mathrm{CI})$ & 151 & & 150 & & & & $100.0 \%$ & $-1.20[-5.23,2.83]$ \\
\hline Heterogeneity, not applic & & & & & & & & \\
\hline Test for overall effect: $Z$ & $=0.58(P=0.56)$ & & & & & & & \\
\hline Test for subgroup differe & nces: $\mathrm{Ch}^{2}=1.27, \mathrm{df}=2$ & $2(P=0.53), 1^{2}=$ & $=0.0 \%$ & & & & & \\
\hline & & & & & $-4 \quad-2$ & 2 & 4 & \\
\hline & & & & & rours treatment & Favours & & \\
\hline
\end{tabular}




\section{Analysis 9.4. Comparison 9 SPECIALISED TEAM vs STANDARD CARE, Outcome 4 User satisfaction: Average endpoint score - by 12 and 24 months (CSQ-8, high score=good)}

Review: Early intervention for psychosis

Comparison: 9 SPECIALISED TEAM vs STANDARD CARE

Outcome: 4 User satisfaction: Average endpoint score - by 12 and 24 months (CSQ-8, high score $=$ good)

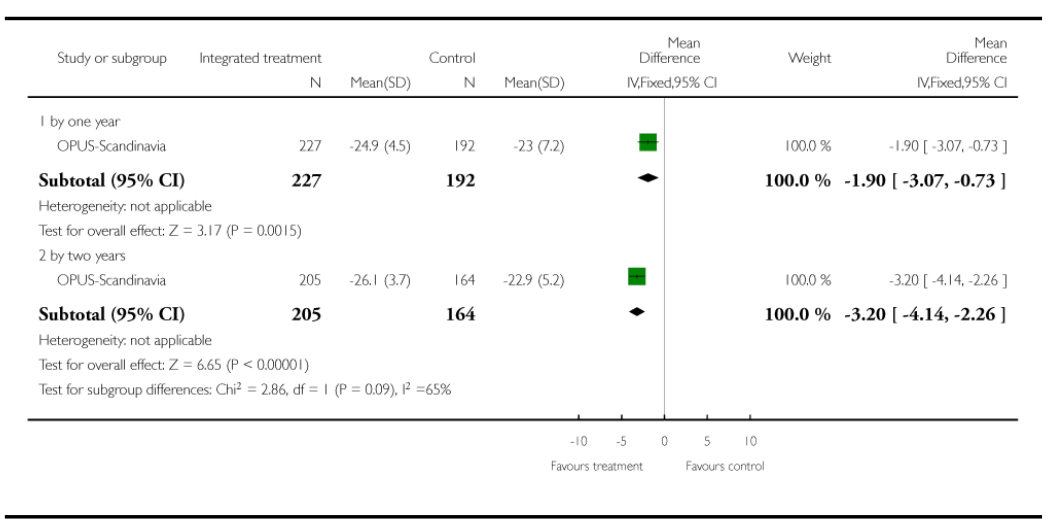

\section{Analysis 9.5. Comparison 9 SPECIALISED TEAM vs STANDARD CARE, Outcome 5 Compliance with treatment}

Review: Early intervention for psychosis

Comparison: 9 SPECIALISED TEAM vs STANDARD CARE

Outcome: 5 Compliance with treatment

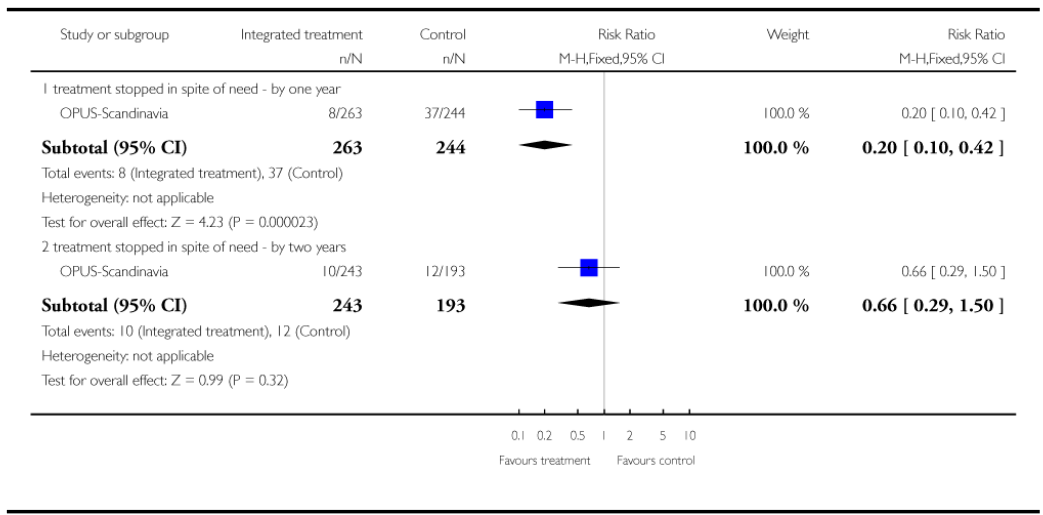




\section{Analysis 9.6. Comparison 9 SPECIALISED TEAM vs STANDARD CARE, Outcome 6 Suicide: Death - by 12 months}

Review: Early intervention for psychosis

Comparison: 9 SPECIALISED TEAM vs STANDARD CARE

Outcome: 6 Suicide: Death - by 12 months

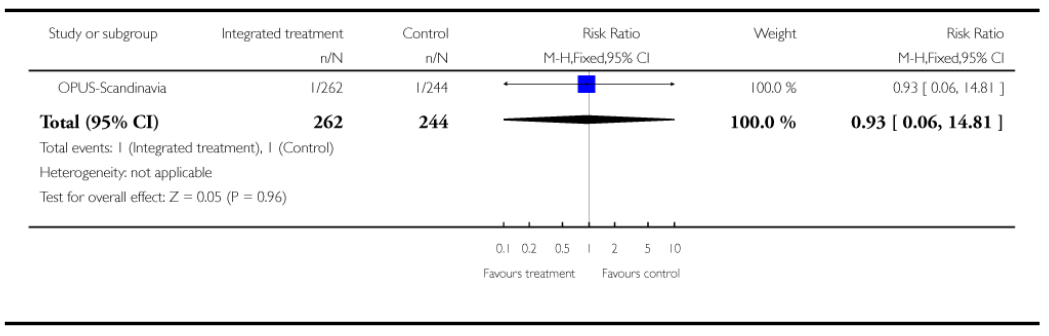

\section{Analysis 9.7. Comparison 9 SPECIALISED TEAM vs STANDARD CARE, Outcome 7 Death other than suicide - by 12 months}

Review: Early intervention for psychosis

Comparison: 9 SPECIALISED TEAM vs STANDARD CARE

Outcome: 7 Death other than suicide - by 12 months

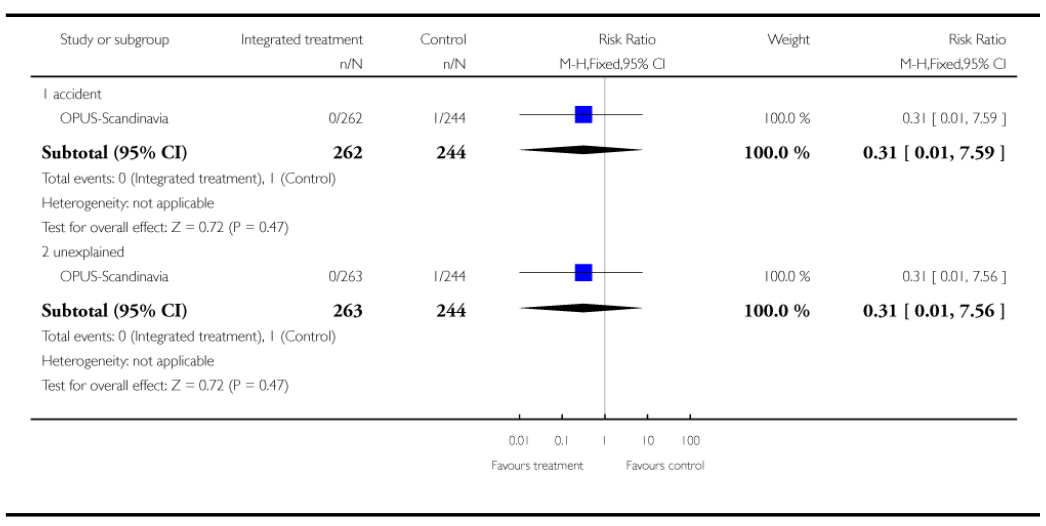

\section{Analysis 9.8. Comparison 9 SPECIALISED TEAM vs STANDARD CARE, Outcome 8 Service use: 1. Average mean number of days per month in hospital}

Review: Early intervention for psychosis 
Comparison: 9 SPECIALISED TEAM vs STANDARD CARE

Outcome: 8 Service use: 1 . Average mean number of days per month in hospital

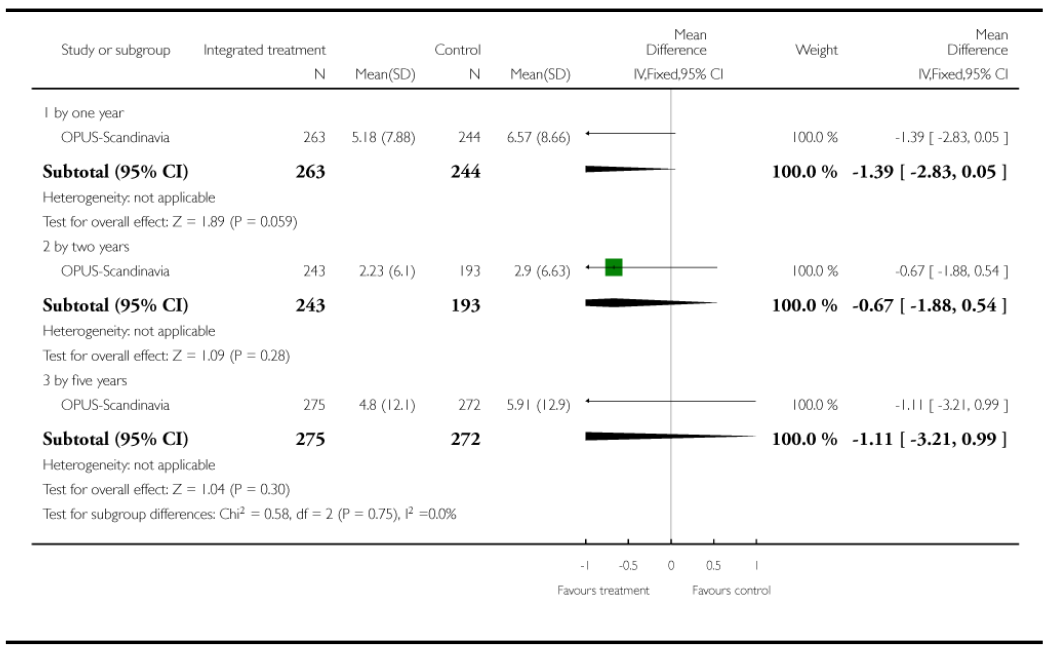

\section{Analysis 9.9. Comparison 9 SPECIALISED TEAM vs STANDARD CARE, Outcome 9 Service use: 2. Not hospitalised - by five years}

Review: Early intervention for psychosis

Comparison: 9 SPECIALISED TEAM vs STANDARD CARE

Outcome: 9 Service use: 2 . Not hospitalised - by five years

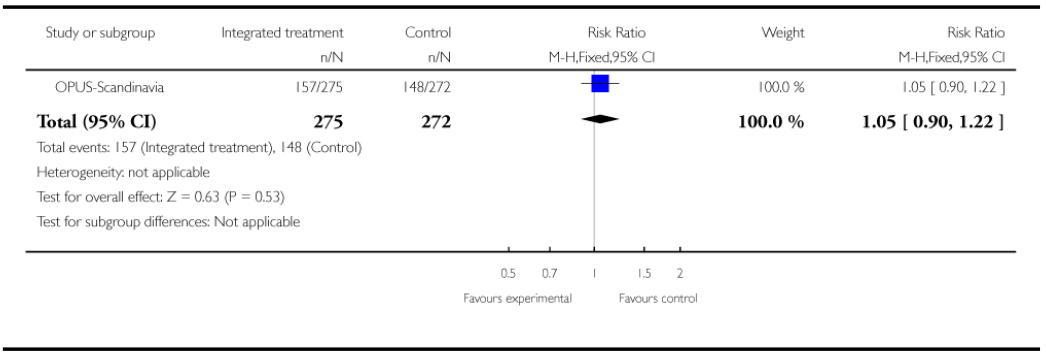

\section{Analysis 9.10. Comparison 9 SPECIALISED TEAM vs STANDARD CARE, Outcome 10 Social outcomes: 1. Not living independently}

Review: Early intervention for psychosis

Comparison: 9 SPECIALISED TEAM vs STANDARD CARE

Outcome: 10 Social outcomes: 1 . Not living independently 


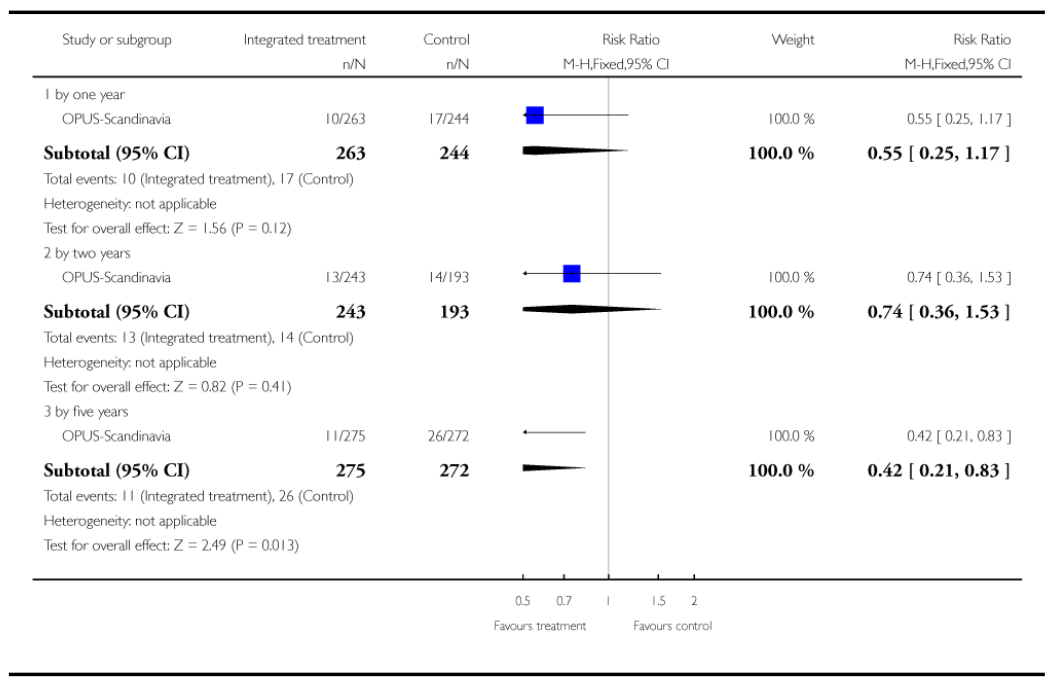

\section{Analysis 9.11. Comparison 9 SPECIALISED TEAM vs STANDARD CARE, Outcome 11 Social outcomes: 2. Not working or in education}

Review: Early intervention for psychosis

Comparison: 9 SPECIALISED TEAM vs STANDARD CARE

Outcome: 11 Social outcomes: 2. Not working or in education

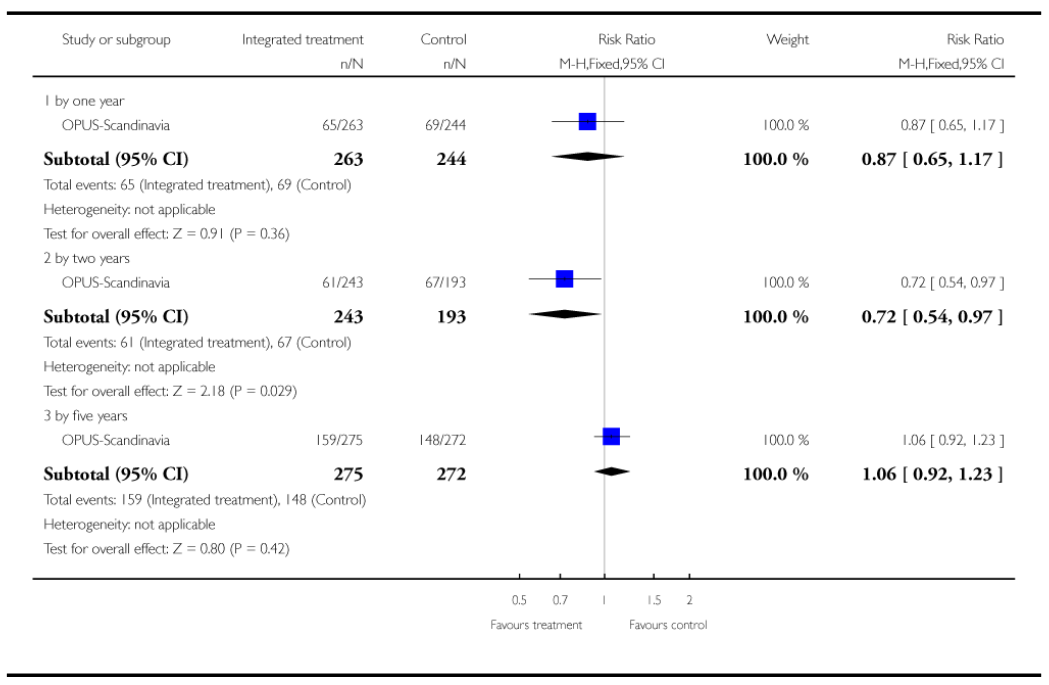




\section{Analysis 10.1. Comparison 10 PHASE-SPECIFIC TREATMENT (CBT) + ANTIPSYCHOTICS vs BEFRIENDING + ANTISYCHOTICS, Outcome 1 Leaving the study early by 12 months}

Review: Early intervention for psychosis

Comparison: 10 PHASE-SPECIFIC TREATMENT (CBT) + ANTIPSYCHOTICS vs BEFRIENDING + ANTISYCHOTICS

Outcome: 1 Leaving the study early by 12 months

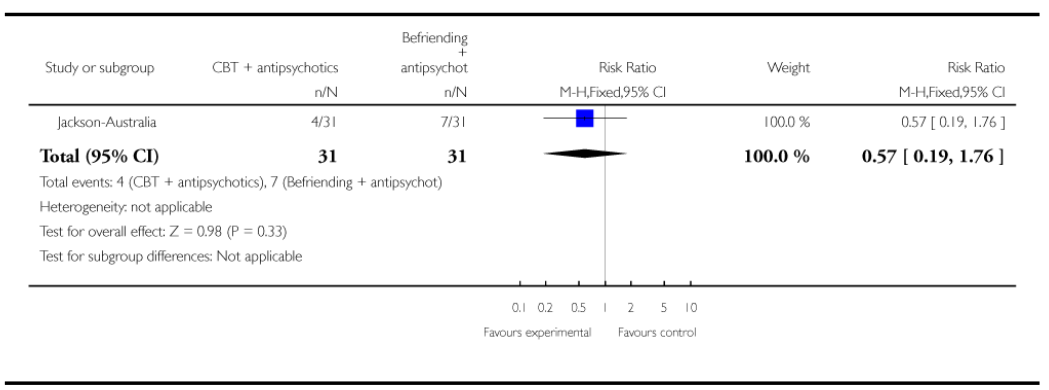

\section{Analysis 10.2. Comparison 10 PHASE-SPECIFIC TREATMENT (CBT) + ANTIPSYCHOTICS vs BEFRIENDING + ANTISYCHOTICS, Outcome 2 Hospitalised by 12 months}

Review: Early intervention for psychosis

Comparison: 10 PHASE-SPECIFIC TREATMENT (CBT) + ANTIPSYCHOTICS vs BEFRIENDING + ANTISYCHOTICS

Outcome: 2 Hospitalised by 12 months

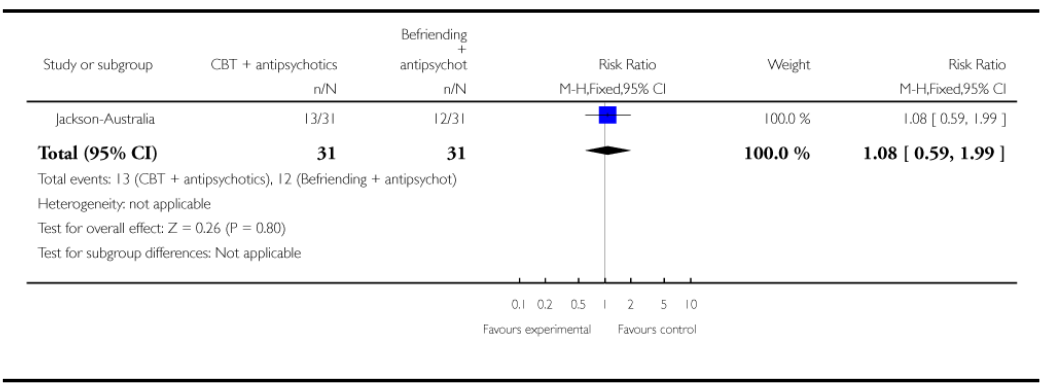




\title{
Analysis 10.3. Comparison 10 PHASE-SPECIFIC TREATMENT (CBT) + ANTIPSYCHOTICS vs BEFRIENDING + ANTISYCHOTICS, Outcome 3 Suicide by 12 months
}

\author{
Review: Early intervention for psychosis \\ Comparison: 10 PHASE-SPECIFIC TREATMENT (CBT) + ANTIPSYCHOTICS vs \\ BEFRIENDING + ANTISYCHOTICS
}

Outcome: 3 Suicide by 12 months

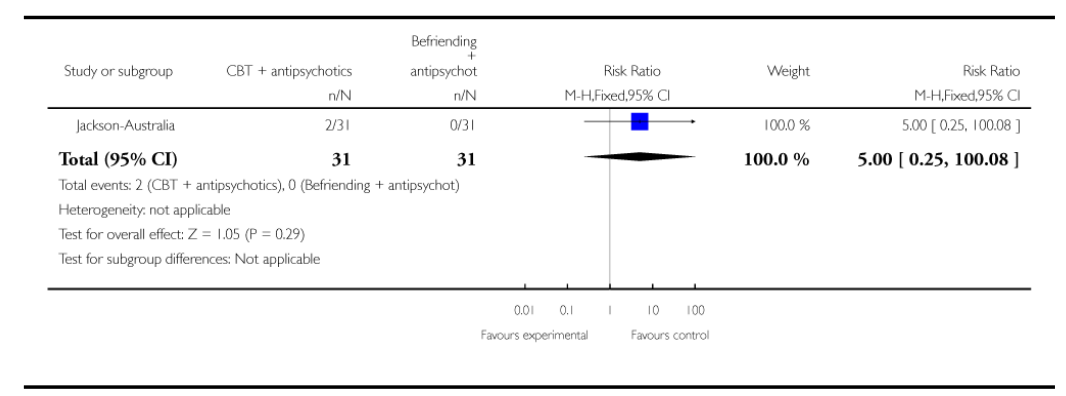

\section{Analysis 10.4. Comparison 10 PHASE-SPECIFIC TREATMENT (CBT) + ANTIPSYCHOTICS vs BEFRIENDING + ANTISYCHOTICS, Outcome 4 Social functioning: SOFRAS by 12 months (higher score=worse)}

\author{
Review: Early intervention for psychosis \\ Comparison: 10 PHASE-SPECIFIC TREATMENT (CBT) + ANTIPSYCHOTICS vs \\ BEFRIENDING + ANTISYCHOTICS
}

Outcome: 4 Social functioning: SOFRAS by 12 months (higher score=worse) 


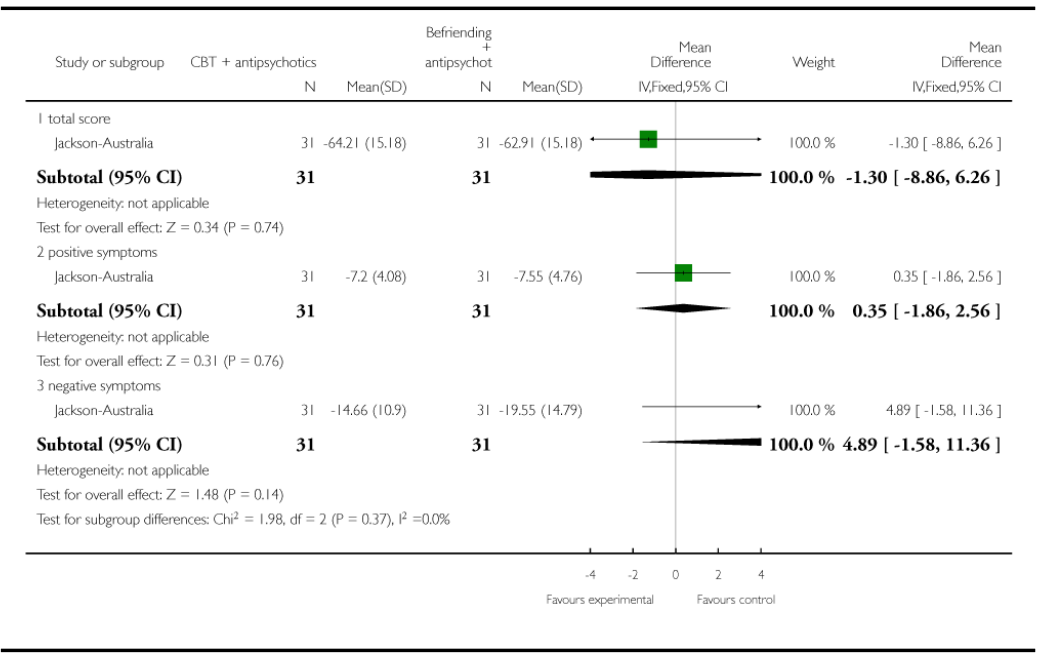

\section{Analysis 11.1. Comparison 11 PHASE-SPECIFIC TREATMENT (E-EPA) +} ATYPICALS vs PLACEBO + ATYPICALS, Outcome 1 Leaving the study early by 12 weeks

Review: Early intervention for psychosis

Comparison: 11 PHASE-SPECIFIC TREATMENT (E-EPA) + ATYPICALS vs PLACEBO + ATYPICALS

Outcome: 1 Leaving the study early by 12 weeks

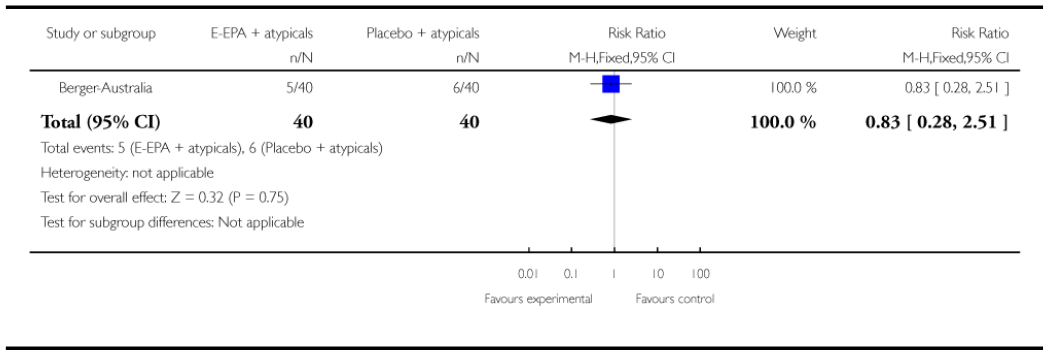

\section{Analysis 11.2. Comparison 11 PHASE-SPECIFIC TREATMENT (E-EPA) + ATYPICALS vs PLACEBO + ATYPICALS, Outcome 2 Global state: Not responded to treatment by 12 weeks}

Review: Early intervention for psychosis

Comparison: 11 PHASE-SPECIFIC TREATMENT (E-EPA) + ATYPICALS vs PLACEBO + ATYPICALS 
Outcome: 2 Global state: Not responded to treatment by 12 weeks

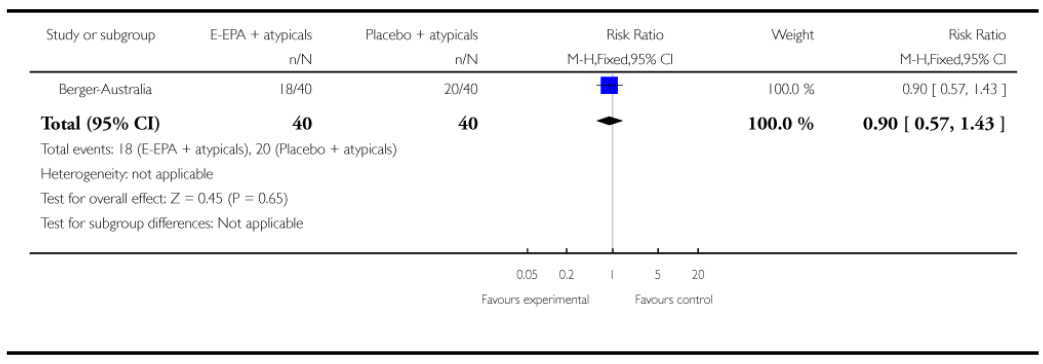

\section{Analysis 12.1. Comparison 12 PHASE-SPECIFIC TREATMENT (BRIEF INTERVENTION) + ANTIPSYCHOTICS vS TREAMENT AS USUAL, Outcome} 1 Leaving the study early by nine months

Review: Early intervention for psychosis

Comparison: 12 PHASE-SPECIFIC TREATMENT (BRIEF INTERVENTION) + ANTIPSYCHOTICS vs TREAMENT AS USUAL

Outcome: 1 Leaving the study early by nine months

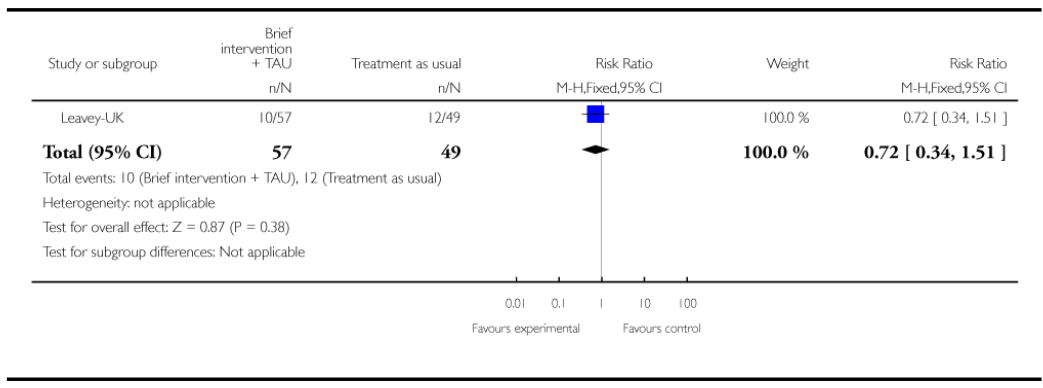

\section{Analysis 12.2. Comparison 12 PHASE-SPECIFIC TREATMENT (BRIEF INTERVENTION) + ANTIPSYCHOTICS vS TREAMENT AS USUAL, Outcome 2 Hospital admission: Hospitalised}

Review: Early intervention for psychosis

Comparison: 12 PHASE-SPECIFIC TREATMENT (BRIEF INTERVENTION) + ANTIPSYCHOTICS vs TREAMENT AS USUAL

Outcome: 2 Hospital admission: Hospitalised 


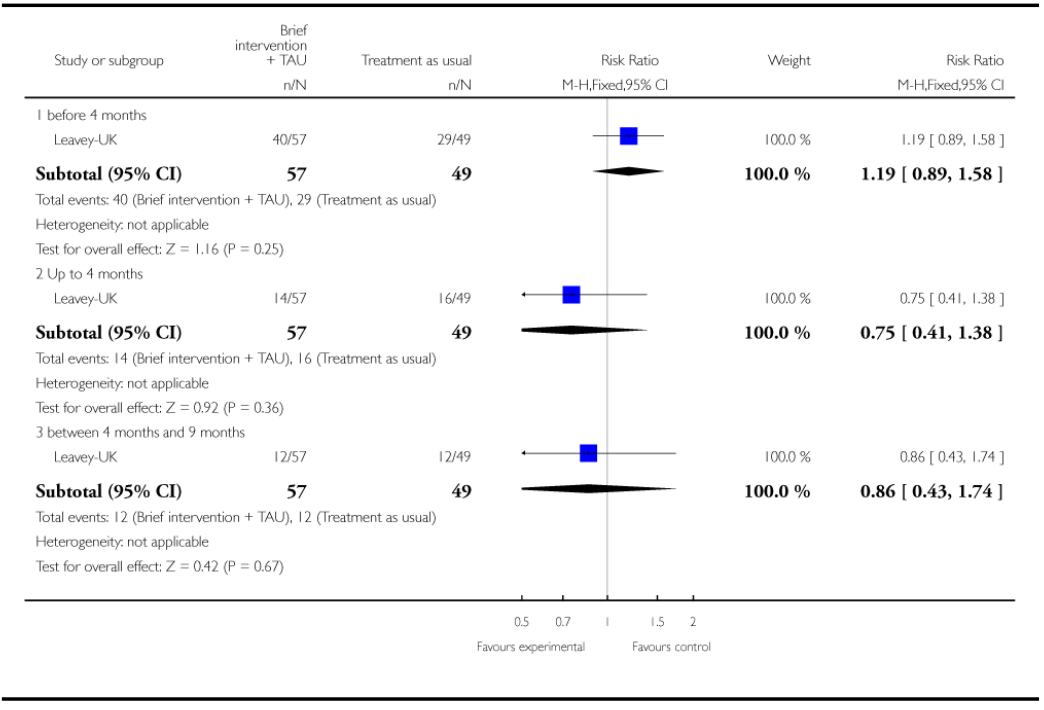

Analysis 13.1. Comparison 13 PHASE-SPECIFIC TREATMENT (ACE) + ANTIPSYCHOTICS vS TREATMENT AS USUAL, Outcome 1 Leaving the study early (6 months)

Review: Early intervention for psychosis

Comparison: 13 PHASE-SPECIFIC TREATMENT (ACE) + ANTIPSYCHOTICS vs TREATMENT AS USUAL

Outcome: 1 Leaving the study early (6 months)

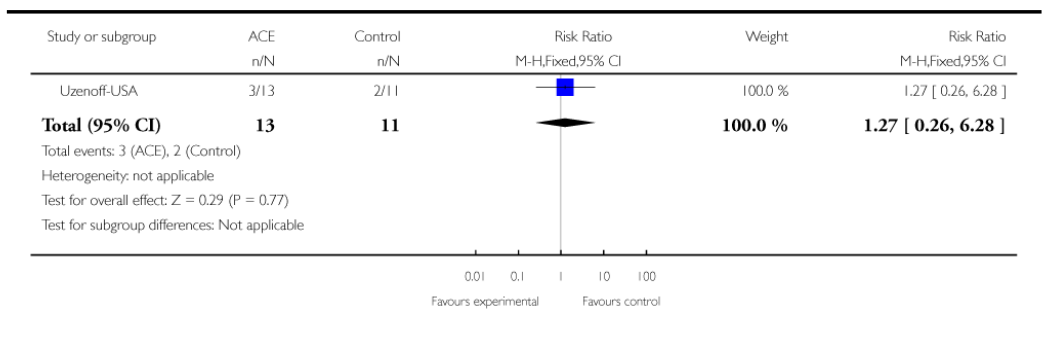

Analysis 13.2. Comparison 13 PHASE-SPECIFIC TREATMENT (ACE) + ANTIPSYCHOTICS vs TREATMENT AS USUAL, Outcome 2 Mental state: 1. PANSS

Review: Early intervention for psychosis 
Comparison: 13 PHASE-SPECIFIC TREATMENT (ACE) + ANTIPSYCHOTICS vs TREATMENT AS USUAL

Outcome: 2 Mental state: 1. PANSS

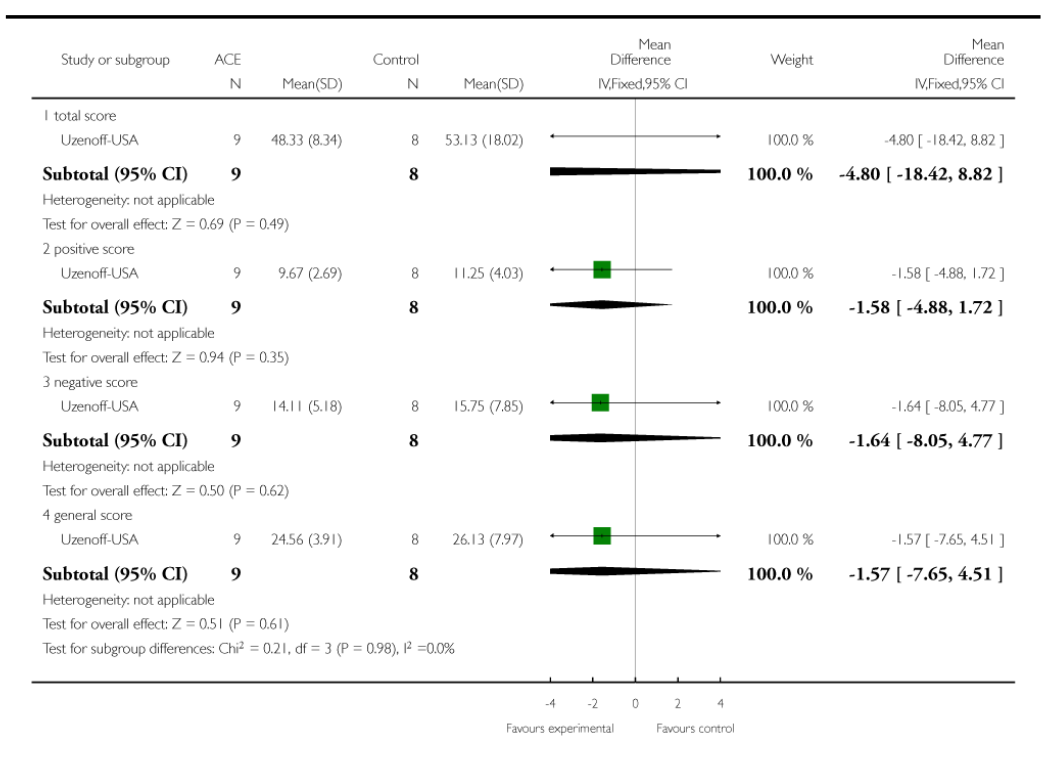

\section{Analysis 13.3. Comparison 13 PHASE-SPECIFIC TREATMENT (ACE) +} ANTIPSYCHOTICS vs TREATMENT AS USUAL, Outcome 3 Mental state: 2. Calgary Depression Rating Scale

Review: Early intervention for psychosis

Comparison: 13 PHASE-SPECIFIC TREATMENT (ACE) + ANTIPSYCHOTICS vs TREATMENT AS USUAL

Outcome: 3 Mental state: 2. Calgary Depression Rating Scale

\begin{tabular}{|c|c|c|c|c|c|c|c|c|}
\hline \multirow[t]{2}{*}{ Study or subgroup } & \multirow{2}{*}{$\begin{array}{r}\text { ACE } \\
N\end{array}$} & \multicolumn{3}{|c|}{ Control } & \multicolumn{2}{|c|}{$\begin{array}{c}\text { Mean } \\
\text { Difference }\end{array}$} & \multirow[t]{2}{*}{ Weight } & \multirow{2}{*}{$\begin{array}{r}\text { Mean } \\
\text { Difference } \\
\text { IV.Fixed,95\% C }\end{array}$} \\
\hline & & $\operatorname{Mean}(\mathrm{SD})$ & $\mathrm{N}$ & $\operatorname{Mean}(\mathrm{SD})$ & IV,fixe & red, $95 \% \mathrm{Cl}$ & & \\
\hline Uzenoff-USA & 9 & $9.67(0.87)$ & 8 & $11.13(3.83)$ & 담 & + & $100.0 \%$ & $-1.46[-4.17,1.25]$ \\
\hline Total $(95 \% \mathrm{CI})$ & 9 & & 8 & & & & $100.0 \%$ & $-1.46[-4.17,1.25]$ \\
\hline \multicolumn{9}{|c|}{ Heterogeneity. not applicable } \\
\hline \multicolumn{9}{|c|}{ Test for overal effect: $Z=1.05(P=0.29)$} \\
\hline \multicolumn{9}{|c|}{ Test for subgroup differences: Not applicable } \\
\hline & & & & & $-4=2 \quad 0$ & $0 \quad 2$ & & \\
\hline
\end{tabular}




\section{Analysis 13.4. Comparison 13 PHASE-SPECIFIC TREATMENT (ACE) + ANTIPSYCHOTICS vs TREATMENT AS USUAL, Outcome 4 Quality of Life:}

\section{Heinrichs-Carpenter}

Review: Early intervention for psychosis

Comparison: 13 PHASE-SPECIFIC TREATMENT (ACE) + ANTIPSYCHOTICS vs TREATMENT AS USUAL

Outcome: 4 Quality of Life: 1. Heinrichs-Carpenter

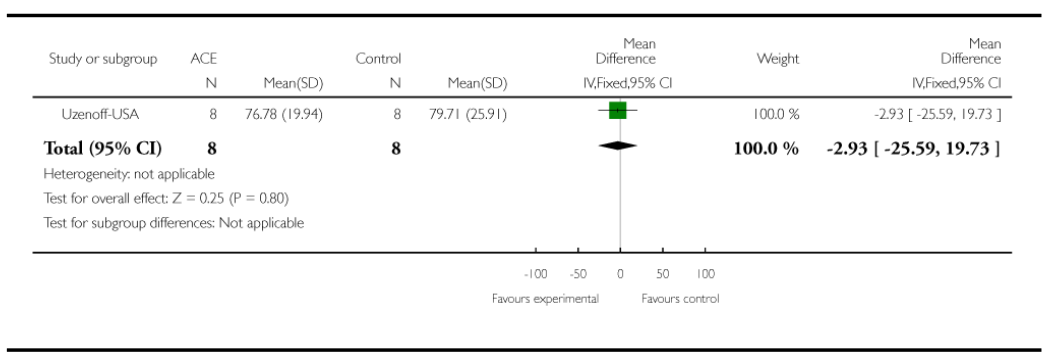

\section{Analysis 14.1. Comparison 14 PHASE-SPECIFIC TREATMENT (VOCATIONAL INTERVENTION) + TAU vS TREATMENT AS USUAL, Outcome 1 Not employed}

Review: Early intervention for psychosis

Comparison: 14 PHASE-SPECIFIC TREATMENT (VOCATIONAL INTERVENTION) + TAU vs TREATMENT AS USUAL

Outcome: 1 Not employed

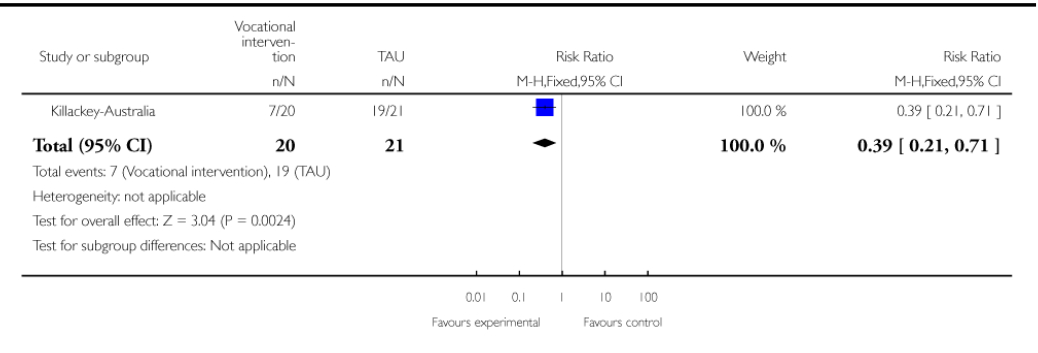




\section{Analysis 14.2. Comparison 14 PHASE-SPECIFIC TREATMENT (VOCATIONAL INTERVENTION) + TAU vS TREATMENT AS USUAL, Outcome 2 Leaving the study early}

Review: Early intervention for psychosis

Comparison: 14 PHASE-SPECIFIC TREATMENT (VOCATIONAL INTERVENTION) + TAU vs TREATMENT AS USUAL

Outcome: 2 Leaving the study early

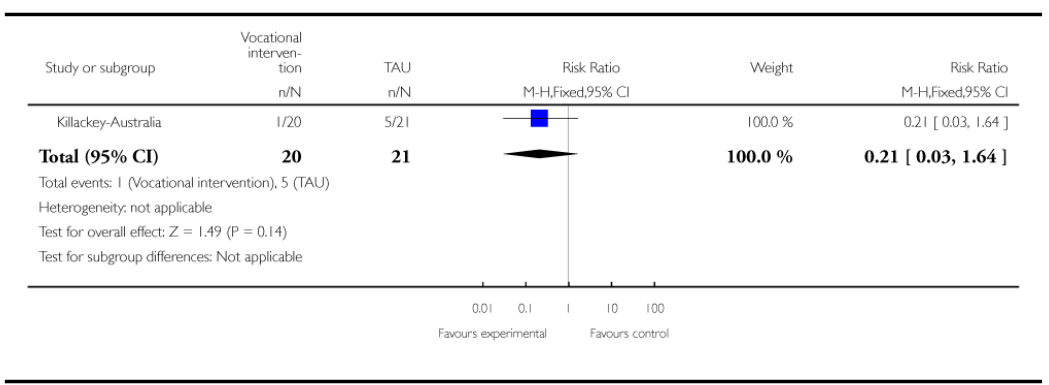

Analysis 15.1. Comparison 15 PHASE-SPECIFIC TREATMENT (CANNABIS AND PSYCHOSIS THERAPY) + ANTIPSYCHOTICS vS PSYCHOEDUCATION + ANTIPSYCHOTICS, Outcome 1 Cannabis use: 1. Used cannabis in last 4 weeks

Review: Early intervention for psychosis

Comparison: 15 PHASE-SPECIFIC TREATMENT (CANNABIS AND PSYCHOSIS THERAPY) + ANTIPSYCHOTICS vs PSYCHOEDUCATION + ANTIPSYCHOTICS

Outcome: 1 Cannabis use: 1 . Used cannabis in last 4 weeks 


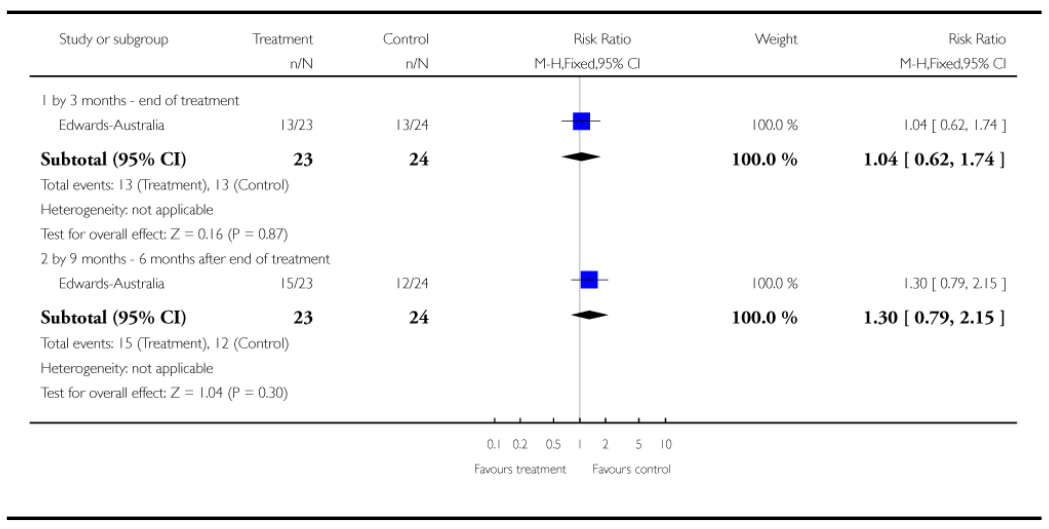

Analysis 15.2. Comparison 15 PHASE-SPECIFIC TREATMENT (CANNABIS AND PSYCHOSIS THERAPY) + ANTIPSYCHOTICS vS PSYCHOEDUCATION + ANTIPSYCHOTICS, Outcome 2 Cannabis use: 2. Percentage days used cannabis in last 4 weeks (skewed data)

Cannabis use: 2. Percentage days used cannabis in last 4 weeks (skewed data)

\begin{tabular}{lllll}
\hline Study & Intervention & Mean & SD & N \\
\hline by 3 months - end of treatment & & & \\
\hline Edwards-Australia & CAP & 30.4 & 41.8 & 23 \\
\hline Edwards-Australia & PE & 18.8 & 30.6 & 24 \\
\hline by 9 months - 6 months after end of treatment & \\
\hline Edwards-Australia & CAP & 32.4 & 44.9 & 23 \\
\hline Edwards-Australia & PE & 19.3 & 30.4 & 24 \\
\hline
\end{tabular}

Analysis 15.3. Comparison 15 PHASE-SPECIFIC TREATMENT (CANNABIS AND PSYCHOSIS THERAPY) + ANTIPSYCHOTICS vS PSYCHOEDUCATION + ANTIPSYCHOTICS, Outcome 3 Cannabis use: 3 . Severity of cannabis use (skewed data)

Cannabis use: 3. Severity of cannabis use (skewed data)

\begin{tabular}{lllll}
\hline Study & Intervention & Mean & SD & N \\
\hline by 3 months - end of treatment & & & \\
\hline Edwards-Australia & CAP & 1.4 & 1.4 & 23 \\
\hline
\end{tabular}




\begin{tabular}{lllll}
\hline Study & Intervention & Mean & SD & N \\
\hline Edwards-Australia & PE & 1.3 & 1.4 & 24 \\
\hline by 9 months - 6 months after end of treatment \\
\hline Edwards-Australia & CAP & 1.4 & 1.4 & 23 \\
\hline Edwards-Australia & PE & 1.3 & 1.5 & 24 \\
\hline
\end{tabular}

\section{Analysis 15.4. Comparison 15 PHASE-SPECIFIC TREATMENT (CANNABIS AND PSYCHOSIS THERAPY) + ANTIPSYCHOTICS vs PSYCHOEDUCATION + ANTIPSYCHOTICS, Outcome 4 Global state: Average score (KAPQ total endpoint, higher=good)}

Review: Early intervention for psychosis

Comparison: 15 PHASE-SPECIFIC TREATMENT (CANNABIS AND PSYCHOSIS THERAPY) + ANTIPSYCHOTICS vs PSYCHOEDUCATION + ANTIPSYCHOTICS

Outcome: 4 Global state: Average score (KAPQ total endpoint, higher=good)

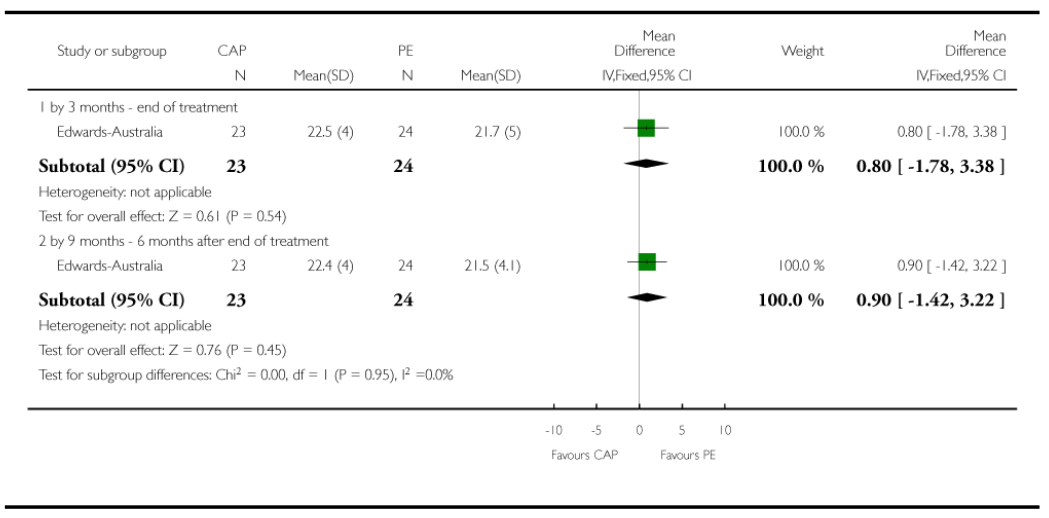

Analysis 15.5. Comparison 15 PHASE-SPECIFIC TREATMENT (CANNABIS AND PSYCHOSIS THERAPY) + ANTIPSYCHOTICS vS PSYCHOEDUCATION + ANTIPSYCHOTICS, Outcome 5 Mental state: 1. Average score (BPRS-E total endpoint, higher scores=poor)

Review: Early intervention for psychosis

Comparison: 15 PHASE-SPECIFIC TREATMENT (CANNABIS AND PSYCHOSIS THERAPY) + ANTIPSYCHOTICS vs PSYCHOEDUCATION + ANTIPSYCHOTICS

Outcome: 5 Mental state: 1. Average score (BPRS-E total endpoint, higher scores=poor) 


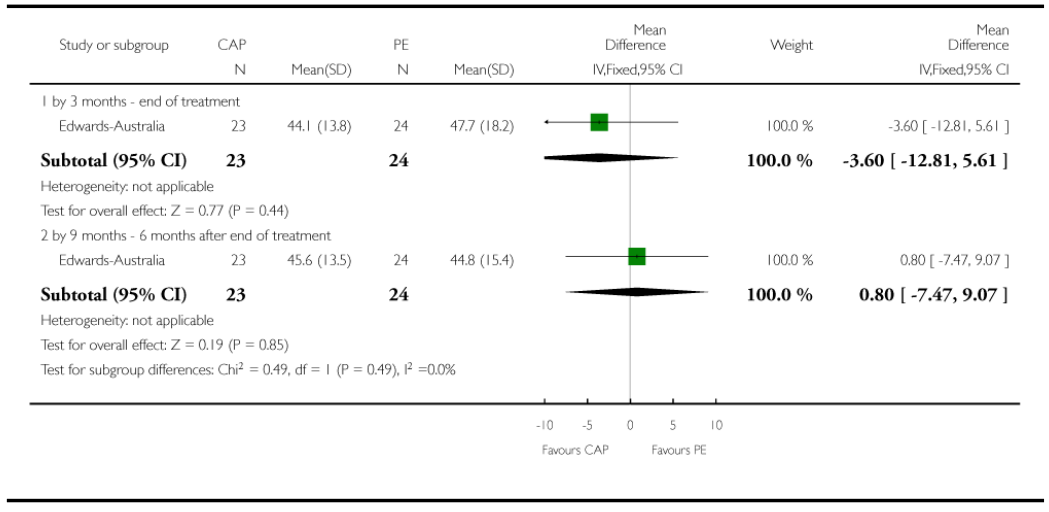

Analysis 15.6. Comparison 15 PHASE-SPECIFIC TREATMENT (CANNABIS AND PSYCHOSIS THERAPY) + ANTIPSYCHOTICS vs PSYCHOEDUCATION + ANTIPSYCHOTICS, Outcome 6 Mental state: 2. Average score (BPRS-PS total endpoint, higher scores=poor) (skewed data)

Mental state: 2. Average score (BPRS-PS total endpoint, higher scores=poor) (skewed data)

\begin{tabular}{lllll}
\hline Study & Intervention & Mean & SD & N \\
\hline by $\mathbf{3}$ months - end of treatment & & & \\
\hline Edwards-Australia & CAP & 8.9 & 4.8 & 23 \\
\hline Edwards-Australia & PE & 9.5 & 5.4 & 24 \\
\hline by 9 months - 6 months after end of treatment & \\
\hline Edwards-Australia & CAP & 9.4 & 4.6 & 23 \\
\hline Edwards-Australia & PE & 8.8 & 4.8 & 24 \\
\hline
\end{tabular}

Analysis 15.7. Comparison 15 PHASE-SPECIFIC TREATMENT (CANNABIS AND PSYCHOSIS THERAPY) + ANTIPSYCHOTICS vS PSYCHOEDUCATION + ANTIPSYCHOTICS, Outcome 7 Mental state: 3. Average negative symptom score (SANS endpoint, higher scores=poor) (skewed data)

Mental state: 3. Average negative symptom score (SANS endpoint, higher scores=poor) (skewed data)

\begin{tabular}{lrrrr}
\hline Study & Intervention & Mean & SD & N \\
\hline by 3 months - end of treatment & & & \\
\hline
\end{tabular}




\begin{tabular}{lllll}
\hline Study & Intervention & Mean & SD & N \\
\hline Edwards-Australia & CAP & 21.8 & 14.9 & 23 \\
\hline Edwards-Australia & PE & 23.5 & 14.0 & 24 \\
\hline by 9 months - 6 months after end of treatment & \\
\hline Edwards-Australia & CAP & 23.7 & 17.2 & 23 \\
\hline Edwards-Australia & PE & 19.4 & 13.5 & 24 \\
\hline
\end{tabular}

Analysis 15.8. Comparison 15 PHASE-SPECIFIC TREATMENT (CANNABIS AND PSYCHOSIS THERAPY) + ANTIPSYCHOTICS vs PSYCHOEDUCATION + ANTIPSYCHOTICS, Outcome 8 Mental state: 4. Average score (BDI-SF total endpoint, higher scores=poor) (skewed data)

Mental state: 4. Average score (BDI-SF total endpoint, higher scores=poor) (skewed data)

\begin{tabular}{lllll}
\hline Study & Intervention & Mean & SD & N \\
\hline by 3 months - end of treatment & & & \\
\hline Edwards-Australia & CAP & 6.2 & 5.9 & 23 \\
\hline Edwards-Australia & PE & 7.8 & 8.1 & 24 \\
\hline by 9 months - 6 months after end of treatment & \\
\hline Edwards-Australia & CAP & 7.5 & 6.3 & 23 \\
\hline Edwards-Australia & PE & 6.3 & 7.2 & 24 \\
\hline & & & &
\end{tabular}

Analysis 15.9. Comparison 15 PHASE-SPECIFIC TREATMENT (CANNABIS AND PSYCHOSIS THERAPY) + ANTIPSYCHOTICS vS PSYCHOEDUCATION + ANTIPSYCHOTICS, Outcome 9 Social functioning: Average score (SOFAS total endpoint, higher scores=good)

Review: Early intervention for psychosis

Comparison: 15 PHASE-SPECIFIC TREATMENT (CANNABIS AND PSYCHOSIS THERAPY) + ANTIPSYCHOTICS vs PSYCHOEDUCATION + ANTIPSYCHOTICS

Outcome: 9 Social functioning: Average score (SOFAS total endpoint, higher scores=good) 


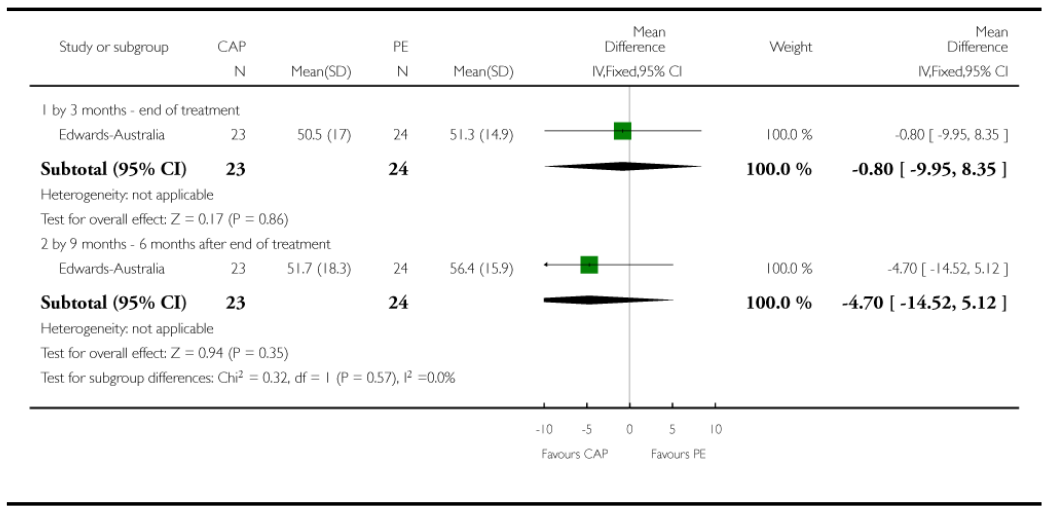

\section{Analysis 16.1. Comparison 16 CRISIS ASSESSMENT versus STANDARD CARE (LEO-CAT), Outcome 1 Hospitalisation}

Review: Early intervention for psychosis

Comparison: 16 CRISIS ASSESSMENT versus STANDARD CARE (LEO-CAT)

Outcome: 1 Hospitalisation

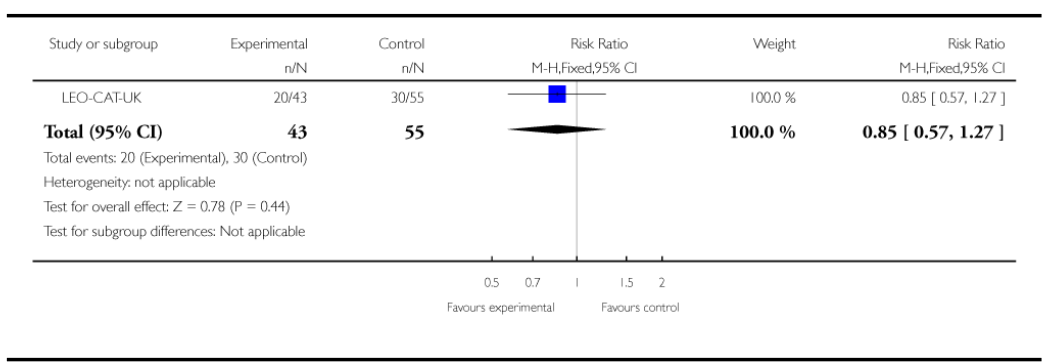

\section{Analysis 16.2. Comparison 16 CRISIS ASSESSMENT versus STANDARD CARE (LEO-CAT), Outcome 2 Referred to Mental Health Services by A\&E or emergency medical services}

Review: Early intervention for psychosis

Comparison: 16 CRISIS ASSESSMENT versus STANDARD CARE (LEO-CAT)

Outcome: 2 Referred to Mental Health Services by A\%E or emergency medical services 


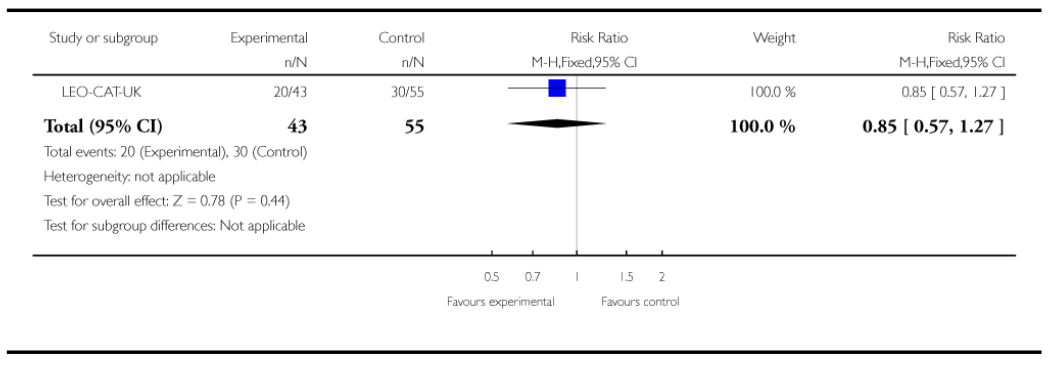

\section{Analysis 17.1. Comparison 17 EARLY BEHAVIOURAL INTERVENTION vS ROUTINE CARE INTERVAL (Alverez-Spain), Outcome 1 Weight}

Weight

\begin{tabular}{lllll}
\hline Study & Intervention & Mean endpoint score & SD & N \\
\hline \multicolumn{2}{l}{ Weight change at 13 weeks } & & & \\
\hline Alvarez-Spain & Early Behavioral Intervention & 4.10 & 3.99 & 28 \\
\hline Alvarez-Spain & Routine Care Intervention & 6.98 & 4.50 & 33 \\
\hline Body Mass Index & & & \\
\hline Alvarez-Spain & Early Behavioral Intervention & 1.40 & 1.34 & 28 \\
\hline Alvarez-Spain & Routine Care Intervention & 2.39 & 1.53 & 33 \\
\hline
\end{tabular}

\section{Analysis 18.1. Comparison 18 PHASE-SPECIFIC INTERVENTION versus CONTROL (Exploratory meta-analysis), Outcome 1 Leaving the study early}

Review: Early intervention for psychosis

Comparison: 18 PHASE-SPECIFIC INTERVENTION versus CONTROL (Exploratory meta-analysis)

Outcome: 1 Leaving the study early 


\begin{tabular}{|c|c|c|c|c|c|c|}
\hline Study or subgroup & $\begin{array}{r}\text { Experimental } \\
n / N\end{array}$ & $\begin{array}{r}\text { Control } \\
\mathrm{n} / \mathrm{N}\end{array}$ & \multicolumn{2}{|c|}{$\begin{array}{c}\text { Risk Ratio } \\
\text { M-H, Fixed,95\% Cl }\end{array}$} & Weight & $\begin{array}{r}\text { Risk Ratio } \\
\text { M-H,Fixed,95\% C }\end{array}$ \\
\hline Jackson-Australia & $4 / 31$ & $7 / 31$ & $=$ & & $31.7 \%$ & $0.57[0.19,1.76]$ \\
\hline Leavey-UK & 10/57 & 12/49 & 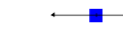 & & $58.5 \%$ & $0.72[0.34,1.51]$ \\
\hline Uzenoff-USA & 3/13 & $2 / 11$ & & $\longrightarrow$ & $9.8 \%$ & $1.27[0.26,6.28]$ \\
\hline Total $(95 \% \mathrm{CI})$ & 101 & 91 & - & - & $100.0 \%$ & $0.72[0.41,1.29]$ \\
\hline \multicolumn{7}{|c|}{ Total events: 17 (Experimental), 21 (Control) } \\
\hline \multicolumn{7}{|c|}{ Heterogeneity. $C i^{2}=0.64, d f=2(P=0.72) ; 1^{2}=0.0 \%$} \\
\hline \multicolumn{7}{|c|}{ Test for overall effect: $Z=1.10(P=0.27)$} \\
\hline \multicolumn{7}{|c|}{ Test for subgroup differences: Not applicable } \\
\hline & & & $0.5 \quad 0.7$ & $1.5 \quad 2$ & & \\
\hline & & & Favours experimental & Favours control & & \\
\hline
\end{tabular}

\section{Analysis 18.2. Comparison 18 PHASE-SPECIFIC INTERVENTION versus CONTROL (Exploratory meta-analysis), Outcome 2 Hospitalisation}

Review: Early intervention for psychosis

Comparison: 18 PHASE-SPECIFIC INTERVENTION versus CONTROL (Exploratory meta-analysis)

Outcome: 2 Hospitalisation

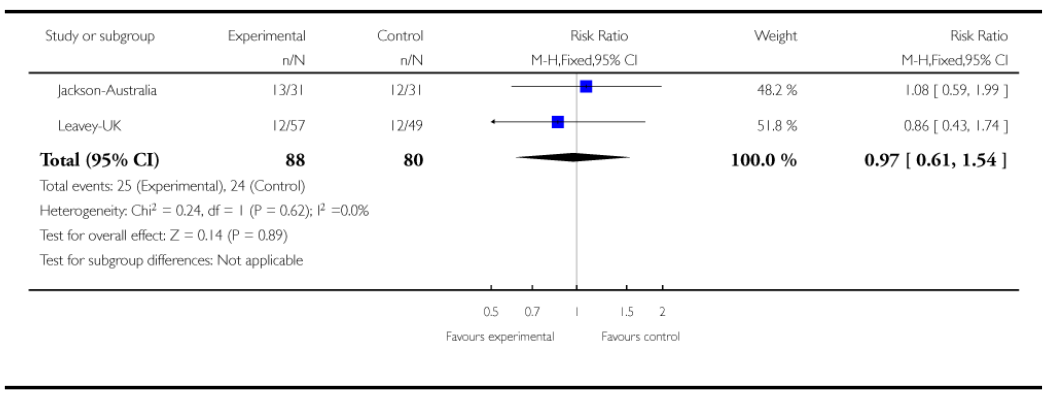

\section{Appendix 1. Previous searches for earlier versions of this review}

1. Electronic search for update (March 2006)

We searched The Cochrane Schizophrenia Group Trials Register (July 2003 to March 2006) using the phrase: [early* in title, abstract or keywords of REFERENCE] or [Early* in intervention or 'prodromal or early*' in HealthCare Condition of STUDY]

This register is compiled by systematic searches of major databases, hand searches and conference proceedings (see Group Module).

2. Details of previous searches

We generated a list of relevant papers from our personal databases. On the basis of the indexing of these papers, we developed the following searches: 
2.1 Electronic searches

2.1.1 We searched The Cochrane Schizophrenia Group's Register (July 2003) using the following phrase:

[Early* in intervention or 'prodromal or early*' in Health Care Condition of STUDY] or [early* in title, abstract or keywords of REFERENCE]

2.1.2 We searched CINAHL (1982 to November 2002, Ovid online) using the following phrase:

1. exp SCHIZOPHRENIA/ or exp SCHIZOPHRENIA, CATATONIC/ or exp SCHIZOPHRENIA, CHILDHOOD/ or exp SCHIZOPHRENIA, DISORGANIZED/ or exp SCHIZOPHRENIA, PARANOID/

2. exp Paranoid Disorders/

3. (schizo $\$$ or psychotic $\$$ or psychosis or psychoses or hebephreni $\$$ or oligophreni\$).mp. [mp=title, abstract, subject headings, drug trade name, original title, device manufacturer, drug manufacturer name]

4. ((CHRONIC \$ or SEVER\$) adj5 MENTAL\$ adj5 (ILL\$ or DISORDER\$)).mp. [mp=title, abstract, subject headings, drug trade name, original title, device manufacturer, drug manufacturer name]

5. 1 or 2 or 3 or 4

6. ((risk\$ adj3 schiz\$) or (screen\$ adj3 schiz\$)).mp.

7. ((duration or length) adj3 untreat\$).mp.

8. ((first or initial or primary) adj3 (admission\$ or hospital\$ or episod\$ or breakdown\$)).mp.

9. (early adj3 (intervent $\$$ or treat $\$$ or recogni $\$$ or detect $\$)$ ).mp.

10. (delay $\$$ adj3 treat\$).mp.

11. (‘ (DUP)' or premorbid\$ or prodrom\$).mp.

12. 6 or 7 or 8 or 9 or 10 or 11

13. 12 and 5

14. (animal not human).mp.

15. 13 not 14

2.1.3 We searched The Cochrane Controlled Trials Register (November 2001) using the following phrase: 


\section{1. exp SCHIZOPHRENIA/ or exp SCHIZOPHRENIA, CATATONIC/ or exp SCHIZOPHRENIA, CHILDHOOD/ or exp SCHIZOPHRENIA, DISORGANIZED/ or exp SCHIZOPHRENIA, PARANOID/}

\section{2. exp Paranoid Disorders/}

3. (schizo $\$$ or psychotic $\$$ or psychosis or psychoses or hebephreni $\$$ or oligophreni\$).mp. [mp=title, abstract, subject headings, drug trade name, original title, device manufacturer, drug manufacturer name]

4. ((CHRONIC\$ or SEVER\$) adj5 MENTAL\$ adj5 (ILL\$ or DISORDER\$)).mp. [mp=title, abstract, subject headings, drug trade name, original title, device manufacturer, drug manufacturer name]

\section{1 or 2 or 3 or 4}

6. ((risk\$ adj3 schiz\$) or (screen\$ adj3 schiz\$)).mp.

7. ((duration or length) adj3 untreat\$).mp.

8. ((first or initial or primary) adj3 (admission\$ or hospital\$ or episod\$ or breakdown\$)).mp.

9. (early adj3 (intervent $\$$ or treat $\$$ or recogni $\$$ or detect $\$)$ ).mp.

10. (delay\$ adj3 treat\$).mp.

11. (‘ (DUP) ’ or premorbid\$ or prodrom\$).mp.

12. 6 or 7 or 8 or 9 or 10 or 11

13. 12 and 5

14. (animal not human).mp.

15. 13 not 14

2.1.4 We searched Embase (1966 to November 2002, Ovid online) using the following phrase:

1. exp SCHIZOPHRENIA/ or exp SCHIZOPHRENIA, CATATONIC/ or exp SCHIZOPHRENIA, CHILDHOOD/ or exp SCHIZOPHRENIA, DISORGANIZED/ or exp SCHIZOPHRENIA, PARANOID/

2. exp Paranoid Disorders/

3. (schizo $\$$ or psychotic $\$$ or psychosis or psychoses or hebephreni\$ or oligophreni\$).mp. [mp=title, abstract, subject headings, drug trade name, original title, device manufacturer, drug manufacturer name] 
4. ((CHRONIC\$ or SEVER\$) adj5 MENTAL\$ adj5 (ILL\$ or DISORDER\$)).mp. [mp=title, abstract, subject headings, drug trade name, original title, device manufacturer, drug manufacturer name]

5. 1 or 2 or 3 or 4

6. ((risk\$ adj3 schiz\$) or (screen\$ adj3 schiz\$)).mp.

7. ((duration or length) adj3 untreat\$).mp.

8. ((first or initial or primary) adj3 (admission\$ or hospital\$ or episod\$ or breakdown\$)).mp.

9. (early adj3 (intervent\$ or treat\$ or recogni\$ or detect\$)).mp.

10. (delay\$ adj3 treat\$).mp.

11. ( ( (DUP) ' or premorbid\$ or prodrom\$).mp.

12. 6 or 7 or 8 or 9 or 10 or 11

13. 12 and 5

14. (animal not human).mp

15. 13 not 14

2.1.5 We searched Medline (1966 to November 2002, Ovid online) using the phrase:

1. exp SCHIZOPHRENIA/ or exp SCHIZOPHRENIA, CATATONIC/ or exp SCHIZOPHRENIA, CHILDHOOD/ or exp SCHIZOPHRENIA, DISORGANIZED/ or exp SCHIZOPHRENIA, PARANOID/

2. exp Paranoid Disorders/

3. (schizo $\$$ or psychotic\$ or psychosis or psychoses or hebephreni \$ or oligophreni\$).mp. [mp=title, abstract, subject headings, drug trade name, original title, device manufacturer, drug manufacturer name]

4. ((CHRONIC\$ or SEVER\$) adj5 MENTAL\$ adj5 (ILL\$ or DISORDER\$)).mp. [mp=title, abstract, subject headings, drug trade name, original title, device manufacturer, drug manufacturer name]

5. 1 or 2 or 3 or 4

6. ((risk $\$ \operatorname{adj} 3$ schiz\$) or (screen $\$ \operatorname{adj} 3$ schiz $\$)) . m p$.

7. ((duration or length) adj3 untreat\$).mp.

8. ((first or initial or primary) adj3 (admission\$ or hospital\$ or episod\$ or breakdown\$)).mp.

9. (early adj3 (intervent $\$$ or treat $\$$ or recogni $\$$ or detect\$)).mp. 
10. (delay\$ adj3 treat\$).mp.

11. (' (DUP) ' or premorbid\$ or prodrom\$).mp.

12. 6 or 7 or 8 or 9 or 10 or 11

13. 12 and 5

14. (animal not human).mp.

15. 13 not 14

2.1.6 We searched PsychINFO (1872 to November 2002, Ovid online) using the following phrase:

1. exp SCHIZOPHRENIA/ or exp SCHIZOPHRENIA, CATATONIC/ or exp SCHIZOPHRENIA, CHILDHOOD/ or exp SCHIZOPHRENIA, DISORGANIZED/ or exp SCHIZOPHRENIA, PARANOID/

2. exp Paranoid Disorders/

3. (schizo $\$$ or psychotic $\$$ or psychosis or psychoses or hebephreni \$ or oligophreni $\$$ ).mp. [mp=title, abstract, subject headings, drug trade name, original title, device manufacturer, drug manufacturer name]

4. ((CHRONIC\$ or SEVER\$) adj5 MENTAL\$ adj5 (ILL\$ or DISORDER\$)).mp. [mp=title, abstract, subject headings, drug trade name, original title, device manufacturer, drug manufacturer name]

5.1 or 2 or 3 or 4

6. ((risk\$ adj3 schiz\$) or (screen $\$ \operatorname{adj} 3$ schiz $\$)) . m p$.

7. ((duration or length) adj3 untreat\$).mp.

8. ((first or initial or primary) adj3 (admission\$ or hospital\$ or episod\$ or breakdown\$)).mp.

9. (early adj3 (intervent\$ or treat\$ or recogni $\$$ or detect\$)).mp.

10. (delay\$ adj3 treat\$).mp.

11. (' (DUP) ' or premorbid\$ or prodrom\$).mp.

12. 6 or 7 or 8 or 9 or 10 or 11

13. 12 and 5

14. (animal not human).mp.

15. 13 not 14 


\section{Appendix 2. Risk of Bias}

Assessment of methodological quality

We assessed the methodological quality of included trials in this review using the criteria described in the Cochrane Handbook (Higgins 2005) and the Jadad scale (Jadad 1996). The former is based on the evidence of a strong relationship between allocation concealment and direction of effect (Schulz 1995). We allocated non-randomised studies (of early detection only, see above) to Category $\mathrm{C}$. We performed a sensitivity analysis excluding trials in randomisation Category $\mathrm{C}$, and trials with a follow up rate of less than $80 \%$. The categories are defined below:

A. Low risk of bias (adequate allocation concealment)

B. Moderate risk of bias (some doubt about the results)

C. High risk of bias (inadequate allocation concealment). For the purpose of the analysis in this review, we excluded trials if they met the Cochrane Handbook criteria A or B.

The Jadad Scale measures a wider range of factors that impact on the quality of a trial. The scale includes three items:

1. Was the study described as randomised?

2. Was the study described as double-blind?

3. Was there a description of withdrawals and drop outs?

Each item receives one point if the answer is positive. In addition, a point can be deducted if either the randomisation or the blinding/masking procedures described are inadequate. For this review we used a cut-off of two points on the Jadad scale to check the assessment made by the Handbook criteria. However we did not use the Jadad Scale was to exclude trials.

\section{HISTORY}

Protocol first published: Issue 1, 2004

Review first published: Issue 2, 2004

\begin{tabular}{lll}
\hline Date & Event & Description \\
\hline 23 August 2006 & New citation required and conclusions have changed & Substantive amendment \\
\hline
\end{tabular}

\section{WHAT'S NEW}

Last assessed as up-to-date: 3 June 2009. 


\begin{tabular}{lll}
\hline Date & Event & Description \\
\hline 11 March 2011 & $\begin{array}{l}\text { New citation required and conclusions have } \\
\text { changed }\end{array}$ & $\begin{array}{l}\text { conclusions changed after addition of 11 new } \\
\text { studies }\end{array}$ \\
\hline 16 February 2010 & New search has been performed & $\begin{array}{l}\text { Updated, 11 new studies added, conclusions } \\
\text { changed. }\end{array}$ \\
\hline
\end{tabular}

\section{DIFFERENCES BETWEEN PROTOCOL AND REVIEW}

For the 2009 update we used a more conservative estimate of $\mathrm{I}^{2}>50 \%$ to indicate heterogeneity. We have extensively reformatted this review but not substantively changed any methods.

\section{SUMMARY OF FINDINGS FOR THE MAIN COMPARISON}

PHASE SPECIFIC TREATMENT (RISPERIDONE + CBT) + SPECIALISED TEAM compared to SPECIALISED TEAM for psychosis

Patient or population: patients with psychosis

Settings: Melbourne, Australia

Intervention: PHASE SPECIFIC TREATMENT (RISPERIDONE + CBT) + SPECIALISED TEAM

Comparison: SPECIALISED TEAM 


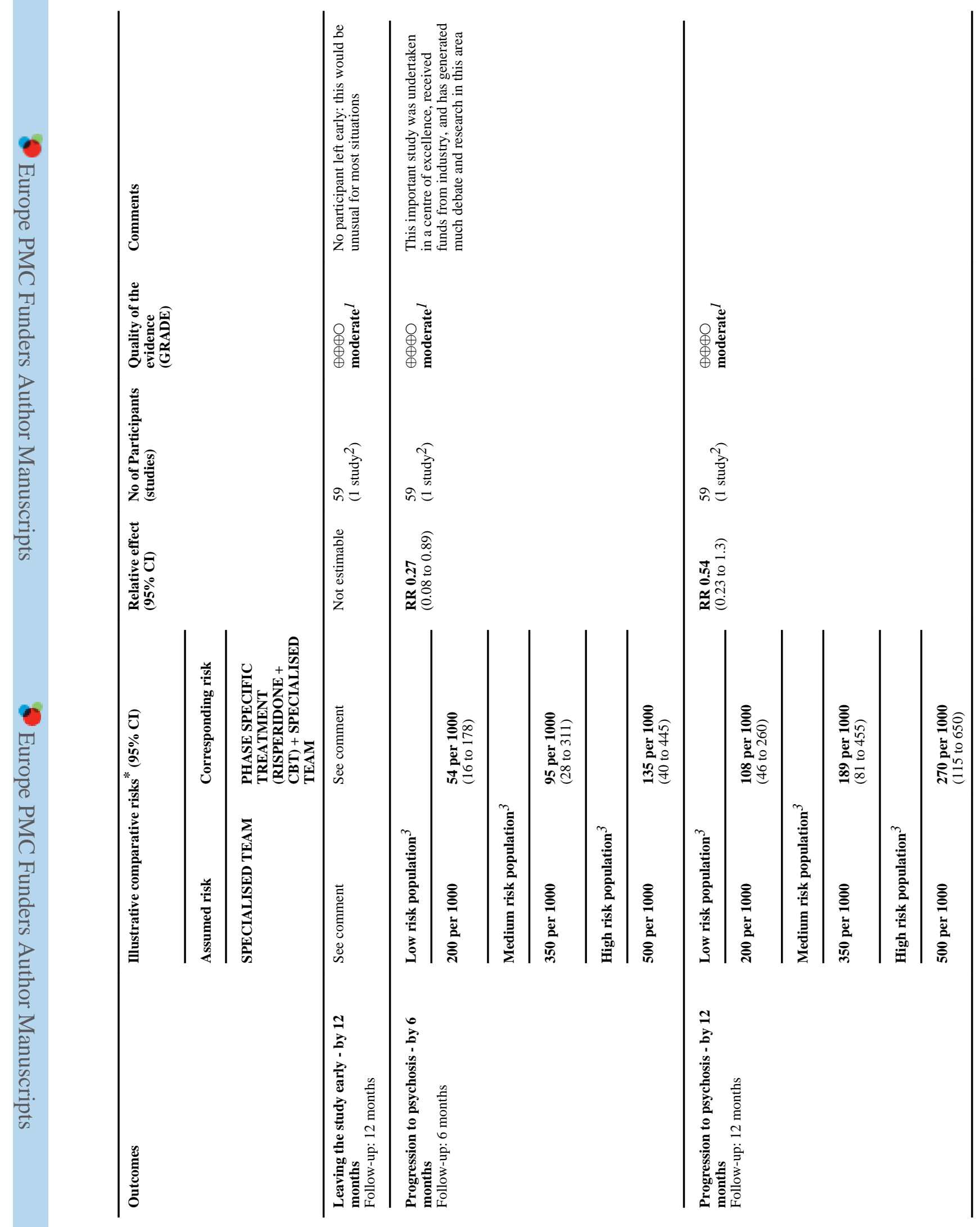




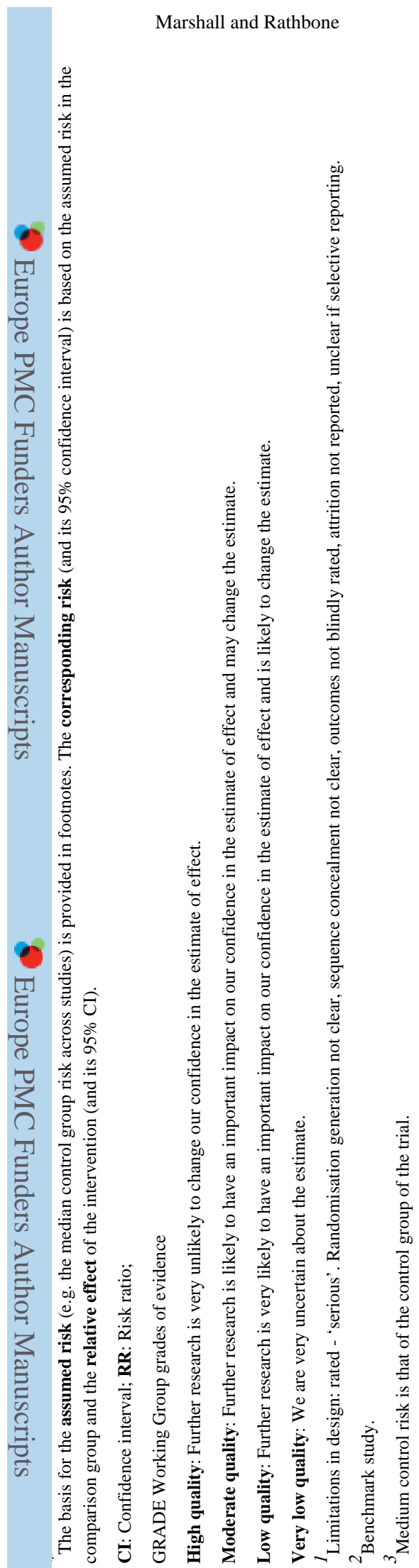

Cochrane Database Syst Rev. Author manuscript; available in PMC 2014 September 15. 


\section{ADDITIONAL SUMMARY OF FINDINGS}

SPECIALISED TEAM compared to STANDARD CARE for psychosis

Patient or population: patients with psychosis

Settings: Scandinavia

Intervention: SPECIALISED TEAM

Comparison: STANDARD CARE 


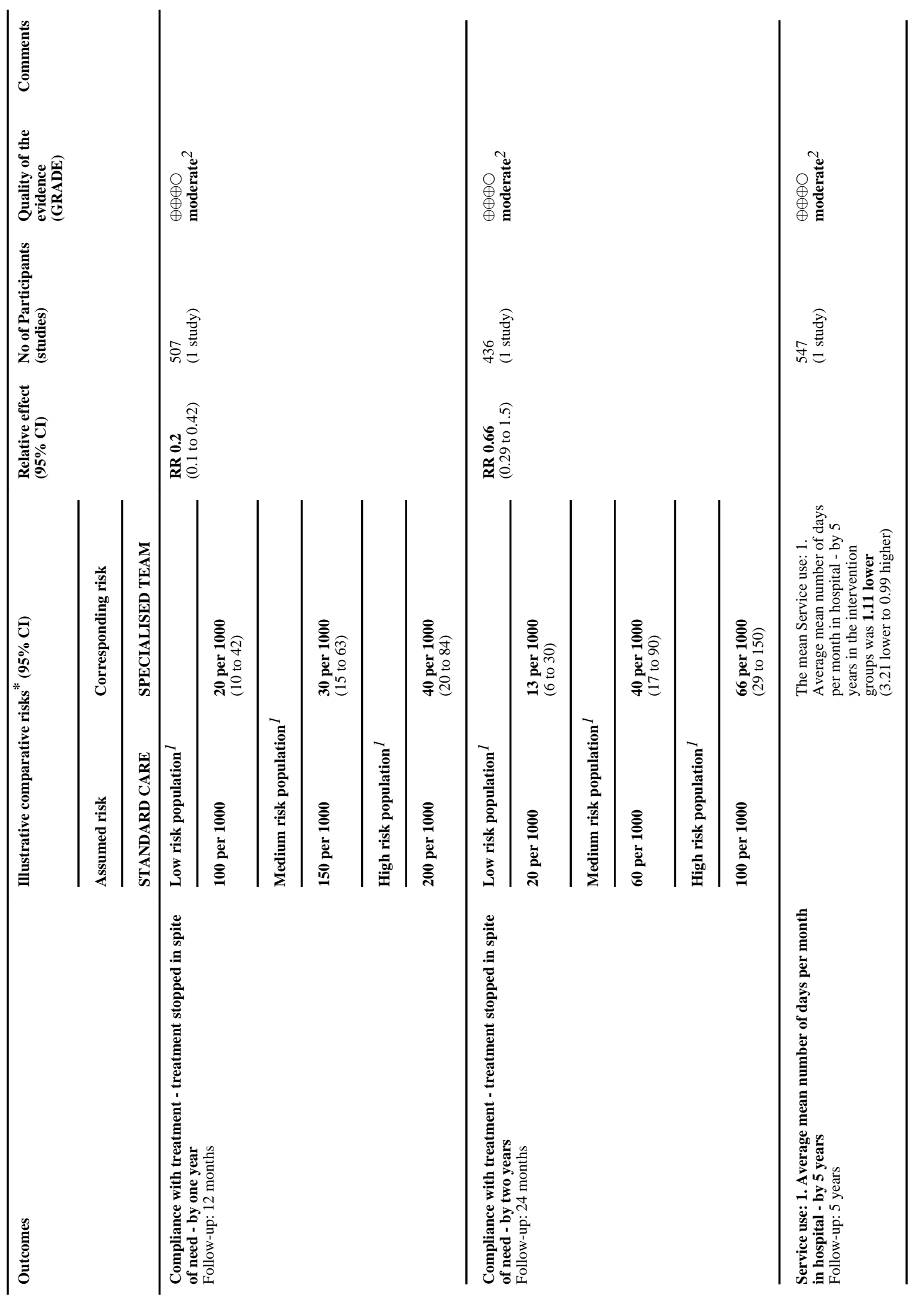




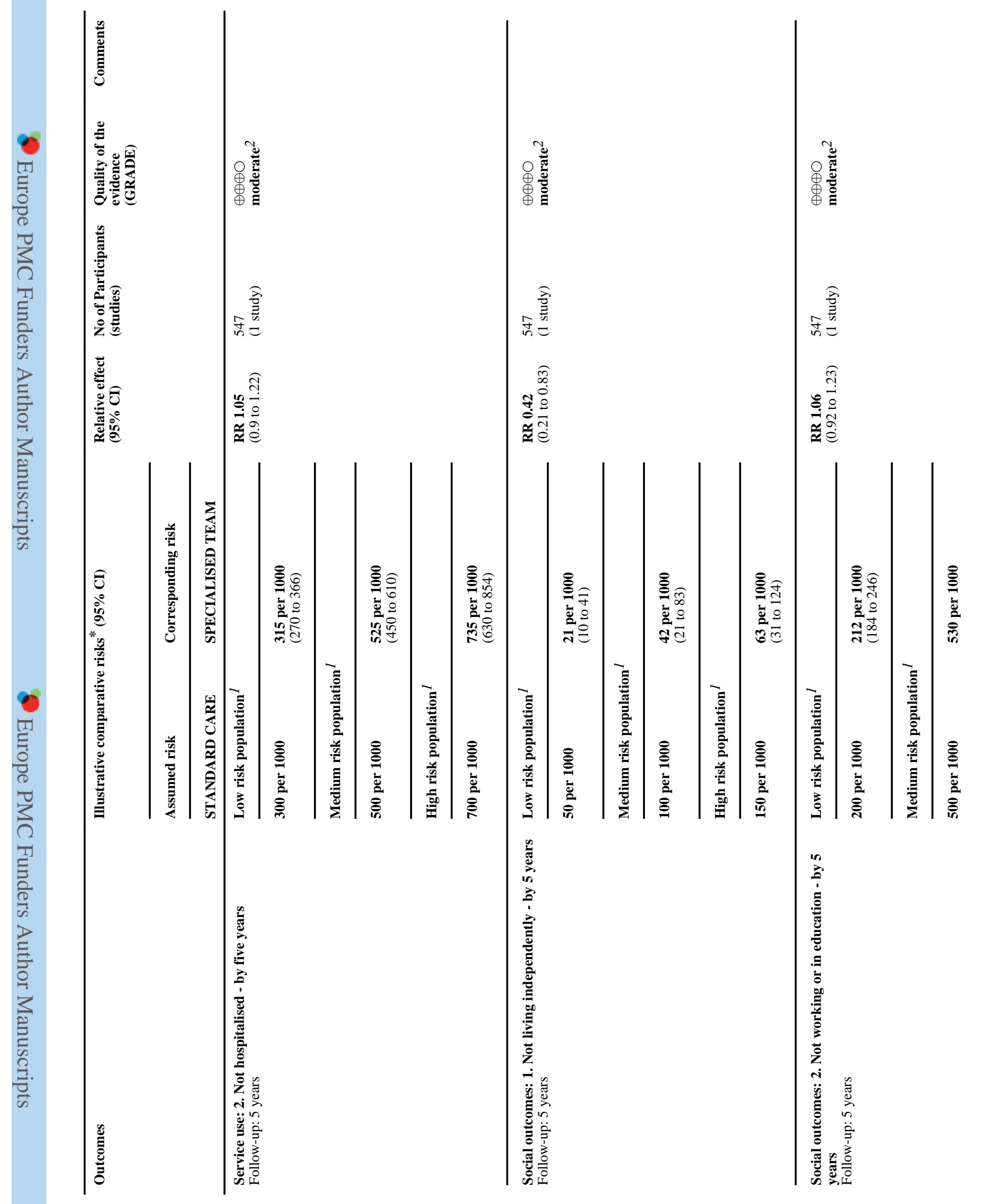




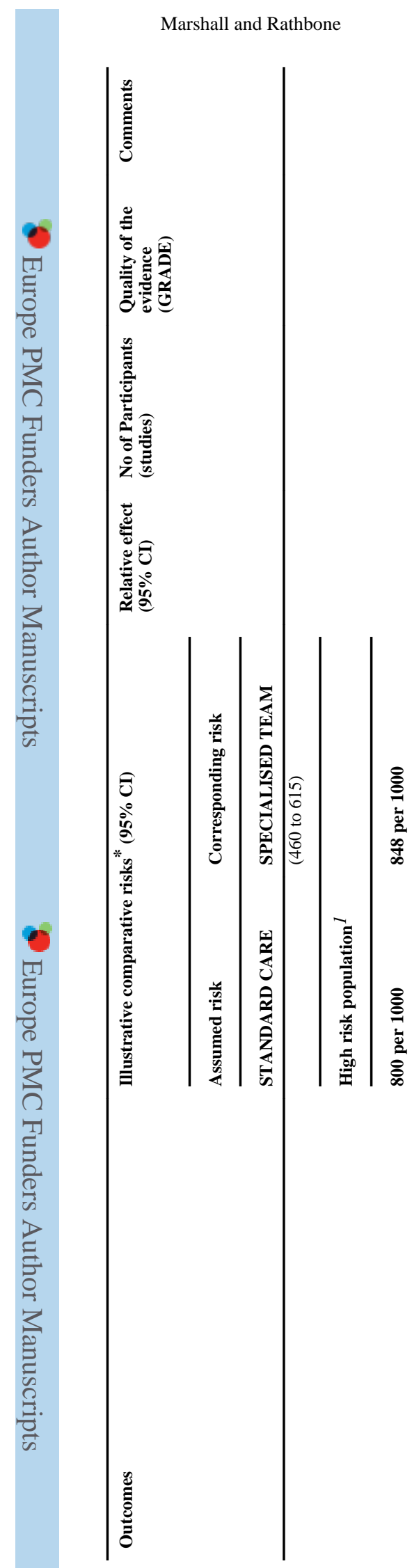

Page 141

章

Cochrane Database Syst Rev. Author manuscript; available in PMC 2014 September 15. 


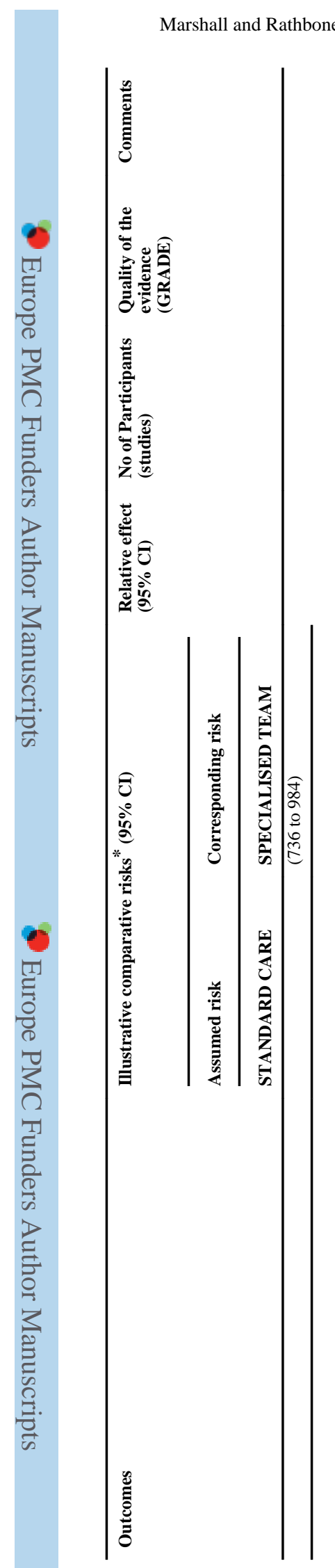

Page 142 


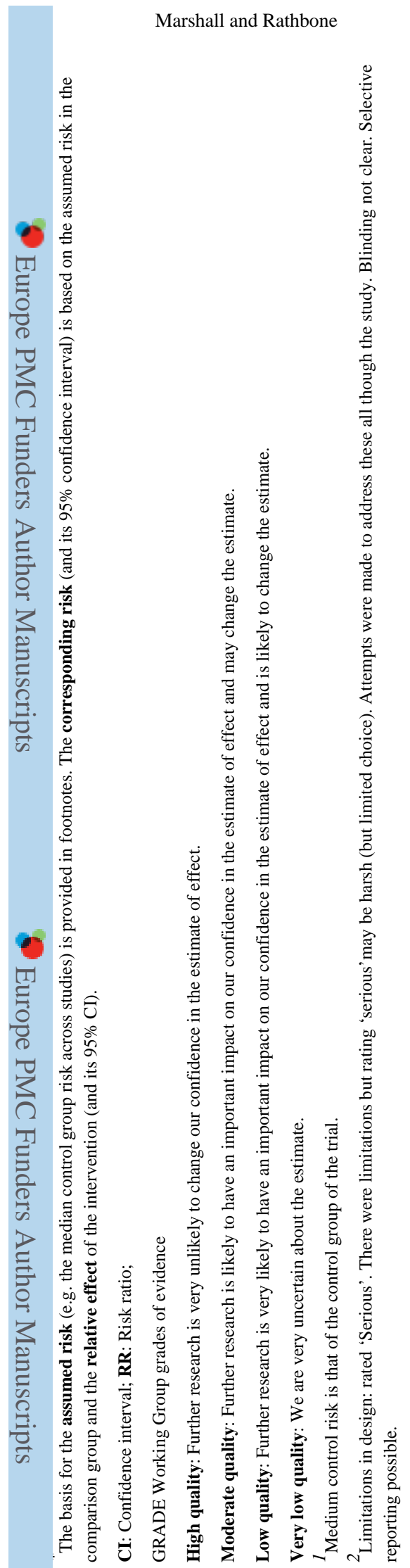

Cochrane Database Syst Rev. Author manuscript; available in PMC 2014 September 15. 


\section{References to studies included in this review}

Alvarez-Spain $\quad$ ppublished data only\} . Alvarez-Jimenez M, Gonzalez-Blanch C, VazquezBarquero JL, Perez-Iglesias R, Martinez-Garcia O, Perez-Pardal T, Ramírez-Bonilla ML, Crespo-Facorro B. Attenuation of antipsychotic-induced weight gain with early behavioral intervention in drug-naive first-episode psychosis patients: a randomized controlled trial. Journal of Clinical Psychiatry. 2006; 67(8):1253-60. [EMBASE: 2006468531]. [PubMed: 16965204] Alvarez M, Gonzalez-Blanch C, Perez-Iglesias R, Perez-Pardal T, Martinez-Garcia O, CrespoFacorro B, Vazquez-Barquero JL. Early intervention in antipsychotic - induced weight gain in first episode psychosis. Schizophrenia Bulletin. 2005; 31:518.

Amminger-Austria \{published data only\} . Amminger G, Schaefer MR, Papageorgiou K, Becker J, Mossaheb N, Harrigan SM, McGorry PD, Berger GE. Omega-3 fatty acids reduce the risk of early transition to psychosis in ultra-high risk individuals: a double blind randomized, placebocontrolled treatment study. Schizophrenia Bulletin. 2007; 33(2):418-9.Amminger GP. Indicated prevention with omega-3 fatty acids in adolescents with 'at-risk-mental-state' for psychosis: a randomised, double blind, placebo-controlled treatment trial. $2006 \mathrm{http}: / / \mathrm{www}$.clinicaltrials.gov. Amminger GP, Schafer MR. Indicated prevention with omega-3 fatty acids in adolescents at ultra-high risk for psychosis - rationale, methods, and 3-months outcome. Schizophrenia Research. 2006; 86(Suppl 1):S97-8.Amminger GP, Schafer MR. Is it feasible to conduct a RCT in ultra-high risk individuals at a child and adolescent psychiatric service? Schizophrenia Research. 2006; 86(Suppl 1):S98.Schafer MR, Klier CM, Papageorgiou K, Friedrich MH, Amminger GP. Early detection of psychotic disorders. Neuropsychiatrie. 2007; 21(1):37-44. [PubMed: 17555006]

Berger-Australia \{published data only\} . Berger G, Wood S, Proffitt T, Mcconchie M, Khan A, O’Donnell C, Yuen H, Smith D, Horrobin D, McGorry P. Ethyl-eicosapentaenoic acid (e-epa) supplementation in early psychosis. A double-blind randomized add on standard therapy study in 80 drug- native or early treated first episode psychosis patients. Schizophrenia Research. 2004; 70(1):41. [: ISI:000224551100105]. Berger GB, Proffitt TM, Mcconchie MA, Wood SJ, Yuen HP, Smith D, Horrobin D, McGorry PD. Ethyleicosapentaenoic acid (e-epa) supplementation in early psychosis. Schizophrenia Research. 2004; 67(1):7-8. [: ISI 000188788100014]. Berger GE, Proffitt T-M, McConchie M, Yuen H, Wood SJ, Amminger GP, Brewer W, McGorry PD. Ethyleicosapentaenoic acid in first-episode psychosis: a randomized, placebo-controlled trial. Journal of Clinical Psychiatry. 2007; 68(12):1867-75. [MEDLINE: 18162017]. [PubMed: 18162017] Berger GE, Proffitt TM, McConchie MA, Wood SJ, Yuen HP, McGorry PD. Ethyl eicosapentaenoic acid (e - epa) supplementation in early psychosis. A double - blind, randomized, placebo - controlled trial (RCT) comparing $2 \mathrm{~g}$ e - epa versus placebo add - on therapy in 80 drug - naive or early treated first - episode psychos. Schizophrenia Bulletin. 2005; 31:475.Berger GE, Wood SJ, Wellard RM, Proffitt TM, McConchie M, Amminger GP, Jackson GD, Velakoulis D, Pantelis C, McGorry PD. Ethyl-eicosapentaenoic acid in first-episode psychosis. A 1H-MRS study. Neuropsychopharmacology. 2008; 33(10):2467-73. [MEDLINE: 18199999]. [PubMed: 18199999] Mcconchie MA, Berger GE, Proffitt TM, Yuen HP, Wood S, Smith D, Horrobin D, McGorry PD. Effect of diagnostic heterogeneity on response to ethyleicosapentaenoic acid (epa) in first-episode psychosis. Schizophrenia Research. 2004; 67(1):1478. [: ISI 000188788100352].

EDIE-UK \{published data only\} . French P, Shryane N, Bentall RP, Lewis SW, Morrison AP. Effects of cognitive therapy on the longitudinal development of psychotic experiences in people at high risk of developing psychosis. British Journal of Psychiatry - Supplementum. 2007; 51:s82-7.Lewis S. EDIE - Early detection and intervention for psychosis. National Research Register. 2001; Vol. 3Morrison A. Early detection and intervention for psychosis in primary care. National Research Register. 2003Morrison A. Follow-up of prodromal symptoms. National Research Register. 2004; Vol. 3Morrison AP. Cognitive therapy for the prevention of psychosis in people at ultra-high risk: results of a randomised controlled trial. Schizophrenia Research. 2006; 86(Suppl 1):s59.Morrison AP, Bentall RP, French P, Walford L, Kilcommons A, Knight A, Kreutz M, Lewis SW. Randomised controlled trial of early detection and cognitive therapy for preventing transition to psychosis in high-risk individuals. Study design and interim analysis of transition rate and psychological risk factors. British Journal of Psychiatry. 2002; 43:s7884.Morrison AP, French P, Parker S, Roberts M, Stevens H, Bentall RP, Lewis SW. Three-year 
follow-up of a randomized controlled trial of cognitive therapy for the prevention of psychosis in people at ultrahigh risk. Schizophrenia Bulletin. 2007; 33(3):682-7. [EMBASE: 2007428663; MEDLINE: 16973786; PSYCINFO: 2007-08119-011]. [PubMed: 16973786] *Morrison AP, French P, Walford L, Lewis SW, Kilcommons A, Green J, Parker S, Bentall RP. Cognitive therapy for the prevention of psychosis in people at ultra-high risk: randomised controlled trial. British Journal of Psychiatry. 2004; 185:291-7. [PubMed: 15458988] Morrison T. Early detection and intervention for psychosis in primary care. National Research Register. 2001; Vol. 1Renton J, Morrison AP. Effectiveness of cognitive therapy for psychosis and implications for early intervention. Schizophrenia Research. 2004; 70(1):142. [: ISI: 000224551100421].

Edwards-Australia \{published data only\} . Edwards J, Elkins K, Hinton M, Harrigan SM, Donovan $\mathrm{K}$, Athanasopoulos O, McGorry PD. Randomized controlled trial of a cannabis-focused intervention for young people with first-episode psychosis. Acta Psychiatrica Scandinavica. 2006; 114:109-17. [PubMed: 16836598]

EIPS-Germany \{published data only\} . Bechdolf A. Development and pilot evaluation of modified cognitive behavioural therapy for adolescents with EARLY onset psychosis. $2007 \mathrm{http}: / /$ www.clinicaltrials.gov. Bechdolf A. Psychological intervention for persons at risk of psychosis in the early initial prodromal state. 2005 http://www.clinicaltrials.gov. Bechdolf A, Buhler B, Berning J, Wagner M, Stamm E, Streit M. Cognitive behavioural therapy in the early initial prodromal state of psychosis: first results. Schizophrenia Research. 2004; 67(1):202. [: ISI 000188788100483]. Bechdolf A, Klosterkotter J. Cognitive-behavioural treatment (CBT) in the early initial prodromal state of psychosis: concept and practical approach. Schizophrenia Research. 2004; 70(1):52. [: ISI:000224551100137]. Bechdolf A, Ruhrmann S, Janssen B, Bottlender R, Wagner M, Maurer K, Hafner H, Maier W, Klosterkotter J. Early recognition and intervention for people at risk of schizophrenia [FRUHERKENNUNG UND - INTERVENTION BEI PERSONEN MIT ERHOHTEM PSYCHOSERISIKO]. Psychoneuro. 2004; 30(11):606-14. [: EMBASE 2004516569]. Bechdolf A, Veith V, Berning J, Stamm E, Decker P, Janssen B, Bottlender R, Wagner M, Klosterkotter J. Cognitive behavioral therapy (CBT) in the early initial prodromal state of psychosis: first results of a randomized trial. Schizophrenia Research. 2004; 70(1):62-3. [: ISI: 000224551100168]. Bechdolf A, Wagner M, Veith V, Ruhrmann R, Janssen $\mathrm{B}$, Bottlender R, et al. A randomised controlled multicenter trial of cognitive behaviour therapy in the early initial prodromal state of psychosis. Schizophrenia Research. 2006; 86(Suppl 1):S8.Bechdolf A, Wagner M, Veith V, Ruhrmann S, Pukrop R, Brockhaus-Dumke A, Berning J, Stamm E, Janssen B, Decker P, Bottlender R, Moller H-J, Gaebel W, Maier W, Klosterkotter J. Randomized controlled multicentre trial of cognitive behaviour therapy in the early initial prodromal state: effects on social adjustment post treatment. Early Intervention in Psychiatry. 2007; 1(1):71-8. [PSYCINFO: 2008-07770-011]. [PubMed: 21352110] Klosterkötter J. Early pharmacological and psychological intervention for late prodromal states of psychosis. http:// www.clinicaltrials.gov. Lammertink, M. FETZ the first German early recognition and intervention centre for schizophrenic psychoses - how it works and what it aims for. Proceedings of the 2nd International Conference on Early Psychosis; New York, USA. 2000 Mar 31-Apr 2; 2000. [: ISI 000188788100381]

Jackson-Australia \{published data only\} . Jackson HJ, Killackey E, Bendall S, Allott K, Dudgeon P, Harrigan S. A randomised controlled trial of CBT for early psychosis with 1 year follow-up. Australian and New Zealand Journal of Psychiatry. 2005; 39(Suppl 2):A42. [CINAHL: 2009775290; PSYCINFO: 2007-19131-008]. *Jackson HJ, McGorry PD, Killackey E, Bendall S, Allott K, Dudgeon P, Gleeson J, Johnson T, Harrigan S. Acute-phase and 1-year follow-up results of a randomized controlled trial of CBT versus befriending for first-episode psychosis: the ACE project. Psychological Medicine. 2008; 38(5):725-35. [EMBASE: 2008165197; MEDLINE: 18005494]. [PubMed: 18005494] Killackey E, Jackson H, McGorry P, Bendall S, Allott K, Johnson T, Gleeson J, Harrigan S. The ACE project: a randomised controlled trial of CBT versus befriending for acute first episode psychosis: acute phase results. Schizophrenia Bulletin. 2005; 31:526-27. [: 114097].

Killackey-Australia \{published data only\} . Killackey E, Jackson H, McGorry P. Vocational intervention in a specialist early psychosis service: first results of a pilot randomised controlled trial. Schizophrenia Research. 2006; 86(Suppl 1):S28-S29.Killackey E, Jackson HJ, McGorry PD. Vocational intervention in first-episode psychosis: individual placement and support versus treatment as usual. British Journal of Psychiatry. 2008; 193(2):114-20. [PubMed: 18669993] 
Leavey-UK \{published data only\} . Leavey G, Gulamhussein S, Papadopoulos C, Johnson-Sabine E, Blizard BKM. A randomized controlled trial of a brief intervention for families of patients with a first episode of psychosis. Psychological Medicine. 2004; 34(3):423-31. [MEDLINE: 15259827]. [PubMed: 15259827]

LEO-CAT-UK \{published data only\} . Power P, Craig T, Mcguire P, Iacoponi E, Garety P, Russell M. A randomised controlled trial of an early detection team in first episode psychosis: the leo cat trial. Schizophrenia Research. 2004; 67(1):36. [: ISI 000188788100082]. Power P, Iacoponi E, Reynolds N, Fisher H, Russell M, Garety P, McGuire PK, Craig T. The Lambeth early onset crisis assessment team crisis assessment study: general practitioner education and access to an early detection team in first-episode psychosis. British Journal of Psychiatry. 2007; (Supp 51):s133-9.Power P, Iacoponi E, Russell M, Fisher H, Mcguire P, Garety P, Valmaggio L, Craig T. A randomised controlled trial of an early detection team in first- episode psychosis: provisional findings of the leo cat study. Schizophrenia Research. 2004; 70(1):131. [: ISI: 000224551100386].

LifeSPAN-Australia $\quad$ ppublished data only\} . Power, P.; Bell, R.; Mills, R.; Herrmann-Doig, T.; Davern, M.; Henry, L.; McGorry, P.; Khademy-Deljo, A. A randomized controlled trial of suicide prevention therapy for young people with first episode psychosis. Proceedings of the Second International Conference on Early Psychosis; New York, USA. 2000 March 31-2; 2000. Power P, Bell R, Mills R, Herrmann-Doig T, Davern M, Yuen H, McGorry P. A randomised controlled trial of a suicide preventative cognitive oriented psychotherapy for suicidal young people with first episode psychosis. Schizophrenia Research. 1999; 36:332.*Power PJ, Bell RJ, Mills R, Herrman-Doig T, Davern M, Henry L, Yuen HP, Khademy-Deljo A, McGorry PD. Suicide prevention in first episode psychosis: the development of a randomised controlled trial of cognitive therapy for acutely suicidal patients with early psychosis. Australian and New Zealand Journal of Psychiatry. 2003; 37(4):414-20. [MEDLINE: 12873325]. [PubMed: 12873325]

Linszen-Amsterdam \{published data only\} . Lenior ME, Dingemans PM, Schene AH, Linszen DH. Predictors and five-year outcome in early-onset schizophrenia. A path analysis. Schizophrenia Research. 2003; 60:292.Lenior ME, Dingemans PMAJ, Schene AH, Linszen DH. Predictors of the early 5-year course of schizophrenia: a path analysis. Schizophrenia Bulletin. 2005; 31(3): 781-91. [PubMed: 16123531] Linszen D. Early and critical period intervention in first episode schizophrenia: relapse, chronicity, early stabilisation, predictors over 4 years and new research. Schizophrenia Research. 2004; 70(1):66. [: ISI:000224551100177]. *Linszen D, Dingemans P, Lenior ME. Early intervention and a five-year follow-up in young adults with a short duration of untreated psychosis: ethical implications. Schizophrenia Research. 2001; 51:55-61. [PubMed: 11479066] Linszen D, Dingemans P, Van Der Does JW, Nugter A, Scholte P, Lenior R, Goldstein MJ. Treatment, expressed emotion and relapse in recent onset schizophrenic disorders. Psychological Medicine. 1996; 26(2):333-42. [PubMed: 8685289] Linszen D, Dingemans PM, Lenior ME, Scholte WF, Goldstein M. Early family and individual interventions and relapse in recent-onset schizophrenia and related disorders. Italian Journal of Psychiatry \& Behavioural Sciences. 1998; 8:77-84.Linszen D, Dingemans PM, Scholte WF, Lenior ME, Goldstein M. Early recognition, intensive intervention and other protective and risk factors for psychotic relapse in patients with first psychotic episodes in schizophrenia. International Clinical Psychopharmacology. 1998; 13(Suppl):S7-S12.Linszen D, Lenior M, De Haan L, Dingemans P, Gersons B. Early intervention, untreated psychosis and the course of early schizophrenia. British Journal of Psychiatry - Supplement. 1998; 172(Suppl):84-9. [PubMed: 9764132] Linszen D, Wouters L, Dingemans P, De Haan L, Nieman D. Early and 3-year sustained intervention in first episode schizophrenia: relapse, stabilization and its predictors. Schizophrenia Research. 2004; 67(1):18. [: ISI 000188788100038]. Linszen DH, De Haan L, Dingemans P, Van Bruggen M, Hofstra N, Van Engelsdorp H, Smitten M. Treatment reluctance in first episode schizophrenia: Lack of insight, non-compliance and cannabis abuse predict bad outcome after eighteen months intervention. Schizophrenia Research. 2003; 60:325. [EMBASE: 2005343078; MEDLINE: 12777272].

LIPS-Germany \{published data only\} . Bechdolf A, Ruhrmann S, Wagner M, Kuhn KU, Janssen B, Bottlender R, Wieneke A, Schulze-Lutter F, Maier W, Klosterkotter J. Interventions in the initial prodromal states of psychosis in Germany: concept and recruitment. British Journal of Psychiatry Supplementum. 2005; 187(Suppl 48):s45-8. [MEDLINE: 16055807]. Klosterkötter J. Secondary prevention of schizophrenia: a randomised controlled trial. Current Controlled Trials. 
Ruhrmann S, Bechdolf A, Kuhn KU, Wagner M, Schultze-Lutter F, Janssen B, Maurer K, Hafner H, Gaebel W, Moller HJ, Maier W, Klosterkotter J, LIPS study group. Acute effects of treatment for prodromal symptoms for people putatively in a late initial prodromal state of psychosis. British Journal of Psychiatry Supplementum. 2007; 51:s88-95. [MEDLINE: 18055944]. Ruhrmann S, Hoppmann B, Theysohn S, Picker H, Kuhn KU, Schultze-Lutter F, Wagner M, Bechdolf A, Moller HJ, Gaebel W, Maier W, Klosterkotter J. Acute symptomatic treatment effects in persons clinically at risk for psychosis. Schizophrenia Research. 2006; 86(Suppl 1):S8.

OPUS-Scandinavia \{published data only\} . Bertelsen M, Jeppesen P, Petersen L, Thorup A, Ohlenschlaeger J, le Quach P, Christensen TO, Krarup G, Jorgensen P, Nordentoft M. Five-year follow-up of a randomized multicenter trial of intensive early intervention vs standard treatment for patients with a first episode of psychotic illness: the OPUS trial. Archives of General Psychiatry. 2008; 65(7):762-71. [MEDLINE: 18606949; PSYCHINFO: 2008-18369-003]. [PubMed: 18606949] Bertelsen M, Thorup A, Petersen L, Jeppesen P, Oehlenschlager J, Joergensen P, Le Quach P, Krarup G, Mortensen P, Nordentoft M. The OPUS trial: results from the five-year follow-up. Schizophrenia Research. 2006; 86(Suppl 1):S43.Jeppesen P, Petersen L, Thorup A, Abel MB, Oehlenschlaeger J, Christensen TO, Krarup G, Hemmingsen R, Jorgensen $\mathrm{P}$, Nordentoft M. Integrated treatment of first-episode psychosis: effect of treatment on family burden: OPUS trial. British Journal of Psychiatry. 2005; 48:s85-90.Jeppesen P, Petersen L, Thorup A, Abel MB, Ohlenschlaeger J, Christensen TO, Krarup G, Jorgensen P, Nordentoft M. The association between pre-morbid adjustment, duration of untreated psychosis and outcome in first-episode psychosis. Psychological Medicine. 2008; 8:1157-66. [PubMed: 18447961] Jorgensen P, Nordentoft M, Abel M, Gouliaev G, Jeppesen P, Kassow P. Early detection and assertive community treatment of young psychotics: the opus study rationale and design of the trial. Social Psychiatry \& Psychiatric Epidemiology. 2000; 35:283-7. [PubMed: 11016522] Jorgensen P, Nordentoft M, Abel MB, Gouliaev G, Jeppesen P, Kassow P. Early detection and assertive community treatment of young psychotics: the opus study rationale and design of the trial. Social Psychiatry Psychiatric Epidemiology. 2000; 35(7):283-7. [PubMed: 11016522] Nordentoft M, Jeppesen P, Abel M, Kassow P, Petersen L, Thorup A, Krarup G, Hemmingsen R, Jorgensen P. OPUS study: suicidal behaviour, suicidal ideation and hopelessness among patients with first-episode psychosis. One-year follow-up of a randomised controlled trial. British Journal of Psychiatry. 2002; 43:s98-106.Nordentoft M, Jeppesen P, Abel M, Kassow P, Petersen L, Thorup A, Krarup G, Hemmingsen R, Jorgensen P. OPUS study: suicidal behaviour, suicidal ideation and hopelessness among patients with first-episode psychosis. One-year follow-up of a randomised controlled trial. British Journal of Psychiatry Supplementum. 2002; 181(Suppl 43):S98-106. [MEDLINE: 12271808; MEDLINE: 22233038]. Nordentoft, M.; Jeppesen, P.; Abel, M.; Petersen, L.; Thorup, A.; Christensen, T.; Øhlenschlæger, J.; Jorgensen, P. Opusproject: a randomised controlled trial of integrated psychiatric treatment in first-episode psychosis - clinical outcome improved. Proceeding of the 3rd International Conference on Early Psychosis; Copenhagen, Denmark. 2002 Sep 25-28; 2002. p. 56Nordentoft, M.; Jeppesen, P.; Jørgensen, P.; Abel, MB.; Kassow, P.; Reisby, N.; Hemmingsen, R. Opus - project : a randomised controlled trial of first episode psychotic patients better compliance. Proceedings of the 2nd International Conference on Early Psychosis; New York, New York, USA. 2000 Mar 31 - Apr 2; 2000. Nordentoft M, Jeppesen P, Kassow P, Abel M, Petersen L, Thorup A, Cristensen T, Øhlenschlæger J, JØrgensen P. Opus-project: a randomised controlled trial of integrated psychiatric treatment in first-episode psychosis-clinical outcome improved. Schizophrenia Research. 2002; 53(3 Suppl 1):51. [MEDLINE: 11016522; MEDLINE: 20468737]. Nordentoft, M.; Jeppesen, P.; Petersen, L.; Thorup, A.; Abel, M. Opus project: a randomised controlled trial of integrated psychiatric treatment in first episode psychosis. Proceedings of the 9th International Congress on Schizophrenia Research; Colorado Springs, USA. 2003 Mar 29 - Apr 2; 2003. [CINAHL: 2009245707; MEDLINE: 16141449][CINAHL: 2009245707; MEDLINE: 16141449]Nordentoft M, Jeppesen P, Petersen L, Thorup A, Jorgensen P. Duration of untreated psychosis predicts psychotic symptoms but not negative symptoms. Schizophrenia Bulletin. 2005; 31:234.Nordentoft M, Petersen L, Jeppesen P, Thorup AA, Abel MB, Ohlenschlaeger J, Christensen TO, Krarup G, Jorgensen P. OPUS: a randomised multicenter trial of integrated versus standard treatment for patients with a first-episode psychosis--secondary publication. Ugeskr Laeger. 2006; 168(4):381-4. [PubMed: 16436240] Nordentoft, M.; Reisby, N.; Jeppesen, P.; Abel, M-B.; Kassow, P.; Jírgensen, P. Opus-project: differences in treatment outcome of a 
randomised controlled trial of integrated psychiatric treatment of first-episode psychotic patients. Proceedings of the 11th World Congress of Psychiatry; Hamburg, Germany. 1999 Aug 6-11; 1999. p. 165Nordentoft M, Thorup A, Petersen L, Ohlenschlaeger J, Melau M, Christensen TO, Krarup G, Jorgensen P, Jeppesen P. Transition rates from schizotypal disorder to psychotic disorder for first-contact patients included in the opus trial. A randomized clinical trial of integrated treatment and standard treatment. Schizophrenia Research. 2006; 83(1):29_ 40.*Petersen L, Jeppesen P, Thorup A, Abel MB, Ohlenschlaeger J, Christensen TO, Krarup G, Jorgensen P, Nordentoft M, Petersen L, Jeppesen P, Thorup A, Abel MB, Ohlenschlaeger J, Christensen TO, Krarup G, Jorgensen P, Nordentoft M. A randomised multicentre trial of integrated versus standard treatment for patients with a first episode of psychotic illness. BMJ. 2005; 331(7517):602. [PubMed: 16141449] Petersen L, Jeppesen P, Thorup A, Ohlenschlaeger J, Christensen T, Krarup G, Jorgensen P, Nordentoft M. Substance abuse in first-episode schizophrenia-spectrum disorders. Schizophrenia Research. 2006; 86(Suppl 1):S44.Petersen L, Jeppesen P, Thorup A, Ohlenschlaeger J, Krarup G, Ostergard T, Jorgensen P, Nordentoft M. Substance abuse and first-episode schizophrenia-spectrum disorders The Danish opus trial. Early Intervention in Psychiatry. 2007; 1(1):88-96. [PubMed: 21352112] Petersen L, Nordentoft M, Jeppesen P, Ohlenschaeger J, Thorup A, Christensen TO, Krarup G, Dahlstrom J, Haastrup B, Jorgensen P. Improving 1-year outcome in first-episode psychosis: Opus trial. British Journal of Psychiatry. 2005; 48(Suppl):s98-103. [MEDLINE: 16055817]. Petersen L, Nordentoft M, Thorup A, Oehlenschlaeger J, Jeppesen P, Christensen T, Krarup G, Joergensen P. The opus trial: a randomised multi-centre trial of integrated versus standard treatment for 547 first-episode psychotic patients. Schizophrenia Bulletin. 2005; 31:531.Thorup A, Petersen L, Jeppesen P, Ohlenschlaeger J, Christensen T, Krarup G, Jorgensen P, Nordentoft M. Integrated treatment ameliorates negative symptoms in first episode psychosis - results from the Danish opus trial. Schizophrenia Research. 2005; 79(1):95-105. [PubMed: 16122909] Thorup A, Petersen L, Jeppesen P, Ohlenschlaeger J, Christensen T, Krarup G, Jorgensen P, Nordentoft M. Social network among young adults with first-episode schizophrenia spectrum disorders: results from the Danish opus trial. Social Psychiatry and Psychiatric Epidemiology. 2006; 41(10):761-70. [MEDLINE: 16900304]. [PubMed: 16900304]

PACE-Australia \{published data only\} . McGorry PD, Yung AR, Phillips LJ, Yuen HP, Francey S, Cosgrave EM, Germano D, Bravin J, McDonald T, Blair A, Adlard S, Jackson H. Randomized controlled trial of interventions designed to reduce the risk of progression to first-episode psychosis in a clinical sample with subthreshold symptoms. Archives of General Psychiatry. 2002; 59(10):921-8. [PubMed: 12365879] Phillips LJ, Leicester SB, O’Dwyer LE, Francey SM, Koutsogiannis J, Abdel-Baki A, Kelly D, Jones S, Vay C, Yung AR, McGorry PD. The PACE Clinic: identification and management of young people at 'ultra' high risk of psychosis. Journal PsychiatrIc Practice. 2002; 8(5):255-69.Phillips LJ, McGorry PD, Yuen HP, Ward J, Donovan K, Kelly D, Francey SM, Yung AR. Medium term follow-up of a randomized controlled trial of interventions for young people at ultra high risk of psychosis. Schizophrenia Research. 2007; 96(1-3):25-33. [PubMed: 17611080] Phillips LJ, Yung AR, Yuen HP, Pantelis C, McGorry PD. Prediction and prevention of transition to psychosis in young people at incipient risk for schizophrenia. American Journal of Medical Genetics. 2002; 114(8):929-37. [PubMed: 12457389]

PRIME-USA \{published data only\} . Hawkins KA, Addington J, Keefe R, Christensen B, Woods S, Zipursky R, Perkins D, Mcglashan T. Neuropsychological functioning in the first episode prodrome and early psychosis. Schizophrenia Research. 2004; 70(1):101. [: ISI: 000224551100287]. [PubMed: 15246469] Hawkins, KA.; Addington, J.; Keefe, RS.; Christensen, B.; Woods, SW.; Zipursky, RB.; Perkins, DO.; McGlashan, TH. Effect of olanzapine versus placebo on the neuropsychological status of prodromal subjects. Proceedings of the 12th Biennial Winter Workshop on Schizophrenia; Davos, Switzerland. 2004 Feb 7-13; 2004. Hawkins KA, Keefe RSE, Christensen BK, Addington J, Woods SW, Callahan J, Zipursky RB, Perkins DO, Tohen M, Breier A, McGlashan TH. Neuropsychological course in the prodrome and first episode of psychosis: findings from the prime North America double blind treatment study. Schizophrenia Research. 2008; 105(1-3):1-9. [EMBASE: 2008459795; PSYCHINFO: 2008-14504-002]. [PubMed: 18774696] Hoffman RE, Woods S, Preda A, Tohen M, Breier A, Glist J, Addington J, Perkins DO, Hawkins K, McGlashan TH. Excessive top-down perceptual processing and reduced real-world investment exhibited by prodromal patients predict 
subsequent conversion to schizophrenia. Schizophrenia Research. 2006; 86(s1):S46.Hoffman RE, Woods SW, Hawkins KA, Pittman B, Tohen M, Preda A, Breier A, Glist J, Addington J, Perkins DO, McGlashan TH. Extracting spurious messages from noise and risk of schizophreniaspectrum disorders in prodromal population. British Journal of Psychiatry. 2007; 191(2):355-6. [PubMed: 17906248] McGlashan, TH. Intervention in the prodrome to first psychosis. Proceedings of the Second International Conference on Early Psychosis; New York, USA. 2000 March 31-2; 2000. McGlashan, TH.; Miller, TJ.; Zipursky, RB.; Woods, SW.; Perkins, DO.; Hawkins, KA.; Addington, JM. Intervention in the schizophrenic prodrome: the prevention through risk identification, management, and education initiative. Proceeding of the 156th Annual Meeting of the American Psychiatric Association; San Francisco, California, USA. 2003 May 17-22; 2003. McGlashan TH, Vaglum P, Friis S, Johannessen JO, Simonsen E, Larsen TK, Melle I, Haahr U, Opjordsmoen S, Zipursky R, Perkins D, Addington J, Miller T, Woods S, Hoffman R, Preda A, Epstein I, Addington D, Lindborg S, Trzaskoma Q, Tohen M, Breier A. Early detection and intervention in first episode psychosis: empirical update of the tips and prime projects. Schizophrenia Bulletin. 2005; 31:496.*McGlashan TH, Zipursky RB, Perkins D, Addington J, Miller T, Woods SW, Hawkins KA, Hoffman RE, Preda A, Epstein I, Addington D, Lindborg S, Trzaskoma Q, Tohen M, Breier A. Randomized, double-blind trial of olanzapine versus placebo in patients prodromally symptomatic for psychosis. American Journal of Psychiatry. 2006; 163(5):790-9. [PubMed: 16648318] McGlashan TH, Zipursky RB, Perkins D, Addington J, Miller T, Woods SW, Hawkins KA, Hoffman RE, Preda A, Epstein L, Addington D, Lindborg S, Trzaskoma Q, Tohen M, Breier A. Randomized, double-blind trial of olanzapine versus placebo in patients prodromally symptomatic for psychosis. American Journal of Psychiatry. 2006; 163(5):790-9. [CINAHL: 2009175479; MEDLINE: 16648318]. [PubMed: 16648318] McGlashan TH, Zipursky RB, Perkins D, Addington J, Miller TJ, Woods SW, Hawkins KA, Hoffman R, Lindborg S, Tohen M, Breier A. The prime North America randomized double-blind clinical trial of olanzapine versus placebo in patients at risk of being prodromally symptomatic for psychosis. I. Study rationale and design. Schizophrenia Research. 2003; 61(1):7-18. [MEDLINE: 12648731]. [PubMed: 12648731] McGlashan TH, Zipursky RB, Perkins DO, Addington J, Woods SW, Miller TJ, Lindborg S, Marquez E, Hawkins K, Hoffman RE. Olanzapine versus placebo treatment of the schizophrenia prodrome: One year results. Schizophrenia Research. 2003; 60:295. [EMBASE: 2008459795; PSYCHINFO: 2008-14504002]. McGlashan, TH.; Zipursky, RB.; Perkins, DO.; Addington, JM.; Woods, SW.; Lindborg, S.; Breier, AF. Olanzapine versus pbo for the schizophrenic prodrome: one-year results. Proceedings of the 156th Annual Meeting of the American Psychiatric Association; San Francisco, California, USA. 2003 May 17-22; 2003.

Uzenoff-USA \{published data only\} . Uzenoff SR, Perkins DO, Hamer RM, Wiesen CA, Penn DL. A preliminary trial of adherence-coping-education (ACE) therapy for early psychosis. Journal of Nervous and Mental Disease. 2008; 196(7):572-5. [CINAHL: 2009976831; MEDLINE: 18626299; PSYCINFO: 2008-10312-009]. [PubMed: 18626299]

Zhang-China \{published data only\} . Zhang M, Wang M, Li J, Phillps MR. Randomised-control trial of family intervention for 78 first-episode male schizophrenic patients: an 18-month study in Suzhou, Jiangsu. British Journal of Psychiatry. 1994; 165(Suppl 24):96-102.

\section{References to studies excluded from this review}

Addington 1999 \{published data only . Addington J, Jones B, Ko T, Addington D. Family intervention in an early psychosis program. Psychiatric Rehabilitation Skills. In press. Addington, J.; Jones, B.; Ko, T.; Addington, D. Intervention strategies for families of first episode patients. Proceedings of the Second International Conference on Early Psychosis; New York, USA. 2000 31st March - 2nd April; 2000. Addington J, McCleery A, Addington D. Threeyear outcome of family work in an early psychosis program. Schizophrenia Research. 2005; 79(1):107-16. [PubMed: 15907375]

Agius 2007 \{published data only\} . Agius M, Shah S, Ramkisson R, Murphy S, Zaman R. Threeyear outcomes of an early intervention for psychosis service as compared with treatment as usual for first psychotic episodes in a standard community mental health team - final results. Psychiatria Danubina. 2007; 19(3):130-8. [MEDLINE: 17914313]. [PubMed: 17914313] 
Alanen 1994 \{published data only\} . Alanen, YO.; Lehtinen, V.; Lehtinen, K.; Aaltonen, J.; Rakkolainen, V. The Finnish Integrated Model for Early Treatment of Schizophrenia and Related Psychoses. Martindale, B.; Bateman, A., editors. Gaskell/Royal College of Psychiatrists; London, England: 2000. p. 235-65.Alanen, YO.; Ugelstad, E.; Armelius, BA.; Lehtinen, K.; Rosenbaum, B.; Sjostrom, R. Early Treatment for Schizophrenic Patients: Scandinavian Psychotherapeutic Approach. Scandinavian University Press; Oslo: 1994. Lehtinen K, Tuori T, Jaaskelain NJ. Using psychosis teams in early intervention. A follow-up study of the Finnish schizophrenia project. Nordic Journal of Psychiatry. 1998; 52(Suppl):74.Lehtinen V, Aaltonen J, Koffert T, Rakkolainen V, Syvalahti E. Two-year outcome in first-episode psychosis treated according to an integrated model. Is immediate neuroleptisation always needed? European Psychiatry. 2000; 15:312-20. [PubMed: 10954876]

Albiston 1998 \{published data only\} . Albiston D, Francey SM, Harrigan SM. Group programmes for recovery from early psychosis. British Journal of Psychiatry. 1998; 172(33):117-21.

Anonymous 1987 \{published data only\}. Anonymous. The Scottish first episode schizophrenia study. ii. Treatment: pimozide versus flupenthixol. British Journal of Psychiatry. 1987; 150:3348. [PubMed: 2889495]

Bao 2005 \{published data only\} . Bao W-Q, Sun X-J, Wang M-L. Research on home intervention to community schizophreniform by applying PDCA. Journal of Practical Nursing. 2005; 21(3A): 9-11.

Birchwood 1989 \{published data only\} . Birchwood M, Smith J, Macmillan F, Hogg B, Prasad R, Harvey C. Predicting relapse in schizophrenia: the development and implementation of an early signs monitoring system using patients and families as observers, a preliminary investigation. Psychological Medicine. 1989; 19:649-56. [PubMed: 2798634]

Clare 1994 \{published data only\} . Clare L, Singh K. Preventing relapse in psychotic illness: a psychological approach to early intervention. Journal of Mental Health. 1994; 3:541-50.

COPE-Melbourne \{published data only\} . Jackson, H.; McGorry, PD.; Edwar, SJ. Cognitively oriented psychotherapy for early psychosis: theory, praxis, outcomes, and challenges. In: Corrigan, PW.; Penn, DL., editors. Social Cognition and Schizophrenia. American Psychological Association; Washington, DC, US: 2001. Jackson H, McGorry P, Edwards J, Hulbert C, Henry L, Francey S, Maude D, Cocks J, Power P, Harrigan SDP. Cognitively-oriented psychotherapy for early psychosis (cope). Preliminary results. British Journal of Psychiatry. 1998; 172(Suppl): 93-100.Jackson H, McGorry P, Edwards J, Hulbert C, Henry L, Harrigan S, Dudgeon P, Francey $\mathrm{S}$, Cocks J, Killackey E. A randomised controlled trial of cognitively-orientated psychotherapy for early psychosis (cope) with 5-year follow-up relapse data. Schizophrenia Research. 2004; 70(1):61. [: ISI:000224551100163]. Jackson H, McGorry P, Henry L, Edwards J, Hulbert C, Harrigan S, Dudgeon P, Francey S, Maude D, Cocks J, Power P. Cognitively oriented psychotherapy for early psychosis (cope): a 1-year follow-up. British Journal of Clinical Psychology. 2001; 40:57-70. [PubMed: 11317949] Jackson, HJ.; Edwards, J.; McGorry, PD.; Hulbert, C. The recognition and management of early psychosis: a preventive approach. In: McGorry, PD.; Jackson, HJ., editors. Recovery From Psychosis: Psychological Interventions. Cambridge University Press; Cambridge: 1999. p. 213-35.Jackson, HJ.; McGorry, PD.; Edwards, J.; Hulbe, TC. Cognitively oriented psychotherapy for early psychosis (cope). In: Cotton; Peter; Jackson; Henry, editors. Early Intervention \& Prevention in Mental Health. Australian Psychological Society Ltd; Carlton South VIC, Australia: 1996.

Craig 2004b \{published data only . . Craig T, Garety P, Power P, Rahaman N, Colbert S, FornellsAmbrojo M. Lambeth early onset service: a randomised controlled trial. Schizophrenia Research. 2004; 70(1):145-6. [: ISI:000224551100433]. Craig TKJ. Brixton early psychosis project. National Research Register. 2000Craig TKJ, Garety P, Power P, Rahaman N, Colbert S, Fornells-Ambrojo M, Dunn G. The Lambeth early onset (LEO) Team: randomised controlled trial of the effectiveness of specialised care for early psychosis. BMJ. 2004; 329(7474):1067-70. [MEDLINE: 15485934; : CINAHL 2005085280]. [PubMed: 15485934]

Crow 1986 \{published data only\} . Crow TJ, MacMillan J, Johnson AL, Johnstone EC. The Northwick Park study of first episodes of schizophrenia: ii. A randomised controlled trial of prophylactic neuroleptic treatment. British Journal of Psychiatry. 1986; 148:120-7. [PubMed: 2870753] 
Culberg 1998 \{published data only\} . Cullberg J. Integrating intensive psychosocial therapy and low dose medical treatment in a total material of first episode psychotic patients compared to 'treatment as usual': a 3-year follow-up. Medicinski Arhiv. 1999; 53:167-70. [PubMed: 10546453] Cullberg J, Levander S, Stefanss C. Symposium 7: early detection and intervention in psychosis. 'the parachute project' - a Swedish multicenter project for first episode psychosis. Nordic Journal of Psychiatry. 1998; 52(Suppl):73-4.Cullberg, J.; Thoren, G.; Abb, S.; Mesterton, A.; Svedb, B. Integrating intensive psychosocial and low-dose neuroleptic treatment: a three-year follow-up. In: Martindale, B.; Bateman, A., et al., editors. Psychosis: Psychological Approaches and Their Effectiveness. Gaskell/Royal College of Psychiatrists; London: 2000. p. 200-9.

Davidson 2004 \{published data only\} . Davidson, M. Reducing the risk of early transition to psychosis: using long-acting atypical antipsychotics in young patients. Proceedings of the Thematic Conference of the World Psychiatric Association on 'Treatments in Psychiatry: An Update'; Florence, Italy. 2004 Nov 10-13; 2004.

DeHaan 1997 \{published data only\} . De Haan L, Linsze D, Gorsira R. Early intervention, social functioning, psychotic relapse and suicide of patients with recent onset schizophrenia and other psychotic disorders [Vroegtijdige intensieve interventie, sociaal functioneren, psychoserecidief en suicide bij patienten met recent ontstane schizofrenie en verwante stoornissen]. Tijdschrift voor Psychiatrie. 1997; 39:24-36.De Haan L, Linsze D, Gorsira R. Early intervention, social functioning and psychotic relapse of patients with recent-onset schizophrenic disorders. International Clinical Psychopharmacology. 1998; 13(suppl1):S63-66.

Drury 2000 \{published data only\} . Drury V, Birchwood M, Cochrane R. Cognitive therapy and recovery from acute psychosis: a controlled trial. 3. Five-year follow-up. British Journal of Psychiatry. 2000; 177:8-14. [PubMed: 10945081] Drury V, Birchwood M, Cochrane R, Macmillan F. Cognitive therapy and recovery from acute psychosis: acontrolled trial. I. Impact on psychotic symptoms. British of Journal of Psychiatry. 1996; 169:593-601.Drury V, Birchwood M, Cochrane R, Macmillan F. Cognitive therapy and recovery from acute psychosis: a controlled trial. II. Impact on recovery time. British Journal of Psychiatry. 1996; 169:602-7. [PubMed: 8932889]

Emsley 1999 \{published data only\} . Emsley R, Lambert T, McGrath J, Power P, Schweitzer I, Bosma G, Mertens C, De Nayer A, De Wilde J. Risperidone in the treatment of first-episode psychotic patients: a double-blind multicenter study. Schizophrenia Bulletin. 1999; 25:721-9. [PubMed: 10667742]

Emsley 2004 \{published data only\} . Emsley R, Davidson M, Rabinowitz J. Risk for akathisia in patients with recent onset schizophrenia treated with risperidone and haloperidol and its association with suicidality. Schizophrenia Research. 2004; 67(1):183. [: ISI 000188788100438].

Falloon 1992 \{published data only\} . Falloon I. Early intervention for first episodes of schizophrenia: a preliminary exploration. Psychiatry. 1992; 55:4-15. [PubMed: 1557469] Falloon I. General practice recruitment for people at risk of schizophrenia: the Buckingham experience. Australian \& New Zealand Journal of Psychiatry. 2000; 34(Suppl):S131-6. discussion S140-4. [PubMed: 11129297]

Fisher 2001 \{published data only\} . Fisher A, Savin-Bade M. The benefits to young people experiencing psychosis, and their families, of an early intervention programme: evaluating a service from the consumers' and the providers' perspectives. British Journal of Occupational Therapy. 2001; 64:58-65.

Fitzgerald 1998 \{published data only\} . Fitzgerald P, Kulkarn J. Home-oriented management programme for people with early psychosis. British Journal of Psychiatry Supplement. 1998; 172:39-44. [PubMed: 9764125] Kulkarni, J. Home-based treatment of first-episode psychosis. In: McGorry, PD.; Jackson, HJ., editors. The Recognition and Management of Early Psychosis: A Preventive Approach. Cambridge University Press; New York, NY, US: 1999. p. 206-25.

Fresan 2001 \{published data only\} . Fresan A, Apiquian R, Ulloa R, Loyzaga C, Garcia-Anaya M, Gutierrez D. Family environment and psychoeducation in first-episode schizophrenia: preliminary results [Ambiente familiar y psicoeducacion en el primer episodio de esquizofrenia: resultados preliminares]. Salud Mental. 2001; 24:36-40.

Gaebel 2004 \{published data only\} . Gaebel W, Moller HJ, Buchkremer G, Ohmann C, Riesbeck M, Wolwer WVWM, Bottlender R, Klingberg S. Pharmacological long-term treatment strategies in first episode schizophrenia--study design and preliminary results of an ongoing RCT within 
the German research network on Schizophrenia. European Archives of Psychiatry and Clinical Neuroscience. 2004; 254(2):129-40. [EMBASE: 2004421362; MEDLINE: 15146342]. [PubMed: 15146342] Gaebel W, Riesbeck M, Von Wilmsdorff M, Zielasek J. Pharmacological long-term treatment strategies in first episode schizophrenia: preliminary results of an ongoing randomised clinical trial within the german research network on schizophrenia. Schizophrenia Bulletin. 2005; 31:483.

Grawe 1998 \{published data only . Grawe R, Widen JH. Result of two years optimal out-patient treatment of first episode schizophrenia: a controlled study. Nordic Journal of Psychiatry Supplement. 1998; 52:76.

Hartmann 1974 \{published data only\} . Hartmann W, Muller P. The therapy of first time hospitalized schizophrenics [Zur stationaren behandlung erstmals hospitalisierter schizophrener]. Fortschritte der Neurologie Neurologie und Medizinische Psychologie. 1974; 42:601-14.

Heydebrand 2004 \{published data only\} . Heydebrand G, Weiser M, Rabinowitz J, Hoff AL, DeLisi LE, Csernansky JG. Correlates of cognitive deficits in first episode schizophrenia. Schizophrenia Research. 2004; 68(1):1-9. [EMBASE: 2004130672]. [PubMed: 15037334]

Jenner 2001 \{published data only\} . Jenner J, Van de Willige G. Hit, hallucination focused integrative treatment as early intervention in psychotic adolescents with auditory hallucinations: a pilot study. Acta Psychiatrica Scandinavica. 2001; 103(2):148-52. [PubMed: 11167318]

Jenner 2004 \{published data only\} . Jenner J, Van De Willige G. Results of integrated treatment (hit) in early psychoses: a pilot study. Schizophrenia Research. 2004; 70(1):16. [: ISI: 000224551100038].

Jolley 2003 \{published data only . Jolley S, Garety P, Craig T, Dunn G, White J, Aitken M. Cognitive therapy in early psychosis: a pilot randomized controlled trial. Behavioural and Cognitive Psychotherapy. 2003; 31(4):473-8.

Jones 2005 \{published data only\} . Fowler D, Hodgekins J, Painter M, Reilly T, Crane C, Macmillan I, Mugford M, Croudace T, Jones PB. Cognitive behaviour therapy for improving social recovery in psychosis: a report from the ISREP MRC trial platform study (Improving social recovery in early psychosis). Psychological Medicine. 2009; 39:1627-36. [PubMed: 19335932] Jones PB. Improving social recovery in early affective and non-affective psychosis: a randomised controlled trial of social recovery orientated cognitive behaviour (SRCBT). National Research Register.

Kadota 1992 \{published data only\} . Kadota K. A study of clinical response to different kinds of neuroleptics in first time medicated schizophrenics. Japanese Journal of Psychiatry \& Neurology. 1992; 46:127-53. [PubMed: 1353124]

Kauranen 2000 \{published data only\} . Kauranen A, Seikkula J, Alakar B. The change of social network of first episode psychotic patients in a network oriented treatment [Akuutin psykoosipotilaan sosiaalinen verkosto ja sen muutos verkostokeskeisessae hoidossa]. Psykologia. 2000; 35:403-15.

Kavanagh 2004 \{published data only\} . Kavanagh DJ, Young R, White A, Saunders JB, Wallis J, Shockley NJL, Clair A. A brief motivational intervention for substance misuse in recent-onset psychosis. Drug and Alcohol Review. 2004; 23(2):151-5. [MEDLINE: 15370020]. [PubMed: 15370020]

Keefe 2000 \{published data only . Keefe, RSE. Treatment of neurocognitive deficits with olanzapine or haloperidol in first episode psychosis. Proceedings of the Second International Conference on Early Psychosis; New York, USA. 2000 31st March - 2nd April; 2000.

Keshavan 1998 \{published data only\} . Keshavan M, Schooler NR, Sweeney JA, Haas GL, Pettegrew JW. Research and treatment strategies in first-episode psychoses. The Pittsburgh experience. British Journal of Psychiatry Supplement. 1998; 172:60-5.

Kopala 2003 \{published data only\} . Kopala L, Rabinowitz J, Davidson M. Extra-pyramidal signs and symptoms (eps) in recent onset schizophrenia: a comparison of risperidone and haloperidol. Journal of the European College of Neuropsychopharmacology. 2003; 13(4):S338.

Kuipers 2004 \{published data only\} . Kuipers E, Holloway F, Rabe-Hesketh S, Tennakoon L. An RCT of early intervention in psychosis: Croydon outreach and assertive support team (COAST). Social Psychiatry and Psychiatric Epidemiology. 2004; 39(5):358-63. [PubMed: 15133591] 
Li 2004 \{published data only\} . Li X-H, Wan J. Effects of the nursing care of mutual participation model on the rehabilitation of inpatients with early schizophrenia. Zhongguo Linchuang Kangfu. 2004; 8(24):4958-9.

Lieberman 2005b \{published data only\} . Lieberman JA, Tollefson GD, Charles C, Zipursky R, Sharma T, Kahn RSKRS, Green AI, Gur RE, McEvoy J, Perkins D, Hamer RM, Gu H, Tohen M, HGDH Study Group. Antipsychotic drug effects on brain morphology in first-episode psychosis. Archives of General Psychiatry. 2005; 62(4):361-70. [EMBASE: 2005157308; MEDLINE: 15809403]. [PubMed: 15809403]

Malla 2001 \{published data only\} . Malla, A.; Norman, R.; McLean, T.; Manchanda, R.; Townsend, L.; Cortese, L.; Harricharan, R.; Takhar, J. Development of a community focussed early intervention program for psychosis: combining service, research and public education. Proceedings of the Second International Conference on Early Psychosis; New York, USA. 2000 31st March - 2nd April; 2000. Malla A, Norman RM, McLean TS, McIntosh E. Impact of phasespecific treatment of first episode of psychosis on wisconsin quality of life index (client version). Acta Psychiatrica Scandinavica. 2001; 103(5):355-61. [PubMed: 11380305]

McCay 2007 \{published data only\} . McCay E, Beanlands H, Leszcz M, Goering P, Seeman MV, Ryan K, Johnston N, Vishnevsky T. A group intervention to promote healthy self-concepts and guide recovery in first episode schizophrenia: a pilot study. Psychiatric Rehabilitation Journal. 2006; 30(2):105-11. [PubMed: 17076053] McCay E, Beanlands H, Zipursky R, Roy P, Leszcz M, Landeen J, Ryan K, Conrad, Romano D, Francis D, Hunt J, Costantini L, Chan E. A randomised controlled trial of a group intervention to reduce engulfment and self-stigmatisation in first episode schizophrenia. Australian E-Journal for the Advancement of Mental Health. 2007; 6(3):1-9. [CINAHL: 2009775290; PSYCINFO: 2007-19131-008].

McGorry 1996 \{published data only\} . Francey, SM. The role of day programmes in recovery in early psychosis. In: McGorry, PD.; Jackson, HJ., editors. The Recognition and Management of Early Psychosis: A Preventive Approach. Cambridge University Press; New York, NY, US: 1999. p. 407-37.McGorry P, Edwards J, Mihalopoulos C, Harrigan SM, Jackson HJ. Eppic: an evolving system of early detection and optimal management. Schizophrenia Bulletin. 1996; 22:305-26. [PubMed: 8782288] Power P, Elkins K, Adlard S, Curry C, McGorry P, Harrigan S. Analysis of the initial treatment phase in first-episode psychosis. British Journal of Psychiatry Supplement. 1998; 172:71-6. [PubMed: 9764130] Yung AR, McGorry PD, McFarlane CA, Jackson HJ, Patton GC, Rakkar A. Monitoring and care of young people at incipient risk of psychosis. Schizophrenia Bulletin. 1996; 22:283-303. [PubMed: 8782287] Yung, AR.; Phillips, LJ.; Drew, LT. Promoting access to care in early psychosis. In: McGorry, PD.; Jackson, HJ., editors. The Recognition and Management of Early Psychosis: A Preventive Approach. Cambridge University Press; New York, NY, US: 1999. p. 80-114.

Mosher 1975 \{published data only\} . Bola JR. Evaluation of treatment in early episode acute psychosis: a secondary analysis of the soteria study. Dissertation Abstracts International (Humanities and Social Sciences). 1999; Vol. 60Hirschfeld RM, Matthews SM, Mosher LR, Menn AZ. Being with madness: personality characteristics of three treatment staffs. Hospital Community Psychiatry. 1977; 28(4):267-73. [PubMed: 844816] Matthews SM, Roper MT, Mosher LR, Menn AZ. A nonneuroleptic treatment for schizophrenia: analysis of the two-year postdischarge risk of relapse. Schizophrenia Bulletin. 1979; 5(2):322-33. [PubMed: 37598] Mosher LR. Soteria and other alternatives to acute psychiatric hospitalization: a personal and professional review. Journal of Nervous and Mental Diseases. 1999; 187(3):142-9.Mosher LR, Menn A. Soteria: an alternative to hospitalization for schizophrenia. Current Psychiatric Therapy. 1975; 15:287-96.Mosher LR, Menn A. Soteria: an alternative tohospitalization for schizophrenics. Current Psychiatric Therapy. 1982; 21:189-203.Mosher LR, Menn A, Matthew SM. Soteria: Evaluation of a home-based treatment for schizophrenia. American Journal of Orthopsychiatry. 1975; 45(3):455-67. [PubMed: 238399] Mosher LR, Menn AZ. Community residential treatment for schizophrenia: two-year follow-up. Hospital Community Psychiatry. 1978; 29(11):715-23. [PubMed: 700610] Mosher LR, Menn AZ. Soteria House: one-year outcome data. Psychopharmacology Bulletin. 1977; 13(2):46-8. [PubMed: 859995] Mosher LR, Vallone R, Menn A. The treatment of acute psychosis without neuroleptics: six-week psychopathology outcome data from The Soteria Project. International Journal of Social Psychiatry. 1995; 41(3):157-73. [PubMed: 8847197] 
Mottaghipour 2000 \{published data only\} . Mottaghipour, Y.; Woodland, L.; Sara, G. Efficacy and effectiveness in early psychosis family education group program. Proceedings of the Second International Conference on Early Psychosis; New York, USA. 2000 31st March - 2nd April; 2000.

Newton 2005 \{published data only\} . Newton E, Landau S, Smith P, Monks P, Shergill S, Wykes T. Early psychological intervention for auditory hallucinations: an exploratory study of young people's voices groups. Journal of Nervous and Mental Disease. 2005; 193(1):58-61. [MEDLINE: 2005088980]. [PubMed: 15674136]

Nuechterlein 2005 \{published data only\} . Nuechterlein KH, Subotnik KL, Ventura J, Gitlin MJ, Green MF, Wallace CJ, Becker DR, Liberman RP, Drake RE, Mintz J. Advances in improving and predicting work outcome in recent - onset schizophrenia. Schizophrenia Bulletin. 2005; $31: 31$.

Parlato 1999 \{published data only . Parlato L, Lloyd C, Basse TJ. Young occupations unlimited: an early intervention programme for young people with psychosis. British Journal of Occupational Therapy. 1999; 62:113-6.

Perez 2003 \{published data only\} . Perez R, Gonzalez-Blanch C, Sierra-Biddle D, Martinez I, Vazquez-Barquero JL, Crespo-Facorro B. Efficacy and safety of olanzapine, risperidone and haloperidol in acute treatment of patients with first episode psychosis. Schizophrenia Research. 2003; 60:298-9. [EMBASE: 2005343078; MEDLINE: 12777272].

Power 2004 \{published data only\} . Garety PA, Craig TKJ, Dunn G, Fornells-Ambrojo M, Colbert S, Rahaman N, Reed J, Power P. Specialised care for early psychosis: symptoms, social functioning and patient satisfaction: randomised controlled trial. British Journal of Psychiatry. 2006; 188:37-45. [PubMed: 16388068]

Purdon 2000 \{published data only\} . Purdon S, Jones BD, Stip E, Labelle A, Addington D, David SR, Breier A, Tollefson GD. Neuropsychological change in early phase schizophrenia during 12 months of treatment with olanzapine, risperidone, or haloperidol. The Canadian collaborative group for research in schizophrenia. Archives of General Psychiatry. 2000; Vol. 57:249-58. [PubMed: 10711911]

Rund 1994 \{published data only\} . Rund B, Moe L, Sollien T, Fjell A, Borchgrevink T, Hallert M, Naess PO. The psychosis project: outcome and cost-effectiveness of a psychoeducational treatment programme for schizophrenic adolescents. Acta Psychiatrica Scandinavica. 1994; Vol. 89:211-8. [PubMed: 7909978]

Sanger 1999 \{published data only\} . Lieberman, J.; Sanger, T.; Tohen, M.; The First Episode Collaborative Study Group. Olanzapine and haloperidol treatment of first episode schizophrenia and schizoaffective disorder: 12 week outcome of a two year randomized double blind trial. Proceedings of the Second International Conference on Early Psychosis; New York, USA. 2000 31st March - 2nd April; Sanger, T. Olanzapine versus haloperidol treatment in first episode psychosis [poster]. Proceedings of the Second International Conference on Early Psychosis; New York, USA. 2000 31st March - 2nd April; Sanger, T. Treatment of neurocognitive deficits with olanzapine or haloperidol in first episode psychosis. Proceedings of the Second International Conference on Early Psychosis; New York, USA. 2000 31st March - 2nd April; Sanger T, Lieberman JA, Tohen M, Grundy S, Beasley C Jr, Tollefson GD. Olanzapine versus haloperidol treatment in first-episode psychosis. American Journal of Psychiatry. 1999; 156:79-87. [PubMed: 9892301]

Schooler 2003 \{published data only . Schooler N, Davidson M, Kopala L. Reduced relapse rates in recent onset schizophrenia patients treated with risperidone vs. haloperidol. Journal of the European College of Neuropsychopharmacology. 2003; 13(4):S337.

SOCRATES-UK \{published data only\} . Drake RJ, Haley CJ, Akhtar S, Lewis SW. Causes and consequences of duration of untreated psychosis in schizophrenia. British Journal of Psychiatry. 2000; 177:511-5. [PubMed: 11102325] Lewis, S.; Tarrier, N.; Haddock, G.; Bentall, R.; Kinderman, P.; Kingdon, D.; Siddle, R.; Everitt, J.; Benn, A.; Leadley, K.; Glazebrook, K.; Drake, R.; Haley, C.; Akhtar, S.; Faragher, B. A randomised, controlled trial of cognitivebehaviour therapy in acute, early schizophrenia: the SOCRATES trial summary. Proceedings of the the Second International Conference on Early Psychosis; New York, USA. 2000 31st March 2nd April; 2000. Lewis SW, Tarrier N, Haddock G, Bentall R, Kinderman P, Kingdon D, Siddle R, Drake R, Everitt J, Leadley K, Benn A, Grazebrook K, Haley C, Akhtar S, Davies L, Palmer 
S, Faragher B, Dunn G. A randomised controlled trial of cognitive behaviour therapy in early schizophrenia: acute phase outcomes. British Journal of Psychiatry. 2002; 181(Suppl 43):s9197. Tarrier N, Lewis S, Haddock G, Bentall R, Drake R, Kinderman P, Kingdon D, Siddle R, Everitt J, Leadley K, Benn A, Grazebrook K, Haley C, Akhtar S, Davies L, Palmer S, Dunn G. Cognitive-behavioural therapy in first-episode and early schizophrenia: 18-month follow-up of a randomised controlled trial. British Journal of Psychiatry. 2004; 184:231-9. [EMBASE: 2004121890]. [PubMed: 14990521]

Szymanski 1994 \{published data only\}. Szymanski S, Masiar S, Mayerhoff D, Loebel A. Clozapine response in treatment-refractory first-episode schizophrenia. Biological Psychiatry. 1994; 35:278-80. [PubMed: 8186332]

Thomas 1979 \{published data only\} . Thomas JL. Loxapine oral liquid concentrate in the treatment of young adult patients with acute schizophrenic symptoms. Current Therapeutic Research. 1979; 25:371-7.

TIPS 2006 \{published data only\} . Melle I, Johannesen JO, Friis S, Haahr U, Joa I, Larsen TK, Opjordsmoen S, Rund BR, Simonsen E, Vaglum P, McGlashan T. Early detection of the first episode of schizophrenia and suicidal behavior. American Journal of Psychiatry. 2006; 163(5): 800-4. [MEDLINE: 16648319]. [PubMed: 16648319] Melle I, Larsen TK, Haahr U, Friis S, Johannessen JO, Opjordsmoen S, Simonsen E, Rund BR, Vaglum P, McGlashan T. Reducing the duration of untreated first-episode psychosis: effects on clinical presentation. Archives of General Psychiatry. 2004; 61(2):143-50. [PubMed: 14757590] Opjordsmoen, S.; Brunsvik, S.; Melle, I.; Dahl, A.; Friis, S.; Haahr, U.; Hustoft, K.; Johannessen, JO.; Larsen, TK.; McGlashan, TH.; Simonsen, E.; Vaglum, P. A comparison between novel and traditional antipsychotics as first-line medication in early psychosis. Proceedings of the Second International Conference on Early Psychosis; New York, USA. 2000 31st March - 2nd April; 2000. Simonsen, E. A randomized comparative trial of an early detection program and treatment as usual in the duration of untreated psychosis. Stanley Foundation Research Programs; Denmark: 2000.

Turetz 1997 \{published data only\} . Turetz M, Mozes T, Toren P, Chernauzan N, Yoran-Hegesh R, Mester R, Wittenberg N, Tyano SWA. An open trial of clozapine in neuroleptic-resistant childhood-onset schizophrenia. British Journal of Psychiatry. 1997; 170:507-10. [PubMed: 9330014]

Ueland 2004 \{published data only\} . Ueland T, Rund BR. A controlled randomized treatment study: the effects of a cognitive remediation program on adolescents with early onset psychosis. Acta Psychiatrica Scandinavica. 2004; 109(1):70-4. [MEDLINE: 14674961]. [PubMed: 14674961]

Walczewski 1998 \{published data only\} . Walczewski K, Wojciechowsk A. Social networks of schizophrenic patients three years after the first psychiatric hospitalization. Differences between a group treated in psychosocial program and patients treated in an individual treatment program. Psychiatria Polska. 1998; 32(1):59-67. [PubMed: 9594584]

Wang 2000 \{published data only\} . Wang, L.; Wang, Z. Risperidone versus clozapine treatment in first-episode psychosis. Proceedings of the Second International Conference on Early Psychosis; New York, USA. 2000 31st March - 2nd April; 2000.

Welch 2000 \{published data only\} . Welch, M. Early intervention in first episode psychosis in a rural mental health service. Proceedings of the Second International Conference on Early Psychosis; New York, USA. 2000 31st March - 2nd April; Welch M, Garland G. The safe way to early intervention: an account of the SAFE (Southern area first episode) project. Australasian Psychiatry. 2000; 8:243-8.

Whitehorn 1998 \{published data only\} . Whitehorn, D. Establishing an early psychosis program in Nova Scotia. Proceedings of the Second International Conference on Early Psychosis; New York, USA. 2000 31st March - 2nd April; 2000. Whitehorn D, Lazier L, Kopala L. Psychosocial rehabilitation early after the onset of psychosis. Psychiatric Services. 1998; 49(9):1135-7. 1147. [PubMed: 9735953]

Whitwell 2000 \{published data only\} . Whitwell, D. Early intervention on a shoestring. Proceedings of the Second International Conference on Early Psychosis; New York, USA. 2000 31st March - 2nd April; Whitwell D. Service innovations: early intervention in psychosis as a core task for general psychiatry. Psychiatric Bulletin. 2001; 25:146-8. 
Wieneke 2000 \{published data only\} . Wieneke A, Bechdolf A, Schultze-Lutter F. Early intervention in increased risk for schizophrenic illnesses. Multimodal psychotherapy antipsychotic drugs only in treatment failure [Fruhintervention bei erhohtem risiko fur schizophrene erkrankungen]. Fortschritte der Medizin. 2000; 142(10):30-2. [PubMed: 10748600]

Wunderink 2003 \{published data only\}. Wunderink L, Nienhuis FJ, Wiersma D, Van Den Bosch RJ, Bruggeman R, Faber G, Van Der Linde J, Noorthoorn E, Slooff CJ, Vlaminck P. Medication strategies in first onset schizophrenia: A randomized trial of effectiveness of short versus sustained antipsychotic treatment and quality of life in first episode psychosis preliminary findings: Incidence, compliance and early course. Schizophrenia Research. 2003; 60:307. [EMBASE: 2005343078; MEDLINE: 12777272].

Wykes 2007 \{published data only\}. Wykes T, Newton E, Landau S, Rice C, Thompson N, Frangou S. Cognitive remediation therapy (CRT) for young early onset patients with schizophrenia: an exploratory randomized controlled trial. Schizophrenia Research. 2007; 94(1-3):221-30. [EMBASE: 2007327184; MEDLINE: 17524620]. [PubMed: 17524620] Wykes T, Newton E, Landau S, Rice C, Thompson N, Frangou S. Remediation in adolescent onset results of a randomised control trial. Schizophrenia Bulletin. 2007; 33(2):610.

Yap 2001 \{published data only\} . Yap H, Mahendran R, Lim D, Liow PH, Lee A, Phang S, Tiong A. Risperidone in the treatment of first episode psychosis. Singapore Medical Journal. 2001; 42:170-3. [PubMed: 11465317]

Zhang-Wong 1999 \{published data only\} . Zhang-Wong J, Zipursk R, Beiser M, Bean G. Optimal haloperidol dosage in first-episode psychosis. Canadian Journal of Psychiatry. 1999; 44:164-7.

\section{References to studies awaiting assessment}

Addington-2001 \{published data only\} . Addington J, Addington D. Impact of an early psychosis program on substance use. Journal of Psychiatric Rehabilitation. 2001; 25(1):60-7.

Alaghband-rad 2006a \{published data only\} . Alaghband-rad J, Shahrivar Z, Mahmoodi J, Salesian N. First episode psychoses among Iranian adolescents. Schizophrenia Research. 2006; 86(Suppl 1):S65.Alaghband-Rad J, Sharifi V, Amini H, Shahrivar Z, Mottaghipour Y, Mahmoodi J, Seddigh A, Salesian N, Ali-Malayeri A, Tabatabaee M. Management of first episode psychoses in Iran: unique features and challenges. Schizophrenia Research. 2006; 86(Suppl 1):S42.

Berger 2006 \{published data only\} . Berger, G. Lithium in patients at ultra high risk of developing a first psychotic episode. Stanley Foundation Research Programs; 2006.

Cornblatt 2009 \{published and unpublished data\} . Cornblatt, B. Risperidone vs sertraline for prodromal schizophrenia. Stanley Foundation Research Programs; 2009. NCT00169988. Sertraline alone vs in combination with risperidone in the treatment of attenuated positive and negative symptoms. 2005 http://www.clinicaltrials.gov.

Dai \{published data only\}. Dai M, Liu F, Fan J. A study on influence of early comprehensive interventions on prognosis of incipient schizophrenia patients. Chinese Nursing Research. 2007; $21: 2393-4$.

Deng 2006 \{published data only\} . Deng Q-Y, Huang Z-L, Xie Z-Y. Research the effect of early intervention of first episode schizophrenia. Medical Journal of Chinese Civil Administration. 2006; 18(9):794-6.

Doering 1998 \{published data only\} . Doering S, Muller E, Kopcke W, Pietzcker A, Gaebel W, Linden M, Muller P, Muller-Spahn F, Tegeler J, Schussler G. Pradiktoren fur rezidiv und rehospitalisierung bei schizophrenie und schizoaffektiver psychose. Psychiatria Danubina. 1998; 10(4):419-30.

Edwards 2003 EPPIC \{published data only\} . Edwards, J. Early psychosis service developments: becoming real. Proceedings of the 3rd International Conference on Early Psychosis; Copenhagen, Denmark. 2002 Sep 25-28; 2003. Edwards J, Wong L, Burnett P, Harrigan SM, McGorry PD, Wade D, Murphy B, Drew L, Albiston D. Enduring positive symptoms in first episode psychosis: A randomised controlled trial of clozapine and CBT. Schizophrenia Research. 2003; 60:321. [EMBASE: 2005343078; MEDLINE: 12777272]. [PubMed: 12591594] 
Fillatre-1998 \{published data only\} . Fillatre M, Fahs H, Rose-Reinhardt H, Degiovanni A, Marc 1D. First acute psychotic disorder of the young [Premier episode psychotique de l'adolescent et de l'adulte jeune]. Annales de Psychiatrie. 1998; 13:256-61.

Furimsky 2005 \{published data only\} . NCT00260273. Access, detection and psychological treatments. $2005 \mathrm{http} / / / \mathrm{www} . c l i n i c a l t r i a l s . g o v$.

Gleeson 2008 \{published data only . Gleeson J, Wade D, Castle D, Gee D, Crisp K, Pearce T, et al. The EPISODE II trial of cognitive and family therapy for relapse prevention in early psychosis: rationale and sample characteristics. Journal of Mental Health. 2008; 17(1):19-32. [CINAHL: 2009815127; EMBASE: 2008078812].

Humphries 2005 \{published data only\}. Humphries B, Honer W. V3: Vancouver-Victoria valacyclovir trial for early psychosis. http://www.clinicaltrials.gov.

Johnson 2004 \{published data only\} . Johnson S. Cluster randomised trial comparing outcomes of early psychosis care by a specialist team and augmented community mental health teams (CMHTs). 2005 http://www.controlled-trials.com/. Johnson, S. Establishing a framework for long-term research in early psychosis: use for research of routine outcome measures. National Research Register;

Keshavan 2003 \{published data only\} . Keshavan, M. A 6-month controlled study of psychoeducation and collaboration enhancement (PEACE) in early psychosis to improve treatment compliance. Stanley Foundation Research Programs; 2003.

Keshavan 2005 \{published data only\} . Keshavan MS, Hogarty GE. Rehabilitation, brain function and early schizophrenia. http://www.clinicaltrials.gov.

Lecomte 2006 \{published data only\} . Lecomte T, Leclerc C, Wykes T, Wallace CJ, Spidel A, Corbiere M. Group CBT vs skills training for first episodes of psychosis - results of a RCT. Schizophrenia Research. 2006; 86(Suppl 1):S45-6.

Lee 2007 ppublished data only . Lee H. Protective and risk factors in adolescents with schizophrenia. Dissertation Abstracts International: Section B: The Sciences and Engineering.

Li 2004b \{published data only\} . Li T-Y, Li Y-Y, Wu T-C, Yan W-Y, Chen Y-H, An Y, Lu C-Y, Zhu H-L, Jiang C-X. Effect of early intervention on quality of life in patients with first episode schizophrenia. Zhongguo Linchuang Kangfu. 2004; 8(18):3464-5. [CENTRAL: CN-00516341]. Li YY, Wu TC, Li M. Efficacy of early intervention on first-episode schizophrenic patients. Journal of Clinical Psychological Medicine. 2004; 14(1):24-6.

Li 2007 \{published data only\} . Li G, Zong L, Tian S. Effect of early psychotherapy on postschizophrenia depression. Chinese Journal of Health Psychology. 2007; 15(1):24-5.

Richtand 2007 \{published data only\} . Richtand N. Omega-3 fatty acid deficiency replacement in early schizophrenia. http://www.clinicaltrials.gov.

Schepp 1999 \{published data only\} . Schepp KG. Self-management therapy for youth with schizophrenia. http://www.clinicaltrials.gov.

Tao 2004 \{published data only\} . Tao YL, Yong YL, Tian CW, Wei YY, Yu HC, Yuan A, Chang YL, Hong LZ, Cai XJ. Effect of early intervention on quality of life in patients with first episode schizophrenia. Chinese Journal of Clinical Rehabilitation. 2004; 8(18):3464-65.

Vinogradov 2008 \{published data only\} . Vinogradov S, May L, Loewy R, Moua K, Carter C. Effectiveness of neuroadaptive cognitive training in adolescents at risk for psychosis. http:// www.clinicaltrials.gov.

Williams 2005 \{published data only\} . Williams, S. Effectiveness trial of systematic psychosocial interventions in early psychosis. National Research Register;

Woo 2009 \{published data only\} . Woo W-U. Addition of tiagabine to second-generation antipsychotics in the treatment of recent-onset schizophrenia by modification of developmental reorganization of the prefrontal cortex. http://www.clinicaltrials.gov. Woo, TU. Tiagabine for schizophrenia. Stanley Research Programmes;

Woods 2005 \{published data only\} . Woods SW. Glycine treatment of prodromal symptoms. http://www.clinicaltrials.gov.

Woods 2008 \{published data only\}. Woods SW, Saksa JR, De Silva S, Cannon TD, Daley M, Shafer K, Cadenhead K, Haroun N, Walsh B, McGlashan T, Gelernter J, Brasifield J, Walker E, Compton M, Groves J, Seidman L, Frazier JA, Atencio J, Cornblatt BA, Auther A, Smith C, 
Correll C, Cook E, Graham K, Perkins D, Anderson G, Addington D, Addington J, Raedler T.

Ziprasidone in the psychosis prodrome. http://www.clinicaltrials.gov.

Xu 2003 \{published data only\} . Xu L, Zhang F, Meng Q. Early recovery psychotheraphy and first episode schizophrenics. Journal of Nursing Science. 2003; 18(10):723-6.

Yu 2005 \{published data only\}. Yu EL, Xiu YL, Zhao XZ. One-year follow-up study of systemic early intervention to first episode schizophrenia. Chinese Journal of Clinical Rehabilitation. 2004; 8(36):8178-81.

\section{References to ongoing studies}

Addington 2007 \{published data only . Addington J, Christensen B, Remington G, Lau M, Monette G. A randomized controlled trial of individual therapy for first episode psychosis. http:// www.clinicaltrials.gov.

Arends 2006 \{published data only\}. Arends J. Prodromal symptoms and early intervention to prevent a relapse. $2006 \mathrm{http}: / / \mathrm{www}$. controlled-trials.com/.

EDIE-2 Morrison 2007 \{published data only\} . Morrison AP. EDIE-2: early detection and psychological intervention for individuals at high risk of psychosis (2). Current Controlled Trials. 2007Morrison T. Early detection and psychological intervention for individuals at high risk of psychosis. EDIE-2. Data on file 2006.

Furimski 2005 \{published data only\} . Furimsky I, Mcmillan S, Zipursky RB, Addington J, Dewa C, Boydell K, Noh S. Access, detection and psychological treatments. http:// www.clinicaltrials.gov.

Gaebel 2005 \{published data only\} . Gaebel W. Prodrome-based early intervention with antipsychotics vs benzodiazepine in patients with first-episode schizophrenia after one year maintenance treatment under further maintenance treatment vs stepwise discontinued drugs. http://www.clinicaltrials.gov. Gaebel W. Maintenance treatment vs stepwise drug discontinuation after one year of maintenance treatment in first-episode schizophrenia. http:// www.clinicaltrials.gov.

Heresco-Levy 2006 \{published data only\} . Heresco-Levy U, Lerer B, Kohn Y, Nashim E. Sarcosine (n-methylglycine) trial for individuals at risk for developing schizophrenia and related disorders. 2006 http://www.clinicaltrials.gov.

Lester 2006 \{published data only\} . Lester H. Birmingham early detection in untreated psychosis trial (REDIRECT). Current Controlled Trials. 2004Lester H. Birmingham early detection in untreated psychosis trial (REDIRECT). National Research Register. 2004; Vol. 1Lester HE, Birchwood M, Tait L, Freemantle N. Redirect: evaluating the effectiveness of an educational intervention about first episode psychosis in primary care. Schizophrenia Research. 2006; 86(Suppl 1):S39-40.Tait L, Lester H, Birchwood M, Freemantle N, Wilson S. Design of the Birmingham early detection in untreated psychosis trial (REDIRECT): cluster randomised controlled trial of general practitioner education in detection of first episode psychosis [ISRCTN87898421]. BMC Health Services Research. 2005; 5(1):19. [MEDLINE: 15755321]. [PubMed: 15755321]

McFarlane 2007 \{published data only\} . NCT00531518. Early detection and intervention for the prevention of psychosis, a multisite study. $2007 \mathrm{http}: / / \mathrm{www}$.clinicaltrials.gov.

Srihari 2006 \{published data only\} . Srihari VH, Woods SW, Walsh B, Saksa JR, Pollard J, Hyman L, Walsh K, Cartier S. Specialized treatment early in psychosis (STEP): a pragmatic randomized controlled trial in the US public sector. Schizophrenia Research. 2006; 86(Suppl 1):S165.

Stain 2006 \{published data only\} . Stain HJ, Startup M, Carr V, Baker A, Schall U. The depth project: a multisite RCT for youths at risk for psychosis. Schizophrenia Research. 2006; 86(Suppl 1):S51-2.

\section{Additional references}

Addington 1990 . Addington D, Addington J, Schissel B. A depression rating scale for schizophrenics. Schizophrenia Research. 1990; 3:247-25. [PubMed: 2278986] 
Altman 1996 . Altman DG, Bland JM. Detecting skewness from summary information. BMJ. 1996; 313:1200. [PubMed: 8916759]

Andreasen 1983 . Andreasen, NC. Schedule for the Assessment of Negative Symptoms. University of Iowa; Iowa City, Iowa: 1983.

APA 1994 . American Psychiatric Association. Diagnostic and Statistical Manual of Mental Disorders (DSM-IV). 4th Edition. APA; Washington, DC: 1994.

Barnes 1989 . Barnes TR. A rating scale for drug-induced akathisia. British Journal of Psychiatry. 1989; 154:672-6. [PubMed: 2574607]

Beck 1961 . Beck AT, Ward CH, Mendelson M, Mock J, Erbaugh J. An inventory for measuring depression. Archives of General Psychiatry. 1961; 4:53-63.

Beck 1976 . Beck, AT. Cognitive Therapy and the Emotional Disorders. International Universities Press; New York: 1976.

Begg 1996 . Begg C, Cho M, Eastwood S, Horton R, Moher D, Olkin I, Pitkin R, Rennie D, Schulz KF, Simel D, Stroup DF. Improving the quality of randomized controlled trials. The CONSORT statement. JAMA. 1996; 276:637-9. [PubMed: 8773637]

Birchwood 1992 . Birchwood M, Smith J, Cochrane R. Specific and nonspecific effects of educational intervention for families living with schizophrenia. A comparison of three methods specific and non-specific effects of educational intervention for families living with schizophrenia. A comparison of three methods. British Journal of Psychiatry. 1992; 160:806-14. [PubMed: 1617364]

Bland 1997 . Bland JM, Kerry SM. Statistics notes. Trials randomised in clusters. BMJ. 1997; 315:600.

Boissel 1999 . Boissel JP, Cucherat M, Li W, Chatellier G, Gueyffier F, Buyse M, Boutitie F, Nony P, Haugh M, Mignot G. The problem of therapeutic efficacy indices. 3. Comparison of the indices and their use. Therapie. 1999; 54(4):405-11. [PubMed: 10667106]

D'Zurilla 1971 . D'Zurilla TJ, Goldfried MR. Problem solving and behavior modification. Journal of Abnormal Psychology. 1971; 78:107-26. [PubMed: 4938262]

D'Zurilla 1986 . D'Zurilla, TJ. Problem-solving therapy: A social competence approach to clinical intervention. Springer; New York: 1986.

De-Wilde 2005 . De Wilde EF, Hendriks VM. The client satisfaction questionnaire: Psychometric properties in a Dutch addict population Dutch addict population psychometric properties in a Dutch addict population. European Addiction Research. 2005; 11:157-62. [PubMed: 16110221]

Deeks 2000 . Deeks, J. Issues in the selection for meta-analyses of binary data. Proceedings of the 8th International Cochrane Colloquium; Cape Town. 2000 Oct 25-28th; 2000.

Divine 1992 . Divine GW, Brown JT, Frazer LM. The unit of analysis error in studies about physicians' patient care behavior. Journal of General Internal Medicine. 1992; 7:623-9. [PubMed: 1453246]

DoH 2000 . Department of Health. The NHS plan: a summary. Department of Health; London: 2000.

Donner 2002 . Donner A, Klar N. Issues in the meta-analysis of cluster randomized trials. Statistics in Medicine. 2002; 21:2971-80. [PubMed: 12325113]

Duggan 2005 . Duggan L, Fenton M, Rathbone J, Dardennes R, El-Dosoky A, Indran S. Olanzapine for schizophrenia. Cochrane Database of Systematic Reviews. 2005; (Issue 2) [DOI: \%3Chtml $\% 3 \mathrm{E} \% 3 \mathrm{Cbody} \% 3 \mathrm{E} \% 3 \mathrm{C}$ !-StartFragment $-\% 3 \mathrm{E} \% 3 \mathrm{Cspan}$ class=\%22Apple-style-span $\% 22$ style $=$ $\% 22$ border-collapse: separate; color: $\operatorname{rgb}(0,0,0)$; font-family: \%27Times New Roman\%27; fontsize: medium; font-style: normal; font-variant: normal; font-weight: normal; letter-spacing: normal; line-height: normal; orphans: 2; text-align: auto; text-indent: 0px; text-transform: none; white-space: normal; widows: 2; word-spacing: 0px; -webkit-border-horizontal-spacing: 0px; webkit-border-vertical-spacing: 0px; -webkit-text-decorations-in-effect: none; -webkit-text-sizeadjust: auto; -webkit-text-stroke-width: 0px; \%22\%3E\%3Cspan class= \%22Apple-style-span $\% 22$ style=\%22font-family: sans-serif; font-size: $13 \mathrm{px}$; -webkit-border-horizontal-spacing: $2 \mathrm{px}$; webkit-border-vertical-spacing: 2px; \%22\%3E10.1002/14651858.CD001359.pub2\%3C/span $\% 3 \mathrm{E} \% 3 \mathrm{C} /$ span\%3E\%3C!-EndFragment-\%3E\%3C/body\%3E\%3C/html\%3E]. 
Edwards 2000 . Edwards, J.; McGorry, PD.; Pennell, K. Models of early intervention in psychosis: an analysis of service approaches. In: Birchwood, M.; Fowler, D.; Jackson, C., editors. Early Intervention in Psychosis. Wiley; Chichester: 2000. p. 281-314.

Edwards 2002 . Edwards, J.; McGorry, P. Multi-component early intervention - models of good practice. In: Edwards, J.; McGorry, PD., editors. Implementing Early Intervention in Psychosis. Martin Dunitz; London: 2002. p. 63-84.

Egger 1997 . Egger M, Davey G, Schneider M, Minder C. Bias in meta-analysis detected by a simple, graphical test. BMJ. 1997; 315:629-34. [PubMed: 9310563]

Elbourne 2002 . Elbourne DR, Altman DG, Higgins JPT, Curtin F, Worthington HV, Vaillancourt JM. Meta-analyses involving cross-over trials: methodological issues. International Journal of Epidemiology. 2002; 31:140-49. [PubMed: 11914310]

Falloon 1984 . Falloon, IRH.; Boyd, JL.; McGill, CW. Family Care of Schizophrenia. Guildford Press; New York: 1984.

Furukawa 2006 . Furukawa TA, Barbui C, Cipriani A, Brambilla P, Watanabe N. Imputing missing standard deviations in meta-analyses can provide accurate results. Journal of Clinical Epidemiology. 2006; 59(7):7-10. [PubMed: 16360555]

Garety 2000 . Garety P, Jolley S. Early intervention in psychosis. Psychiatric Bulletin. 2000; 24:3213.

Gulliford 1999 . Gulliford MC, Ukoumunne OC, Chinn S. Components of variance and intraclass correlations for the design of community-based surveys and intervention studies: data from the Health Survey for England 1994. American Journal of Epidemiology. 1999; 149:876-83. [PubMed: 10221325]

Guy 1970 . Guy, W.; Bonato, RR., editors. Manual for the ECDEU Assessment Battery 2. National Institute of Mental Health; 1970. Revised

Guy 1976 . Guy, W. ECDEU Assessment Manual for Psychopharmacology (DOTES: Dosage Record and Treatment Emergent Symptom Scale). National Institute of Mental Health; Rockville: 1976.

Hamilton 1959 . Hamilton M. The assessment of anxiety states by rating. British Journal of Psychiatry. 1959; 32:50-5.

Hamilton 1960 . Hamilton M. A rating scale for depression. Journal of Neurology, Neurosurgery and Psychiatry. 1960; 23:56-62.

Heinrichs 1984 . Heinrichs DW, Hanlon TE, Carpenter WT. The quality of life scale: an instrument for rating the schizophrenic deficit syndrome. Schizophrenia Bulletin. 1984; 10:389-98.

Higgins 2003 . Higgins JP, Thompson SG, Deeks JJ, Altman DG. Measuring inconsistency in metaanalyses. BMJ. 2003; 327:557-60. [PubMed: 12958120]

Higgins 2005 . Higgins, JPT.; Green, S., editors. Cochrane Handbook for Systematic Reviews of Interventions 4.2.5 [updated May 2005]. The Cochrane Collaboration; 2005.

Higgins 2006 . Higgins, JPT.; Green, S., editors. Cochrane Handbook for Systematic Reviews of Interventions 4.2.6 [updated September 2006]. The Cochrane Collaboration; 2006.

Higgins 2008 . Higgins, JPT.; Green, S., editors. Cochrane Handbook for Systematic Reviews of Interventions. John Wiley \& Sons; Chicester: 2008.

Jadad 1996 . Jadad AR, Moore A, Carroll D, Jenkinson C, Reynolds JM, Gavaghan DJ, McQuay HJ. Assessing the quality of reports of randomized clinical trials: is blinding necessary? Controlled Clinical Trials. 1996; 17:1-12. [PubMed: 8721797]

Kay 1986 . Kay, SR.; Opler, LA.; Fiszbein, A. Positive and negative syndrome scale (PANSS) manual. Multi-Health Systems; North Tonawanda, NY: 1986.

Kay 1987 . Kay SR, Fiszbein A, Opler LA. The positive and negative syndrome scale (PANSS) for schizophrenia. Schizophrenia Bulletin. 1987; 13:261-76. [PubMed: 3616518]

Larsen 1998 . Larsen TK, Johannssem JO, Opjordsmoen S. First-episode schizophrenia with long duration of untreated psychosis. Pathways to care. British Journal of Psychiatry. 1998; 172(Suppl $33): 45-52$.

Leucht 2005a . Leucht S, Kane JM, Kissling W, Hamann J, Etschel E, Engel R. Clinical implications of Brief Psychiatric Rating Scale scores. British Journal of Psychiatry. 2005; 187:366-71. [PubMed: 16199797] 
Leucht 2005b . Leucht S, Kane JM, Kissling W, Hamann J, Etschel E, Engel RR. What does the PANSS mean? Schizophrenia Research. 2005; 79(2-3):231-8. [PubMed: 15982856]

Lieberman 2005 . Lieberman JA, Stroup TS, McEvoy JP, Swartz MS, Rosenheck RA, Perkins DO, Keefe RS, Davis SM, Davis CE, Lebowitz BD, Severe J, Hsiao JK. Effectiveness of antipsychotic drugs in patients with chronic schizophrenia. New England Journal of Medicine. Sep 22; 2005 353(12):1209-23. [PubMed: 16172203]

Mangalore 2007 . Mangalore R, Knapp M. Cost of Schizophrenia in England. Journal of Mental Health Policy and Economics. 2007; 109:23-41. [PubMed: 17417045]

Marshall 2000 . Marshall M, Lockwood A, Adams C, Bradley C, Joy C, Fenton M. Unpublished rating scales - a major source of bias in randomised controlled trials of treatments for schizophrenia? British Journal of Psychiatry. 2000; 176:249-52. [PubMed: 10755072]

Mason 1997 . Mason P, Harrison G, Glazebrook C, Medley I, Dalkin T, Croudace TJ. Characteristics of outcome in schizophrenia at 13 years. British Journal of Psychiatry. 1997; 167:596-603. [PubMed: 8564314]

McGorry 1999 . McGorry, PD. 'A stitch in time' the scope for preventive strategies in early psychosis. In: McGorry, PD.; Jackson, HJ., editors. The Recognition and Management of Early Psychosis. Cambridge University Press; Cambridge: 1999. p. 3-23.

Miller 1999 . Miller R, Mason S. Phase-specific psychosocial interventions for first-episode schizophrenia. Bulletin of the Menninger Clinic. 1999; 63:499-519. [PubMed: 10589141]

Moher 2001 . Moher D, Altman D, Schulz KF. The CONSORT statement: Revised recommendations for improving the quality of reports parallel-group randomized trials. Journal of the American Medical Association. 2001; 285:1987-91. [PubMed: 11308435]

Montgomery 1979 . Montgomery SA, Asberg M. Montgomery asberg depression rating scale. British Journal of Psychiatry. 1979; 134:382-89. [PubMed: 444788]

NICE 2002 . National Institute for Clinical Excellence. Schizophrenia: Core Interventions in the Treatment and Management of Schizophrenia in Primary and Secondary Care. National Institute for Clinical Excellence; London: 2002.

Norman 2001 . Norman R, Malla AK. Duration of untreated psychosis: a critical examination of the concept and its importance. Psychological Medicine. 2001; 31(3):381-400. [PubMed: 11305847]

Olsen 2006 . Olsen KA, Rosenbaum B. Prospective investigations of the prodromal state of schizophrenia: assessment instruments state of schizophrenia: assessment instruments. Acta Psychiatrica Scandinavica. 2006; 113:273-82. [PubMed: 16638071]

Overall 1962 . Overall JE, Gorham DR. The brief psychiatric rating scale. Psychological Report. $1962 ; 10: 799-812$.

Pharoah 2006 . Pharoah FM, Rathbone J, Mari JJ. Family intervention for schizophrenia. Cochrane Database of Systematic Reviews. 2006; (Issue 4) [DOI: 10.1002/14651858.CD000088.pub2].

RevMan 2008 . The Nordic Cochrane Centre, The Cochrane Collaboration. Review Manager (RevMan). 5.0. The Nordic Cochrane Centre, The Cochrane Collaboration; Copenhagen: 2008.

Rosen 2000 . Rosen A. Ethics of early prevention in schizophrenia. Australian \& New Zealand Journal of Psychiatry. 2000; 34(Suppl):S208-12. [PubMed: 11129311]

Schaffner 2001 . Schaffner K, McGorry PD. Preventing severe mental illnesses - new prospects and ethical challenges. Schizophrenia Research. 2001; 51(1):3-15. [PubMed: 11479061]

Schultze-Lutter 2007 . Schultze-Lutter F, Ruhrmann S, Picker H, Von Reventlow HG, BrockhausDumke A, Klosterkotter J. Basic symptoms in early psychotic and depressive disorders. British Journal of Psychiatry Supplement. 2007; 51:s31-7. [PubMed: 18055935]

Schulz 1995 . Schulz KF, Chalmers I, Hayes RJ, Altman DG. Empirical evidence of bias: dimensions of methodological quality associated with estimates of treatment effects in controlled trials. JAMA. 1995; 273:408-12. [PubMed: 7823387]

Sheitman 1998 . Sheitman B, Lieberman JA. The natural history and pathophysiology of treatment resistant schizophrenia. Journal of Psychiatric Research. 1998; 32:143-50. [PubMed: 9793867]

Simpson 1970 . Simpson GM, Angus JWS. A rating scale for extrapyramidal side effects. Acta Psychiatrica Scandinavica Supplementum. 1970; 212:11-9. [PubMed: 4917967] 
Ukoumunne 1999 . Ukoumunne OC, Gulliford MC, Chinn S, Sterne JAC, Burney PGJ. Methods for evaluating area-wide and organisation-based intervention in health and health care: a systematic review. Health Technology Assessment. 1999; 3(5):1-75.

Weissman 1976 . Weissman MM, Bothwell S. Assessment of social adjustment by patient self report. Archives of General Psychiatry. 1976; 33:1111-15. [PubMed: 962494]

Wiersma 1998 . Wiersma D, Nienhuis FJ, Slooff CJ, Giel R. Natural course of schizophrenic disorders: a 15-year follow up of a Dutch incidence cohort. Schizophrenia Bulletin. 1998; 24(1): 75-85. [PubMed: 9502547]

Wing 1990 . Wing, Jk; Barbo, T.; Brugha, T.; Burke, J.; Cooper, J.; Giel, R.; Jablenski, A.; Regier, D.; Sartorius, N. Schedules for clinical assessment in neuropsychiatry. Archives of General Psychiatry. 1990; 47:589-93. [PubMed: 2190539]

Wyatt 1991 . Wyatt R. Early intervention with neuroleptics may decrease the long-term morbidity of schizophrenia. Schizophrenia Research. 1991; 5(3):201-2. [PubMed: 1684719]

Wyatt 2001 . Wyatt R, Henter I. Rationale for the study of early intervention. Schizophrenia Research. 2001; 51(1):69-76. [PubMed: 11479068]

Xia 2007 . Xia, J.; Adams, CE.; Bhagat, N.; Bhagat, V.; Bhoopathi, P.; El-Sayeh, H.; Pinfold, V.; Takriti, Y. The Leeds outcomes stakeholders survey (LOSS) study. Proceeings of the 15th Cochrane Colloquium; Sao Paulo, Brazil. 2007 October 23-27; 2007.

Young 1978 . Young RC, Biggs JT, Ziegler VE, Meyer DA. A rating scale for mania: reliability, validity and sensitivity. British Journal of Psychiatry. 1978; 133:429-35. [PubMed: 728692]

Yung 2005 . Yung AR, Yuen HP, McGorry PD, Phillips LJ, Kelly D, Dell'Olio M, Francey SM, Cosgrave EM, Killackey E, Stanford C, Godfrey K, Buckby J. Mapping the onset of psychosis: the comprehensive assessment of at-risk mental states. Australian and New Zealand Journal of Psychiatry. 2005; 39(11-12):964-71. [PubMed: 16343296]

\section{References to other published versions of this review}

Marshall 2004 . Marshall M, Lockwood A. Early Intervention for psychosis. Cochrane Database of Systematic Reviews. 2004; (Issue 2) [DOI: 10.1002/14651858.CD004718].

* Indicates the major publication for the study 


\section{PLAIN LANGUAGE SUMMARY}

\section{Early Intervention for psychosis}

Schizophrenia typically begins in young adulthood and may lead to disability that lasts a lifetime. The onset of psychosis is usually preceded by a period of non-psychotic symptoms, known as prodromal symptoms. The symptoms of full-blown schizophrenia include hallucinations, delusions, disordered thinking and emotional withdrawal. There is some evidence that a delay in receiving adequate treatment reduces the chances or the extent of recovery.

In broad terms, early intervention has two objectives: the first is to prevent the onset of schizophrenia in people with prodromal symptoms; the second is to provide effective treatment to people in the early stages of schizophrenia, with the goal of reducing the ultimate severity of the illness. Early intervention services are now widespread in America, Europe and Australia.

We sought to review all trials that involved early intervention for people with prodromal symptoms, or a first episode of psychosis. We identified 18 studies, most were underpowered and at present we have insufficient data to draw any definitive conclusions, although further trials are expected. 


\section{PRISMA 2009 Flow Diagram}

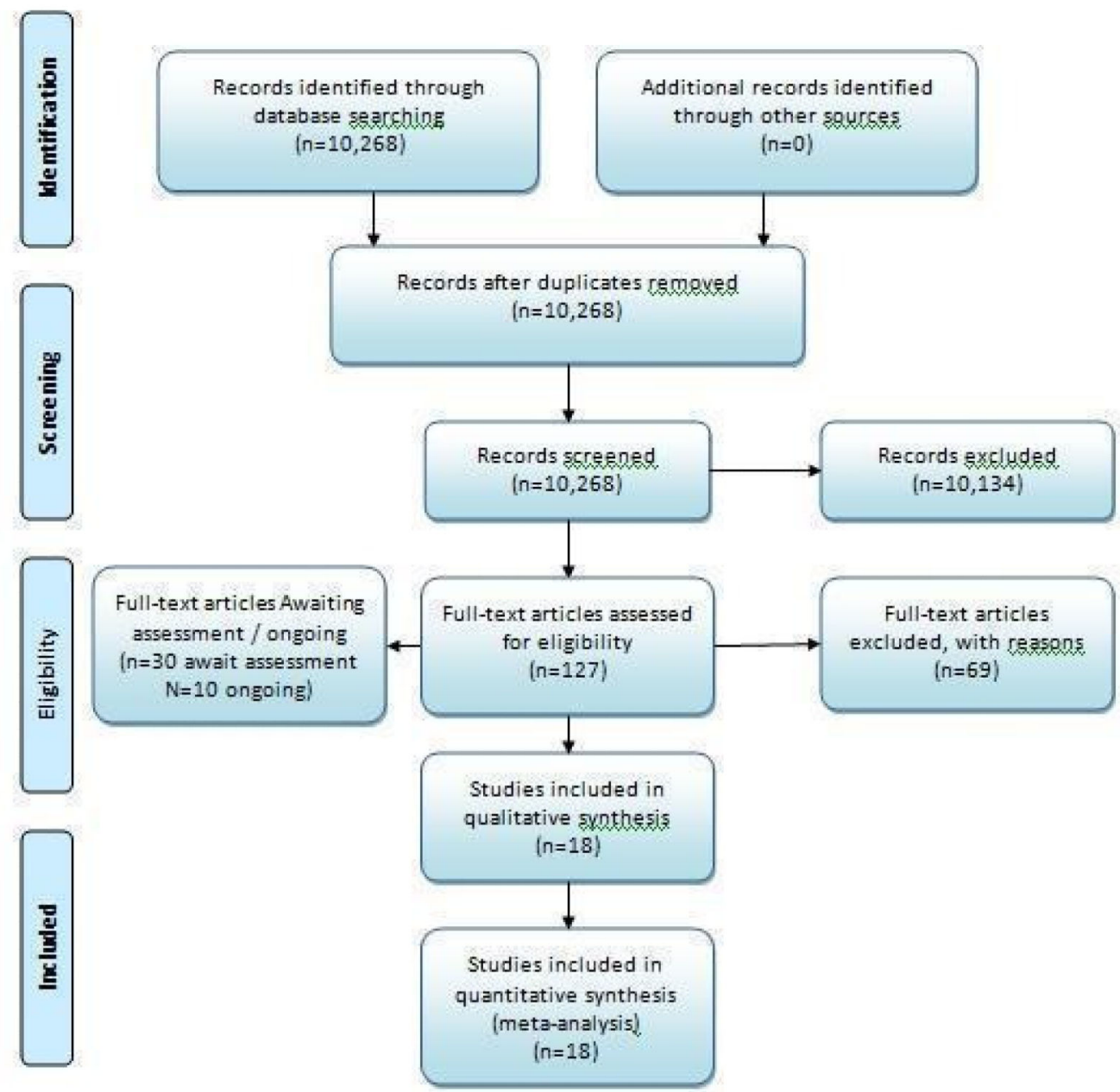

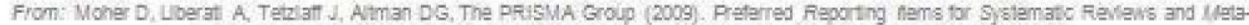

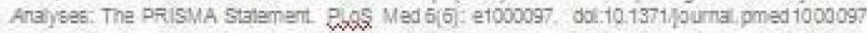

$$
\text { For mare informstion, visit www.prisma-statementoris. }
$$

Figure 1.

PRISMA diagram 


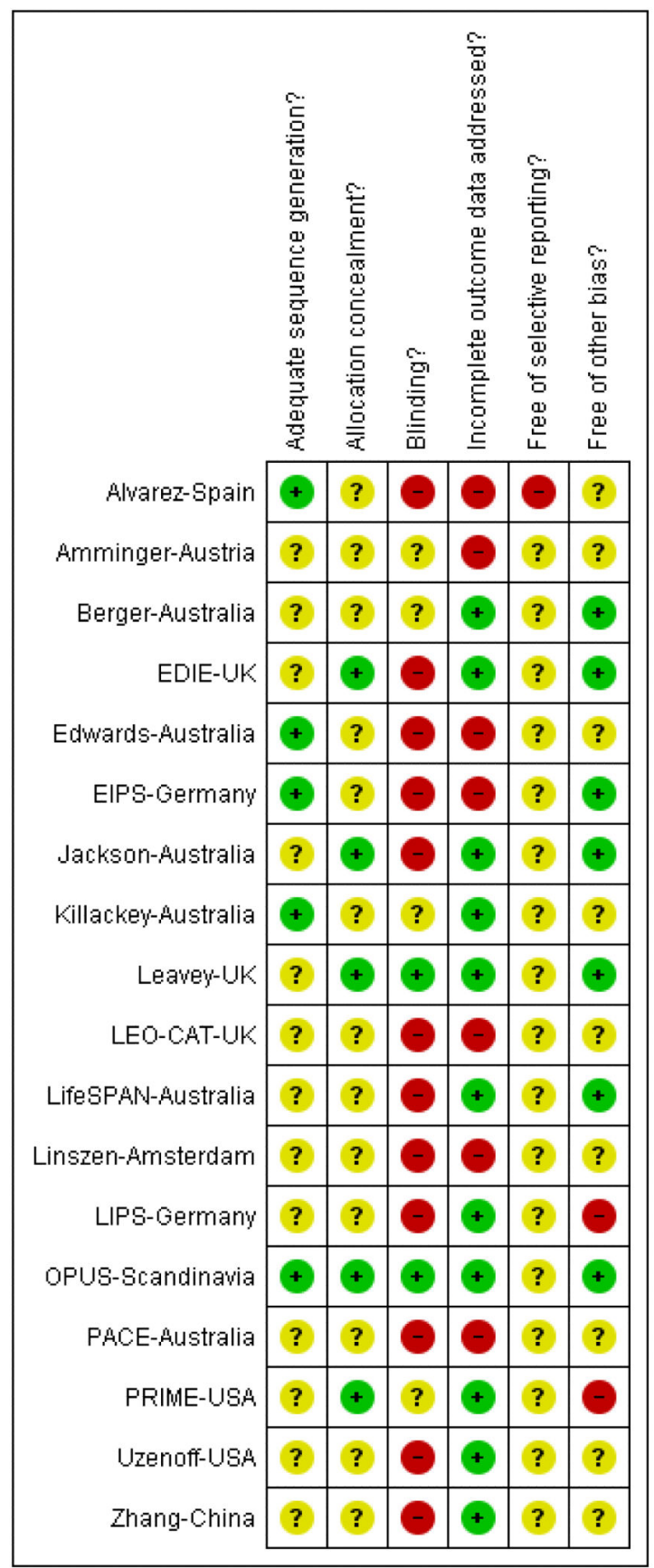

Figure 2.

Methodological quality summary: review authors' judgements about each methodological quality item for each included study. 


\section{Table 1}

\section{Reasons for excluding studies}

\begin{tabular}{|c|c|c|c|c|c|}
\hline Totals & Reasons & Totals & Reasons & Totals & References \\
\hline \multirow[t]{7}{*}{68} & Randomised & 32 & not first episode & 13 & $\begin{array}{l}\text { Craig 2004b, Drury 2000, Grawe 1998, Jenner 2004, Jones } \\
\text { 2005, Jolley 2003, Keshavan 1998, Kuipers 2004, Li 2004, } \\
\text { Nuechterlein 2005, Power 2004, SOCRATESUK, Ueland 2004, } \\
\text { Wykes } 2007\end{array}$ \\
\hline & & & drug studies & 16 & $\begin{array}{l}\text { Anonymous 1987, Crow 1986, Davidson 2004, Emsley 2004, } \\
\text { Emsley 1999, Gaebel 2004, Heydebrand 2004, Keefe 2000, } \\
\text { Kopala 2003, Lieberman 2005b, Sanger 1999, Perez 2003, } \\
\text { Purdon 2000, Schooler 2003, Wang 2000, Wunderink } 2003\end{array}$ \\
\hline & Not randomised & 36 & descriptions of services & 7 & $\begin{array}{l}\text { Bao 2005, Birchwood 1989, Clare 1994, Fisher 2001, Parlato } \\
\text { 1999, Welch 2000, Whitwell 2000, Wieneke } 2000\end{array}$ \\
\hline & & & before and after studies & 12 & $\begin{array}{l}\text { Addington 1999, Alanen 1994, Albiston 1998, Culberg } 1998, \\
\text { DeHaan 1997, Fitzgerald 1998, Fresan 2001, Newton 2005, } \\
\text { Rund 1994, Szymanski 1994, Whitehorn 1998, Yap } 2001\end{array}$ \\
\hline & & & quasi-experimental studies & 3 & COPE-Melbourne, TIPS 2006, Walczewski 1998 \\
\hline & & & inadequate randomisation & 2 & McCay 2007, Mosher 1975 \\
\hline & & & uncontrolled studies & 13 & $\begin{array}{l}\text { Agius 2007, Falloon 1992, Hartmann 1974, Jenner 2001, Kadota } \\
\text { 1992, Kauranen 2000, Keshavan 1998, Malla 2001, McGorry } \\
\text { 1996, Mottaghipour 2000, Thomas 1979, Turetz 1997, Zhang- } \\
\text { Wong } 1999\end{array}$ \\
\hline
\end{tabular}




\section{Table 2}

\section{Percentage followed up}

\begin{tabular}{lllll}
\hline \multirow{2}{*}{ Study } & \multicolumn{4}{l}{ Duration of follow up (months) } \\
\cline { 2 - 5 } & $\mathbf{6}$ & $\mathbf{1 2}$ & $\mathbf{1 8}$ & $\mathbf{2 4}$ \\
\hline Amminger-Austria & No data & No data & No data & No data \\
\hline Berger-Australia & \multicolumn{5}{l}{} \\
\hline EDIE-UK & $86 \%$ & & \\
\hline Edwards-Australia & No data & No data & No data & No data \\
\hline EIPS-Germany & No data & No data & No data & No data \\
\hline Jackson-Australia & & $82 \%$ & & \\
\hline Killackey-Australia & $75 \%$ & & & \\
\hline Leavey-UK & $79 \%(9$ months) & & & \\
\hline LEO-CAT-UK & No data & No data & No data & No data \\
\hline LifeSPAN-Australia & $75 \%$ & & & \\
\hline Linszen-Amsterdam* & & & \\
\hline LIPS-Germany & & & & \\
\hline OPUS-Scandinavia & & & \\
\hline PACE-Australia & & $77 \%$ & \\
\hline PRIME-USA & & $100 \%$ & \\
\hline Uzenoff-USA & $79 \%$ & & & \\
\hline Zhang-China & & & \\
\hline
\end{tabular}

Loss to follow-up did not appear to be substantial 